This report was prepared as an account of work sponsored by an agency of the United States Government. Neither the United States Government nor any agency thereof, nor any of their employees, makes any warranty, express or implied, or assumes any legal liability or responsibility for the accuracy, completeness, or usefulness of any information, apparatus, product, or process disclosed, or represents that its use would not infringe privately owned rights. Reference herein to any specific commercial product, process, or service by trade name, trademark, manufacturer, or otherwise does not necessarily constitute or imply its endorsement, recommendation, or favoring by the United States Government or any agency thereof. The views and opinions of authors expressed herein do not necessarily state or reflect those of the United States Government or any agency thereof.

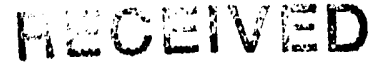

JUN 101993

\title{
OSTI
}

\section{ARTI REFRIGERANT DATABASE}

30 April 1993

\author{
prepared by \\ James M. Calm \\ Engineering Consultant \\ 10887 Woodleaf Lane \\ Great Falls, VA 22066-3003 USA
}

for the

Air-Conditioning and Refrigeration Technology Institute

4301 North Fairfax Drive, Suite 425

Arlington, VA 22203 USA

This report is one in a series prepared for the Materials Compatibility and Lubricant Rosearch (MCLR) Program, under ARTI contract number $0650-50000$ for grant number DE.FG02-91 CE23810 from the U.S. Department of Energy. 
Please refer questions or comments on this document to:

\author{
James M. Calm \\ Engineering Consultant \\ 10887 Woodleaf Lane \\ Great Falls, VA 22066-3003 USA \\ telephone: \\ $703 / 450-4313$ \\ telefax: \\ $703 / 450-4313$
}

Glenn C. Hnurahan

Project Manager

Air-Conditioning and Refrigeration Technology Institute

4301 North Fairfax Drive, Suite 425

Arlington, VA 22203 USA

telephone: $\quad 703 / 524-8800$

telefax: $\quad 703 / 528-3816$

Neither James $M$. Calm, the Air-Conditioning and Refrigeration Technology Institute (ARTI), nor any person acting on behalf of them: (a) makes any warranty, expressed or implied, with respect to the accuracy, completeness, $r$ usefulness of any information, apparatus, material, method, or process disclosed in this document or that such use may not infringe privately owned rights; or (b) assumes any liabilities with respect to use of, or damages resulting from use of, any information, apparatus, material, method, or process disclosed in this document. Reference herein to any specific commercial product, process, or service by trade name, trademark, manufacturer, or otherwise, does not necessarily constitute or imply its endorsement, recommendation, or favoring.

All product and brand names referenced by (TM) or (A) are trademarks or registered trademarks, respectively, of their owners. 


\section{TABLE OF CONTENTS}

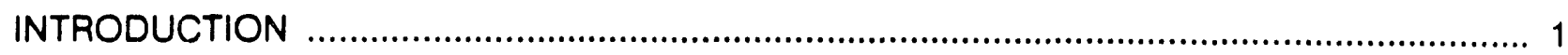

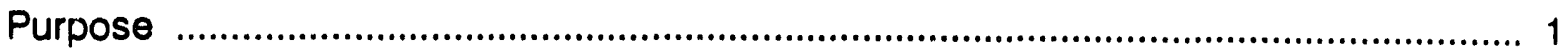

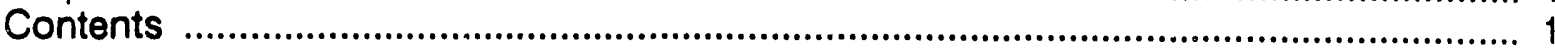

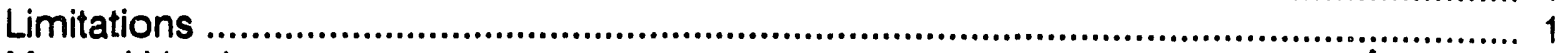

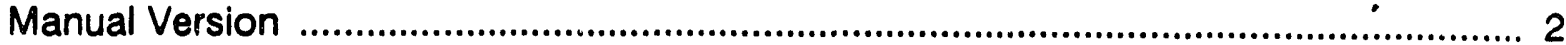

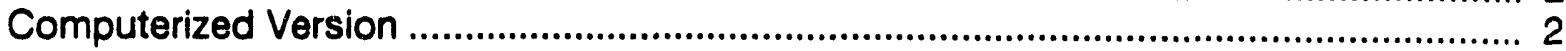

Distribution of the Refrigerant Database ...................................................................... 3

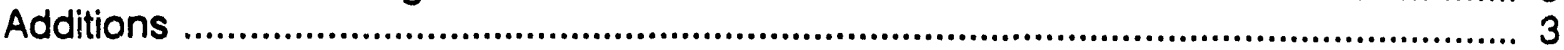

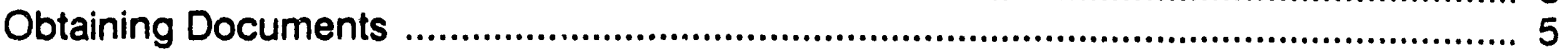

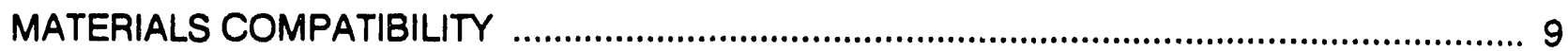

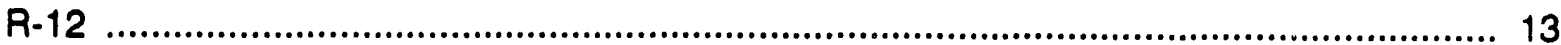

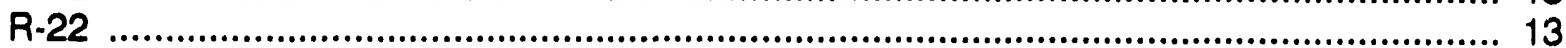

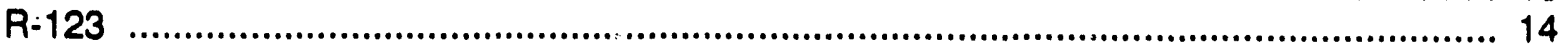

R-124

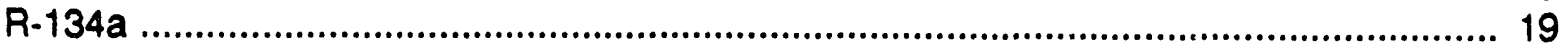

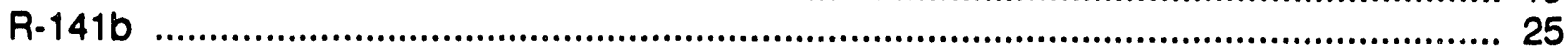

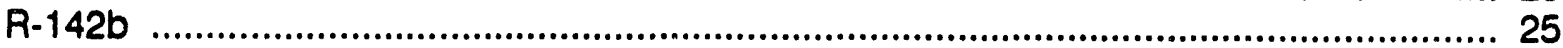

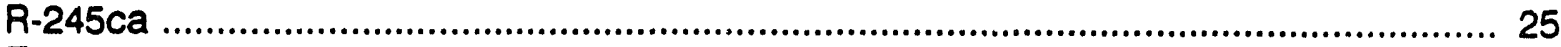

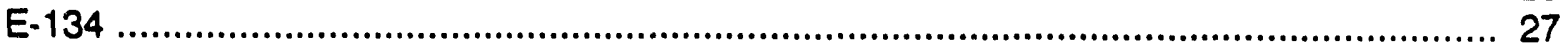

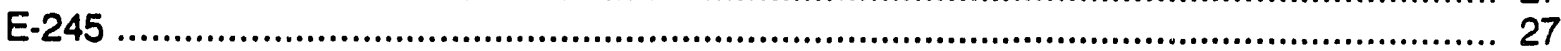

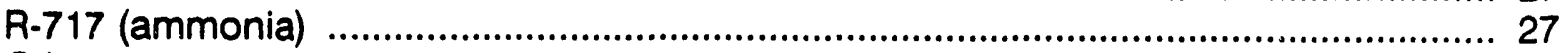

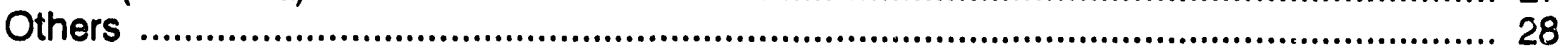

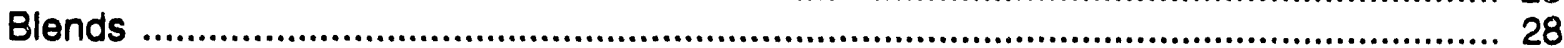

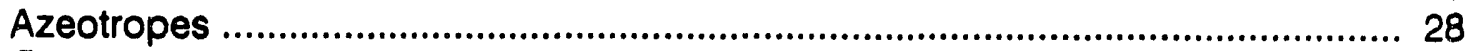

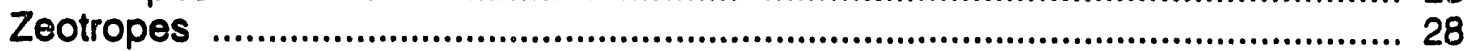

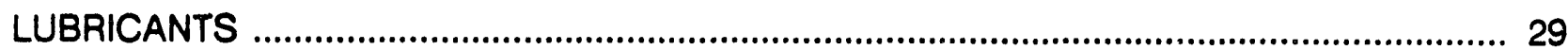

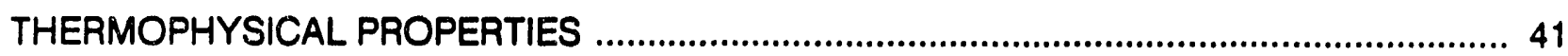

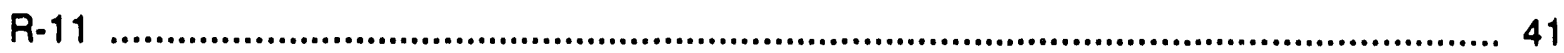

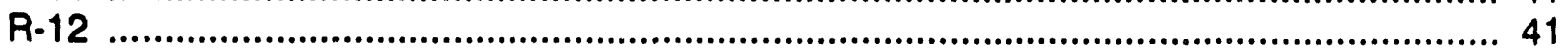

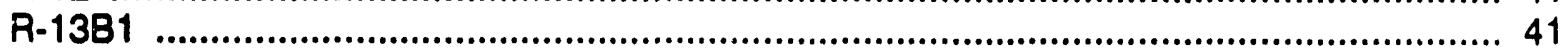

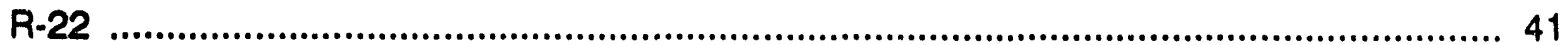

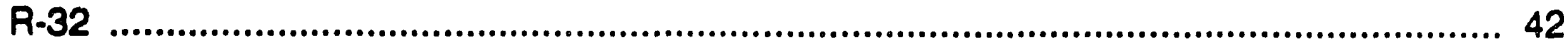

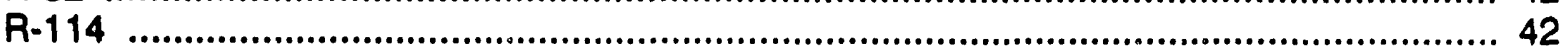

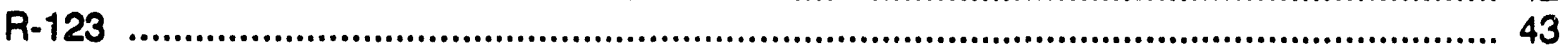

R-124

R-125

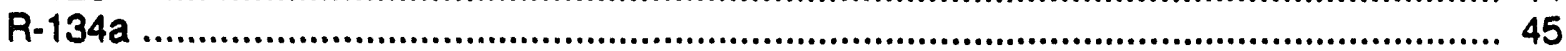

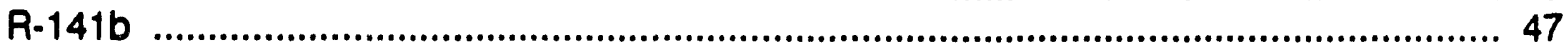

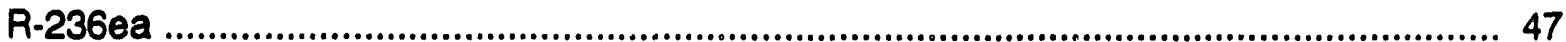

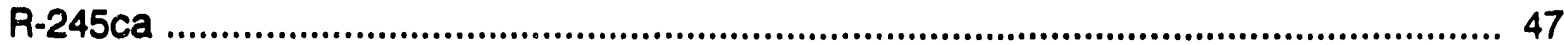

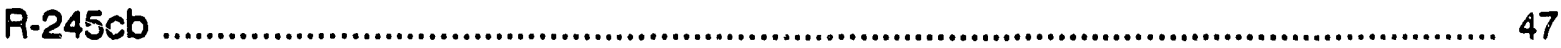




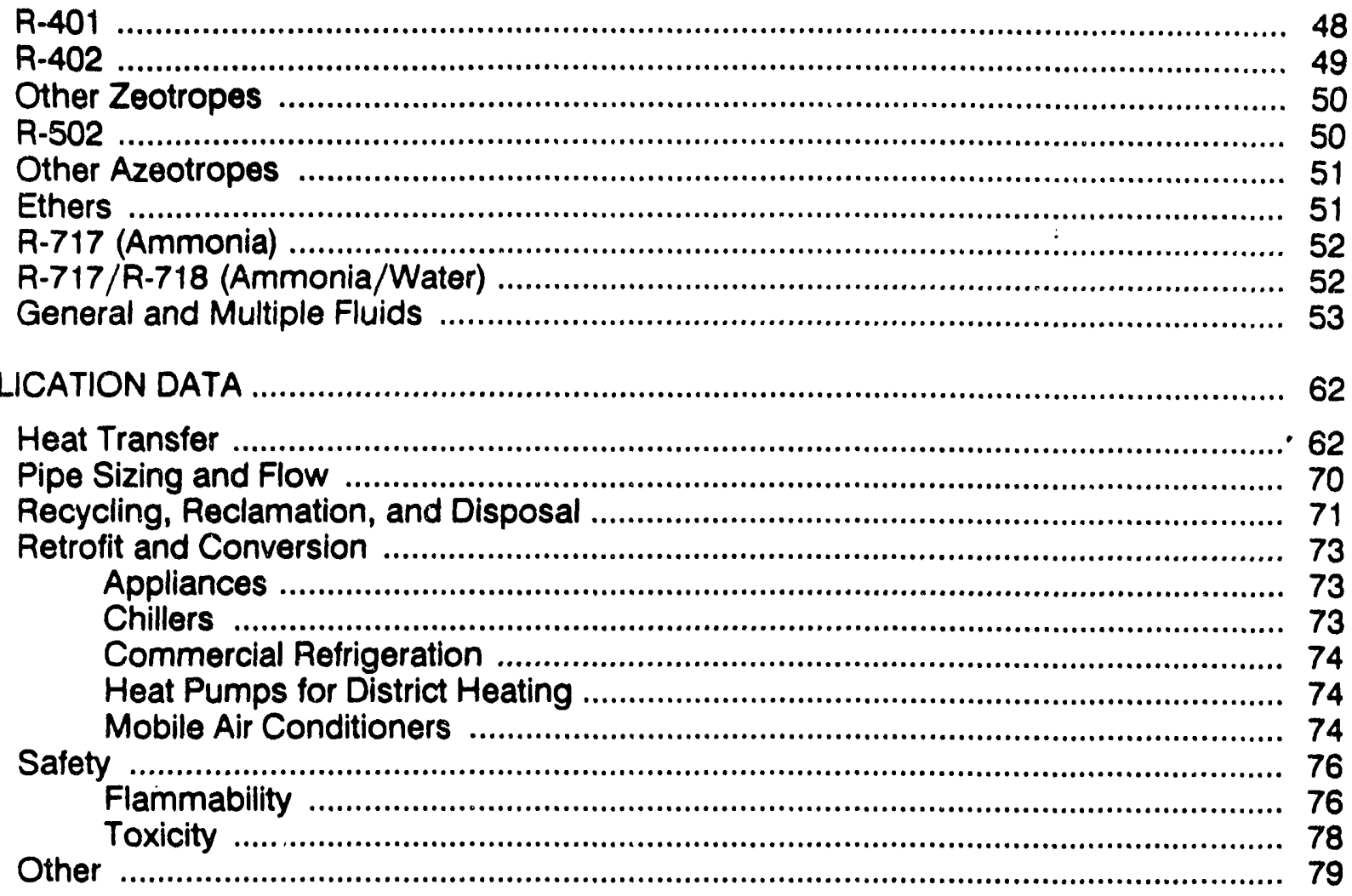

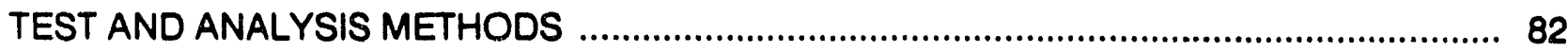

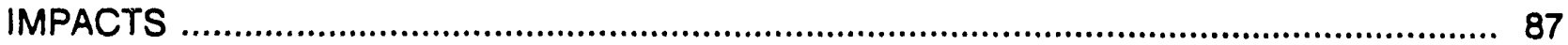

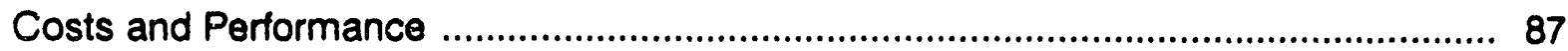

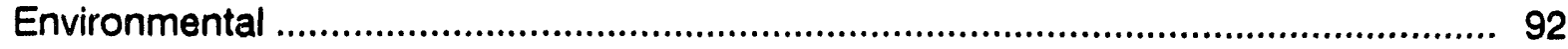

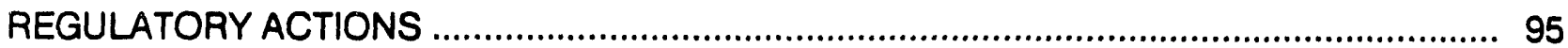

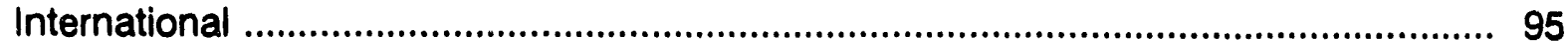

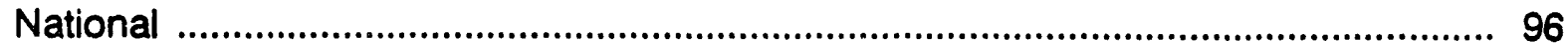

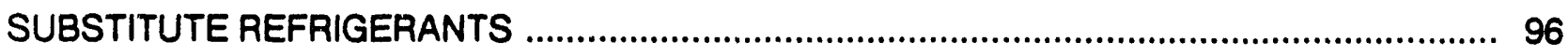

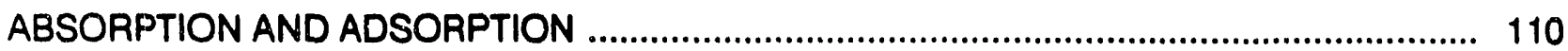

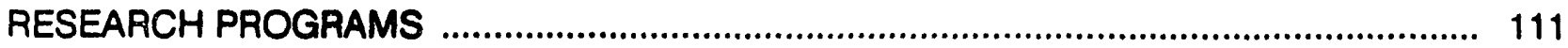

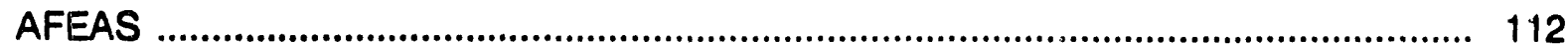

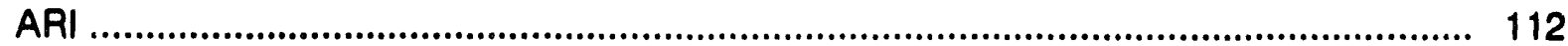

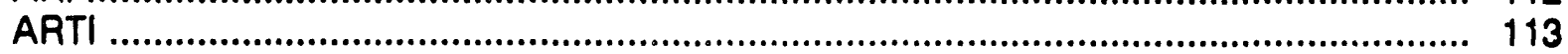

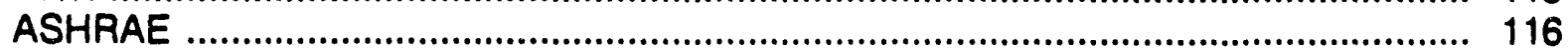

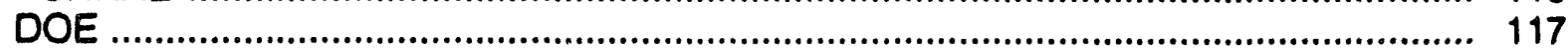

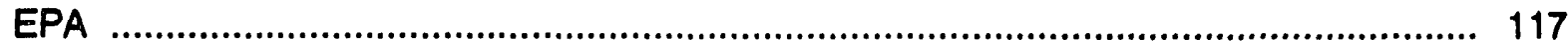

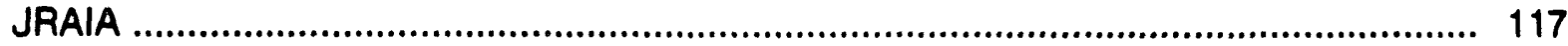

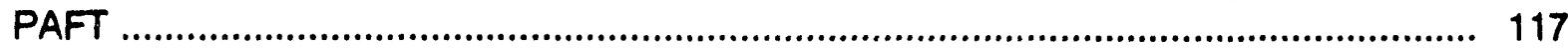

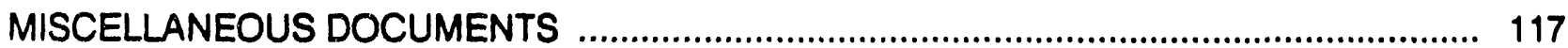




\section{INTRODUCTION}

\section{Purpose}

The Refrigerant Database consolidates and facilitates access to information to assist industry in developing equipment using alternative refrigerants. The underlying purpose is to accelerate phase out of chemical compounds of environmental concern.

\section{Contents}

The database provides bibliographic citations and abstracts for publications that may be useful in research and design of air-conditioning and refrigeration equipment. The complete documents are not included, though some may be added at a later date.

The database identifies sources of specific information on $R-32, R-123, R-124, R-125, R-134$, R134a, R-141b, R-142b, R-143a, R-152a, R-245ca, R-290 (propane), R-717 (ammonia), ethers, and others as well as azeotropic and zeotropic blends of these fluids. It addresses lubricants including alkylbenzene, polyalkylene glycol, ester, and other synthetics as well as mineral oils. It also references documents addressing compatibility of refrigerants and lubricants with metals, plastics, elastomers, motor insulation, and other materials used in refrigerant circuits.

Incomplete citations or abstracts are provided for some documents. They are included to accelerate availability of the information and will be completed or replaced in future updates.

\section{Limitations}

The Refrigerant Database is intended as a means to assist users in locating sources of information on altemative refrigerants. But, the database is:

- neither a comprehensive nor authoritative reference source,

- not a substitute for independent data collection by users,

- not a substitute for examination of the data, information on how they were arrived at, assumptions, and caveats in the cited documents, and

- not an endorsement of suitability or accuracy of referenced publications. 
Materials compatibility, properties, safety considerations, and other characteristics affecting suitability or desirability may be influenced by a number of factors. Among them are specific application conditions, preparation such as drying before use, additives including fillers, impurities, catalytic interactions with other materials used, and changes in compounding between one source or batch and another. Similarly, new findings or corrections may supersede previously published data. The database is an aid in locating data that may be pertinent; it is not and should not be viewed as the source of data for research, design, analysis, or other purposes.

\section{Manual Version}

A listing of the database contents is provided in this document. Citations are grouped under the primary or first subject addressed, but are not cross-referenced under other topics. The computerized version, therefore, is better suited to search for information by subject.

Documents added since the February 1993 release of the database are flagged by a bar in the margin, as shown to the left. Users looking for new references, as well as added or substantively updated abstracts, will need to review only the citations so indicated.

Some superseded and older citations and abstracts have been removed from this document. They remain accessible through the computerized version, discussed below. A periodic report, containing the removed citations and abstracts for the historic documents, may be prepared if users indicate a need for it.

\section{Computerizea Version}

A companion version of this listing, in computerized form, also is available. This version includes the same citations and abstracts as the manual version; it also includes citations and abstracts for superseded and older documents. The automated version includes retrieval software to help users locate desired subjects. The computerized database provides a very fast and user-friendly means to performs searches for information on specific refrigerants, lubricants, materials, properties, topics, authors, or publications of interest. Individual words or combinations of words - using Boolean logic through a simplified means of specification - may be used to retrieve desired references. Prior searches, within a session, may be recalled, narrowed, broadened, or merged with other searches. The program includes prompts users for automatic inclusion of selected synonyms and related terms. The program also provides means to print selected citations and abstracts and to prepare lists of citations for ordering.

The computerized version also includes searchable tables of summary information for 90 refrigerants and refrigerant blends. The data include designations, molecular mass, critical properties (pressure, temperature, specific volume, and density), flammability, safety classification, 


\begin{tabular}{lccc}
\hline & $\begin{array}{c}\text { computerized } \\
\text { (diskette) }\end{array}$ & $\begin{array}{c}\text { manual } \\
\text { (report) }\end{array}$ & $\begin{array}{c}\text { documents } \\
\text { (copies) }\end{array}$ \\
\hline $\begin{array}{l}\text { bibliographic citations and } \\
\text { detailed abstracts } \\
\text { - current }\end{array}$ & yes & yes & a \\
- additions and changes flagged & no & yes & no \\
historical and superseded & yes & no & a \\
$\begin{array}{l}\text { refrigerant summaries } \\
\text { search and retrieval software }\end{array}$ & yes & no & a \\
$\begin{array}{l}\text { distributed on cost-recovery basis } \\
\text { - subscription (quarterly updates) }\end{array}$ & yes b & no & no \\
- as ordered & yes & yes & no \\
\hline
\end{tabular}

a Selected citations, abstracts, and refrigerant summarles may be printed with the computerized version.

b Use of the search and retrieval software is subject to acceptance of the license agreement for it; both accompany the computerized version.

C Distribution is limited to documents in the public domain or for which authorization has been obtained. Others may be ordered from their publishers, which are identified in the bibliographic citations.

ozone depletion potential, global warming potential, and common uses. Information on additional refrigerants will be added in future updates.

The prices and ordering instructions for the computerized version of the database are indicated on page 7.

\section{Additions}

Updates are planned for this database, with replacement releases scheduled four times a year. Please help in making the database more useful, and facilitating use of alternative refrigerants, by submitting the following:

- corrections to errors identified in the database,

- copies of helpful papers - whether your own or written by others - for citation, and

- suggestions for improving the database. 
Authors or those holding rights to published or unpublished works pertinent to the database are invited - and encouraged - to authorize their reproduction and unrestricted distribution through the database. Product literature normally is not included, but studies providing relevant information, whether on proprietary or generic substances, will be considered.

Please send your inputs to: James $M$. Calm

Engineering Consultant

10887 Woodleaf Lane

Great Falls, VA 22066-3003 USA

Thank you for your help with and use of the database. Its objective is to accelerate phase out of chemical compounds of environmental concern by sharing the information needed to do so. 


\section{Cbtaining Documents}

With the exception of documents for which availability from an alternative source is indicated, referenced publications should be ordered from the organization that published them. Many of these documents also may be obtained from libraries, including the ESL (see below). An effort will be made to secure permission for JMC to distribute additional documents, to facilitate access to them, but compliance with copyright provisions precludes doing so until appropriate arrangements are made. Reports from national laboratories and the Gas Research Institute may be ordered from the NTIS; most other publications from the U.S. Government may be obtained from the GPO. Addresses for several alternative sources follow:

\begin{tabular}{|c|c|}
\hline ASHRAE & $\begin{array}{l}\text { Publication Sales } \\
\text { American Society of Heating, Refrigerating, } \\
\text { and Air-Conditioning Engineers } \\
1791 \text { Tullie Circle NE } \\
\text { Atlanta, GA } 30329 \text { USA }\end{array}$ \\
\hline EPRI & $\begin{array}{l}\text { EPRI Distribution Center } \\
207 \text { Coggins Drive } \\
\text { Post Office Box } 23205 \\
\text { Pleasant Hill, CA } 94523 \text { USA }\end{array}$ \\
\hline ESL & $\begin{array}{l}\text { Document Delivery } \\
\text { Engineering Societies Library } \\
345 \text { East } 47 \text { th Street } \\
\text { New York, NY } 10017 \text { USA }\end{array}$ \\
\hline GPO & $\begin{array}{l}\text { Superintendent of Documents } \\
\text { U.S. Government Printing Office } \\
\text { Washington, DC } 20402 \text { USA }\end{array}$ \\
\hline$\|R /\| F$ & $\begin{array}{l}\text { Institut International du Froid } \\
177, \text { Boulevard Malesherbes } \\
\text { F-75017 Paris, France }\end{array}$ \\
\hline JAR & $\begin{array}{l}\text { Japanese Association of Refrigeration } \\
\text { Nippon Reito Kyokai } \\
\text { 4th Floor, San-ei Building, } 8 \text { San-ei-cho } \\
\text { Shinjuku-ku, Tokyo } 160 \text { Japan }\end{array}$ \\
\hline JMC & $\begin{array}{l}\text { James M. Caim } \\
\text { Engineering Consultant }\end{array}$ \\
\hline NTIS & $\begin{array}{l}\text { National Technical Information Service } \\
\text { U.S. Department of Commerce } \\
5285 \text { Port Royal Road } \\
\text { Springfield, VA } 22161 \text { USA }\end{array}$ \\
\hline SAE & $\begin{array}{l}\text { Society of Automotive Engineers } \\
400 \text { Commonwealth Drive } \\
\text { Warrendale, PA } 15096-0001 \text { USA }\end{array}$ \\
\hline
\end{tabular}

call $1-404 / 636-8400$ or fax $1-404 / 321-5478$ to request publications catalog which provides prices

order catalog MD-7201 or call $1.510 / 934-4212$ for current prices

call 1-212/705-7606 or fax 1-212/486-1086 for current prices

call $1-202 / 783-3238$ for current prices

call 33-1/42.27.32.35 fax 33-1/47.63.17.98 for current prices

call 81-3/3359-5231 or fax $81-3 / 3359-5233$ for current prices

prices and address on next page

call $1-703 / 487-4780$ for current prices

write for current prices 400 Commonwealth Drive
Warrendale, PA 15096-0001 USA 
REFRIGERANT DATABASE ORDER FORM (please reproduce as needed)

\begin{tabular}{|c|c|c|c|c|c|c|}
\hline & quantity & & $\begin{array}{l}\text { United } \\
\text { States }\end{array}$ & $\begin{array}{l}\text { Canada, } \\
\text { Mexico }\end{array}$ & $\begin{array}{l}\text { other } \\
\text { foreign }\end{array}$ & $\begin{array}{c}\text { cost } \\
\text { (US \$) }\end{array}$ \\
\hline $\begin{array}{l}\text { REFRIGERANT DATABASE } \\
\text { computerized version: a,b } \\
\text { circle preferred diskette size: } 31 / 2 \text { "HD or } 51 / 4 \text { "HD } \\
\text { database listing (report) a }\end{array}$ & & $x$ & $\begin{array}{l}\$ 100 \\
\$ 78\end{array}$ & $\begin{array}{l}\$ 150 \\
\$ 106\end{array}$ & $\begin{array}{l}\$ 165 \\
\$ 134\end{array}$ & \\
\hline $\begin{array}{l}\text { DATABASE DOCUMENTS (attach list) }{ }^{c} \\
\text { per document (handling, packing) documents: }\end{array}$ & & $x$ & $\$ 2.00$ & $\$ 2.00$ & $\$ 2.00$ & \\
\hline + per page (copying, added postage) $a, d$ pages: & & $x$ & $\$ 0.10$ & $\$ 0.20$ & $\$ 0.30$ & \\
\hline+ per order (processing, base postage) ${ }^{a}$ & 1 & $x$ & $\$ 4.00$ & $\$ 8.00$ & $\$ 8.00$ & \\
\hline $\begin{array}{l}\text { SALES TAXES } \\
\text { (orders for delivery in Virginia only) }\end{array}$ & & & & & $\begin{array}{l}\text { subtotal: } \\
\times 41 \% 2 \%\end{array}$ & \\
\hline $\begin{array}{l}\text { OPTIONAL EXPRESS DELIVERY } \\
+\$ 3.00 \text {. for each } 1.60 \text { pages } c \text { after } \\
\text { the first } 30 \text { for database documents }\end{array}$ & & $x$ & $\begin{array}{l}\$ 20.00 \\
\$ 3.00\end{array}$ & $\begin{array}{l}\text { see } \\
\text { reverse } \\
\text { side }\end{array}$ & $\begin{array}{l}\text { see } \\
\text { reverse } \\
\text { side }\end{array}$ & \\
\hline
\end{tabular}

DEPOSIT ACCOUNT (for future orders)

PREPAID TOTAL

US\$

a Price differences by country reflect postal costs and preparation of customs form(s).

b Subscription rates outside the United States also include a $\$ 25$ license fee for the retrieval software accompanying the database.

c Please include document numbers, which begin with RDB; a document list may be printed with the computerized version to simplify ordering.

$\checkmark$ Charges are based on the page counts indicated in the database. MAIL/SHIP TO $\begin{aligned} & \text { (only your name and company are required for current database } \\ & \text { subscribers unless the other information has changed): }\end{aligned}$

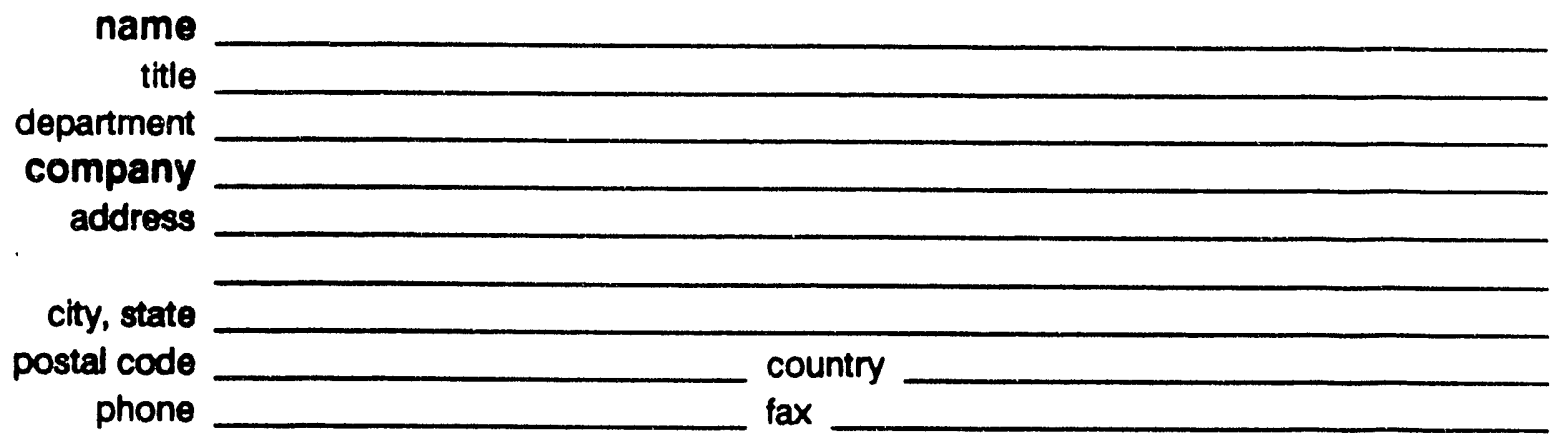

Please mail completed form, list for document orders, and payment (checks drawn on U.S. banks only) to:

All orders are subject to the terms on the reverse side.
James M. Calm Engineering Consultant 10887 Woodleaf Lane Great Falls, VA 22066-3003 USA 


\section{Explanations}

Database Subscriptions: Subscribers to the Refrigerant Database will recelve an initial release and quarterly updates through January 1994 -- a total of four distributions for now subscriptions beginning prior to 15 July 1993.

Computerized Version: The computerized version is distributed on diskette, with an accompanying Users' Manual, for use on IBM PC-compatible systems. Retrieval software is supplied with the database and is subject to an accompanying IIcense agreement. The computerized version in. cludes summaries of identifiers, critical parameters, safety classifications, environmental indices, and uses for approximately 100 fluids.

Database Listing: The database also is available in a noncomputerized (manual) version, in report form; the refrigerant summaries and automated search capability are not included.

Database Documents: Both versions identify sources to obtain documents cited in the database - currently more than 600 and projected to exceed 1100 in the subscription period. Approximately a third are distributed through the database and may be ordered at the rates shown on the reverse side.

Shipping: Normal delvery is by first class or priority mail in the USA or by air mail outside the USA. Most orders are mailed within two business days; all are sent within one week. Express delivery (by UPS Next Day Air, Federal Express Priority, or Express Mail depending on the destination) is available either for documents or the initlal version of the database. Express orders are shipped on the day received if possible. Delivery is before 10:30 am on the next business day in most metropolitan locations in the USA; please specify Saturday delivery (normally by $12: 30 \mathrm{pm}$ ) and add $\$ 12$ if desired. Express delivery to other countries normally takes $1-4$ days depending on the destination and time for customs clearance; please inquire for international express shipping costs in advance.

Deposit Accounts: Several companies have established accounts to facilitate and expedite document ordering by authorized staft. Accounts may be initiated by payment of not less than $\$ 200$. Users may then simply fex or mail document $r e-$ quests to be filled. Each shipment will include an updated statement of transactlons and the account balance. Accounts may be closed and the balance refunded upon request.

\section{Terms and Conditions}

Prices: The prices shown are valld through July 1993 and include postage (by air mail with customs form outside the USA).

Business Identification: The Refrigerant Database has been developed and is administered by James
M. Calm, Engineering Consultant, hereinafter referred to as JMC. JMC is a sole proprietorship; Social Security Number 043406443 is used for tax identification purposes. JMC qualifies as a small business under federal classifications. JMC does not qualify as elther a Socially and Economically Disadvantaged Business Enterprise or a Women's Business Enterprise; JMC is not located in an Eligible Labor Surplus Area.

Compliance whth Federal and State Regulations: Requirements for compllance with applicable federal and state laws as well as affirmative action, work place, and other programs are governed by the contract between JMC and the Air-Conditioning and Refrigeration Technology Institute (ARTI) for Development and Administration of the Refrigerant Database (Contract 650-50000), awarded pursuant to U.S. Department of Energy (DOE) Grant number DE-FG02-91CE23810. The agreement specifically stipulates compliance with Executive Order 11246 on Equal Employment Opportunity, the Clean Air Act of 1970, and the Federal Water Pollution Act. It inclucies provisions addressing National Security Information, accounting procedures, intellectual property, and eligibility. JMC voluntarily complies with the Environmental Protection Clause contained in 41 CFA $\$ 1-1.2303 .2$, Employment of the Handicapped Clause in 41 CFR \$60-741, and Equal Opportunity Clause in 41 CFR $\$ 60-1.4$.

Governing Law: Licenses to use the Refrigerant Database and related document purchases shall be governed by laws of the Commonwealth of Virginia.

Purpose and Disclaimer: The Refrigerant Database was established to faciltate access in inf Jrmation to accelerate use of alternative rerrigerants, to enable phase out of chemicals of environmental concern. The information contained in the database is not complete and has not been verified. Its sultabllity for speciflc uses has not been established, and no representation is made to support reliance on it. Users must determine the appropriateness and adequacy of the data.

Warranty: No warrantles of accuracy, comprehensiveness, merchantability, or fitness for any specficic purpose are implied. No liability for special, incidental, consequentlal, indirect, or similar damages; indemnification; or obllgation to defend users against claims of any kind is assumed by JMC based on distribution or use of the database or documents. The sole warranty offered is for provision of database releases and document copies propenly ordered, or refund of amounts pald therefor.

Other Terms and Conditions: No terms and conditions (including but not limited to those addressing warranties, indemnification, insurance, inspection, records, confidentiality, or social or affirmativeaction programs) stipulated in purchase orders for the database, or documents from it, will apply. Subscriber identities and addresses may be disclosed to ARTI. 


\section{REFRIGERANT DATABASE - CITATIONS AND ABSTRACTS}

\section{MATERIALS COMPATIBILITY}

T. Atwood (AlliedSignal Incorporated), E. M. Clark (E. I. DuPont de Nemours and Company), R. C. Downing (Consultant), and $\mathrm{M}$. O. McLinden (National Institute of Standards and Technology, NIST), Refrigerants, ASHRAE Handbook - Fundamenta/s (published in separate editions with inchpound and SI metric units), American Society of Heating, Refrigerating, and Air-Conditioning Engineers (ASHRAE), Atlanta, GA, chapter 16, pages 16.1-16.10, 1989 (10 pages, RDBO036)

This chapter summarizes information on common refrigerants, including designations, physical and electrical properties, performance, safety data, leak detection methods, and effects on construction materials. The refrigerants addressed include R-10, R-11, R-12, R-13, R-13B1, R-14, R-20, R-21, R-22, R-23, R-30, R-31, R-32, R-40, R-41, R-50, R-110, R-111, R-112, R-112a, R-113, R-113a, R-114, R-114a, R-114B2, R-115, R-116, R-120, R-123, R-124, R-124a, R-125, R133a, R-134a, R-140a, R-142b, R-143a, R-150a, R-152a, R-160, R-170, R-218, R-290, R-C316, RC317, R-C318, R-500, R-501, R-502, R-503, R504, R-505, R-506, R-600, R-600a, R-610, R-611, R-630, R-631, R-702, R-704, R-717, R-718, P.720, R-728, R-729, R-732, R-740, R-744, R-744A, R-764, R-1112a, R-1113, R-1114, R-1120, R1130, R-1132a, R-1140, R-1141, R-1150, and R1270. Molecular mass, normal (atmospheric) bolling point, freezing point, crttical properties, surface tension, and refractive index are tabulated for most of these fluids. Dielectric constants, volume resistwity, velocity of sound, latent heat of vaporization, safety classifications, and explostve limits are presented for the more common fluids. Swell data are tabulated for $R$ 11, R-12, R-13, R-13B1, R-21, R-22, R-30, R-40, $R-113, R-114, R-502$, and $R-600$ for eight elastomers. They include nitrile butyl rubber (Bu-
na(TM) $N$ ), butadiene styrene (Buna(TM) S, GRS), Butyl(TM) (GR-1), natural rubber, neoprene $G N$, polysulfide rubber (Thiokol(R) FA), fluoroelastomer (DuPont Viton(R) B), and silicone. Diffusion data are tabulated for water, R-12, and $R$ 22 through neoprene, Buna $N$, synthetic rubber (DuPont Hypalon(R) 40), Butyl, Viton, polyethylene, and naturat rubber. Mass density, specific heat, and viscosity are plotted for water/lithium bromide solutions (for absorption cycles) as functions of the mass fraction of lithlum bromide.

R. C. Cavestri "magination Resources, Incorporated), Compatibility of Refrigerants and Lubricants with Plastics, report DOE/CE/23810-8E, Air-Conditioning and Refrigeration Technology Institute (ARTI), Arlington, VA, January 1993 (76 pages with 1 figure and 58 tables, available from JMC as RDB3203; type on page A-2 is small and may be difficult to read)

This interim report summarizes progress to provide compatibility information on engineering plastics with alternative refrigerants and suitable lubricants. A narrative summary outlines the work methods used, including modifications to standard or planned test procsdures, and notes significant findings. A table provides the manufacturer specifications and actual conditions for molding 23 plastic materials. They include acetal (DuPont Delrin(R) II 11500), acrylonitrilebutadiene-styrene terpolymer (ABS, GE Cycolac(R) GPM4700), liquid crystal polymer (LCP, Amoco Xydar(R) MG450), phenolic (Hooker Durez(R) 153), poly(anyletheretherketone) (PEEK, ICl Victrex(TM) PEEK 450G), polyamióu nyton 6/6 (DuPont Zytel(R) 101), polyamideimide (Amoco Torton (R) 4203L and 4301), polyaryletherketone (PAEK, BASF Ultrapek(R)), polyarylsulfone (Amoco Radel(R) A-200), polybutylene terephthalate (PBT, GE Valox(R) 325PBT), polycarbonate (GE Lexan(R) 161), polyetherim- 
ide (GE Ultem(R) 1000), modified polyetherimide (GE Ultem(R) CRS5001), polyethylene terephthalate (PET, DuPont Rynite(R) 530, polyimide thermoset (DuPont Vespel(R) DF and DF-ISO), modified polyphenylene oxide (PPE, GE Noryl(R) 731), polyphenylene sulfide (PPS, GE SUpec(TM) G401), polyphthalamide (Amoco Amo$\operatorname{del}(\mathrm{R}) \mathrm{AD}-1000 \mathrm{HS}$ ), polypropylene (Himont Profax(TM) 6331 NW), polytetrafluoroethylene (PTFE, DuPont Teflon(R)), and polyvinytidene fluoride (Atochem Kynar(R) 720). Seven tables summarize the changes for immersions in lubricants, including mineral oil (BVA R015), alkylbenzene (Shrieve Zerol(R) 150), polypropylene glycol butyl monoether (ICl Emkarox(R) VG32), polypropylene glycol diol (Dow P-425), and a modfied polyglycol (AlledSignal BRL-150), penta erythritol ester mixed acid (ICl Emkarate(TM) RL $22 \mathrm{H}$, formerly RL 244), and penta erythritol ester branched acid (Henkel Emery(R) 2927-A). Seven tables summarize changes in the plastics following immersions in the lubricants, each at 60 and $100{ }^{\circ} \mathrm{C}(140$ and $212^{\circ} \mathrm{F}$ ). Observations of particulates, cracking, crazing, softening, and color change are presented. Quanthathe data are provided for dimensional (length, width, and thickness) and weight changes. Ten tables summarize corresponding changes following exposures to R-22, R-32, R-123, R-124, R-125, R-134, R-134a, R142b, R-143a, and R-152a. The refrigerant immersions were at room temperature and $60^{\circ} \mathrm{C}$ $\left(140{ }^{\circ} \mathrm{F}\right)$ for 14 days. Three tables summarize the creep modulus of the plastics at $10-300$ hours for immersions in R-22, R-134a, and R152a with branched acid polyol ester. 36 tables summarize physical changes and tensile-property changes following exposures to refrigerantlubricant mixtures. All of the plastics were affected by the lubricants; mineral oil and alkybenzene caused the greatest effects. The refrigerants generally resulted in softening or weight change; hydrofluorocarbons (HFCs) had the least impact. The report documents several combinations that failed at ambient conditions or are likely to fail at elevated temperatures.

R. G. Doerr and S. Kujak (The Trane Company), Compatibility of Rofrigerants and Lubricants with Motor Materlale, repon DOE/CE/23810-4B, Air-Conditioning and Refrigeration Technology Institute (ARTI), Arlington, VA, October 1992 (36 pages with 43 tables, available from JMC as RDB2B01)

This interim report summarizes progress to provide compatibility information for motor materials (for hermetic compressors) in refrlgerants and refrigerant-lubricant combinations. Tabular findings are reported for exposures to R-22, R123, R-124, R-134, R-134a, R-142b, and R-152a at $90^{\circ} \mathrm{C}\left(194{ }^{\circ} \mathrm{F}\right)$; to R-32, R-125, and R-143a at $60^{\circ} \mathrm{C}\left(140^{\circ} \mathrm{F}\right)$; and to nitrogen (R-728) at both temperatures, as a reference. Tests of dielectric strength, burnout resistance, and bond strength have not been completed yet for R-134; future tests are planned for R-245ca. Data are provided both after 500 hour exposures and after a subsequent air bake for 24 hours at $150^{\circ} \mathrm{C}$ (302 ${ }^{\circ} \mathrm{F}$ ), to remove absorbed refrigerant. Bond strength, burnout resistance, and dielectric strength are compared to the unexposed values for three magnet wires, both uncoated and prepared with slx varnishes. The wire specimens included an ester base with amide-imide overcoat (Phelps Dodge Armored Poly-Thermaleze 2000), Dacron(R)/glass served wire (Phelps Dodge Armored Poly-Thermaleze Daglass 2000), and ester-Imide overcoated with amideimide (Phelps Dodge / Schenectady Chemical). The varnishes tested include two solvent epoxies (Sterling(R) U-475 EH and P. D. George 923), a solvent epoxy phenolic (Sterling(A) Y-390 PG), 93\% solids epoxy (Sterling(P) ER-610), and $100 \%$ solids VPI epoxy (Sterling(R) Y-833), and water-borne epoxy (Schenectady Isopoxy(R) 800). Weight change also is reported for exposed disks of the six varnishes. Weight, tensile strength, elongation, and dielectric strength are compared to unexposed values for six sheet insulations Westinghouse Nomex-Mylar-Nomex(R), Westinghouse Dacron-Mylar-Dacron( $\mathrm{P})$, DuPont Mylar(R) MO, DuPont Nomex(R) 410, DuPont Nomex(R) Mica 418, and ICl Melinex(R) 228). Weight change is tabulated for Insulations Sales Nomex(R), Mylar(R), and Nomex-Mylar(R) spiral-wrapped sleeving insulation. Changes in weight and dielectric strength are presented for A. O. Smith Dacron-Mylar-Dacron(A) and Dacron-Teflon-Dacron(R) lead wire insulations. Weight and breaking load changes are supplied for woven glass tape (Carolina Narrow), heat shrinkable braided polyester tape (Electrolock), glass-acrylic tape (Essex Permacel P247), and polyester tie cord (Ludlow Textiles). A final table compares gas chromatographic analyses of the refrigerants before and after $500 \mathrm{hr}$ exposures. The report concludes that R-123 exhibited higher absorption and extraction than the other refrigerants tested. The most severe effect of refrigerants on motor materials was caused by high absorption followed by rapid desorption at higher temperatures. R-22 caused the most damage in this case; based on the excellent reliability history of this refrigerant with many of the materials tested, compesibility with the other refrigerants is highly probable. Final judgements should be postponed unth studies are completed for the refrigerant-lubricant mixtures.

H. L Emmons, Latest Technology for Hermetic Motor Insulation Testing - Part 2, Magnet Wire 
Overload, Insulation, pages 57-61, September 1967 (RDB2510)

G. R. Hamed and R. H. Selple (University of Akron), Compatibility of Refrigerants and Lubricants with Elastomers, report DOE/CE/23810-8D, AirConditioning and Refrigeration Technology Institute (ARTI), Arlington, VA, January 1993 (310 pages with 32 figures and 100 tables, available from JMC as RDB3202)

This interim report summarizes swell measurements for 95 elastomeric gasket and seal materials in refrigerants and lubricants. Swell behavior was determined using weight and in-situ diameter measurements for the refrigerants and diameter and thickness measurements for the lubricants. The refrigerants include both hydrochlorofluorocarbons (HCFCs R-22, R-123, R124, and R-142b) and hydrofluorocarbons (HFCs R-32, R-125, R-134, R-134a, R-143a, and R-152a). The lubricants include a mineral oil Witco Suniso(R) 3GS), alkylbenzene (Shrieve Zerol(R) 150), and three polyalkylene glycols (PAGs), namely a polypropylene glycol butyl monoether (ICl Emkarox(R)), a polypropylene glycol did (Dow P425), and a modified polyglycol (AlliedSignal BRL-150). Two polyol ester (POE) lubricants also are included, namely a penta erythritol ester branched acid (Henkel Emery(R) 2927-A) and a penta erythritol ester mixed acid (ICl Emkarate(TM) RL 22H, formerly RL 244). An appendlx identifies the elastomer formulations, which include polyisoprene (Natsyn 2200), polychloroprene (Neoprene W), isobutyl isoprene (Polysar Buty), bromobutyl (Polysar X2), chlorobutyl 1068, styrene butadiene rubber (SBR 1502 and Stereon 730A and $840 \mathrm{~A}$ ), nitrile (Chemigum N206, N300, N615B, and N917), hydrogenated nitrile (Polysar Tomac A3850 and A4555), fluoroelastomers (DuPont Viton( $\mathrm{A}) \mathrm{A}, \mathrm{B}$, and GF), KEL-F 3700, epichlorohydrin (Hydrin H-65, C-65, and T-75), silicones (SE-33(VMQ), SE-436U, SE$565 \mathrm{U}, \mathrm{SE}-3808 \mathrm{U}$, and LS-63U), thermoplastics (Santoprene 201-87, 201-73, 203-40, and 20350, Geolast 701-87, 701-80, and 703-40, and Hytrel EPDM 4056, 5526, G6356, and 7246), FA and ST polysulfide rubber, polyurethanes (Airthane PET-95A, PET-60D, Cyanaprene A-8, D-55, Millathane 76, and E-34), chiorosulfonated polyethylenes (Hypalon 20, 40, and 4085), EPM (Vistalon 404 and 707), ethylene acrylics Namac G and B-124), chlorinated polyethylenes (Dow CM0136 and 4211P), and ethylene propylene diene (EPDM rubbers (Royalene 552, 525, and 359). Another appendix identifies ten gasket materials supplied by ARTI including filled chloroprene (Precision Rubber 2167), acrylonitrile (Precision Rubber 7507), neoprene (Garlock 2930), non-asbestos (Armstrong N8092, Specialty Paperboard NI-2085G, Victopac
69, and Klinger C-4401), nitrile-aramid (Specialty Paperboard 2099), fluorocarbon (Parker V747. 75), and neoprene (Green Tweed 956). The physical properties of the samples were tabulated prior to exposures. 17 figures summarize the diameter change for exposures in the individual refrigerants and lubricants. 95 tables present data on swell after immersions of 1,3 , and 14 days, weight change after 14 days, diameter and weight after removal, and shore hardness after 1 day of drying. The test methodology and apparatus also are described. R-123 generally resulted in the greatest swelling, but EPDM/PP/TPE, butyl rubber/PP TPE, and several vendor-supplied compositions swelled little in this refrigerant. R-134 and R-134a caused much less swelling in general, with the exception of with fluoroelastomers and fluorosilicone elastomers. Some vendor compositions are identified that resisted swelling in all refrigerants and lubricants tested. The HFCs generally gave much less swelling than the HCFCs, though the fluoroelastomers and fluorosilicones exhibit high swelling in them. Some of the industry-supplied samples resisted swelling in all refrigerants. Several compositions were identified that resisted swelling in the lubricants as well. 17 refrigerant-fubricant systems are identified, and pressure calibration curves are provided, for an ongoing second phase of the project. 25 selected elastomers will be tested in Phase II. Completion is expected in April 1993, contingent on the availability of R-32 for testing.

G. R. Hamed and R. H. Seiple (University of Akron), Compatibility of Refrigerants and Lubricants with Elastomers, report DOE/CE/23810-3E, AirConditioning and Refrigeration Technology Institute (ARTI), Arlington, VA, July 1992 (102 pages with 31 figures and 60 tables, available from JMC as RDB2805)

This interim report summarizes swell measurements for approximately half of the 94 elastomers being tested in refrigerants and lubricants. Swell behavior was determined using weight and in situ diameter measurements for the refrigerants and diameter and thickness measurements for the lubricants. The refrigerants include both hydrochlorofluorocarbons (HCFCs R-22, R-123, R-124, and R-142b) and hydrofluorocarbons (HFCs R-32, R-125, R-134, R-134a, R-143a, R-152a). The lubricants include an unidentified mineral oll, alkylbenzene, three polyalkylene glycols (PAGs: a polypropylene glycol butyl monoether, a polypropylene glycol diol, and a modified polyglycol), and both a branched acid and a mixed acid penta erythritol ester (PE). Appropriately cured elastomers, encompassing both general purpose and specialty 
rubbers, were tested. Gum and black-filled compounds were tested, as were some thermoplastic olastomers (TPEs). Compositions containing carton black had reduced swelling compared to their unfilled counterparts. Among the HCFCs, R-123 generally resulted in the highest swelling, although an EPDM/PP TPE, butyl rubber/PP TPE, and a fiber-filled nooprene were quite resistant to it. Some compositions shrunk, suggesting that the swellant was removing a component, probably plasticizer, from the elastomer. All the HFCs resulted in substantially lower swelling than the HCFCs. R143a, the least acidic of the refrigerants tested, gave the least swelling overall. A series of figures summarize the diameter changes. Swell data also are tabulated, for exposures of 1,3 , and 14 days; weight change is tabulated after 14 days. The elastomers tested include polyisoprene, neoprene, butyl, bromobutyl, SBR/styrene, nitrile, hydrogenater! nitrile, fluoroelastomer, fluoro/chloroelastomer, epichlorohydrin (homopolymer, ethylene oxide copolymer, and terpolymers), dimethyl silicone rubber, methylphenylvinylsilozane rubber, silicone rubber, fluorosilicone, EPDM/PP/TPE, nitrile/PP/TPR, chlorosulfonated PE, ethylene/propylene copolymer (EPM), ethylene/acrylic elastomer, chlorinated PE, EPDM, butyl rubber, chioroprene, and ACN compound. [see RDB2806 for supplemental data]

G. R. Hamed and R. H. Selple (University of Akron), Compatibility of Refrigerants and Lubricants with Elastomers - Supplement, supplement to report $\mathrm{DOE} / \mathrm{CE} / 23810-3 \mathrm{E}$, Air-Conditioning and Refrigeration Technology Institute (ARTI), Arlington, VA, July 1992 (144 pages with 135 flgures and 2 tables, available from JMC as RDB2806)

This supplement provides gas chromatograms and results for the refrigerant specimens, FTIR data (infrared absorbance) for the refrigerants and lubricants, and thermogravimetric analyses (TGA) and oscillating disk meometer (ODR) plots for the elastomers tested. See RDB2805 for further information.

J. P. Harrington and R. J. Ward, Polyester Fillm insulation for Hermetic Motors. ASHRAE Journal, American Society of Heating, Refrigerating, and AirConditioning Engineers (ASHRAE), Attanta, GA, volume 1, number 4, pages 75 fi, Aprii 1959 (RDB2302)

S. Nishizaki and A. Muramoto, Evaluation of Hermetic Motor Insulation Systems, Proceeclings of the Ninth Electrical Insulation Conference, Boston, MA, pages 250-253, 1969 (RDB2918)

H. M. Parmelee (E. I. DuPont de Nemours and Company), Sealed-Tube Stability Tests on Re- frigeration Materials, paper 1924, Transactions, American Society of Heating, Refrigerating, and AirConditioning Engineers (ASHRAE), Atlanta, GA, volume 71, part 1, pages 154-161 and 167-168, January 1965 (10 pages with 29 tables, RDB0013)

This paper summarizes an investigation into the stability of fluorocarbon refrigerants alone and in the presence of oils, metals, nonmetallic components of refrigeration systems, and residual cleaning and degreasing agents. It is based on sealed-tube stability tests, performed at elevated temperatures, for periods as long as three years. Results are reported for R-11, R-12, R13B1, R-22, R-113, R-114, R-115, R-124, R-216, R-C318, R-500, and R-502. The lesting included examination of decomposition products, specifically including the fraction converted into other refrigerants. The metals tested included aluminum, brass, cadrnium, copper, iron, lead, magnesium, mercury, steel, and zinc. The effects of selected additives and inhibitors, including phenyl alpha naphthylamine, molybdenum disulfide, and tricresyl phosphate (TCP), also were examined. The paper concludes that the life of a system should be longer if made chemically simpler, because every added material provides a possibility of increased chemical reactions.

K. S. Sanvordenker (Teeumseh Products Company). Materials Compatibility Concerris for Retrigerator-Freazers - A Historic Perspective and a Look to the Future, paper 3.2, Proceedings of the International Seminar on New Technology of A/ternative Refrigerants - Lubricants and Materials Compatibility (Tokyo, February 1983), Japanese Association of Refrigeration (JAR), Tokyo, Japan, pages 39-44, February 1993 (8 pages with 2 tables, preprint available from JMC as RDB3116)

The paper traces compatibility concerns for refrigerator-freezers, from historic use of R-764 (sulfur dioxide) and R-40 (methyl chloride) to present use of R-12. Sludge deposition with oils led to an oil-free, belt-ditven model, using R-764, as early as 1913. R-764 achieved 90\% penetration around 1925, but was limited to open-drive compressors. The diving force for hermetic systems was the problem of leaks, particularly with sulfur dioxide. Identification of an appropriate lubricant led to introduction of hermetic compressors. The initial solution was a highly refined mineral ofl, referred to as white oil. The paper reviews introduction of R-40 in the 1930s, in both open and hermetic compressors. reaching a peak of $20 \%$ penetration. It avoided subatmospheric operation, thereby eliminating introduction of air and moisture. The required compressor displacement was smaller, discharge temperatures much lower, and compati- 
billty with mineral oils higher; but, it was flammable and toxic. Incompatibility with aluminum, particularty in dry systems, led to demise of R-40 use. R-12 came in as the successor fluid in the late 1930s, though the paper also cites early use of R-21 and F-114. R-12 became dominant because of its thermodynamic properties, positive pressure operation, full miscibility with mineral oils, and compatibility with metals and other materials of construction. Compatibility problems resulted later, in seeking smaller compressors and associated increases in discharge temperatures. The paper briefly outlines the resolution of these problems. It then turns to recent environmental concerns with chlorofluorocarbon refrigerants, and introduction of R-134a. Compatibility issues are discussed, with emphasis on lubricant interactions. Tables are included to summarize the effects of temperature and metals (steel, copper, and aluminum) on decomposition for tuth polyalkylene glycol (PAG) and polyol ester (PCE' lubricants. The role of metal passivation is outlined, particularly for POEs with steel. Chemical reactivity, miscibility, solubility, lubricity, suitability with motor materials, and contaminant issues are reviewed. The paper cites consideration of $R$ 152a, particularly in developing countries, and future refrigerant candidates. Compatibility is indicated as manageable with R-152a, partly based on experience with R-500 of which it is a component; flammability is cited as a concern. The paper concludes by noting the role of the Materials Compatibility and Lubricant Research (MCLR) Program.

H. O. Spauschus (Spauschus Associates, Incorporated), Compatibility Requirements for CFC ALternatives, International Journal of Refrigeration, Paris, France, volume 13, number 3, March 1990, pages 73-78 (6 pages, RDB1101)

This paper reviews the materials compatibility and fluid property information required for design and successful commercial application of air-conditioning and refrigeration equipment. Information on alternative refrigerants, including the leading candidates, future prospects, and long-term possibilties, are summarized. Methods of prodicting compatibility based on structural information and modeling are proposed.

W. O. Walker, S. Rosen, and S. L. Levy, Stability of Mixtures of Refrigerants and Refrigerating Oils, ASHRAE Journal, American Society of Heating, Refrigerating, and Air-Conditioning Engineers (ASHRAE), Atlanta, GA, volume 4, number 8 , pages 5972, August 1961 (RDB2323)

\section{R-12}

A. Factor and P. M. Miranda (General Electric Company). An Investigation of the Mechanism of the R12-Oil-Steel Reaction, Wear, Elsevier Sequoia, Lausanne, Switzerland, volume 150, pages 41-58, 1991 (18 pages with 3 figures and 12 tables, RDB2309)

A study of chemical interactions between R-12, hydrocarbon lubricating oils, and steel is summarized. While R-12 is quite stable thermally, it deromposes rapidly when heated above $150^{\circ} \mathrm{C}$ $\left(300^{\circ} \mathrm{C}\right)$ in the presence of oils and metals, such as iron or aluminum. Sealed-tube tests were performed for 3 days at $200^{\circ} \mathrm{C}\left(392^{\circ} \mathrm{F}\right)$, using a naphthenic mineral oil (Witco Suniso(P) 3GS), to simulate conditions in an operating hermetic refrigeration compressor. The mechanism of the degradation reaction was explored by testing the effect of the presence of various probe and model compounds. The paper reviews prior studies, presents the experimental approach, and summarizes the subsequent analyses. It identifies the additives, free radical initiators, and inhibitors used to explore reactions and to passivate steel surfaces. The results of gas chromatography and GPC analyses are tabulated. The results indicate that except for formation of some $\mathrm{FeCl}_{3}$ and $\mathrm{R}-22$, free radical reactions do not appear to play a major role. The preponderance of the data indicates that Friedel-Crafts reactions, especially alkylation, play a key role in the decomposition.

D. E. Kvalnes and H. M. Parmelee, Behavior of Freon-12 and Freon-22 in Sealed Tube Tests, Refrigerating Engineering, American Society of Refrigerating Engineers (ASRE, now merged into the American Society of Heating, Refrigerating, and Air-Condtioning Engineers, ASHRAE), Atlanta, GA, volume 65, number 11, pages 4 ff, November 1957; republished as bulletin 25, E. I. DuPont de Nemours and Company, Incorporated, Wilmington, DE (RDB2322)

\section{$\underline{\mathbf{R}-22}$}

J. P. Hurtgen, R-22 Blister Testing of Magnet Wire, Proceedings of the Tenth Electrical Insulation Conference, Chicago, IL, pages 183-185, 1971 (RDB2917)

H. O. Spauschus and G. C. Doderer (General Electric Company). Chemical Reactions of Refrigerant 22, Transactions, American Society of Heating, Refrigerating, and Air-Condhioning Engineers (ASHRAE), Atlanta, GA, volume 71, part I, pages $162 \mathrm{ff}, 1965$ (RDB2327) 


\section{R-123}

R. G. Doerr (The Trane Company), Abserption of HCFC-123 and CFC-11 by Epoxy Motor Varnish, paper 3621 (Annual Meeting, Baltimore, MD, June 1992; previously presented at Annual Meeting, Indianapolis, IN, June 1991), Transactions, American Society of Heating, Refrigerating, and Air-Conditioning Engineers (ASHRAE), Atlanta, GA, volume 98, part 2, pages 227-234, 1992 (8 pages with 9 figures, RDB2606)

This paper summarizes a study to determine the parameters that influence absorption of R-11 and $R-123$ by varnishes and the effect of the $a b$ sorbed refrigerants on chemical and physical properties. These varnishes hold motor windings together and act as secondary electrical insulation, filling in voids created during the winding process. Interest in the subject stems from observations that motor varnishes can absorb considerable amounts of R-123 with varying effects. The effects of cyclic and continuous exposures at high temperature and pressure, relative rates of absorption and desorption, existence of an equilibrium absorption value, and effects of temperature on the rate of absorption and the equilibrium are discussed. The experimental procedure, based on weight gain during thermal aging followed by drying, is outlined. Four varnishes were tested; they are identified as a recently introduced solventless type, a common solvent-based type, a 100\% solids type, and a water-borne epoxy. The paper concludes that absorption is the same for cyclic and continuous exposures, that desorption is extremely slow to nonexistent at $21^{\circ} \mathrm{C}\left(70{ }^{\circ} \mathrm{F}\right)$, and that full desorption would require in excess of 1000 hours at $121^{\circ} \mathrm{C}\left(250^{\circ} \mathrm{F}\right)$. It also notes that absorption increases until an equilibrium is established; while the rate differs widely for different varnishes, the rate is more rapid at higher temperatures. The equilibrium value is linearly dependent on temperature, with greater absorption at lower temperatures, for R-123, but relatively independent of temperature for R-11. The paper outlines two key implications for compatibility testing: 1) Low temperature and pressure may be a more severe environment for materials than high temperature and pressure, and 2) tests must be continued long enough to be certain that equillbrium is reached at lower temperatures.

H. B. Ginder, Compatibility Test - 15\# Carbon Bursting Disk (2.5"), York International Corporation, York, PA, July 1989 (1 page, available from JMC as RDBO011)

A $64 \mathrm{~mm}\left(21 / \mathrm{k}^{\prime \prime}\right)$ carbon bursting disk was immersed in R-123 at room temperature for 16 days. Subsequent testing for leaks and poros- ity, using R-22, indicated that the disk did not develop leaks.

H. B. Ginder, Compatiblilty Test - O-Rings, Gasket, OII Fitter, Etc., York International Corporation, York, PA, July 1989 (1 page with 1 table, available from JMC as RDBO009)

A table summarizes the swelling of various materials immersed in R-123 and R-11. The materials include elastomeric (DuPont Viton(R), Buna(TM) $N$, and neoprene) o-rings, a Buna(TM) $\mathrm{N}$ bushing, and components of a Kaydon oil-line filter (cork and Buna(TM) $\mathrm{N}$ gaskets, pleated paper, and adhesive). Quantitative results are presented after a two week exposure at room temperature in a mixture of $90 \%$ refrigerant and $10 \%$ naphthenic oil. The R-123 test samples swelled considerably more than the R-11 samples. The Buna N bushing swelled $79 \%$ in R-123, as compared to $7.1 \%$ in R-11. The document concludes that Buna $N$ formulations are not too compatible with R-123, but that Viton and neoprene appear to be acceptable. Compatibility concerns also are cited for the gaskets and adhesive in the oil filter.

T. P. Gross, Compatibility Test - Green-Colored Viton O-Ring, York International Corporation, York, PA, July 1989 (1 page, available from JMC as RDB0012)

Swell data are presented for green-colored fluoroelastomeric (DuPont Viton(R) o-rings) immersed in R-123 and R-11 for three week at room temperature. The o-rings showed initial linear swell of $19.8 \%$ in R-123, which changed to 4.4\% after drying overnight. Samples exposed to R-11 showed initial linear swell of 3.0\%. The elastomers exhibited no significant loss in physical properties in either fluid.

T. P. Gross, Compatibility Test - Loctite Sealants (Plpe Sealant with Teflon, Grade AV), York International Corporation, York, PA, July 1989 (1 page, available from JMC as RDB0010)

Two Loctite(R) compounds (pipe sealant with DuPont Tefion(R) and Grade AV) were applied to threaded fittings and tested with liquid R-123. The report indicates that the two compounds tested appear to be compatible with R-123, based on a seven-day perlod of exposure and curing. The test procedure and curing considerations for sealants are discussed.

Compatibility of Alternative Refrigerants with Elastomers, report NIST-11, E. I. DuPont de Nemours and Company, Incorporated, Wilmington, $D E$, undated (3 pages available from JMC as RDB0307) 
This report summarizes an investigation to determine the compatibility of two elastomers, Neoprene W and Buna(TM) N, with R-123 and R124. Swell data are tabulated after immersions for 1 hour and 1, 2, and 3 days at room iemperature. Qualitative observations on discoloration of the refrigerant also are reported. Based on a criterion of swell substantially exceeding $10 \%$, both elastomers were deemed incompatible with R-123 and Buna $N$ was judged incompatible with R-124. The experimental procedure is outlined.

Decomposition Rates of R-11 and R-123, Carrier Corporation, Syracuse, NY, September 1989 (3 pages with 3 figures, available from JMC as RDB0019)

The fraction of R-123 that decomposes in solution with alkylbenzene lubricant after 14 days is plotted as a function of temperature. Less than $1 \%$ decomposition was measured at 82 and 121 ${ }^{\circ} \mathrm{C}\left(180\right.$ and $250^{\circ} \mathrm{F}$ ), but this increased to $6.2 \%$ at $177^{\circ} \mathrm{C}\left(350^{\circ} \mathrm{F}\right)$. Decomposition of R-11 and R-123 after 4 and 14 days, respectlvely, at 121 ${ }^{\circ} \mathrm{C}\left(250^{\circ} \mathrm{F}\right)$ is compared for mixtures of $5 \%$ lubricant by weight. One alkylbenzene (Zerol(R) 300) and four mineral oils (Mobil DTE Heavy Medium, Mobil DTE 26, Rando HD-68, and Witco Suniso(R) 4GS) were tested.

Elastomer Immersion Tests for Fluorocarbon123, technical report NIST-8, Freon(R) Products Laboratory, E. I. DuPont de Nemours and Company, Incorporated, Wilmington, DE, undated i5 pages with 2 tables, available from JMC as RDB. 0304)

Results are summarized for immersion tests of 13 elastomers in R-123 for up to seven days at 75 and $130{ }^{\circ} \mathrm{F}\left(24\right.$ and $\left.54{ }^{\circ} \mathrm{C}\right)$. Quantitative results of the linear-swell tests are provided, including intermediate and final changes in length and weight as well as the fraction of extractaciss. Qualitative changes in appearance and physical properties of the elastomers and in the appearance of the liquid are tabulated. The tested elastomers were two urethane rubbers (Uniroyal Adiprene(R) C and Adiprene(R) $L$ ), a hydrocarbon rubber (DuPont Nordel(R)), a fluoroelastomer (DuPont Viton(R) A), a silicone rubber (General Electric SE-361), a nitrile sillcone rubber (NSR-X5602), a synthetic rubber (DuPont Hypalon(R) 40), natural rubber, polysulfide rubber (Thiokol(R) FA), Buna(TM) N, Buna(TM) S, chloroprene (neoprene $W$ ), and Butyl(TM). Of those tested, only Thiokol FA appears suitable for use and prolonged contact with R-123.

Evaluation of Epoxy Varnish Materials for Alternative Refrigerant HCFC-123, report NIST-13,
Chemistry Laboratory, The Trane Company, La Crosse, WI, 25 August 1989 (9 pages with 8 tables, avallable from JMC as RDB0034)

This report presents measured and observed findings for sealed-tube tests varnishes used as insulation for motors in hermetic compressors. Results are tabulated before and after thermal aging in air, R-11, and R-123 for Sterling(R) 364, water-borne opoxy (Schenectady Isopoxy(R) 800). Schenectady 8620, Epoxylite 477, and solvent epoxy (P. D. George 923) varnishes. The exposures were made at $121^{\circ} \mathrm{C}\left(250^{\circ} \mathrm{F}\right)$ for 168 hours (1 week). Changes to the pre-exposure conditions are reported immediately after exposures and after drying for different periods, depending on the material. A final table summarizes extraction measurements on the varnishes after exposures. The preparatory curing conditions for the samples also are documented.

HCFC-123 Compatibility with Teflex NPG V-214 O-Rings Covered with High Density Tefion, report NIST-11, Chemistry Laboratory, The Trane Company, La Crosse, WI, 16 March 1989 (1 page, available from JMC as RDB0032)

Results of swell testing tetrafiuoroethylene (TFE, DuPont Tefion(R)) coated DuPont Viton(R) 0rings in R-123 at $100^{\circ} \mathrm{C}\left(21{ }^{\circ} \mathrm{F}\right)$ are reported. The Teflon $(R)$ coating was permeated, causing the Viton core to swell. Testing stopped after 72 hours due to o-ring fallure.

HCFC-123 Retrigerant Analyses, report NIST-9, Chemistry Laboratory, The Trane Company, La Crosse, WI, 24 November 1988 (1 page with 1 table, available from JMC as RDB0030)

A table compares the purtty of new, used, and distilled-used specimens of R-123. No change from now R-123 was found by gas chromatography after use in model CVHE hermetic centrifugal chillers. Quantitative results are compared for moisture content and high-boiling residue. The high-boiling residues increased from 6 to $1591 \mathrm{ppm}$ in use, but dropped to 1 $\mathrm{ppm}$ after redistillation. Moisture content decreased from 36 to $21 \mathrm{ppm}$, but increased to 31 ppm after redistillation.

Material Compatibility of Alternative Refrigerants: Usability/Compatibility of R-123 Received from Retrigeramt Suppliers, report NIST-2, Chemistry Laboratory. The Trane Company, La Crosse, WI, 15 April 1988 (2 pages with 1 table, available from JMC as RDB0023)

This report of chemical analyses addresses the compatibility of R-123 samples from AlliedSignal and DuPont Chemicals with red neoprene 2337 elastomer material. Test rings were exposed to 
R-123 in both vapor and llquid phases for 168 hours at $77^{\circ} \mathrm{C}\left(170^{\circ} \mathrm{F}\right)$ using Trane Standard Test Method 3.7-04. Control samples were similarly exposed to R-11. Cross-sectional diameter, volume swell, and durometer hardness are tabulated before and after exposures. Some extraction of processing and/or base oils was observed with all three refrigerant samples. No precipitation of waxllke materials, cracks, or blisters were evident in any of the refrigerants. The increases in dlameter and volume and decreases in durometer hardness were lower in R123 than in R-11. The differences between results from the two R-123 samples were minor.

Material Compatibility of Alternative Retrigerants: Usability/Compatibility of R-123 Received from Refrigerant Suppliers, report NIST-3, Chemistry Laboratory, The Trane Company, La Crosse, WI, 15 April 1988 (4 pages with 2 tables, available from JMC as RDB0024)

Swell tests of elastomeric compounds in R-11 and $\mathrm{R}-123$ at $77^{\circ} \mathrm{C}\left(170^{\circ} \mathrm{F}\right)$ for 72 hours are reported. The elastomers included yellow nitrile 7507, red neoprene 2337, and green neoprene 2167. Quanttative data are presented for volume swell, cross-sectional diameter, and durometer hardness. Nitrile swelled $400-600 \%$ more in R-123 than in R-11. The neoprene samples exposed to R-123 exhibited less or comparable swelling to those exposed to R-11.

Material Compatibility of Alternative Refrigerants: Usability/Compatibility of R-123 Received from Refrigerant Suppliers with Elastomer Materials, report NIST-4, Chemistry Laboratory, The T.ane Company, La Crosse, WI, 10 May 1988 (3 pages with 2 tables, avallable from JMC as RDB0025)

Swell and durometer test data are tabulated for yellow nitrile 7507, red neoprene 2337, and green neoprene 2167 test rings exposed to $50 / 50$ mixtures of R-11 and R-123 with 250 SUS white oil. The tests were repeated for separate samples of R-123 from AlliedSignal and DuPont Chemicals. Samples were aged in stainless steel test vessels for 3 days ( 72 hours) at $77^{\circ} \mathrm{C}$ $\left(170{ }^{\circ} \mathrm{F}\right)$. Cross-sectional dlameter, volume swell, and durometer hardness were measured both before and after exposures, for both the vapor and liquid phases of the refrigerants, and compared. The hardness measurements were repeated after 2-3 days of drying to allow offgasing.

Material Compatibility of Alternative Refrigerants: Compatibility of R-123 Recelved from Refrigerant Suppliers with Proposed Elastomer Materials, report NIST-5, Chemistry Laboratory, The Trane Company, La Crosse, WI, 6 June 1988 (2 pages with 1 table, available from JMC as RDB0026)

Measurements of weight, volume, density, dimensions, and durometer hardness are reported for polysulfide rubber (Morton Thlokol(R) ST). Data are compared before and after exposures to both the vapor and liquid phases of R123. Aging was performed in stainless steel test vessels for 3 days $\left(72\right.$ hours) at $77^{\circ} \mathrm{C}(170$ \% $\mathrm{F}$. The tabulated data summarize measurements for tests in the refrigerant alone and in a 50/50 mixture with 250 SU'S white oll. The tests were repeated for separate samples of R-123 from AVliedSignal and DuPont Chemicals. Data for exposures to the AlliedSignal R-123 refrigerant withciut lubricant were lost, due to an experimental problem, and were not remeasured. The document concludes that this rubber formulation would not be acceptable as an elastomer for use in a R-123 environment, but it does not rule out use of other polysulfide rubbers. The test data suggest that this rubber compound is affected more severely by $100 \%$ R-123 than by the mixture of R-123 and lubricant.

Material Compatibility of Alternative Refrigerant 123: Elastomer Chemistry of and Specifications for Chloroprene, report NIST-8, Chemistry Laboratory, The Trane Company, La Crosse, WI, 10 November 1988 (2 pages with 1 table, avallable from JMC as RDBO029)

This document compares the elastomer chemistry of chloroprene rubber for use in R-123. The formulations tested included 2337 (red dot), 2167 (green dot), and 2347 (new compound) orings as well as 2167 (green dot) cord ring. Chemical properties obtained from infrared spectra, volumetric swell, and durometer hardness were compared as recelved, after heat aging in ail for $168 \mathrm{hr}$ at $100^{\circ} \mathrm{C}\left(212^{\circ} \mathrm{F}\right)$, and after thermal aging at the same conditions in ASTM \#3 oil, 250 SUS white oil, and R.123 vapor. Tests also were performed after immersion in R-11 liquild, R-11 vapor, and R-123 llquid for neoprene 2347. The resulting data are tabulated.

Material Compatibility of Alternative Refrigerant 123: Physical Properties of O-Rings for Appltcability in Alternative Refrigerant 123 and Retrigerant 11, report NIST-7, Chemistry Laboratory, The Trane Company, La Crosse, WI, 27 October 1988 (2 pages with 2 tables, available from JMC as RDB0028)

The tensile strength, elongation, and fluid resistance of neoprene 2347 (size 222) o-rings were tested. Measured values were compared for materials as recelved, after heat aging in air for $168 \mathrm{hr}$ at $100^{\circ} \mathrm{C}\left(212^{\circ} \mathrm{F}\right)$, and after thermal ag-
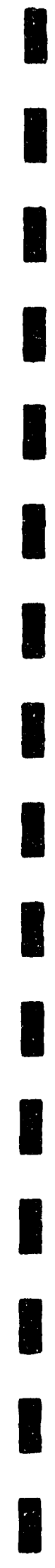

I 
Ing at the same conditions in ASTM *3 oll, 250 SUS white oll, R-11, and R-123. Heat aging was performed and fluid resistance was measured in accordance with ASTM D573 and D471, P $\theta-$ spectively. The tabulated data indicate less change for R-123 than for R-11, and that the decrease in tensile strength and elongation for $R$ 123 is similar to that after immersion in ASTM \#3 oil.

Material Compatibility of Alternative Refrigerant 123: Short Term Sultability of Chloroprene Sheet Gasket Material, report NIST-6, Chemistry Laboratory, The Trane Cornpany, La Crosse, Wi, 7 OCtober 1988 (1 page, available from JMC as RDB0027)

Results are qualitatively summarized for compression and flexibility tests of Reinz chloroprene sheet gasket material exposed to R-123. The exposures were for 24 hour at $25^{\circ} \mathrm{C}\left(77^{\circ} \mathrm{F}\right)$ and at $100^{\circ} \mathrm{C}\left(212^{\circ} \mathrm{F}\right)$. All samples (hot and cold) failed when folded before reacining a $180^{\circ}$ angle.

Metal Corrosion Tests with [HC]FC-123 and Distilled Water, report NIST-10, E. I. DuPont de Nemours and Company, Incorporated, Wilmington, $D E$, undated (5 pages with 2 tables, available from JMC as RDB0306)

Compatibility results of R-123 and distilled water with cold-rolled steel 1020, stainless steel 304, nicket, monel, copper, aluminum 2S, zinc, and magnesium alloy FS-1 are reported for dry and wet conditions. Results are tabulated at the liquid boiling point after exposure for 100 hours and after 100 days at $55^{\circ} \mathrm{C}\left(130^{\circ} \mathrm{F}\right)$. Decomposition of the R-123, metal corrosion rates, and the appearances of the liquid and metal are presented. R-123 was judged sultable with all of the metals under dry-test conditions, but sultable only with the stainless sted after 100-day wet exposure. Additionally, only the stainless steel, nickel, and monel showed no corrosion after the 100 -day wet-exposure test.

Moisture Solubility in R-123 and R-134a, research project 602-RP, American Society of Heating, Refrigerating, and Air-Conditloning Engineers (ASHRAE), Atlanta, GA, March 1989 - ongoing (ASH0602)

This project will determine the moisture solubility of R-123 and R-134a. Measurements will be made in the range of -23 to $66^{\circ} \mathrm{C}\left(-10\right.$ to $\left.150^{\circ} \mathrm{F}\right)$ for the llquid phase and at a single temperature in the vapor phase. The data are needed to determine the corrosion characteristics of these refrigerants. The contractor is the University of Alabama, led by J. S. Thrasher; the project is sponsored by ASHRAE Technical Committee

\section{3, Contaminant Control in Refrigerating Sys- tems.}

Motor Insulations in R-123 and R-134a, Carrier Corporation, Syracuse, NY, September 1989 (2 pages with 2 figures, available from JMC as RDB. 0015)

Two charts show the effects of R-123 and R134a on cured motor insulations. XV-572, XV. 587, water-borne epoxy (Schenectady Isopoxy(F) 800), solvent epoxy (Sterling(R) U-475), and polyester (Dolphon) varnishes were tested for weight change, percent extraçtables, and Shore D hardness loss. Quantitatlve data, after aging for ten days at $93^{\circ} \mathrm{C}\left(200^{\circ} \mathrm{F}\right)$ for $\mathrm{R}-123$ and at $38^{\circ} \mathrm{C}\left(100^{\circ} \mathrm{F}\right)$ for R-134a, are given.

Mutual Solubilities of Water with Fluorocarbons and Fluorocarbon-Hydrate Formation, report NIST-12, E. I. DuPont de Nemours and Company, Incorporated, Wilmington, DE, undated (16 pages with 4 figures and 7 tables, available from JMC as RDB0308)

Test procedures and results are described for an investigation of the mutual solubility of water and of solld hydrate formation with R-123, R124, and R-125. Measured and calculated solubility data are tabulated in the temperature range of $77-167{ }^{\circ} \mathrm{C}\left(171-333^{\circ} \mathrm{F}\right)$ for $\mathrm{R}-123$ and $\mathrm{R}$ 124 and $77-138^{\circ} \mathrm{C}$ (171-280 $\left.{ }^{\circ} \mathrm{F}\right)$ for $\mathrm{R}-125$. Regression equations and plots of the data are provided to compare the data to prior measurements for R-22, R-113, and an unidentified fluid. Solubility coefficients are plotted for these fluorocarbons in water for $0-120^{\circ} \mathrm{C}\left(30-250^{\circ} \mathrm{F}\right)$ at saturated vapor pressure conditions. The fraction of fluorocarbon by weight in water are similarly presented and plotted at saturated vapor and atmospheric pressures. The results coupled with those of earlier work indicate that R-125, R-134a, R-142b, and R-152a form solid water hydrates, but that R-123 and R-124 do not. The document discusses implications of the findings on specifications for water content in the refrigerants examined.

Plastic Immersion Tests in Fluorocarbon-123, report NIST-7, E. I. DuPont de Nemours and Company, Incorporated, Wilmington, DE, undated (5 pages with 2 tables, avallable from JMC as RDB0303)

Results of compatibility tests are presented for 13 plastics, after immersion for four hours at 24 ${ }^{\circ} \mathrm{C}\left(75^{\circ} \mathrm{F}\right)$ and after thermal-aging for 100 hours at $54^{\circ} \mathrm{C}\left(130^{\circ} \mathrm{F}\right)$ in $\mathrm{R}-123$. The plastics included linear polyethylene (Alathon(A) 7050), polypropylene (Alathon(R) 9140), cast methy'methacrylate resin (Lucite(R)), nyton (DuPont Zytel(R) 101), tetrafluoroethylene (TFE, DuPont Teflon(R) type 1), polycarbonate resin (GE 
Lexan(R)), ABS polymer (Kralastic(R)), polystyrene (Styron(TM) 475), epoxy (G-10-3675), ethyl celluiose, acetal resin (DuPont Delrin(R) $500 \mathrm{X}$ ), polyvinyl alcohol, and unplasticized polyvinyl chlorlde. Quantitative data are presented for length change, weight change, and for percent extractables. The appearances of the plastic and liquild R-123 are described. The linear polyethylene, nylon, epoxy, acetal, and polyvinyl chloride plastics tested were judged to be compatible with R-123.

Polymer/Elastomer Performance in R-123 and R-134a, Carrier Corporation, Syracuse, NY, September 1989 (4 pages with 3 figures, avallable from JMC as RDBO018)

Two graphs compare swell for polymers and elastomers in R-11 and R-123 at room temperature and at $93^{\circ} \mathrm{C}\left(200^{\circ} \mathrm{F}\right)$. The materials include a nitrile copolymer, fluoroelastomer (DuPont Viton(R) A), isoprene (neoprene), nylon, phosphazene (Eypel-F), polytetrafluoroethylene (PTFE, Gylon), polyolefin (Alcryn), polypropylene, olefinic thermoplastic (Geolast(R)), and polyester thermoplastic (DuPont Hytrel(R)). R123 produced much greater swelling than did $R$ 11. Quantitative values are given for swell and extractables of elastomeric materials in R-134a at $93^{\circ} \mathrm{C}\left(200{ }^{\circ} \mathrm{F}\right)$ for ten days. These materials include Gylon, neoprene, nitrile, nylon 6/6, polypropylene, and Viton $A$.

[R-]123 Refrigerant Analyses, report NIST-1, Chemistry Laboratory, The Trane Company, La Crosse, WI, 14 March 1988 (1 page with 1 table, available from JMC as RDB0022)

A table compares the chemical purity of R-123 samples, from AlliedSignal and DuPont Chemicals, with distllled R-11. Results are tabulated for chloride-ion content, high boiling temperature impurties, neutralization value, moisture content, and organic purity determined by gas chromatography. The moisture content in the R-123 samples was higher than expected, but not judged to be significant.

Refrigerant Breakdown Voltage, Buffalo Research Laboratory, AlliedSignal Incorporated, Buffalo, NY, 1 May 1990 (1 page wth 1 table, avallable from JMC as RDB0512)

Refrigerant breakdown voltages, as determined by ASTM D-2477-84, are tabulated for R-11, R12, R-22, R-123, and R-134a at $21^{\circ} \mathrm{C}\left(70^{\circ} \mathrm{F}\right)$ and $93^{\circ} \mathrm{C}\left(200^{\circ} \mathrm{F}\right)$.

See $:$ : Tube Stability Test Results: Alternative Refrigerants, Carrier Corporation, Syracuse, NY. September 1989 (1 page with 1 table, available from JMC as RDBO020)
A table summarizes the decomposition fraction of R-11, R-12, R-123, and R-134a with Witco Suniso(R) 3GS and MobN DTE 26 mineral oils and with Zerol(A) 150 and Zerol 300 alkylbenzene lubricants. No decomposition was detected for R-134a; some R-12 decomposed into R-22. R-123 decomposed less than R-11 for all four lubricants.

Stability of CFC-11 and HCFC-123, report NIST12. Chemistry Laboratory, The Trane Company, La Crosse, WI, 17 April 1989 (3 pages with 1 table, available from JMC as RDB0033)

Sealed-tube test results are compared for $R-11$ and R-123 after exposure to 250 SUS white mineral oil and metallic catalysts (aluminum, copper, and steel). Qualitative and quantitative decomposition effects are presented after 168 hours at $100^{\circ} \mathrm{C}\left(212^{\circ} \mathrm{F}\right), 121^{\circ} \mathrm{C}\left(250^{\circ} \mathrm{F}\right)$, and $150^{\circ} \mathrm{C}\left(302^{\circ} \mathrm{F}\right)$. The thermal stability of R-123 and oil was judged to be greater than the thermal stability of R-11 and ofl.

Summary of Physical Property, Solubility, and Compatibility Data for [HC]FC-123, report NIST-9, E. I. DuPont de Nemours and Company, Incorporated, Wilmington, DE, undated (11 pages with 3 figures and 4 tables, avallable from JMC as RDB0305)

Liquid density, vapor pressure, viscosity, surface tension, and Kauri-butanol number are provided for R-123. The solubility of water and various substances in R-123 also are given. Additionally, the report qualitatively summarizes compatibility tests with various magnet wire varnishes, including Alkanex terephthalate polyester, enamel oleoresin, Ensolex acrylic, epoxy. Anavar isocyanate-modified polyvinyl, Lecton acrylic, Nylclad nylon-coated polyvinyl, polyimide, polyurethane, and Formvar polyvinyl.

Teflex O-Rings, Size 214, Sealmore Industries, report NIST-10, Chemistry Laboratory. The Trane Company, La Crosse, WI, 27 January 1989 (1 page with 1 table, available from JMC as RDB0031)

A table compares the swell properties of Teflex O-rings in R-11, R-123, and in 250 SUS white oil with each refrigerant in a $50 \%$ refrigerant $\mathrm{mix}$. ture. Quantitative results are presented after a 70 -hour exposure at $77^{\circ} \mathrm{C}\left(170^{\circ} \mathrm{F}\right)$. The R-123 samples exhibited a volume change thre-times higher than those of the R-11 samples. However, the o-ring density changes were comparable for the R-11 and R-123 refrigerant-lubricant mixtures.

Viton O-Ring and Cord Ring Swell Data in Both R-11 and HCFC-123, report NIST-14, Chemistry Laboratory, The Trane Company, La Crosse, WI, 13 
September 1989 (1 page with 1 table, available from JMC as RDB0035)

Comparisons are presented for immersion of fluoroelastomer (DuPont Viton(R)) o-rings and cord rings in R-11 and R-123. Data are tabulated for 70 -hour exposures at $77^{\circ} \mathrm{C}\left(170^{\circ} \mathrm{F}\right)$. The volume change of the Viton materials in R. 123 was found to be approximately three times that for R-11.

UL 984 Tests with R-123 and Oils, Carrier Corporation, Syracuse, NY (1 page with 1 table, avallable from JMC as RDB0016)

A table summarizes modified UL 984 tests of motor materials aged at $82{ }^{\circ} \mathrm{C}\left(180^{\circ} \mathrm{F}\right)$ for 60 days. Control results are compared to those after separate exposures to R-11 and R-123 mixed with 5\% M'Jbil DTE 26 mineral oil, Zerol(R) 150 alkylbenzene oil, and Rando HD-68. Insulation failures (1 ma current leakage to ground after 1 minute at $1.5 \mathrm{kV}$ ) and breakdown voltages are reported. Results are summarized for polyester-imide magnet wire, Dacron-Valox(R) lead wire, DuPont Teflon(R) wire sleeving, DuPont Mylar(R) end cap, Mylar-Dacron(R) thermosleeve, Mylar(R) and Melinex(R) slot liners, and Mylar and Melinex phase separators. Breakdown voltages of 2.7-17.0 kV, but no current leakage failures, are indicated.

\section{R-124}

P. R. Reed (DuPont Chemicals) and $H . O$. Spauschus (Spauschus Associates, Incorporated), HCFC-124 Applications and Properties: Comparisons with CFC-114, presentation charts prepared by Spauschus Associates, Incorporated, for E. I. DuPont de Nemours and Company, Incorporated, Wilmington, DE, undated (22 pages with 9 figures and 1 table, available from JMC as RDB. 1206)

The stability, miscibility, and lubricity of R-124 are compared to those of R-114. Qualitative data are presented for sealed-tube tests with metals (copper and steel) and unspecified 300 SUS mineral olls (paraffinic and naphthenic) and with an alkybenzene lubricant after 14 days at $175^{\circ} \mathrm{C}\left(350^{\circ} \mathrm{F}\right)$. The effects of high moisture content and of lubricant additives on refrigerant stability also are discussed. Alkylbenzene lubricants were judged to be the most suitable for use with R-124.

\section{R-134a}

D. J. Bateman (DuPont Chemicals), Current Development Status of HFC-134a for Automotive Air Condkioning, paper 900213 (SAE International Congress and Exposition, Detrolt, MI, 26 February. 2 March 1990), Socjety of Automotive Engineers (SAE). Warrendale, PA, February 1990 (15 pages with 6 figures and 11 tables, RDB2201)

A. P. Cohen, S. R. Dunne, and J. J. Seman, Desiccants for Drying R-134a in Refrigeration Systems, UOP Research and Molecular Sieve Tech. nology, Tarrytown, NY, Aprll 1988 (16 pages with 8 figures and 4 tables, avallable from JMC as RDB0003)

Thls document summarizes tests of the effectiveness, compatibility, and physical strength of three Union Carbide Molecular Sieves for use as desiccants for R-134a. The molecular sieves tested were $4 A-X H-5$ and $4 A-X H-6$, both commercial products, as well as XH-7, a developmental item; all three were tested as $8 \times 12$ mesh beads. These desiccants were exposed to R134a and a polyalkylene glycol lubricant (Union Carbide UCON LB-525) at $82{ }^{\circ} \mathrm{C}\left(180^{\circ} \mathrm{F}\right)$ and then tested for fluoride content, water capacity. crush strength, and attrition. Plots of fluoride uptake and water-retention capacity, as functions of equivalent exposure time, are provided along with plots of water capacity, crush strength, and attrition versus fluoride content. Isotherms were generated for the three desiccants in R-134a. The document recommends against use of $4 A-X H-5$, currently used for $R-12$ drying, with R-134a. It suggests that the choice between the remaining types be based on the cost versus required performance, especially with respect to their relative strength characteristics. Significant build-up of fluoride was detected on the 4A-XH-5 molecular sieve, due to chemical reaction between R-134a and the desiccant. Further information on a long-term test of a 4A-XH-6 sample addressed is provided in document RDB0309.

S. Corr, P. D. Guy, R. D. Gregson, N. M. Sammes, G. Tompsett (ICl Chemicals and Polymers, Limited), and T. W. Dekleva (ICl Americas, Incorporated), Materials Compatibility and System Stability Studies with R-134a and Alternative Lubricants, seminar presentation at the ASHRAE Annual Meeting, (St. Louis, MO), ICl Americas Incorporated, New Castle, DE, USA, 12 June 1990 (30 pages with 23 charts, RDB2523)

P. D. Guy, G. Tompsett (ICl Chemicals and Polymers, Limited), and T. W. Dekleva (ICI Americas, Incorporated), Compatibilinies of Nonmetallic Materials with R-134a and Alternative Lubricants in Refrigeration Systems, paper AN-92-5-4 Winter 
Moeting, Anahoim, CA, January 1992), Transactions, American Soclety of Heating, Refrigerating, and Air-Condtiloning Engineers (ASHRAE), Atlanta, $\mathrm{GA}$, volume 98, part 1, pages 804-816, 1992 (13 pages with 17 tables, RDB2104)

This paper reviews the compatiblity of nonmetallic materials with R-134a and associated lubricants, based on sealed-tube tests as well as analytical investigations of compressor life tests and field evaluations. The test and analytical methods used also are reviewed. The materials addressed include ethylene propylene dimer monomer (EPDM) rubber, fluorinated polymer, natural rubber, nitrile rubber, nylon, and polyethylene terephthalate (PET). Data on weight, volume, tensile-strength, and elongation change as well as on hardness are compared to those for R-12 with naphthenic mineral oil. The paper notes that while an enormous amount of information has been developed by industry for compatibility of alternative refrigerants with associated lubricants and materials, most of it has not been published.

J. G. Johnson and T. E. Watson (SnyderGeneral Corporation), Retrigerant $134 a$ Compatibility with Centrifugal Chillers, paper 5.1, Proceedings of the International Seminar on New Technology of Alternative Refrigerants - Lubricants and Materials Compatibility (Tokyo, Fobruary 1983), Japanese Association of Refrigeration (JAR), Tokyo, Japan, pages $83-88$, February 1983 (6 pages with 4 figures and 6 tables, preprint available from JMC as RDB3117)

This paper reviews requirements for use of R$134 a$ in chillers with centrifugal compressors. The paper compares the thermodynamic properties of R-134a to those of R-12 and R-500. Data are tabulated to substantiate $4 \%$ lower mass flow, but higher isentropic lift requirements. Heat transfer characteristics also are compared, noting an overall improvement of $12 \%$ in condensers for R-134a over R-12 and 2$10 \%$ in evaporators. A plot compares the film coefficients for pool boiling for a range of typical heat fluxes. Scaling opportunities through dimensional analysis, to attain a range of capacities and accommodate different refrigerants, are illustrated. Tabular data compare efficiency with R-134a or R-500 to that with R-12. The paper then reviews materials compatibility issues, with attention to elastomers, plastics, metals, and motor materials. A plot compares swell for three nitrlles with R-134a, polyol ester mixed acid, polyol ester branched acid, and naphthenic mineral oils. Stability data based on sealed-tube tests, are compared for R-12, R-22, $R-123, R-134 a$, and R-500 and associated lubricants. The paper addresses lubricant solubllity, miscibility, and lubricity. A plot shows oil retum with R-12 and R-134a, with mineral oil and penta erythritol ester respectlvely, for a flooded evaporator. Test results are tabulated for a retrofit from R-500 to R-134a, showing a $10 \%$ loss in capacity and $2 \%$ increase in efficiency. Conversion requirements are outlined from R-12 to R134a. A final table compares pool boiling for $R$ 12 with mineral oil, R-134a with ester, and the latter pair with $5 \%$ residual mineral oil. The paper concludes that R-134a with ester lubricants offers similar or improved compatibility and better oil return and heat transfer. The efficiency is nearly the same for R-12, R-134a, and R-500. Conversions of R-500 machines can achieve $90 \%$ of original capacity without hardware changes. Retrofit of R-12 chillers requires changing the gear set and impeller, but results in comparable efficiency.

J. G. Johnson, R-134a, R-123, and Mineral Oil Compatibility with Steel, Aluminum, and Copper, SnyderGeneral Corporation, Staunton, VA, 4 September 1990 (4 pages with 1 figure and 1 table, available from JMC as RDB0902)

The chemical and thermal stability of R-123 and $R-134 a$ with Witco Suniso(R) 4GS mineral oil in the presence of ferrous and nonferrous metals were compared to that of R-12 and R-500 under the same conditions. Stability was gauged using sealed-tube tests for 14 days at $175^{\circ} \mathrm{C}$ (350 ${ }^{\circ}$ F); test results are compared by gas chromatography, to identify decomposition products, and by visual analysis. The metals used for the tests were Sandvik valve steel, OFHC copper wire, and aluminum 85 bearing material. R-134a was found to be superior to R12 and R-500 in stability and reactlity, but immediate decomposition was evident for R-123.

E. D. Lawler, HFC-134a and Mineral Oil Materials Compatibility with Hermetic Motor Insulation System for McQuay PEH048/050 Centrifugal Water Chillers, SnyderGeneral Corporation, Staunton, VA, 29 August 1990 (2 pages with 4 tables, available from JMC as RDB0901)

The compatibillty of R-134a and mineral oils (both naphthenic and paraffinic) with the hermetic motor insulation materials used in centrifugal water chillers are examined. Baseline tests were run with R-12 and naphthenic oll for comparison purposes. Results are presented for varnish bonding for amide-imide-polyester film and dielectric retention of copper magnet wire with and without varnish treatment. Results also are summarized for retention of flexibility for DuPont Mylar(R), DuPont Nomex(R), and Dacron(R)-Mylar(R)-Dacron(R) sheot insulation, as well as for dielectric retention of flexible hermetic lead wire. The materials were generally unaffected. One exception was a weakening of 
epoxy vamish in the presence of R-134a and naphthenic oll (reduced 13.5\% compared to the mixture of R-12 and naphthenic oil). Flexibility of film insulation was adequately maintained and retained dielectric was acceptable.

E. D. Lawler, Compatibility of Various Elastomers in Retrigerant HFC-134a with Several Lubricants, SnyderGeneral Corporation, Staunton, VA, 5 September 1990 (3 pages with 3 tables, available from JMC as RDB0903)

Results of materials compatibility testing of orings with R-134a and naphthenic mineral oil, alkylbenzene, and polyalkylene glycol (PAG) lubricants are presented. The elastomers evaluated were nitrile HSN, nitrile ASM 3215, and neoprene ASM 3209. Thermal aging tests were conducted separately for the refrigerant and lubricants and for refrigerant-lubricant mixtures. Changes are noted for hardness, tensile strength, elongation, and volume. The property changes experienced by the elastomers were no greater than, and generally less than, those experienced when aged in the presence of either R-12 or R-22. Nitrile, however, appears to shrink slightly when soaked in alkytbenzene. The neoprene swelled slightly when subjected individually to either R-134a or the PAG, and there was an unacceptable amount of shrinkage when aged in a mixture of R-134a and 5\% PAG.

K. S. Sanvordenker (Tecumseh Products Company), Materials Compatibility of R-134a in Rofrigerant Systems. Transactions, volume 95, part 2: republished in ASHRAE Special Publication, CFCs: Time of Transition. American Society of Heating, Refrigerating, and Air-Conditioning Engineers (ASHRAE), Atlanta, GA, pages 211-216, January 1989 (6 pages with 5 figures and 1 table, 20 page preprint available from JMC as RDB0001)

Miscibility and pressure-temperature solubility diagrams are presented for R-134a with polyglycol (butyl monoether, polyoxyethyiene-propylene, and polyoxypropylene glycol) and polyol ester (dibasic acid ester and neopentyl ester) lubricants. The effects of R-134a on two magnet-wire Insulations (polyester-Imide and polyester enamel overcoated with amide-imide). two unidentffied anaerobic adhesives, three elastomeric o-rings (chloroprene, ethylene propylene rubber, and nitrile), and a type $4 A$ molecular-sleve desiccant are addressed. Compressor and refrigerator-freezer tests with R-134a and selected lubricants are described.

H. O. Spauschus (Spauschus Assoclates, Incorporated), HFC-134a as a Substhute Refrigerant for CFC-12, Status of CFCs - Refrigeration Systems and Refrigerant Properties (proceedings of the meetings of IIR Commissions B1, B2, E1, and E2,
Purdue University, West Lafayette, IN), International Institute of Refrigeration, Paris, France, pages 397. 400, July 1988; republished in International Journal of Refrigeration, Paris, France, volume 13, number 11 . November 1988, pages $389-392$ (4 pages, RDB1102)

This paper discusses compressor and refrigeration system requirements and information gaps for R-134a applications. It summarizes the reasons R-134a is viowed as a leading candidate for replacement of R-12. The paper reviews some of the basic properties of R-134a. including stability, system chemistry, solubility, and lubriclty. Additional information that is systemspecific will need to be developed for each mafor application: automotive, home appllance, or centrifugal chillers.

R. H. P. Thomas and H. T. Pham (AlliedSignal Incorporated), Evaluation of Environmentally $A c$ ceptable Refrigerant-Lubricant Mixtures for Retrigeration and Alr Conditioning, paper 891967 (Passenger Car Meeting, Dearborn, MI), Society of Automotive Engineers, Warrendale, PA. September 1989 (9 pages with 6 tables and 5 figures as RDB. 0503)

Laboratory data on the compatibility of R-134a with lubricants and the compatibility of the $r \theta-$ frigerant-fubricant mixtures with elastomers and other materials are reviewed. Miscibility of R134a in three polyglycols, a dihydroxy and two butyl-capped monhydroxy polyalkylene glycols (PAGs), and solubility for R-134a with the first of these are discussed. Stability, dry and with moisture present, also is addressed by comparing copper plating at $149^{\circ} \mathrm{C}\left(300^{\circ} \mathrm{F}\right)$ for the systems with R-134a and PAGs to R-12 with mineral oil. Tests of fluoride-ion production in sealed-tube tests, to determine the effects of air and water, are presented. Hose permeability with the refrigerant alone and with the refrigerant-lubricant mixtures, lubricity test using pin and v-block (Falex machine) tests, and swell tests with elastomers are described. The elastomers tested include three nitriles, epichlorohydrin, two neoprenes, a chlorosulfonated polyethylene, and a chlorinated polyethylene. The basic finding is that the combination of R-134a and PAGs is workable.

S. G. Sundaresan and W. R. Finkenstadt (Copeland Corporation), Polyalkyiene Glycol and Polyol Ester Lubricant Candlates for Use with HFC1349 in Retrigeration Compressors, paper AN-92. 5-3 (Winter Meoting, Anaheim, CA. January 1992), Transactions, American Society of Heating, Refrigerating, and Air-Conditioning Engineers (ASHRAE), Atlanta, GA, volume 98, part 1, pages 796-803, 
1992 (8 pages with 4 figures and 6 tables, RDB2103)

This paper addresses polyalkylene glycol (PAG) and ester lubricants for use with R-134a in refrigeration compressors, with emphasis on lubricity and materials compatibility. The PAGs include diols (having two freo hydroxyl groups), monoethers (one hydroxyl group), and endcapped PAGs (no tree hydroxyl groups). The esters include dibasic (DBE), penta erythritol (PE), trimethylolpropane (TMP), and neopenty glycol (NPG). Properties of 17 PAG and 22 ester candidates are presented along with miscibility profiles for five of them. Sealed-tube test results are tabulated for four lubriciants with metals (aluminum, stainless steel, and copper), magnet wire enamel, epoxy, PET film and fiber. polyamide (nyion 6/6), polyimide, polyetherketone (PEK), chloroprene o-ring, and nonasbestos (nitrile binder with clay silicate filler) gasket material. Hygroscopicity and wear from life testing, in semihermetic reciprocating-piston compressors, are summarized. While the exact cause-and-effect mechanisms leading to fallure of a connecting rod in one test and wrist pin distress in others have not been establlshed, noticeable differences are reported for the sev. eral lubricants. The results indicate that endcapped PAGs and PEs are viable candidates. Esters are preferred over PAGs for retrofit due to their miscibility with hydrocarbon lubricants and compatibility with residual chlorine.

S. G. Sundaresan and W. R. Finkenstadt (Copeland Corporation), Degradation of Polyethylene Terephthalate Films in the Presence of Lubricants for HFC-134a: A Critical lssue for Hermetic Motor Insulation Systems, International Journal of Refrigeration, Paris, France, volume 14, number 11. November 1991, pages 317-320 (4 pages with 3 figures and 2 tables, RDB2202)

An investigation of polyethylene terephthalate (PET) embrittlement mechanisms with lubricants is summarized. PET is widely used as an insulating material in motors for hermetic compressors. The paper reviews related studies and summarizes both the experimental approach and findings. Degradation was measured after thermal-aging in sealed tubes at 130,150, and $175^{\circ} \mathrm{C}\left(168,302\right.$, and $\left.347^{\circ} \mathrm{F}\right)$ for 7,14 , and 28 days. The effects of drying the PET film and lubricants were evaluated. Three polyalkylene glycols (PAGs) were studied including mond, diol, and end-capped (modified) polypropylene glycols. A penta enythritol (PE) ester and a blend of PAG-monol and PE-ester also were investigated. All five lubricants were ISO 32 (150 SUS) viscosity for use with R-134a. The effects of moisture contert, temperature, and lubricant structure were examined. The results were compared to those of PET in R-12 with mineral oil. The study confirmed earlier findings that PET films must be dried, to less than $0.1 \%$ moisture content by weight, to minimize embrittlement by moisture. Residual water in the PET. even after drying, may exceed ten times that contributed by the lubricant and has a greater effect. The extent of embrittlement increases with the number of free hydroxyl groups in PAGs, and nelther the monol nor did was found to be acceptable. The end-capped PAG and ester lubricants showed no adverse reaction with dried PET film.

S. G. Sundaresan and W. R. Finkenstadt, Evaluation of Polyalkylene Glycol Candidates with HFC-134a in Refrigeration Compressors, presentation charts (ASHRAE Annual Meeting, Vancouver, BC, Canada, June 1989), Copeland Corporation, Sidney, OH, June 1989 (25 pages with 2 figures and 7 tables, available from JMC as RDB0529)

Miscibility is shown for $55-100 \%$ R-134a with four unidentfied polyalkylene glycol (PAG) lubricants (150-180 SUS). Compatibility of the refrigerant-polyglycol mixtures with metals, motor materlals, and structural polymers are qualitatwely presented. The metals include copper, aluminum, and stainless steel. The motor materials include two magnet-wire insulations (epoxy coz:ed and polyester enamel overcoated whth polyamide-imide), a polyethylene terephthalate (PET) slot liner, and an unspecified lead wire insulation. The structural polymers include a chloroprene seal, nonasbestos gasket (nitrile binder and clay silicates as filler), nylon $6 / 6$, polyetherketone (PEK), and polyimide. Effects of the refrigerant-lubricant mixtures on compressor durability were quantitatively reported for test conditions of break-in, normal load, start/stop, high load, high compression ratio, and flooded start.

Polyglycol Sealed-Tube Teats, Carrier Corporation, Syracuse, NY, September 1989 (1 page with 1 table, available from JMC as RDBO021)

A table compares tests of R-12 and R-134a whth two polyalkylene glycol (PAG) lubricants (Nippon RS680 and Glygoyle 11). No decomposition was detected for R-134a with elther oll. R12 decomposition was reported at $75-90 \%$ with the two lubricants.

Elastomer Compatibllity with HFC-134a: Experimental Details, report NIST-1, Freon(R) Products Laboratory, E. I. DuPont de Nemours and Company, Incorporated, Wilmington, DE, undated circa 1989 (2 pages with 2 tables, available from JMC as RDB0531)

Compatibility tests of elastomers with R-134a and a naphthenic mineral oll Witco Suniso(P) 
5GS) are summarized. Duplicate samples two neoprene $W$ samples, National O-Ring and Parker, were exposed for 18 days. Lengths and weights were measured before exposure, immediately after removal, and after storage in ambient air for an additional 15 days. No color change or particulate residue were noted. Temporary and final linear swelling by $4.43-$ $5.76 \%$ and $3.07-4.37 \%$ was measured. Weight chianges of -0.77 to $+1.86 \%$ were noted upon removal, but they rhanged to $-3.71 \%$ to $-1.01 \%$ after drying.

Compatibility of Elastomers with HFC-134a at About $25^{\circ} \mathrm{C}$, report NIST-2, Freon(R) Products Laboratory, E. I. DuPont de Nemours and Company, incorporated. Wilmington DE, 17 July 1989 (15 pages with 13 tajoles, avail :ble from JMC as RDBC532)

A broad range of elastomers were tested to compare compatibility with R-134a to that with R-12. The tests were performed at approxlmately $25^{\circ} \mathrm{C}\left(77^{\circ} \mathrm{F}\right)$, for consistency with hisieric data. The influences of the refrigerant were mieasured after immersion for 27 days and again after ${ }^{A}$ days of drying in air. Length, weight, Shore $A$ hardness, appearance and physical properties are tahulated, the last based on qualitative observations for stretching, bending, squeezing, and flexing. The elastomers tested were Uniroyal Adiprene(R) L, Buna N, Buna S, Buty(TM) rubher. DuPont Hypalon(R) 48, natural rubber, neoprene $W$, hydrocarbon rubber (DuFont Nordel(R)), sillicone, polysulfide rubber (Thiok.ll (R) FA), and fluoroelastomer (DuPont VIton(R) A). For R-134a, Adiprene L, Buna $N$, Buty(TM) rubber, DuPont Hypalon(R) 48, natural rubber, neoprene $W$, and Nordel(R) were judged to be preferrad and Thiokol(P) FA recommended, but not preferred. For R-12, Adiprene L, Buna N, and DuPont Hypalon(R) 48 were preferred, and neoprene $W$. Nordel(R), Thiokol( $(A) F A$ recommended, but not at the preferred level. Buna S, silicone, and Viton A were not recommended for either R-12 or R$134 a$.

Compatibility of Elastomers with HFC-134a, document ARTD-5, E. I. DuPont de Nemours and Company, Incorporated, Wilmington, DE, 7 Novembar 1989 (16 pages, available from JMC as RDB0538)

Compatibility of [H]FC-134a with Refrigeration System Materials, report NIST-4, Freon(R) Projucts Laboratory, E. I. DuPont de Nemours and Company, Incorporated, Wilmington, DE, $14 \mathrm{De}$ cember 1976 (7 pages with 3 tables, available from JMC as RDB0534)
The Compatibility of Polymeric / Elastomeric Materials with "Klea"(TM) 134 and Polyalkylene Glycol (PAG) Based Lubricants, technical note 1, ICl Americas Incorporated, New Castle, DE, USA, August 1990 (8 pages with 5 tables, RDB2515)

Test results are tabulated to summarize changes ir: weight, volume, length, thickness, strength, elongation to break, and hardness for polymeric and blastomeric materials exposed to refrigerants and lubricants for 14 days. These tests are based on immersions at $130{ }^{\circ} \mathrm{C}$ (266 $\left.{ }^{\circ} \mathrm{F}\right)$ with $50 \mathrm{ppm}$ water for R-12 and mineral oil and at $85^{\circ} \mathrm{C}\left(185^{\circ} \mathrm{F}\right)$ with $200 \mathrm{ppm}$ water for $\mathrm{R}$ 134a with Emkarox(R) RL 68 PAG. the materials tested include chloroprene (chlorinated isoprene, neoprene $W$ ), chlorinated rubber (neoprene), ethylene propylene dierie monomer (EPDM), fluorinated propylene monomer (FPM) copolymer, FPM terpolymer, hydrogenated nitrile $(H N)$ rubber $N$ grade, $H N$ rubber $E$ grade, $H N$ buryl rubber, $H N$ green rubber, natural rubber, nitrile butyl rubber (Buna(TM) N), butadieneacrylonitrile copolymer (Buna(TM) N), nylon $6 / 6$, poly butyiene terephthalate (PBT), PBT with $10 \%$ glass, polyether ether ketone (PEEK), poly ether sulfone (PES 75), polyethylene terephthalate (PET), polyimide 75 (ICI U jilex(R) R), polyimide 50 (ICl Upilex(R) S), polyimide (DuPont Kapton(R)), poly phenyl sulfone (PPS), and fluorinated copolymer of vinylidene fluoride and hexafluoropropylene (DuPont Viton(R)). Additional data are provided for R-134a and four PAGs (Emkaro: (PI RL) for EPDM, natural, and nitrile rubbers as vell as for nylon, and Viton. These lubricants include a monol PAG ISO 22 with $65 \mathrm{ppm}$ water, modified PAG ISO 22 with 165 ppm water, modified PAG ISO 32 with 190 ppm water, and modified PAG ISO 70 with 85 $\mathrm{ppm}$ water. The second set of tests were for thermal aging at $130^{\circ} \mathrm{C}\left(266^{\circ} \mathrm{F}\right)$ for 14 days. The experimental approach is briefly outlined.

The Compatibility of Polymeric / Elastomeric Materials with "Klea"(TM) $134 a$ and Ester Based Lubricante, technical note 2, ICI Americas Incorporated, New Castle, DE, USA, August 1990 (6 pages with 4 tables, RDB2516)

Test results are tabulated to summarize changes in weight, volume, length, thickness, strength, elongation to break, and hardness for polymeric and elastorneric materials exposed to refrigerants and lubricants for 14 days. These tests are based on immersions at $130^{\circ} \mathrm{C}$ (266 $\left.{ }^{\circ} \mathrm{F}\right)$ with $50 \mathrm{ppm}$ water for R-12 and mineral oil and with $180 \mathrm{ppm}$ water for R-134a with Emkarate(TM) RL $32 S$ (formerty RLE DE 184). The materials tested include chloroprene (chlorinated isoprene, neoprene W), chlorinated rubber (neoprene), ethylene propylene diene monomer (EPDM), fluorinated propylene 
monomer (FPM) copolymer, FPM terpolymer, hydrogenated nitrile (HN) rubber $N$ grade, $H N$ rubber $E$ grade, $H N$ butyl rubber, $H N$ green rubber, natural rubber, nitrile butyl rubber (Buna(TM) N), butadlene-acrylonitrile copolymei (Buna(TM) N), nyion 6/6, poly butylene terephthalate (PBT), PBT with 10\% glass, polyether ether ketone (PEEK), poly ether sulfone (PES 75), polyethylene terephthalate (PET), polyimide 75 (ICl Upilex(R) R), polyimide 50 (ICl Upilex(R) S), polyimide (DuPont Kapton(R)), poly phenyl sulfone (PPS), and fluorinated copolymer of vinylidene fluoride and hexafluoropropylene (DuPont Viton(R)). Additional data are provided for R-134a and Emkarate(TM) RL 15S (formerly RLE DE 212) with 180 ppm water for EPDM, natural, and nitrile rubbers as well as for nylon, PBT, and Viton. The experimental appioach is briefly outlined.

Compatibility of Nonmetallic Materials with Refrigerants and Lubricants, $\mathrm{ICl}$ Chemicals and Polymers Limited, Runcorn, Cheshire, UK, 16 May 1989 (3 pages with 1 table, available from JMC as RDB0004)

A table sul marizes the swell (dimensional change) and veight gain of various elastomeric and plastic materials immersed in R-134a. The materials incluond Buna(TM), Butyl(TM), DuPont Hypalon(R), NBR, Garlock neoprene, nitrile, nitrile Dunlop, nylon, Oilte and M229 rubber asbestos, polyetheretherketone (PEEK), Polypenco Nylatron, polytetrafluoroethylene (PTFE), Reinz Thermolit $K$, terylene braid, and fluoroelastomer (DuPont Viton(R)). Quantitative results are presented for refrigerant-lubricant mixtures with 10\% polyalkylene glycol (PAG); the lubricants, ranging in viscosity from ISO 33 to 120 , are not specifically identified. Some results also are given with $100 \%$ refrigerant.

Copper Plating in R-134a Systems, technical note 5. ICl Americas Incorporated, New Castle, DE, USA, August 1990 (4 pages, RDB2518)

This document discusses copper plating, formation of a film of metallic copper on one or more areas of the compressor. Observations are compared for R-134a and synthetic lubricants to those for R-12 and mineral ofl. The mechanisms are identified as copper dissolution, transport, and deposition. High occurrence traditionally has been regarded as being a property of poorly refined oils (via their high oleo-resin contents, which are rich in heteroatoms). The high heteroatom contents of esters and PAGs suggests greater inherent aggression towards copper and tts alloys, leading to greater dissolution and a relatively high equilibrium copper content in the oil. This would not in itself lead to higher copper plating in the ab- sence of an effective deposition route. Limited experience and published reports of copper plating are discussed. Whereas $R-134 a$ has been shown to be chemically and thermally more stable than R-12 and does not react with ester or PAG lubricants, no copper plating was observed in sealed tube tests. A number of antiwear additives for synthetic lubricants are corrosive toward copper, but noncorrosive alternathes have been identified. Inhibiting the dissoIution stage, rather than use of chelation compounds to sequester the copper once in solution, and thereby inhibit its deposition, appears to be the most satlsfactory approach. Well known copper passivators, such as benzotriazole (BTA), benzothiazole (BTZ), and 2-mercaptobenzothiazole (MBTZ) have been examined. To date, it has proved possible to eliminate copper plating in systems utilizing ester lubricants.

Disassembly and Inspection of Compressor in Laboratory Refrigerator Charged with R-134a, report NIST-13, E. I. DuPont de Nemours and Company, Incorporated, Wilmington, DE, undated (40 pages with 50 flgures and 3 tables, available from JMC as RDB0309)

This report documents a detailed inspection of a hermetic compressor, operated for $\mathbf{8 . 7}$ years with R-134a and a polyalkylene glycol (PAG) lubricant, Union Carbide UCON LB-525. An unmodifled Frigidaire refrigerator was charged with R-134a in November 1977, but the compressor failed a month later. The failure analysis was not located, but the cause is belleved to have been a manufacturing defect. The compressor was replaced and the refrigerator returned to service in July 1978; it operated without incident untll March 1987. The refrigerator was functioning normally when shut down for compressor disassembly, to determine the longterm effects of this refrigerant-oil system. This report provides a photographic record of the disassembly, summarizes detailed chemical and metallurgical analyses, and includes profilometer readings to evaluate the effect of slight copper plating on steel bearing surfaces. A hardened steel vane spring, which broke when dropped, had been severely fatigued during service. The polyethylene slot liner insulation showed embrittlement, but was not analyzed. Very limited refrigerant decomposition was found, and the report concludes that R-134a use had very little effect on the metal parts of the compressor. Particles trapped in the oil produced slight scars on metallic contact surfaces. The molecular sieve drier contained $5 \%$ residual water, compared to a saturation value of 19 $20 \%$. Unanswered questions remain concerning the refrigerant-lubricant stability; addition of 
an oil stabilizer or use of a different oil ma: be indicated. General Electric Company and Tecumseh Products Company assisted in disassembling the compressor and interpreting the visual evidence. Further examination of the desiccant used, Union Carbide molecular sieve type $4 A-X H-6$, is reported in document RDB0003.

Current Development Status of HFC-134a for Automotive Air Conditioning, document ARTD-2, E. I. DuPont de Nemours and Company, Incorporated, Wilmington, $D E$, undated (16 pages, available from JMC as RDB.5536)

UL 984 Tests with R-134a and Oils, Carrier Corporation, Syracuse, NY (1 page with 1 table, available from JMC as RDBO017)

A table summarizes UL 984 tests of motor materials aged at $110^{\circ} \mathrm{C}\left(230^{\circ} \mathrm{F}\right)$ for 60 days. Control results are compared to those after separate exposures to R-12 mixed with mineral oil (Witco Suniso(R) 3GS) and R-134a mixed with the same oil and with alkylbenzene oil (Zerol(R) 150). Insulation fallures (1 ma current leakage to ground after 1 minute at $1.5 \mathrm{kV}$ and breakdown voltages are reported. Results are summarized for polyester-imide magnet wire, DacronValox(R) lead wire, DuPont Teflon(R) wire sleoving, DuPont Mylar(R) end cap, Mylar-Dacron(R) therm.osleeve, Mylar(R) and Melinex(R) slot liners, and Mylar(R) and Melinex(R) phase separators. Breakdown voltages of $0.7-15.5 \mathrm{kV}$ are indicated; current leakage failures resulted only for the polyesterimide magnet wire.

\section{R-141b}

Isotron R-141b Foam Blowing Agent: Material Compatibility, preliminary information bulletin, Elf Atochem North America, Incorporated (provided by the former Pennwalt Corporation), King of Prussia, PA, May 139 (1 page with 1 table, avallable from JMC as Rüso519)

A table provides quantitative and qualitative data on weight change and swelling for common elastomers, plastics, refrigerator liner materials, and roofing membrane materials after a twoweek exposure to R-11 and R-141b. The elastomeric materials include neoprene, Butyl(TM), Buna(TM) $N$, and fluoroelastomer (DuPont Viton(R)). The plastics and refrigerator liner materials include ABS polymer, FEP, Kynar PVDF, polyethylene, polypropylene, polystyrene, polytetrafluoroethylene (PTFE), and polyviny' chloride (PVC). The ABS polymer, Buna N, VIton, and PVC materials exhibited much greater swelling and weight gain after exposure to $R$.
$141 \mathrm{~b}$ than to R-11. The other materials exhibited results lower than, or comparable to, $R$ 11 after R-141b exposures.

\section{R-142b}

K. S. Sanvordenker, Materials Compatibility of R142b for Hermetic Units. Tecumseh Products Company, Ann Arbor, MI, June 1989 (7 pages with 2 figures and 5 tables, available from JMC as RDB0002)

Two figures compare the miscibility of R-142b and R-22 with Capella $B$ and Calumet R015 mineral sils. The miscibility of R-142b with Ze$\mathrm{rol}(\mathrm{R}) \mathbf{1 5 0}$ alkylbenzene lubricant also is discussed. Quantitative data on two magnet wire insulations (polyester-imide and polyester enamel overcoated with amide-imide) with R$142 \mathrm{~b}$ and R-22 are given for refrigerant absorption, softening, blistering, and retained dielectric strength. R-142b and R-22 effects on the corebond tensile strength of two unidentffied solvent-based epoxy-type varnishes also are presented. Additionally, swell tests of R-142b with four elastomeric (neoprene, EPR, nitrlie, and fluoroelastomeric (DuPont Viton(R) B) o-rings are given. In each investigation, R-142b exhibited characteristics comparable to, or better than, R-22.

\section{R-245ca}

R. G. Doerr, D. Lambert, R. Schafer, and D. Steinke (The Trane Company), Stability and Compatibility Studies of R-245ca, $\mathrm{CHF}_{2} \mathrm{CF}_{2} \mathrm{CH}_{2} \mathrm{~F}, \mathrm{~A}$ Potential Low-Pressure Refrigerant, Proceedings of the International CFC and Halon Alternatives Conference (Washington, DC), Alliance for Responsible CFC Pollcy, Arlington, VA, pages 147-152, September 1992 ( 6 pages with 1 figure and 4 tables, available from JMC as RDB2A10)

This paper reviews the selection of R-245 isomers as low-pressure refrigerant candidates. This series offers the highest number of hydrogen atoms without becoming flammable and, therefore, the best potential among fiuoropropanes. R-245ca was selected for further examination, based on performance modelling and its reported synthesis. Slightly lower efficiency is expected compared to R-123. Physical and chemical properties are tabulated for $R$ $11, R-123, R-134 a$, and R-245ca for comparison. $\mathrm{R}-245 \mathrm{ca}$ is expected to be nontoxic, and it is indicated to be very similar to R-11 in terms of molecular weight, boiling point, and critical 
temperature. Its ozone depletion potential (ODP) is zero, but its 5.5 year atmospheric lifotime leads to a global warming potentlal (GWP) higher than for R-123 but lower than for R-134a. [Newer data indicate an aimospheric lifetime of 6.4 years.] The paper summarizes stability and compatibility studies. Sealed-tube tests, with and without lubricants, indicate that R-245ca is extremely stable; no evidence of decomposition was noted after 500 hours at $175^{\circ} \mathrm{C}\left(347^{\circ} \mathrm{F}\right)$. Parr bomb compatibility tests with electric motor materials and elastomers showed lower refrigerant absorption than for "R-11 and R-123. The compatibility of R-245ca was found to be very similar to R-134a toward both motor materials and elastomers; no degradation was found for the materials tested. They included varnishes, slot liners, DuPont Mylar(R) sheet and tape, Dacron-Mylar-Dacron(R) and DuPont Nomex(R) wedges, DuPont Dacron(R) tape and cord, and reinforced tape. The varnishes tested included solvent epoxy (Sterling(R) U-475 EH), $100 \%$ solids epoxy (Sterling(P) Y-833), and water-borne epoxy (Schenectady Isopoxy(R) 800). Weight, volume, and hardness change results are tabulated for a proprietary, chloroprene, and nitrile elastomers. The results suggest further investigation of R-245ca as a potentlal refrigerant. Commercialization is not expected for a number of years pending flammability, toxicity, and other testing as well as development of a competitive manufacturing process. [see RDB$2 A 11$ for presentation chants]

R. G. Doerr, D. Lambert, R. Schafer, and D. Steinke (The Trane Company), Stability and Compatibility Studies of R-245ca, $\mathrm{CHF}_{2} \mathrm{CF}_{2} \mathrm{CH}_{2} \mathrm{~F}$, A Potential Low-Pressure Refrigerant, presentation charts (International CFC and Halon Alternatives Conference, Washington, DC), September 1992 (4 pages, available from JMC as RDB2A11)

This presentation reviews the selection of R-245 isomers as low-pressure refrigerant candidates. This series offers the highest number of hydrogen atoms without becoming flammable and, therefore, the best potential among fluoropropanes. R-245ca was selected for further examination, based on performance modelling and its reported symthesis. Slightly lower efficiency is expected compared to R-123. Physical and chemical propertles are tabulated for $R$ $11, R-123, R-134 a$, and R-245ca for comparison. $\mathrm{R}-245 \mathrm{ca}$ is expected to be nontoxic, and it is indicated to be very similar to R-11 in terms of molecular weight, boiling point, and critical temperature. Its ozone depletion potential (ODP) is zero, but its 5.5 year atmospheric lifetime leads to a global warming potential (GWP) higher than for R-123 but lower than for R-134a. [Newer data indicate an atmospheric lifetime of 6.4 years.] The presentation summarizes stabil-
Ity and compatibility studles. Sealed-tube tests, with and without lubricants, indicate that $R$ $245 \mathrm{ca}$ is extremely stable; no evidence of decomposition was noted after 500 hours at 175 ${ }^{\circ} \mathrm{C}\left(347^{\circ} \mathrm{F}\right)$. Parr bomb compatibility tests with electric motor materials and elastomers showed lower refrigerant absorption than for R-11 and R123. The compatibility of R-245ca was found to be very similar to R-134a loward both motor materials and elastomers; no degradation was found for the materials tested. They included varnishes, slot liners, DuPont Mylar(R) sheot and tape, Dacron-Myiar-Dacron(R) and DuPont Nomex(R) wedges, DuPont Dacron(R) tape and cord, and reinforced tape. The varnishes tested included solvent epoxy (Sterling(R) U-475 EH), $100 \%$ solids epoxy (Sterting(R) Y-833), and water-borne epoxy (Schenectady Isopoxy(R) 800). Weight, volume, and hardness change results are tabulated for a proprietary, chloroprene, and nitrile elastomers. The results suggest further investigation of R-245ca as a potentlal reirigerant. Commercialization is not expected for a number of years pending flammability, toxicity, and other testing as well as development of a competithe manufacturing process. [see RDB2A10 for text]

N. D. Smith (U.S. Environmental Protection Agency, EPA), K. Ratanaphruks, M. W. Tutts, and A. S. Ng, (Acurex Environmental Corporation), R245ca: A Potential Far-Term Alternative lor R-11, ASHRAE Journal, American Society of Heating, Refrigerating, and Air-Conditioning Engineers (ASHRAE), Atlanta, GA, pages 19-23, February 1992 (5 pages with 3 tables, RDB3301)

This article summarizes tests and modelling of $R-245$, a candidate refrigerant to eventually replace R-11 and R-123. Thermophysical properties measurements are described. The results and findings of performance modelling are compared to data for R-11 and R-123; the efficiency of R-245ca is indicated to be 3-4\% lower than for R-11. Flammability measurements based on the ASTM E681-85 procedure are described. The flammability was found to be sensitive both to the presence of moisture and the ignition source. Lower and upper fiammability limits (LFL and UFL) of $7.0-14.4 \%$ are reported at $30^{\circ} \mathrm{C}\left(84^{\circ} \mathrm{F}\right)$ for $43.5 \%$ relative humidity; the fluid was nonflammable in dry air. Tests of miscibility witi two unidentified polyd ester (POE) lubricants are discussed, indlcating complete miscibility, insensitive to moisture content, for -30 to $+125^{\circ} \mathrm{C}\left(-22\right.$ to $\left.257^{\circ} \mathrm{F}\right)$ for concentrations of 10,20 , and $30 \%$ lubricant by weight. Sealed-tube tests to gauge compatibility with aluminum, copper, valve steel, fluoroelastomer (DuPont Viton(R)), nitrile butyl rubber (Buna(TM) N), neoprene, DuPont Nomex(R), and DuPont 
Mylar(R) are descrtbed. Observations, results of gas chromatography and infrared spectrometry, acidlty, weight change, and swell are summarized. The paper indicates that R-245ca with a POE lubricant is compatible with the metals tested, Mylar, Viton; possibly compatible with Buna $\mathrm{N}$ and Nomex; and incompatible with neoprene. As a chlorine and bromine-free compound, R-245a is expected to have an ozone depletion potential (ODP) of zero. Its atmospheric lifetime was estimated as 6.4 years by measuring its reaction rate with atmospheric hydroxyl radicals; its global warming potential (GWP) was estimated to be one-third that of R134a. Very preliminary testing of acute inhalation toxicity tests are outlined; no signs of concern were identified at a concentration level of $993 \mathrm{ppm}$. The paper concludes that R-245ca has been shown to be a good candidate for $r e-$ placement of R-11 or R-123 in the far-term.

\section{E-134}

T. P. Gross, Sealed-Tube Tests - Grace Ether (E134), York International Corporation, York, PA, 28 March 1990 (2 pages with 3 tables, available from JMC as RDB0904)

This memo summarizes sealed-tube tests to compare the stability of R-114 and E-134 when aged for up to 72 hours with several lubricants at temperatures as high as $182^{\circ} \mathrm{C}\left(360^{\circ} \mathrm{F}\right)$. The lubricants tested included York $C$, Zerol(R) 300 alkylbenzene, and UCON LB-165 polyglycol. Aluminum, copper, and iron wires were included as catalysts. E-134 was founif to be somewhat less stable than R-114.

\section{$\underline{E-245}$}

R. G. Doerr, R. Schafer, D. Lambert, and D. Steinke (The Trane Company), Stability Studies of E-245 Filuoroether $\mathrm{CF}_{3} \mathrm{CH}_{2} \mathrm{OCHF}$, presentation at the International CFC and Halon Alternatives Conference (Baltimore, MD), Alliance for Responsible CFC Policy, Airlington, VA, December 1991 (4 pages with 14 charts, avallable from JMC as RDB2811)

These presentation charts summarize an investigation into the use of E-245, a proposed lowpressure refrigerant for centrfugal chillers. The charts summarize properties of this fluid and sealed-tube tests to determine its stability. Tests in glass tubes, both with and without an unidentified oll, resulted in vident explosions. Tests of R-123 and E-245 with copper and iron coupons in Parr bombs are presented, indicat-
Ing stable results. Repettion of the E-245 tests with copper, iron, and glass coupons led to reactions. Analyses of the pressure build-up as well as a gas chromatogram and quantitative analysis 0 , the reaction products are presented. Further tests with glass are outlined to examine the role of water, air, oxygen, and peroxide. The charts note that E-245 can react autocatalytically with glass to produce high pressures, hydrogen fluoride, and 2,2,2-trifluoroethyl ether (a convulsant). This reaction is accelerated by air (oxygen) and peroxide. The fraction of E-245 remaining after exposures at $121^{\circ} \mathrm{C}\left(250^{\circ} \mathrm{F}\right)$ for 14 days are tabulated to indicate the effects of various materials. They included elastomers, motor materlals, copper, iron, water, glass-like materials. Tests with copper, iron, and aluminum at 166 and $177^{\circ} \mathrm{C}\left(330\right.$ and $350{ }^{\circ} \mathrm{F}$ ) also are presented. E-245 was found to be unstable with fiberglass motor materials.

\section{R-717 (ammonia)}

G. D. Short (CPI Engineering Services, Incorporated), Refrigeration Lubricants Update: Synthetic and Semi-Synthetic Oils Are Solving Problems with Ammonia and Alternative Refrigerants, Technical Papers of the 12th Annual Meeting (4-7 March 1990, Memphls, TN), International Institute of Ammonia Refrigeration (IIAR), Washington, DC, pages 19-53, March 1990 (36 pages with 12 figures and 4 tables, available from JMC as RDB2203)

This paper reviews bench tests and field experience with synthetic lubricants. The first part addresses semi-synthetic, high-viscosity index (HVI), hydrocracked lubricants for improved performance with ammonia. These lubricants also are referred to as "hydrocracked paraffinic oils" and as "restructured, semi-synthetic lubricants" to distinguish them from hydrogen finished olls, which contain more aromatic components. The paper discusses the benefits of these lubricants and briefly reviews case histories for two applications. Advantages cited, leading to longer drain intervals, include good thermal and chemical stablity, lower mutual solubility, low foaming and volatility, excellent low-temperature fluidity, high viscosity, and good demulsibility. The hydrotreating process also removes nearly all aromatics, including carcinogenic poly nuclear aromatics found in some lubricants. The second part addresses polyalkylene glycols (PAGs) and esters in posithe displacement compressors for R-134a and refrigerant blends. Previously documented concerns with PAGs and low-viscosity, neopentyl esters are outlined. A new complex ester, which yields improved energy efficiency in 
screw compressors and superior miscibility with R-22, is discussed. The composition of naphthenic, solvent-refined paraffinic, and hydrocracked paraffinic lubricants are tabulated for comparison. Similar data are provided on oxidation resistance and emulsion characteristics. Plots of viscosity and antioxidant level, as functions of time in use, are provided for the lubricants discussed. Solubility with ammonia, volatility, and viscosity are plotted for the hydrocracked oils. The miscibillty of two complex esters are shown for R-134a, and the viscositytemperature relationships are graphically compared for R-22 with a complex ester and a naphthenic oil. A figure compares the isentropic efficiency of complex esters with R-22 to that for a polyalphaolefin (PAO) lubricant for a range of pressure ratios.

G. D. Short (CPI Engineering Services, Incorporated), Hydrotreated Olls for Ammonia Retrigeration. Technical Papers of the 7th Annual Meeting (10-13 March 1985, San Antonio, TX), International Institute of Ammonia Refrigeration (IIAR), Washington, DC, pages 149-176, March 1985 (28 pages with 8 figures and 4 tables, available from JMC as RDB2204)

\section{Qthers}

D. J. Bushouse, Degradation of Polyester Films by Alcohols, ASHRAE Journal, American Society of Heating, Refrigerating, and Air-Conditioning Engineers (ASHRAE), Atlanta, GA, volume 3, number 9 , pages $61 \mathrm{H}$, September 1961 (RDB2301)

J. F. Wilson, Effect of Methanol on the Performance of Polyester Film in Reciprocating Refrigeration Compressors, ASHRAE Journal, American Society of Heating, Refrigerating, and Air-Conditioning Engineers (ASHRAE), Atlarita, GA, volume 10 , number 1, pages $43 \mathrm{ff}$, January 1968 (RDB2205)

\section{Blends}

\section{Azeotropes}

Isotron 22/142b Blends for Retrigeration: Material Compatiblity, preliminary information bulletin, Elf Atochem North America, Incorporated (provided by the former Penmwalt Corporation), King of Prussia, PA, May 1989 (1 page with 1 table, avallable from JMC as RDB0520)
This bulletin summarizes the procedure and findings for two-week exposures of selected refrigeration system materials both to R-12 and to $a$ blend of R-22/R-142b (55/25). The materials tested included copper wire, polyimide insulation, and several plastics and elastomers. The plastics included nylon (DuPont Zytel(R) 101), polytetrafluoroethylene (PTFE), FEP, PVDF (Kynar), PVC, low-density polyethylene, polypropylene, polystyrene, high-impact polystyrene, and high-gloss ABS. The elastomers included neoprene, Butyl(TM), Buna(TM) N, and fluoroelastomer (DuPont Viton(R)). Swell (length increase percentage), weight gain (percentage), and appearance (including qualitative observations on hardness and embrittlement) are tabulated.

\section{Zeotropes}

D. J. Bateman, D. B. Bivens, R. A. Gorski, W. D. Wells (DuPont Chemicals), R. A. Lindstrom, R. L Morse, and R. L. Shimon (Tecumseh Products Company), Retrigerant Blends for the Automotive Air Conditioning Aftermarket, paper 900216 (SAE International Congress and Exposition, Detroit, MI, 26 February - 2 March 1990), Society of Automotive Engineers (SAE), Warrendale, PA, February 1990 (14 pages with 12 figures and 8 tables, RDB2206)

Alternative Refrigerant Blends, E. I. DuPont de Nemours and Company, Incorporated, Wilmington, DE, 1989 (18 pages, available from JMC as RDB0530)

Compatibility of Elastomers with the Ternary Blends of HCFC-22/HFC-152a/CFC-114 and HCFC-22/HFC-152a/HCFC-124, document ARTD 3, E. I. DuPont de Nemours and Company, Incorporated, Wilmington, DE, 7 November 1989 (26 pages, available from JMC as RDB0537)

Ternary Retrigerant Blends, document ARTD-10, E. I. DuPont de Nemours and Company, Incorporated, Wilmington, DE, undated (6 pages, available from JMC as RDB0539)

Ternary Refrigerant Blends for the Automotive Aftermarket, document ARTD-1, E. I. DuPont de Nemours and Company, Incorporated, Wilmington, $D E$, undated (12 pages, available from JMC as RDB0535)

test results for R-22/152a/114 (36/24/40) (blend KCD-9430) and R-22/152a/124 (36/24/ 40) (blend KCD-9433) for automotive use; concludes that the blends are not drop-in replacements for R-12, but that technologies exist or can be developed to accomplish retrofit while 
maintaining acceptable perfomance; topics covered include erivironmental impacts; toxicity; propertles; fiammability; compatiblity data for hoses constructed of nylon, DuPont Hypalon(R) 48, nitrile; compatibility data for elastomers including epichlorohydrin, neoprene, nitrile; compatibility data for molecular-sieve desiccants; and solubility and lubricity data for BVM. $100 \mathrm{~N}$, Idemitsu, and Mopar mineral olls and $\mathrm{Z} \theta$ rol(P) 500 alkylbenzene oils, the last with three additives for the lubricity tests.

Sealed-Tube Stability Tests: Ternary Blends (KCD-9430 and 9433), document ARTD-13, E. I. DuPont de Nemours and Company, Incorporated, Wilmington, DE, April 1990 (11 pages with 6 tables, avallable from JMC as RDB0542)

\section{LUBRICANTS}

L. F. Albright and J. D. Lawler, Viscosity-Solubility Characteristics of Mixtures of R-13Bi and Lubricating Oils, ASHRAE Journal, American Society of Heating, Refrigerating, and Air-Conditioning Englneers (ASHRAE), Atlanta, GA, pages 67-70, April 1959 (RDB2207)

L. F. Albright and A. S. Mendelbaum, Solubility and Viscosity Characteristics of Mixtures of Lubricating Olls and Freon 13 and 115, Refrigerating Engineering, American Society of Refrigerating Engineers (now merged into the American Society of Heating, Refrigerating, and Air-Conditioning Engineers, ASHRAE), Atlanta, GA, volume 64, number 10, pages 37-47 and 106, October 1956 (RDB2208)

K. Azami, H. Hosol, and N. Ishikawa (Sanden Corporation), Lubricant Screening for HFC-134a Car Air Conditioning Compressor Rellablitty, paper 901735, Society of Automotive Engineers, Warrendale, PA, September 1990 (12 pages with 5 figures and 11 tables, RDB2209)

C. M. Bosworth (Carrier Corporation), Predicting the Behavior of Olls in Refrigeration Systems. Refrigerating Engineering, American Society of Refrigerating Engineers (ASRE, now merged into the American Society of Heating, Refrigerating, and AirConditioning Engineөrs, ASHRAE), Atlanta, GA, volume 60, number 6, pages 617-620 and 654-655, June 1952 (7 pages with 12 figures and 5 tables, RDB2503)

This paper discusses the solublity of lubricating oils in refrigerants, absorption of refrigerants, solvent effects on nonmetallic materials, and stability of oils. Differences among paraffinic, intermediate, and naphthenic lubricants are discussed, and recommendations are presented for selection of oll types for specific applications. Solubility curves are presented for R-12, R-22, and R-114 in four olls. The paper notes that the volumes of refrigerant-lubricant mixtures do not necessarlly correspond to the sum of their separate volumes due to absorption; data on increases and decreases are provided for several examples.

R. C. Cavestri and J. Munk (Imagination Resources, Incorporated), Measurement of Viscosity, Density, and Gas Solubility of Refrigerant Blends. report DOE/CE/23810-11B, Air-Condtioning and Refrigeration Technology institute (ARTI), Arlington, VA, April 1993 (32 pages with 17 figures and 1 table, available from JMC as RDB3418)

This progress report summarizes a project to measure the viscosity, density, and solubility of four refrigerant blends as well as their components using a single polyol ester lubricant. The refrigerants include R-32/R-125 (60/40), R32/R-125/R-134a (10/70/20), R-32/R-134a (30/70), and R-125/R-143a/R-134a (44/52/4). The report describes examination of four different penta erythritol polyol esters including two branched acids (Castrol Icematic(A) SW32 and Henkel Emery(R) 2927a) and two mixed acids (Emkarate(TM) RL 32S, formerly RL 184, and Mobil EAL(A) Arctic 224R). The second of the four was chosen for the study based on liquidliquid miscibility and low influence on refrigerant blend fractionation. An alkylbenzene (Shrieve Zerol(R) 150) was introduced to examine aromatic properties toward miscibility. R-22 and R502 also were examined with a mineral oil Witco Suniso(R) 3GS) for comparison. Miscibility plots are provided for the four blends with each of the ester and alkylbenzene lubricants for compositions of 5, 25 and $60 \%$ lubricant. A plot relates viscosity to temperature for R-22 and mineral of for -20 to $+125^{\circ} \mathrm{C}$ (-4 to $257^{\circ} \mathrm{F}$ ), at pressures of $69-1720 \mathrm{kPa}(10-250 \mathrm{psia})$ and 0 $60 \%$ refrigerant by weight. The viscosity and solubility of R-22 with mineral oll are plotted against pressure for the isotherms in the same ranges and for R-502 at 40 and $70{ }^{\circ} \mathrm{C}$ (104 and $\left.158^{\circ} \mathrm{F}\right)$.

K. W. Cooper and A. G. Mount, The Effect of Oll Circulation on Compressor Capacity, ASHRAE Journal, American Society of Heating, Refrigerating, and Air-Conditioning Engineers (ASHRAE), Atlanta, GA, pages 39-42, October 1972 (RDB3322)

S. Corr, P. D. Guy, A. A. Undley, F. T. Murphy, G. Tompsett (ICl Chemicals and Polymers, Limited), and T. W. Dekleva (ICl Americas, Incorporated), The Effect of Miscibility on Performance of R- 
1349 and Alternative Lubricants, seminar prosentation at the ASHRAE Annual Meeting, (Indianapolis, IN), ICl Americas Incorporated, New Castle, DE, USA, 24 June 1991 (20 pages with 24 charts, RDB2521)

S. Corr ( $\mathrm{Cl}$ Chemicals and Polymers, Limited), Solubility and Misciblilty - Relevance to Klea (TM) 1340 Refrigeration Systems, ICl Americas Incorporated, Wilmington, DE, USA, 8 February 1991 (11 pages with 8 figures, RDB2520)

This document explains the meaning and relevance of solubility and miscibility within refrigeration systems. It notes that the solubility of refrigerant gas in the lubricant usually is an important lubricant feature. In general, lubricants that display miscibility with the refrigerant liquid over a wide range of conditions will also have good refrigerant gas solubilities, but the reverse is not necessarily true. Although the solubility of refrigerant gas in liquid lubricant is important in determining the viscosity of fluid at the evaporator outlet, other factors also are likely to have an effect. An example is the lubricant structure (e.g., polarity or hydrogen bonding). The viscosity of the circulating liquid phase and the velocity of the driving gas are the two most important considerations for lubricant return to the compressor. Lubricant viscosity and the solubility-related viscosity of the refrigerant-lubricant mixture would be expected to govern lubricant holdup, a measure of the lubricant quantity avallable to interfere with heat transfer. Experience indicates that the concentration of lubricant in the liquid refrigerant phase is below $1 \%$ over the majortty of the evaporation process, so lubricant miscibility actually does not appear to be significant in determining oil holdup. Separate liquid phases for the refrigerant and lubricant will be present only over a very short length of the evaporator. Plots and tabular data are provided for low-temperature miscibility for ester lubricants (Emkarate(TM) RL) in R-134a. The fraction of lubricant in refrigerant also is plotted for the evaporator length.

G. Daniel, M. J. Anderson, W. Schmid, and M. Tokumitsu (Mobil OA), Performance of Selected Synthetic Lubricants in Industrial Heat Pumps, paper B3, Proceedings of the International Symposium on the Industrial Application of Heat Pumps (University of Warwick, UK, 24-26 March 1982), BHRA Fluid Engineering, Cranfleld, Bedford, UK, pages 41-53, 1982; republished in Journal of Heat Recovery Systems, Pergamon Press Limited, UK, volume 2, number 4, pages 359-368, 1982 (12 pages with 3 figures and 4 tables, RDB2210)

This paper reviews lubrication requirements at high condensing temperatures $\left(120-130^{\circ} \mathrm{C}, 248\right.$ $266^{\circ} \mathrm{F}$. typical of those encountered in in- dustrial heat pumps. Potential limitations of mineral oils are examined and physical data are reviewed for synthetic lubricants, particularly synthetic hydrocarbon flulds (SHF) of the polyalphaolefin type and selected polyglycols. Viscosity, vapor pressure, and stability data are reviewed for selected synthetic lubricants with halogenated refrigerants. The fleld results in several installations with R-12 and R-114 are examined, to document satisfactory operation under the severe conditions encountered.

K. E. Davis and J. N. Vinci (Lubrizol Corporation), Formulation of Polyol Ester Lubricants for'Use with HFC Retrigerants, paper 1.3, Proceedings of the International Seminar on New Technology of Alternative Refrigerants - Lubricants and Materials Compatibility (Tokyo, February 1983), Japanese Association of Refrigeration (JAR), Tokyo, Japan, pages 15-20, February 1983 (6 pages with 9 tables, RDB3308)

K. E. Davis and J. N. Vinci (Lubrizol Corporation), Effect of Additives in Synthetic Ester Lubricants Used with HFC-134a Refrigeram, Proceedings of the International CFC and Halon Alternatives Conference Washington, DC), Alllance for Responsible CFC Policy. Arlington, VA, pages 125. 133. September 1992 (9 pages with 5 figures, RDB2.408)

This paper reviews tests of anthear additives with synthetic ester lubricants, for use with R$134 \mathrm{a}$ in automottve and stationery compressors. The lubricants addressed are polyol-carboxylic acid condensation products. The additive screening and tests focused on sultability for wear protection of aluminum on steel, steel on steel, and bronze on steel. The advantages of R-12 lost in conversion to R-134a are outlined; they include inherent antiwear properties, assoclated with formation of metal-chloride boundary layers, and miscibility with mineral oils. The R-134a advantages, specifically avoidance of ozone depletion and high relative stability, also are noted. A need for a balanced additive approach, respecting both protection of contacting surfaces and low aggressivity toward copper and aluminum design components, is cited. The paper notes that the issue of copper plating is a selection constraint, in light of its prominence with R-134a and use of polar, potentially active lubricants. The paper reviews a screening protocol based on Falex pin and v-block tests. Results are plotted for R-12 with mineral oil, R-134a with the ester, and the latter pair with six unidentified additive systems. The most promising of the additive packages was further tested with three polyol ester lubricants for viscosities of 15-130 cSt. This additive is described as carefully balanced for multi-metal 
compatibility, namely sufficiently acthe for antiwear protection yet relathely inactive toward aluminum and copper-containing components. The findings of the compressor tests, including visual examination for distress, deposit formation, and copper plating are reviewed. A figure qualtathely compares the Falex and compressor results. The figure show the Falex test to be a good predictor, though it indlcates greater bronze-on-steel concern for the optimized addlthe than was experlenced in the compressor tests.

T. W. Dekleva (ICl Americas, Incorporated), Lubrt cants for Use whth R-134h in Domestlc Appltances, presentation at the International CFC and Halon Aiternatives Conference (Baltimore, MD), AJllance for Responsible CFC Pollcy, Arlington, VA, November 1990 (40 pages with 30 charts, RDB2524)

F. Espinoux, G. Bardy, B. Constans, P. Sanvi, and N. Genet (Elf Research Center, France), Lubriclty Evaluation for Lubricants Used in Refrigeration with HFC-134n, Proceedings of the 1992 International Refrigeration Conference - Energy Efilciency and New Refrigerants, edted by D. R. Tree and J. E. Braun, Purdue University, West Lafayette, IN, volume 2, pages 405-414, July 1992 (10 pages with 6 figures and 3 tables, RDB2823)

D. J. Glova, High-Temperature Solubillty of Refrigerants in Lubricating Oll, Transactions, American Society of Heating, Refrigerating, and Air-Conditloning Engineers, ASHRAE), Atlanta, GA, volume 90, part 2B, pages 806-825, 1984 (RDB2211)

B. D. Greig (Castrol Limited), Formulated Polyol Ester Lubricants with HFC-134a: The Role of Addhives and Conversion of Existing CFC-12 Plant to HFC-134a, Proceedings of the International CFC and Halon Alternatives Conference Washington, DC), Alliance for Responsible CFC Policy, Arlington, VA, pages 135-145, September 1992 (11 pages with 3 figures and 3 tables, RDB. 2A09)

J. H. Grim, Lubiteation Requirements for the Refrigeration and Alr-Condilioning Industry. Trans. actions, American Soclety of Heating, Refrigerating, and Air-Condlitoning Engineers (ASHRAE), Atlanta, GA, volume 82, part II, pages 567-571, 1976 (RDB2528)

P. E. Hansen (Danfoss-Flensburg GmbH, Germany). On the Oil Selection Methodology for New Refrigerants for Small Hermotic Compressors, paper 3.3. Proceedings of the International Seminar on Now Technology of Alternative Refrigerants - Lubricants and Materials Compatibility (Tokyo, February 1983), Japanese Association of
Refrigeration (JAR), Tokyo, Japan, pages 45-50, February 1993 (6 pages with 3 figures and 3 tables, RDB3312)

D. R. Henderson (Spauschus Associates, Incorporated), Solubility, Viscostty, and Densthy of $R e$ frigerant-Lubricant. Mixtures, report DOE/CE/ 23810-8F, Alr-Conditioning and Refrigeration Technology Instltute (ARTI), Arlington, VA, January 1993 (20 pages with 8 figures and 9 tables, available from JMC as RDB3207)

This interim report presents results of measurements to determine the solubility (pressure), viscosity, and density of refrigerant-lubricant mixtures. It summarizes initial findings for low refrigerant concentrations $(70,80,90$, and $100 \%$ lubricant by weight) for R-12 and R-22 with ISO 32 mineral oil (Witco Suniso(R) 3GS) and R-134a with ISO 32 penta enthrttol ester mixed acid (Mobll EAL(R) Arctic 32) for $0-100^{\circ} \mathrm{C}\left(32-212^{\circ} \mathrm{F}\right)$. The data have been reduced to engineering form and are presented as Danlel Charts. Scatter dlagrams, overlain with curve fits, are provided for R-12 with mineral oll. These diagrams lllustrate both the quality of data and rationale for the manner chosen to represent the data. The regression equations and correlation statistics are reported. Viscosity, pressure, and density data are represented by Walther, quadratic polynomial, and linear equations, respectlvely. Measured data are tabulated for each of the fluids. The report outlines work performed for the project, lists the refrigerantlubricant pairs to be studled along with associated temperature ranges, and summarizes the data reduction. 35 mbxtures will ultimately be tested over selected ranges of composition and temperature.

H. G. Hirschberg (Gebrüder Sulzer AG, Switzerland), Determining the Viscostly of Mixtures of Mineral Oll and Refrigerants, Sulzer Technical Review, Winterthur, Switzerland, February 1964; ropublished in Modern Refrigeration, pages 711-713 (3 pages with 4 figures, RDB2501)

The viscosity of lubricating olls is substantially lowered by dissolved hydrocarbons. Determination of viscosity for refrigerant-fubricant $\mathrm{mb}$ tures, therefore, is very important in equipment and application design. The need is heightened by variations in the hydrocarbon content, related to the origin of the crude oll used, and the way in which it is refined. This paper outlines calculation methods to determine the viscosity based on ring analysis, mean molecular weight, viscosity-temperature relation, and density. The ring analysis determines the paraffins, cyclic parafiins (naphthenic substances, and benzene dertvatives (aromatics) present in the oll. The 
molecular weight is a measure of the size of the oil molecules. The viscosity index, or alternative viscosity pole height, may be obtained from manufacturer data. The paper discusses viscosity equations developed by a number of investigators, including Arthenius, E. R. Epperson and $H$. L Dunlap, L. Grunberg and A. H. Nissan, and $H$. Umstătter. It lllustrates comparathe results based on a mixture of R.114 and mineral oil. It concludes that a modified version of the Grunberg and Nissan equation is useful for representing and calculating the viscosities of refrigerant-Jubricant mixtures.

D. F. Huttenlocher (Spauschus Associates, Incorporated), Chemical and Thermal Stability of Rofrigerant-Lubricant Mixtures with Metals, report DOE/CE/23810-3B, Air-Conditioning and Refrigeration Technology Institute (ARTI), Arlington, VA, 10 july 1992 (64 pages with 37 figures and 24 tables, available from JMC as RDB2802)

This interim report presents stability data, based on sealed tube tests, for mixtures of refrigerants and lubricants in the presence of a valve steel strip. Tabular results are presented for R-22 with mineral oll, R-124 with alkylbenzene, R$134 a$ with three penta erythritol esters (PEs). R$142 b$ with alkylbenzene; R-143a with PE branched acid, and R-152a with alkyibenzene. Partial results are provided for eight additional refrigerant-Iubricant mixtures, including those containing R-11, R-32, R-123, R-125, and R-134. The information provided includes visual observations on the aged sealed tubes and gas chromatographic analyses on their vapor-phase contents. Chloride lon contents are provided for hydrochlorofluorocarbon (HCFC) cortaining mixtures and fiuoride lon contents for hydrofluorocarbon (HFC) mixtures. Total acid number values and infrared analyses are presented for mixtures containing ester lubricants. The mineral oils tested were Witco Suniso(R) 3GS (ISO 32) and Freezene Naphthenic Heavy white oil (ISO 46). The alkylbenzene was Shrieve Zerol(R) 150. The polyalkylene glycols (PAGs) included ICl Emkarox(R) polypropylene olycol butyl monoether (ISO 32) and Dow Chemical P245 polypropylene glycol dld (1SO 22). The penta eny. thritol esters (PEs) Included Castrol Icematic(R) SW32 branched acld, ICl Emkarate(TM) RL mixed aclds, and Henkel Emery(R) 4078X (2928 ISO 100) $100 \mathrm{cSt}$. Most of the tests were repeated at three temperature levels, namely 150. 175 , and $200^{\circ} \mathrm{C}\left(221,302\right.$, and $\left.347^{\circ} \mathrm{F}\right)$; additional tests were performed at $105^{\circ} \mathrm{C}\left(221^{\circ} \mathrm{F}\right)$ when indicated. The preliminary findings indicate that the HFCs tested are very stable and did not undergo measurable chemical reactlons or thermal decomposition, even in the presence of lubricants. The high-viscosity ester is the only lubricant that showed significant signs of instability, based on decarboxylation of the ester molecule, especially at $200^{\circ} \mathrm{C}\left(347^{\circ} \mathrm{F}\right)$. All of the HCFCs tested, possibly excepting R-22, are less stable than the HFCs. Except for R-123, however, they are no more reactive than $R-12$ under equivalent test conditions. While R-123 is significantly more reacthe, it offers a stabllity improvement by a factor of ten over R-11.

D. F. Huttenlocher (Spauschus Assoclates, Incorporated). Chemical and Thermal Stabillty of Refigerant-Lubricant Mixtures with Motals, Proceedings of the 1992 International Refrigeration Conference - Energy Efficiency and New Refrigerants, edted by D. ה. Tree and J. E. Braun, Purdue Untversity, West Lafayette, IN, volume 2, page 679, July 1992 (1 page, avallable from JMC as RDB. 2813)

D. F. Huttenlocher (Spauschus Associates, Incorporated), Chemical and Thermal Stabllity of Refrigerant-Lubricant Mlxtures whth Motale, report DOE/CE/23810-2B, Alr-Conditioning and Refrigeration Technology Institute (ARTI), Arlington, VA, 31 March 1992 (28 pages with 11 figures and 12 tables, avallable from JMC as RDB2416)

This interim report summarizes stability data, based on sealed tube tests, for mixtures of refrigerants and lubricants in the presence of a valve steol strip. Tabular results are presented for $\mathrm{R}-123$ with mineral oll at 105,150 , and $175^{\circ} \mathrm{C}$ $\left(221,302\right.$, and $\left.347^{\circ} \mathrm{F}\right)$. The findings indicate that prolonged exposures to temperatures $\theta x$ ceeding approximately $150^{\circ} \mathrm{C}$ (302 ${ }^{\circ} \mathrm{F}$ ) lead to rapid chemical deterioration, yielding $R-133 a$ and R-143a as decomposition products. Preliminary data, for tests at 150 and $175^{\circ} \mathrm{C}(302$, and $347^{\circ} \mathrm{F}$ ), are presented for R-22 with a mineral oil Witco Suniso(R) 3GS), R-124 and R$142 \mathrm{~b}$ with an alkylbenzene (Zerol(A) 150), and $R$ 32. R-125, R-134a, and R-143a with penta orythritol ester branched acid (Castrol lcematic(R) SW32). Prellminary results also are presented for R-134a with a higher-viscosity penta erythritol ester (Henkel Emery(R) 2928 iso 100). The information provided Includes visual observations, chemical analyses, and gas chromatograms with summary data indicating the fraction of refrigerant that reacted. The preliminary results suggest that the seven refrigerantlubricant systems are very stable at the temperatures tested, and that funther testing is needed to define the upper temperature limits. Isee RDB2802 for update]

S. T. Jolley, The Performance of Symthotlc Ester Lubricants in Mobile Air-Condtioning Systems, Lubrizol Corporation, Wickliffe, OH, 1992 (14 pages with 3 figures and 6 tables, RDB2C07) 
The publication reviews polyol ester chemistry and the reactions of alcohol and carboxylic acid to produce them. The variety of lubricants that can be produced from neopentylglycol (NPG), glycerine (GLY), trimethylolpropane (TMP) and pentaerythrttol (PER) polyols (alcohols with multiple hydroxyl reaction sites) is Illustrated. A table demonstrates the influence of the alcohol type on viscosity and miscibility using the same carboxylic acid. A second table shows that when similar lubricants, with the same viscosity are prepared, differences occur in miscibility with R-134a. GLY and NPG flulds exhibit the poorest and high solubility, respectively. Tabulated results of sealed-tube tests of R-134a and lubricant in the presence of iron, copper, and aluminum show high thermal stability for a number of polyol esters, generally superior to that of R-12 with mineral oil. The more reactive systems tended to be those with high water content or residual carboxylc acid. Data are presented on the same refrigerant-fubricant pairs with addition of controlled amounts of water, to examine hydrolytic stability. Resultant increases in acid number are discussed, but caveated that higher acid levels might occur with addtives instead of the base lubricants tested. A figure summarizes elastomer swell for mineral oil as well as NPG, TMP, and PER esters for NBR, H-NBR, EPDM, nitrile, neoprene, and Butyl; the paper notes that further testing is needed. It then discusses miscibility with mineral oil, a concern for retroft of automobile air conditioners with R-134a and esters. TMP and PER esters are indicated to be fully compatible with both residual R-12 and mineral oil. Compressor tests are summarized, to address the influence of viscosity on durability and the role of unidentifled additives. The paper indicates that equivalent performance to R-12 and mineral oil can be obtained with polyol esters and appropriate additive packages. The paper concludes that polyol esters appear ideal for use in automobile air condtioner systems, and that they can be tailored for specific needs.

S. T. Jolley, Now and Unique Lubricants for Use in Compreasors Utillizing R-134a Refrigerant, Proceedings of the 1990 USNC/IIR-Purdue Refrig. eration Conference and ASHRAE-Purdue CFC Conference, edked by D. R. Tree, Purdue University, West Lafayette, IN, pages 145-152, July 1990 (8 pages with 1 figure and 5 tables, RDB2C06)

S. Komatsuzakl, Y. Homma, K. Kawashima, and Y. Itoh (Hitachi Limited), Polyalkylene Glycol as LuLicant for HFC-134a Compressors, Lubrication Engineoring. Society of Tribologists and Lubrication Engineers (STLE), volume 47, number 12, pages 1018-1025, December 1991 (RDB2212)
S. Komatsuzakl and Y. Homma, Antiseizure and Antiwear Properties of Lubricating Olls Under Refrigerant Gas Environments, paper 90-AM-6C. 1 (45th Annual Meoting, Denver, CO, 7-10 May 1990), Society of Tribologists and Lubrication Engineers (STLE), May 1990; republlshed in Lubrication Engineering, STLE, volume 47, pages 193-198, 1991, May 1990 (RDB2213)

S. Komatsuzakl, T. Tomobe, and Y. Homma (Hitachi Limited), Additive Effects on Lubriclty and Thermal Stability of Refrigerator Olis, Lubrication Engineering. Society of Tribologists and Lubrication Engineers (STLE), volume 43, pages 3136, 1987 (RDB2423)

$H$. Kruse and M. Schroeder (Universităt Hannover, Germany), Fundamentals of Lubrication in Rotrigeration Systems and Heat Pumps, ASHRAE Journal, Amerlcan Society of Heating. Refrigerating, and Alr-Conditioning Engineers (ASHRAE), Atlanta, GA, volume 26, number 5, pages 5-9, May 1984 (RDB3411)

J. L. Little, Viscosity of Lubricating OII - Freon 22 Mixtures, Refrigerating Engineering. American Soclety of Refrigerating Engineers (now merged into the American Society of Heating. Refrigerating, and Air-Conditloning Engineers, ASHRAE), Atlanta, GA, pages 1191-1195, November 1952 (RDB2214)

K. Mall, Messeinrichtung zur Ermittlung des Dampldruckes von OfKaltomittol Gomischen (Measuring Apparatus for Determination of the Vapor Pressure of Oil-Refrigeramt Mixtures), $K a ̈ /-$ tetechnik-Klimatisierung, volume 22, number 8 , pages 257 ff, 1970 (in German, RDB2502)

T. Matsuzakl and M. Akel (Calsonic Corporation), The Friction and Wear Behavior in Refrigerant Atmosphere, paper 2.2. Proceedings of the International Seminar on New Technology of Atternative Refrigerants - Lubricants and Materials Compatibility (Tokyo, February 1983), Japanese Association of Refrigeration (JAR), Tolyo, Japan. pages 27-32, February 1983 (6 pages with 13 figures, RDB3310)

Y. Natsume (Nippondenso Company, Limited), Retrigerating Machine Laubricanis for Now Refrigerant, paper 2.1, Procetdings of the International Seminar on New Technology of Aternative Refrigerants - Lubricants and Materials Compatibility (Tokyo, February 1983), Japanese Association of Refrigeration (JAR), Tokyo, Japan, pages 21-26, February 1983 (6 pages with 11 figures and 1 table, RDB3309)

M. B. Pate, S. C. Zoz, and L. J. Berkenbosch (lowa State University of Science and Technology), Miscibility of Lubricants with Rofrigerants, report 
DOE/CE/23810-3C. Air-Condtiloning and Refrigeration Technology Insttute (ARTI), Arlington, VA, July 1992 (22 pages with 24 tables, avallable from JMC as RDB2803)

This progress report summarizes the status and initial data obtained from an investlgation of miscibility of lubricants with refrigerants. Ex. periments are being performed in two phases, namely screening tests and preparation of miscibility plots. Qualtative miscibility observations are tabulated for R-32, R-125, R-134, R-134a, R142b, and R-143a with four lubricants. They include two penta erythritol esters, a mixed acld (ICI Emkarate(TM) RL 22H, formerly RL 244) and a branched acid (Castrol Icematic(R) SW32), and for two polyalkylene glycols (PAGs), a polypropylene glycol did (Dow P425) and a polypropylene glycol butyl monoether (ICl Emkarox(R) VG32). These tests were performed for three lubricant concentrations over a temperature range of -50 to $+60^{\circ} \mathrm{C}\left(-58\right.$ to $\left.+140^{\circ} \mathrm{F}\right)$ for R-32, R-125, R-134, and R-143a. The range was extended to $+90^{\circ} \mathrm{C}\left(+194^{\circ} \mathrm{F}\right)$ for R-134a and R-142b. R-22, R-123, R-124, and R-152a will be tested later. The refrigerant concentrations varied due to the method of charging the test cells, but future tests will provide data at nomlnal concentrations of 10,50 , and $95 \%$ by weight for all of the combinations. Composition changes as the density of the vapor decreases and the vapor volume increases are discussed. Minor problems with leakage and corrections are described. Summary observations are provided for each refrigerant-lubricant combination.

M. B. Pate, S. C. Zoz, and L. J. Berkenbosch (lowa State University of Science and Technology). Miscibility of Lubricants with Refrigerants, Proceedings of the 1992 International Refrigeration Conference - Energy Efficiency and New Refrigerants. edited by D. R. Tree and J. E. Braun, Purdue University. West Lafayette, IN volume 2, pages 681 . 686. July 1992 (6 pages with 4 figures and 2 tables, available from JMC as RDB2814)

H. M. Parmelee, Viscosity of Refrigerant-Oil Mixtures at Evaporator CondHions, Transactions, American Soclety of Heating, Refrigerating, and AirConditioning Engineors (ASHRAE), Atlanta, GA, volume 70, pages 173-180, 1964 (RDB2215)

K. S. Sanvordenker Tecumsoh Products Company). Durability of HFC 1340 Compressors the Role of the Lubricam. (proceedings of the 42nd Annual International Appllance Technical Conference, University of Wisconsin, Madison, WI, May 1991), reprint by Tecumseh Products Company, Tecumseh, MI, 1991 (8 pages with 2 figures and 2 tables, RDB2215)
Properties of polyalkylene glycol (PAG) and polyol ester lubricants are examined, with omphasis on inherent thermal stability and sultability for use with R-134a in refrigeration compressors. The PAGs addressed include diols, monoethers, ester-ethers, and diethers, all stabilized with 200 ppm BHT. Plots of hygroscopicity and miscibility of PAGs with mineral oils are provlded. The decomposition kinetics, based on sealed-tube tests, are tabulated. The effects summarized include temperature $\left(177-260^{\circ} \mathrm{C}\right.$, 350-500 ${ }^{\circ} \mathrm{F}$ ), presence of metals (steel, copper, and aluminum) or R-134a, and PAG type. Problems of hygroscopiclty, incomplete miscibility with mineral oils, and incompatibility with chlorinated solvents exist, but they can be handled by proper housekeeping procedures. Lack of thermal stability, even in the absence of metals, at $177-204{ }^{\circ} \mathrm{C}\left(350-400{ }^{\circ} \mathrm{F}\right)$ is identified as a key shortcoming for the PAG candidates. The effects of time, metal catalysts, and initial moisture are tabulated for polyol esters, again at elovated temperatures $\left(204-260^{\circ} \mathrm{C}, 400-500{ }^{\circ} \mathrm{F}\right)$. Penta emprited tetra ester is emphasized due, in part, to its better misclbility with R-134a compared to other neopentyl esters. Decomposition also was observed, but only in the presence of steel. A metal passivator specific to steel was found to provide a simple remedy.

K. S. Sanvordenker (Tecumseh Products Company). Mechanism of Oil-R12 Reactions - the Role of Iron Catalyst in Glase Sealed Tubes, paper 2881, Transactions, American Society of Heating. Refrigerating, and Air-Conditioning Engineers (ASHRAE), Atlanta, GA, volume 91, pant 1A, pages 356-369, January 1985 (14 pages with 7 figures and 1 table, RDB2217)

This frequently cted paper presents the chemistry of oil and R-12 reactions in sealed-tube tests in detall. The paper reviews the mechanisms postulated in earlier publications iseo RDB2326 and RDB2526] and observations based on infrared absorbance. The paper concludes that iron acts as a participant in the reaction, rather than as a catalyst. Large amounts can be solubilized, and the process of solubilization begins early. The iron-oll molecule and R-12 react with the glass; this reaction also starts much earlier than previously Indicated. The reaction forms boron-hydrogen and sillicone fluorine compounds, while precipitating oun the solubillzed iron. Based on gas analysis by infrared, a criterion is defined to identlfy the entry of glass in sealed-tube reactions. The paper traces through the postulated reactions and ex. periments conducted, to identify actual reactions by elimination of participating materials. Based on the finding that reactions involving glass start at an early stage in systems containing R-12, oil, and steel, data in prior puillications 
that show large amounts of reaction products need to be reexamined.

K. S. Sanvordenker Tecumseh Products Company), Lubrication by Oll-Refrigerant Mixtures: Behavior in tho Falox Tester, paper KC-84-14-3, Transactions, American Society of Heating, Refrigerating, and Alr-Conditioning Engineers (ASHRAE), Atlanta, GA, volume 90 , part 2, pages 799-805, June 1984 (7 pages with 2 figures and 3 tables, RDB2422)

The effects of test parameters, with reference to the fundamentals of boundary lubrication, are discussed for Falex pin and v-block tests. Such tests are widely used by equipment manufacturers and lubricant suppliers to simulate lubrication in refrigerant compressors and to screen refrigeration lubricants. When modified to provide a closed, pressure-tight chamber, the Falex machine permits laboratory simulation of lubricants in hermetic compressors. The paper review fundamental theories of boundary lubrication and wear to explain laboratory data that may appear to be anomalous. In doing so, the paper explains that trouble-free operation of hermetic compressors under high-oil dilution conditions of liquid feedback has been simulated. The unanticipated result is explained on the basis of dissipation of frictional heat from the rubbing surfaces. The behavior of additive-free lubricants is described and compared to that with antiwear additives, such as tricresyl phosphate (TCP).

K. S. Sanvordenker and M. W. Larime (Tecumseh Products Company). A Roviow of Synthetlc Oils for Refrigeration Use, Transactions, American Soclety of Heating, Refrigerating, and Air-Conditioning Engineers (ASHRAE), Atlanta, GA, volume 78, part 2, 1972; republished in symposium bulletin NA-72-5 (ASHRAE Annual Meeting, Nassau, Bahamas), June 1972 (6 pages with 1 table, RDB2218)

B. H. Shoemaker, Synthetic Lubricating Oils, Industrial Engineering Chemistry, volume 42, number 12, page 2414, 1959 (RDB2219)

G. D. Short and T. E. Rajewskl (CPI Engineering Services, Incorporated), Lubricants for Use With Highly Fluorinated Rofrigerants, Technical Papers of the 15th Annual Meeting (21-24 March 1993, Vancouver, BC, Canada), International Institute of Ammonia Refrigeration (IIAR), Washington, DC, pages 139-169 as misnumbered, March 1993 (31 pages with 4 figures and 6 tables, RDB3410)

This paper provides an update on lubricants for use with hydrofluorocarbon (HFC) refrigerants and HFC blends. It also summarizes evalua. tlons of several synthetic lubricants and the tests necessary to insure that a lubricant will provide expected durability and performance with refrlgerants. The paper identifies near-term alternatives for common chlorofluorocarbon (CFC) refrigerants, and provides tabular summaries of both candidate refrigerants and recommended lubricant types for use with R-22, R23, R-123, and R-134a. The paper describes the derivation, applications, characteristics, and experience with several lubricants. They include polyol ester (POEs), polyalkylene glycols (PAGs), modifled PAGs, diesters, PAG esters, carbonates, fluoroethers, fluorosilicones, and alkylbenzenes. Tables provide recommended viscosity ranges for different compressor types, refrigerant-lubricant miscibility data for R-22 and replacement candidates, lubricity findings (based on Falex pin-and-vee-block tests) for ester lubricants and mineral oil with steet on steel, and the effects of additives on lubricant stability. The paper discusses miscibility, viscosity dilution, lubricity tests, chemical and thermal stability, and compatibility of refrigerantlubricant combinations with other materials. Four figures illustrate the viscosity-temperaturepressure relations for R-22 with a 32 ISO alkytbenzene, R-134a with a 68 ISO PAG, R-134a with a 68 ISO POE, and R-134a and R-12 with a 46 ISO POE. The paper briefly cites findings with retroftis and field experience of PAGs and POEs, and notes that nether are sultable for use with R-717 (ammonia). The paper concludes that POEs appear to be the choice for HFCs and dialkyl benzenes with HCFC-123 and HFC/HCFC blends. It notes that POEs are preferred over PAGs for reiroft due to their miscibility and their compatibility with residual chlorine.

G. D. Short (CPI Engineering Services, Incorporated) and R. C. Cavestri (Imagination Resources, Incorporated). High-Viscosity Ester Lubricants for Alternative Refrigeramts, paper AN-92-5-2 Winter Meeting. Anaheim, CA, January 1992), Transactions, American Society of Heating, Refrigerating, and Air-Conditioning Engineers (ASHRAE), Atlanta, GA, volume 98, part 1, pages 789-795, 1992 (7 pages with 3 figures and 5 tables, RDB2102)

This paper describes the development of highviscosity (ISO 68 and above), modified polyol ester lubricants and their interactions with refrigerants. Typical properties are presented for 11 conventional and modified penta erythrttol (PE) esters, including several dl- and tr-PEs, as well as for a modified trimethylolpropane (TMP) ester. Data are reported with R-123, R-134a, R152a, E-134, and E-245. The apparatus used to measure viscosity and density is described. The viscosity of a modifled, high-viscosity ester with R-134a is presented for evaluation of the hydro- 
dynamic lubrication and sealing of compression areas. Chemlcal and thermal stability and lubricity test results are provided for durability considerations.

G. D. Short (CPI Engineering Services, Incorporated) and R. C. Cavestri (Imagination Resources, incorporated), Selection and Performance of Synthetic and Semi-Synthetic Lubricants for Use with Alternative Retrigerants in Retrigeration Applications, Proceedings of the 1990 USNC/IIRPurdue Refrigeration Conference and ASHRAE. Purdue CFC Conference, edited by D. R. Tree, Purdue University, West Lafayette, IN, pages 163 . 172. July 1990 (10 pages with 10 figures, RDB2.220)

G. D. Short (CPI Engineering Services, Incorporated), Synthetic Lubricants and Their Retrigeration Applications, (paper 89-AM-7A-1, 44th Annual Meeting, Atlanta, GA, May 1989), Lubrication Engineering. Society of Tribologists and Lubrication Engineers (STLE), volume 46, number 4, pages 239-247, April 1990 (RDB2221)

This paper reviews the requirements and use of synthetic fluids as lubricants for refrigeration systems. R-12, R-13, R-22, R-114, R-134a, R502, R-503, propane (R-290), and ammonia ( $R$ 717) are addressed. Requirements are discussed for thermal and chemical stability, miscibility, solubillty, and viscosity. Failure mechanisms including improper viscosity, dilution, loss or breakdown of lubricant, fallure of hydrodynamic lubrication, foaming, and starvation related to solubility and miscibility characteristics are reviewed for rotary screw, reciprocating piston, and rotary vane (both fixed and rotating) compressors. Petroleum-based, including both naphthenic and high-viscosity index (HVI) paraffinic mineral oils, and synthetic lubricants are discussed. The synthatics are grouped as polyalphaolefin (PAO), alkylbenzene, and polyalkylene glycol (PAGs) synthetic hydrocarbon (SHC) oils. They also include esters such as diesters (or dibasic acid esters), neopentyl (or polyol) esters, and modifled complex esters. The chemical structures and characteristics of these lubricants are reviewed, and viscosity and miscibility plots are provided for representative refrigerant fubricant systems. Typical properties are tabulated for complex esters of ISO 150 and 320 viscosity. The unique requirements for $R$ 134a, propane (R-290), and ammonla (R-717) are outlined, concluding that the synthetic lubricants described offer a major contribution for system advancement.

H. W. Sibley (Carrier Corporation), Oil Foaming Characteristics - The Forgotten Design Parameter with HFC-134a, paper 5.4. Proceedings of the International Seminar on New Technology of Alter- native Refrigerants - Lubricants and Materials Compatibility (Tokyo, February 1983), Japanese Association of Refrigeration (JAR), Tokyo, Japan, pages 101-104, February 1993 (4 pages with 5 fig. ures, RDB3319)

This paper addresses differences in interactions between R-134a with synthetic lubricants and chlorofluorocarbons (CFCs) with mineral olls. The discussion notes the importance of refrigerant-lubricant solubility for oil return to the compressor. The consequent role of the refrigerant as a lubricant contaminant, and specifically reduction in viscosity and hydrodynamic lubrication, is examined. The effect of rapld refrigerant vapor release, called foaming, is explained. A plot compares the vapor pressure of R-134a in a polyol ester (POE) to R-12 in a mineral oil (MO) at 27 and $79^{\circ} \mathrm{C}$ (80 and $174^{\circ} \mathrm{F}$ ) with $10.70 \%$ refrigerant. The nature of the resultant foams are characterized, that for $R-12 / \mathrm{MO}$ as a stable froth and that of R-134a/POE as an unstable or quick breaking foam. Comparative foam heights are plotted and contrasted for oll-rich conditions, as in compressor crankcases, and oil-lean condtions, as in evaporators of centrifugal chillers. Significant differences are noted for the former. Desorption dynamics of the two refrigerant-lubricant pairs are discussed and plotted under driving temperature differences of 37 and $171^{\circ} \mathrm{C}\left(67\right.$ and $\left.308{ }^{\circ} \mathrm{F}\right)$. R-134a is shown to desorb more rapldiy at common thermal gradients. The paper concludes that vapor-venting needs to be altered in R-134a compressors. While the change can be readily dealt with in now designs, the difference in venting must be considered in equipment conversions. The paper notes a need to examine effects of different foaming characteristics on heat transfer.

L. I. Sjöholm (Teknikgruppen AB) and G. D. Short (CPI Engineering Services, Incorporated). TwinScrew Compressor Performance and Complex Ester Lubricants with HCFC-22, Proceedings of the 1990 Intemational Compressor Engineering Conference at Purdue, edited by W. Soedel, Purdue University, West Lafayette, IN, payes 724-732, July 1990 (9 pages with 8 figures, RDB2222)

L. I. Sjöholm (Teknikgruppen AB) and G. D. Shon (CPI Engineering Services, Incorporated), TwinScrew Compressor Pertormance and Sultable Lubricants with HFC-134a, Proceedings of the 1990 International Compressor Engineering Conference at Purdue, edited by W. Soedel, Purdue University, West Lafayette, IN, pages 733-740, July 1990 (8 pages whth 7 figures (RDB2223)

H. O. Spauschus, D. R. Henderson, and D. F. Huttenlocher (Spauschus Assoclates, Incorporated), 
Boundary Lubrication Properties of Alternative Working Flulds, paper 3.1, Proceedings of the Int6.national Seminar on New Tochnology of Avternative Refrigerants - Lubricants and Materials Compatibility (Tokyo, February 1983), Japanese Association of Refrigeration (JAR), Tokyo, Japan, pages i3-38, February 1983 (6 pages with 7 figures and 2 tables, RDB3311)

H. O. Spauschus, D. R. Henderson, and R. Rohatghi (Spauschus Associates, Incorporated), SAE Cocperative Research Program: HFC-134a LUbricant Study, Final Report, Society of Automotive Engineers (SAE), Warrendale, PA, 6 November 1992 (130 pages with 105 figures and 49 tables, RDB3107)

H. O. Spauschus (Georgia Institute of Technology) and $L . M$. Speaker, A Review of Viscosity Data for Oil-rsetrigerant Solutions, Transactions, American Society of Heating, Refrigerating, and Air-Conditioning Engineers (ASHRAE), Atlanta, GA, volume 93. part 2, pages 667.681, 1987 (RDB2224)

H. O. Spauschus (Georgia Institute of Technology), Evaluation of Lubricants for Refrigeration and Air-Conditioning Compressors, Transactions, American Society of Heating, Refrigerating, and AlrConditioning Eng.neers (ASHRAE), Atlanta, GA, volume 90, part 2, pages 784-798, 1984; republished in ASHRAE Journal, volume 26, number 5 , pages $59 \mathrm{ff}, 1984$ (RDB2225)

H. O. Spauschus (General ílectric Company), Vapor Pressures, Volumes, and Miscibility Lirnits of Pefrigerant 22-Oil Solutions, Transuctions, American Society of Heating, Refrigerating, and AirConditioning Engineers (ASHRAE), Atlanta, GA, 1964 (RDB2226)

H. O. Spauschus (General Electric Company), Thermodynamic Properties of Refrigerant-Oil Solutions: Dichlorodifluoromethane $(\boldsymbol{R}-12)$ and Petroleum Oil, ASHRAE Journal, American Society of Heating, Refrigerating, and Air-Conditioning Engineers (ASHRAE), Atlanta, GA, pages $63 \mathrm{ff}$, August 1963 (RDB2227)

L. M. Speaker and H. O. Spauschus (Georgia Institute of Technology). A Study to Increase the State-oi-the-Art Solubility and Viscosity Relationships for Oll-Refrigerant Mixtures, final report for 444-RP, American Sociely of Heating, Refrigerating, and Air-Conditloning Ingineers (ASHRAE), Atlanta, GA, 20 February $10 \% 3$ (PiDB2504)

Y. Tanaka, H. Kawachi, C. Takata, H. Kubota, and T. Makita (Kobe University), Solubility of 1,1,1,2tetrafluoroethane (R-134a) in Refrigeration Oils. Proceedings of the Second Asian Thermophysical
Properties Conference, pages 375-379, 1989 (6 pages with 6 figures, available from JMC as RDB. 2B11)

This paper discusses the solubility of R-134a in lubricants at temperatures of $303-363 \mathrm{~K}$ (86-194 $\left.{ }^{\circ} \mathrm{F}\right)$ and pressures up to $2.5 \mathrm{MPa}$ (360 psia). It describes experimental apparatus, procedures, and calculations to determine solubility. The lubricants tested incli ided a naphthenic mineral oil Witco Suniso(R) 4GS), perfluoropolyethe. (Daikin Demnum(A) S-65), polyethylene glyco. (Wako), and polypropylene glycol (Wako). R134a was found to be completely miscible with the perfluoropolyether, partially miscible with the two polyglycols, and almost immiscible with the naphthenic oil. Solubility plots are presented.

R. H. P. Thomas and H. T. Pham (AlledSignal Incorporated), Solubility and Misclbility of Environmentally Safer Refrigerant-Lubricant Mixtures, paper AN-92-5-1 Winter Meeting, Anaheim, CA, January 1992), Transactions, American Society of Heating, Refrigerating, and Air-Conditioning Engineers (AS,4RAE), Atlanta, GA, volume 98, part 1 . pages $783.788,1992$ (6 pages with 9 flgures and 1 table as RDB2101)

Solubility and miscibility data are presented for R-134a with two polyalkylene glycol (PAG) lubricants (AP-150 and AP-500) and threo modifled PAGs (BRL-150, BRL-300, and BRL-500). Solubility was determined by measuring the equilibrium vapor pressure of mixtures of 10 . $90 \%$ refrigerant (by weight) in the lubricants for $10-70^{\circ} \mathrm{C}\left(50-158^{\circ} \mathrm{F}\right)$. Miscibllity was determined by visual observation of a sealed sample immersed in a thermostated bath for a range of $-\infty 0$ to $+70^{\circ} \mathrm{C}\left(-76\right.$ to $\left.+158^{\circ} \mathrm{F}\right)$. Differences in miscibility curve characteristics are contrasted to mineral oils. The paper examines occurrence of lower critical solution temperatures (LCSTs). Similartiles of refrigerant-oll systems to solventpolymer solutions are addressed, leading to correlations of the solubility data using the Flory. Huggins theory. While further analysis is indicated, Flory-Huggins type plots allow dedustion of composition in a refrigerant-lubricant system, given the temperature and pressure and assuming equillibrium.

R. H. P. Thomas, R. P. Robinson, R. H. Chen, and $W-T$. Wu (AlliedSignal Incorporated), The Solubility of R-32/125 in Modified Polyalkylene Giycols, Proceedings of the International CFC and Halon Alternatives Conference (Baltimore, MD), Alliance for Responsible CFC Policy, Arlington, VA, pages 375-383, December 1991 (9 pages with 2 figures and 2 tables, RDB2228) 
This paper provides solubility data on a mixture of $60.32 \%$ R.32 and $39.68 \%$ R.125, by weight, with two synthetic lubricants. This nonsegregating refrigerant blend is proposed as a candldate replacement for R-22 in medium- and hightemperature applications, with evaporator temperatures of -23 to $4^{\circ} \mathrm{C}\left(-10\right.$ to $\left.+40^{\circ} \mathrm{F}\right)$. The lubricants examined were a modifled polyalkylene glycol (PAG) and a PAG diol, BRL-150 and AP150 respectively. Tests also were made with mineral oils and alkylbenzene lubricants, but the refrigerant mixture was found to be immiscible with them. By contıast, the refrigerant was found miscible in the two PAGs from 60 to at least $+55^{\circ} \mathrm{C}\left(-76\right.$ to $\left.+131^{\circ} \mathrm{F}\right)$. The same lubricants also are suitable for use with R-134a. The miscibility of the refrigerant-lubricant mixture was determined by sealing samples in thermostated glass tubes and visually observing the contents. The solubility was studied by determining the equilibrium vapor pressure at constant compositions as a function of temperature. The experimental apparatus and procedure is descrihed. Measured vapor-pressures are tabulated, compared to earlier data, and extrapolated using Flory-Huggins theory. The relative pressure is tabulated at different temperatures for fixed fractions of lubricant by volume for verification. Plots are provided for both pressure and relative pressure versus volume fraction of lubricant, from 0.0 to 1.0 , for R.32/125 in the modified PAG. The text observes that the solubility for the PAG did is of the same order.

R. H. P. Thomas, W-T. Wu, and H. T. Pham (AlliedSignal Incorporated), The Solubility and Viscosity of Mixtures of R-134a with Modified Polyglycols, paper 48, proceedings of the XVIIlth International Congress of Refrigeration (Montreal, Québec, Canada, August 1991), International Institute of Refrigeration, Paris, France, August 1991 (9 pages with 7 figures, RDB2229)

The solubilities and viscosities of mixtures of R$134 a$ with two modified polyalkylene glycol (PAG) lubricants are reported. The piston-cylinder type viscometer and apparatus for measuring solubility are described The solubillty of $R$ $134 a$ in BRL-150 (a 150 SUS experimental lubricant) is plotted for $10-70^{\circ} \mathrm{C}\left(50-158{ }^{\circ} \mathrm{F}\right)$ in concentrations of $0-100 \%$. Its viscosity in BRL-150 and BRL- 300 ( 300 SUS) is plotted both as functions of temperature for -20 to $+80^{\circ} \mathrm{C}(-4$ to 176 ${ }^{\circ} \mathrm{F}$ ) and pressure. Analysis of the solubility shows that it can be described by the Flory-Hugins theory.

R. H. P. Thomas, W-T. Wis, and H. T. Pham (AlliedSignal Incorporated), Solubility and Viscosity of R-134a Refrigerant-Lubricant Mixtures, ASHRAE Journal, American Society of Heating, Refrigerating, and Alr-Condtioning Engineers
(ASHRAE), Atlanta, GA, pages 37-38, February 1991 (2 pages with 3 figures, RDB2230)

N. A. Van Gaalen, S. C. Zoz, and M. B. Pate (lowa State University of Science and Technology). The Solubility and Viscosity of Solutions of R-502 in a Naphthenic Oll and in an Alkylbenzene at High Pressures and Temperatures, paper 3519 (580. RP), Transactions, American Society of Heating, Refrigerating, and Air-Conditioning Engineers (ASHRAE), Atlanta, GA, volume 97, part 2, pages 285-292, 1991 (B pages with 14 figures and 2 tables, RDB2344)

N. A. Van Gaalen and M. B. Pate, Methods of Measuring the Solubility and Viscosity of Lubricating Oil/Refrigerant Mixtures, report ISU-ERIAmes-91191 (ASHRAE 580-RP), lowa State University of Science and Technology, Ames, IA, 199: (RDB2345)

N. A. Van Gaalen, M. B. Pate, and S. C. Zoz (lowa State University of Sclence and Technology). The Measurement of Solubility and Viscosity of Oil/Refrigerant Mixtures at High Pressures and Temperatures: Test Facility and Initial Rosults for R-22/Naphthenic Oil Mixtures, Transactions, American Society of Heating, Refrigerating, and AlrConditioning Engineers (ASHRAE), Atlanta, GA, volume 96, part 2, pages 183-190, 1990 (RDB2231)

N. A. Van Gaalen, M. B. Pate, and S. C. Zoz (lowa State University of Science and Teshnology). The Solubility and Viscosity of Solutions of HCFC-22 in Naphthenic Oll and in Alkylbenzene at High Pressures and Temperatures, Transactions, American Society of Heating, Refrigerating, and AirConditioning Engineers (ASHRAE), Atlanta, GA, volume 96, part 2, pages $100 \mathrm{ff}, 1990$ (RDB2232)

G. van der Waal (Unichema Chemie BV), The Relationship Between the Chemical Structure of Ester Base Fluids and Their Influence on Elastomer Seals, and Wear Characteristics, Joumal of Synthetic Lubricants, volume 1, pages 280-301, 1985 (22 pages with 20 figures and 4 tables, RDB2233)

M. J. Zion, Lubricating Olls for Refrigeration Systems, Technical Papers of the Eighth Annual Meeting, International Institute of Ammonia Refrigeration (IIAR), Washington, DC, pages 137-154, 1986 (RDB3340)

Boundary Lubrication of Ternary Blends (KCD9430 and 9433), document ARTD-12, E. I. DuPont de Nemours and Company, Incorporated, Wilmington, DE, undated (3 pages, available from JMC as RDB0541) 
This document summarizes a study to determine the lubricity of a 150 SUS viscosity alkylbenzene (Shrieve Zerol(R) 150) lubricant with two developmental refrigerants, KCD-9430 and KCD-9433. Both are ternary zeotropic blends, R-22/R-152a/R-114 (36/24/40) and R-22/R152a/R-124 (36/24/40), respectively. Measurements were made using a modified Falex pin and v-block test machine, with refrigerant bubbled through the lubricant; the test procedure is outlined. Failure loads are tabulated for the lubricant alone, with R-12 for comparison, and with the two blends. Data are provided for the neat lubricant, with two unidentified additives, and with both additives together. The document concludes that the alkylbenzene lubricant with additives provides acceptable lubrication with either blend. The refrigerant-lubricant mixtures were deemed sultable for further compressor durability testing.

Measurement of Solubility, Viscosity, and Density of Synthetic Lubricants in HFC-134a Mixtures, research project 716-RP, American Society of Heating, Refrigerating, and Alr-Conditioning Engineers (ASHRAE), Atlanta, GA, September 1991 . October 1992 (ASH0716)

This project addresses the gas solubility (refrigerant concentration), density, and viscosity of $\mathrm{R}$. 134a in solutions with synthetic lubricants. The pressures and temperatures for these determinations will range from 70 to $3450 \mathrm{kPa}(10-500$ psia) and -25 to $125{ }^{\circ} \mathrm{C}\left(-13\right.$ to $\left.257^{\circ} \mathrm{F}\right)$. The contractor for the project is Imagination $R \theta-$ sources, Incorporated, led by R. C. Cavestri; it is sponsored by Technical Committees 3.4, Lubrication, and 8.1, Positive Displacement Compressors.

Methods of Measuring the Solubility and Viscosity of Lubricating Oil-Refrigerant Mixtures at High Discharge Pressures and Temperatures, research project 580-RP. American Society of Heating, Refrigerating, and Air-Conditioning Engineers (ASHRAE), Atlanta, GA, June 1988 (ASH. 0580)

The contractor for the project was lowa State University of Science and Technology, led by M. B. Pate. The project was sponsored by Technical Committees 3.4, Lubrication, and 8.1, Positive Displacement Compressors. [see RDB. 2344 and RDB2345 for findings]

Oils for Alternatlve Refrigerants, document ARTD-11, E. I. DuPont de Nemours and Company, Incorporated, Wilmington, DE, undated circa 1990 (4 pages, available from JMC as RDB0540)

This bulletin reviews the properties desired in developmental lubricants, including acceptable solubility, lubricity, stability, compatibility, toxic-
Ity, and cors. Test results are reported for nonproprietary oils with ternary zeotropic blends and for proprietary lubricants with R-134a. The solubility of four unidentffied polyalkylene glycols (PAGs) with different viscosities, covering appliance through automotive applications, are plotted for mixtures whi R-134a. Their phase separation indicates incomplete solubility, as contrasted to full solubility for mineral olls used with R-12. Implications on flow, heat transfer, and oil return are briefly mentioned. The results of stability tests with aluminum, copper, and steel coupons are tabulated for R-12 with both naphthenic and paraffinic mineral oils and for $R$ $134 a$ with a PAG. One test with nylon also present is included. The results indicate that the $R$ 134a and PAG system has acceptable stability. Plans for ongoing and future tests are noted. Solubility and lubricity tests for mineral oils and alkylbenzenes with ternary zeotropic blends, comprising R-22/R-152a/R-114 (36/24/40) and 7-22/R-152a/R-124 (36/24/40), are briefly reviewed. They indicate that the mineral oils did not meet solubility goals. The blend and alkybenzene systems did not perform favorably without additives, but responded well with addition of extreme pressure (EP) additives already used in air-conditioning and refrigeration systems. Chemical stability test results are tabulated for two paraffinic and one naphthenic mineral oils and an alkylbenzene lubricant (all unidentffied) with R-12 and the two zeotropes. Qualitative findings are presented for liquid color, effect on metals, and copper plating: quantitative data are included for chloride and fluoride ion content. The bulletin concludes that the blend/alkylbenzene combination is more stable than R-12/mineral oil systems and that the blend containing R-124 (KCD-9433) is more stable than that containing R-114 (KCD-9430). Further test needs are briefly summarized.

Real Time Determination of Lubricant Concentrations Dissolved in Alternative Refrigerants. proposed research project 761-TRP, American Society of Heating, Refrigerating. Air-Conditioning Engineers (ASHRAE), Atlanta, GA, in planning (ASH0761)

This project will evaluate three means of measuring the concentration of lubricants circulating in refrigeration systems. The apparatus to be addressed include a viscometer, a densimeter, and an acoustic velocity sensor. The project is a follow-up to a prior project, Real Time Determination of Concentration of Oil Dissolved in Refrigerant Flow Stream Without Sample Removal (365-RP, see ASH0365), completed in January 1988. Three alternattve refrigerants will be evaluated, Including R-123, R-134a, and a third to be determined. Each will be tested with 
two lubricants in concentrations of $0.6 \%$ at temperatures representathe of condenser outlets, namely $24-49^{\circ} \mathrm{C}\left(75-120^{\circ} \mathrm{F}\right)$. This project is sponsored by ASHRAE Technical Committee 1.2, Instruments and Measurements. Further information is avallable from the ASHRAE Manager of Research (+1-404/636-8500).

Solubility of R-123 and R-1340 in Oils, Carrier Corporation, Syracuse, NY, September 1989 (3 pages with 3 figures, available from JMC as RDB. $0014)$

Two figures summarize the solubility of R-123 with Mobil DTE 26 and Mobil DTE Heavy Medium mineral oils for -29 to $-23^{\circ} \mathrm{C}$ ( -20 to -10 $\left.{ }^{\circ} \mathrm{F}\right)$. Critical solution temperatures are shown for solutions of $70-95 \%$ R-134a in unidentified 300 and 750 SUS polyglycol lubricants.

Solubility of Refrigerant in Lubricants: HFC. 134a, report NIST-3, Freon(R) Products Laboratory, E. I. DuPont de Nemours and Company, Incorporated, Wilmington, DE, undated circa 1989 (3 pages with 2 tables, available from JMC as RDB0533)

Solubility data for R-134a are presented for a range of lubricants based on tests run from -50 to $+93^{\circ} \mathrm{C}$ ( -58 to $199^{\circ} \mathrm{F}$ ). Mixtures of 30,60 , and $90 \%$ refrigerant by weight were tested with the lubricants in air-free sealed tubes. Solubility was determined, following a minimum of 15 minutes with agitation at each temperature; the blends were considered immiscible when they acquired and retained schlieren lines, formed floc, or formed two liquid layers. The lubricants include a polychlorotrifluoroethylene (Halocarbon blend 700/95-6.7/93.3 500 SUS), four perfluorinated poly alkyl ether oils (Krytox(R) GPL 150 and 480 SUS and Fomblin(R) $Y 25 / 5$ and $Z$ 15, both 417 SUS), and Daikin Demnum(R) S-65 300 SUS), dipenta erythritol esters of fatty acids (Hercules 240 and 290 SUS), PEG esters of fatty acids (CPI Engineering 144, 620, and 830 SUS). naphthenic oils (Witco Suniso(R) 5 GS 500 SUS $38 \%$ aromatic. Witco 500 SUS and two experimental oils at 520 SUS $47 \%$ aromatic and 529 SUS $75 \%$ aromatlc), paraffinic of (BVM-100N 500 SUS), three allibylbenzenes (Zerol(R) 300 SUS, Conoco DN600 125 SUS, and Nippon Oil Atmos HAB15F 78 SUS), and three sillicone oils (Union Carbide L- 45 163, 231, and 462 SUS).

Study of the Segregation or Fractionation of Refrigerant Blends in Contact with Lubricants and Measurement of Viscostty, Solubillty, and Density, proposed research project 779-TRP, American Society of Heating. Refrigerating, and Alr-Conditioning Engineers (ASHRAE), Attanta, GA, in planning (ASH0779)

This project will measure the solubility, viscosity, and density of refrigerant blends comprising hydrofluorocarbons (HFCs) with a representative lubricant. An addlional objective is to determine the influence, if any, of the lubricant on segregation and fractionation of the refrigerant mixtures. R-32/134a (30/70), R-32/134a (70/30), and pure alone will be examined with a 32 ISO polyol ester lubricant in compositions of $0-100 \%$, vapor pressures of $70-2350 \mathrm{kPa}$ (10500 psia), and -40 to $125^{\circ} \mathrm{C}$ (-40 to $257^{\circ} \mathrm{F}$ ). The miscibiltty and composition, in the gas and liquid phases (dissolved in the lubricant or as a separate liquid phase), of the cited fluids and of R-134a also will be measured. The results will be plotted. This project is cosponsored by ASHRAE Technical Committees 3.4, Lubrication, and 8.1, Positive Displacement Compressors. Proposals are due at ASHRAE Headquarters by 28 May 1993; further information is available from the ASHRAE Manager of $R_{\theta}$ search $(+1-404 / 636-8500)$.

The Compatiblity of Motals with "Klea"(TM) 1340 and Ester or PAG Based Lubricants, technical note 3, ICl Americas Incorporated, New Castle, DE, USA, August 1990 (5 pages with 3 tables, RDB2517)

The corrosion rates of metals and comments on their appearance are tabulated for selected metals, following exposures to R-134a and two lubricants for 14 days at $200^{\circ} \mathrm{C}\left(392{ }^{\circ} \mathrm{F}\right)$. The lubricants tested were DE184 (32 CSt at $\left.40^{\circ} \mathrm{C}\right)$ with 90 ppm water and DE214 (14 CSt at $40^{\circ} \mathrm{C}$ ) with $246 \mathrm{ppm}$ water. The metals include copper, $60 / 40$ brass, OHFC copper, grade 12 cast iron, aluminum (99.6\%), and aluminum alloys LM2 and LM24. Weight gain, indicating that the lubricant has entered the porosity of the metals, was observed for cast iron and the aluminum alloys for lubricant DE184 and also for the aluminum for DE214. The report notes that chemical reaction of the metallic coupons is negliglble. It suggests that the effect of corrosion products due to tribological wear causes their corrosion rather than a straight chemical attack. The experimental approach is briefly outlined. A table is provided to faciltate comparisons of British Standard and ASTM designations, since the test specimens were obtained according to the former.

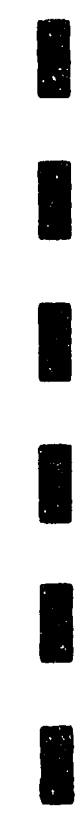

1

I

I

I

I

I

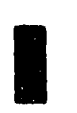

।

I

।

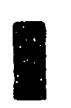

I 


\section{THERMOPHYSICAL PROPERTIES}

Thermophysical Properties of Refrigerants (R12, Dichlorodifluoromethane), Japanese Association of Refrigeration, Tokyo, Japan, August 1981 with errata dated 1986 (160 pages with 23 figures and 90 tables in both Japanese and English, RDB. 0401)

This comprehensive volume summarizes critlcal, thermodynamic, transport, physical, chemical, compatibility, and other data available on R12. Included are tabular data and/or plots for PVT properties, enthalpy, entropy, isobaric and isochoric specific heat capacity, specific heat ratio, speed of sound, surface tension, viscosity, kinematic viscosity, thermal conductivity, thermal diffusivity, Prandtl number, solubility, refractive index, dielectric constant, volume resistivity, and dielectric strength. A 32-term polynomial equation of state is presented and compared to other equations and data. Relations also are presented for key equilibrium properties. Data are tabulated for the solubility of R-12 in water, moisture contents of saturated R-12 liquid and vapor, and R-12 in a naphthenic mineral oil. Data, including decomposition products by pyrolysis and hydrolysis rates, are provided on the stability of R-12 in the presence of metals and oil. Linear swell, weight change, and observations are provided for R-12 with plastics including polytetrafluoroethylene (PTEF), tetrafluoroethylene-hexafluoropropylene copolymer, polyethylene, polyvinyl alcohol, polypropylene, polyvinylchloride (PVC), polyvinylidene chloride, nyton resin, acrylic resin (polymethacrylate). polystyrene, phenolic resin, epoxy resin, acetal resin, cellutose acetate, cellulose nitrate, acryl fiber, and polyester fiber. Linear swell data are tabulated for neat R-12, oll, and a 50/50 mixture with elastomers including neoprene $W$, neoprene GN, neoprene RT, Buna(TM) N, Buna(TM) $S$, natural rubber, polysulfide rubber, epichlorohydrin rubber, butyl rubber GR-I, chlorosulfonated polyethylene (DuPont Hypalon(R) 40), polyvinyt alcohol (PVA), fluoroelastomers (DuPont Viton(R) A and B), and urethane rubber. Published safety data, including toxicity and flammability, are summarized. The volume contains an extenstve list of references as well as discussion of the ranges and differences among property sources Identified. An introductory section outlines conversions among several metric systems, including SI, and inchpound units. An appendix summarizes quality requirements for complance with the Japanese Industrial Standards (JIS) and specifically JIS K1517-1973.

\section{R-13B1}

Thermophysical Properties of Refrigerants (R13B1, Bromotrifluoromethane), Japanese Association of Refrigeration, Tokyo, Japan, March 1989 (162 pages with 25 figures and 50 tables in both Japanese and English, RDB0402)

This comprehensive volume summarizes critical, thermodynamic, transport, physical, chemical, compatibility, and other data available on R13B1. Included are tabular data and/or plots for PVT properties, enthalpy, entropy, isobaric and isochoric specific heat capacity, specific heat ratio, speed of sound, surface tension, viscosity, kinematic viscosity, thermal conductivity, th ormal diffusivity, Prandtl number, solubility, refractive index, dielectric constant, volume resisthity, and dielectric strength. An equation of state is presented and compared to other equations and data. Relations also are presented for key equilibrium properties. Data are tabulated for the solubility of R-13B1 in both a naphthenic mineral oil and a synthetic polyglycol lubricant. Limited stability and compatibility data are outlined. Published safety data, including toxicity and flammability, are summarized. The volume contains an extensive list of references as well as discussion of the ranges and differences among property sources identified. An introductory section outtines conversions among several metric systems, including SI, and inchpound units. An appendix addresses compliance with the Japanese Industrial Standards (JIS), noting that the quality of R-13B1 is not covered; requirements for the quality of R-13B1 as a fire exilinguishant, Halon 1301, under an ordinance of the Ministry of Home Affairs are summarized. R-13B1 also is regulated as a "liquified gas" by the Japanese Regulation on High-Pressure Gases.

\section{$\underline{\text { R-22 }}$}

K. Stephan and J. Blermann (Universităt Stuttgart, Germany), Thermal Diffusivity Measurement of Refrigerant 22 at Low Pressures Using the Photoacoustic Effect, Proceedings of the 1992 Inter- 
national Refrigeration Conference - Energy Efficiency and New Refrigerants, edtted by D. R. Tree and J. E. Braun, Purdue University, West Lafayette, IN volume 1, pages 149-156, July 1992 (8 pages with 5 figures and 2 tables, RDB2716)

Thermophysical Properties of Retrigerants (R22, Chlorodifluoromethane), Japanese Association of Refrigeration, Tokyo, Japan, November 1975 with errata dated 1986 (164 pages with 22 figures and 78 tables in both Japanese and English, RDB0403)

This comprehensive volume summarizes critical, thermodynamic, transport, physical, chemical, compatibility, and other data available on R22. Included are tabular data and/or plots for PVT properties, enthalpy, entropy, isobaric and isochoric specific heat capacity, specific heat ratio, speed of sound, surface tension, viscosity, kinematic viscosity, thermal conductlvity, thermal diffusivity, Prandtl number, solubility, refractive index, dielectric constant, volume resistivity, and dielectric strength. An equation of state is presented and compared to other equations and data. Relations also are presented for key equilibrium properties. Published safety data, including toxicity and flammability, are summarized. The volume contains an extensive list of references as well as discussion of the ranges and differences among property sources identifled. An introductory section outlines conversions among several metric systems, including SI, and inch-pound units.

\section{$\underline{\text { R-32 }}$}

P. F. Ma!brunot, P. A. Meunier, G. M. Scatena (Laboratoire des Hauts Pressions, France), W. H. Meurs, K. P. Murphy, and J. V. Sinka (AlliedSignal Incorporated, then Allied Chemical Corporation), Pressure-Volume-Temperature Behavior of Difluoromethane, Journal of Chemical and Engineering Data, volume 13, number 1, pages 16-21, January 1968 (6 pages with 3 figures and 7 lables, RDB2310)

The pressure-volume-temperature (PVT) properties of R.32 are correlated using the MartinHou equation of state to within $\pm 0.94 \%$ standard deviation over the experimental ranges: $25-200{ }^{\circ} \mathrm{C}$ (77-392 $\left.{ }^{\circ} \mathrm{F}\right), 0.8-20 \mathrm{MPa}(120-2900$ psia), and 47-1.8 cc/g (0.75-0.03 ct/lb). Vapor pressures have been determined from $-83^{\circ} \mathrm{C}$ ($\left.117^{\circ} \mathrm{F}\right)$ to $78.4^{\circ} \mathrm{C}\left(173^{\circ} \mathrm{F}\right)$, the measured critical temperature. Using liquid densitles measured between -25 and $+78^{\circ} \mathrm{C}\left(-13\right.$ and $\left.+172{ }^{\circ} \mathrm{F}\right)$ and densities of saturated vapor computed from the Martin-Hou equation, a rectilinear diameter line has been developed. The critical pressure and density are $5.830 \mathrm{MPa}$ (846 psia) and $430 \mathrm{~kg} / \mathrm{m}^{3}$ $(26.8 \mathrm{lb} / \mathrm{cf})$, respectively.

O. Z-Y. Qian, $H$. Matsunobe, $H$. Sato, and $K$. Watanabe (Keio University, Japan), Thermodynamic Property Measurements for Difluoromethane (HFC-32) by a Burnett Method, paper B103, Proceedings of the Tweltth Japan Symposium on Thermophysical Properties, pages 73-76, 1991 (4 pages with 8 figures, RDB2428)

This paper summarlzes measurements of vapor pressures of R-32 at temperatures of $300-330 \mathrm{~K}$ $\left(80-134^{\circ} \mathrm{F}\right)$ and compressibility factors for 300 $350 \mathrm{~K}(80-170$ of $)$ and $0.15-4.3 \mathrm{MPa}(22-624$ psia). The experimental apparatus used, based on a Burnett method, is briefly described. Second and third virial coefficients for property calculations are presented. A systematic error, related to an adsorption effect in the Burnett experimental procedure, and a and correction are discussed.

\section{R-114}

Thermophysical Properties of Retrigerants (R114, 1,2-Dichlorotetraftuoroethane), Japanese Association of Refrigeration, Tokyo, Japan, March 1986 (162 pages with 23 figures and 46 tables in both Japanese and English, RDB0404)

This comprehensive volume summarizes critical, thermodynamic, transport, physical, chemical, compatibility, and other data available on R114. Included are tabular data and/or plots for PVT properties, enthalpy, entropy, isobaric and isochoric specific heat capacity, specific heat ratio, speed of sound, surface tension, viscosity, kinematic viscosity, thermal conductivity, thermal diffusivity, Prandt number, solubility, refractive index, dielectric constant, volume resistivity, and dielectric strength. An extended Martin-Hou equation of state is presented and compared to other equations and data. Relations also are presented for key equilibrium properties. Data are tabulated for the solubility of R114 in water, moisture contents of saturated R114 liquid and vapor, and R-114 in both a naphthenic mineral oll and a synthetic polyperfluoroether lubricant. Limited data on hydrolysis rates, stability of R-114 in the presence of metals and oil, and compatibility with other materials are outlined. Published safety data, including toxicity and flammability, are summarized. The volume contains an extensive list of references as well as discussion of the ranges and differences among property sources identified. An introductory section outtines conversions 
among several metric systems, including SI, and inch-pound units. An appendlx summarizes quality requirements for compllance with the Japanese Industrial Standards (JIS) and specifically JIS K1528-1982. R-114 also is regulated as a "liquified gas" by the Japanese Regulation on High-Pressure Gases.

\section{$\underline{R-123}$}

L. A. Weber and J. M. H. Levelt Sengers (National Institute of Standards and Technoiogy, NIST), Critical Parameters and Saturation Densities of 1,1-Dichloro-2,2,2-Trifluoroethane. Fluid Phase Equilibria, Elsevier Science Publishers B.V., Amsterdam, The Netherlands, volume 55, pages 241 . 249, 1990 (9 pages, RDB0915)

An optical cell has been used to determine the critical parameters, $T_{c}$ and $p_{c}$, and densities along the liquid-vapor phase boundary of R-123. The critical temperature was found to be 456.87 $\mathrm{K}\left(363^{\circ} \mathrm{F}\right)$ and the critical density is $550 \mathrm{~kg} / \mathrm{m}^{3}$. The critical pressure was calculated from vapor pressure data to be 36.74 bar, which yields a value of 0.269 for the critical compressibility factor, $Z_{c}$. Measurement temperatures varied from $298^{\circ} \mathrm{K}\left(77^{\circ} \mathrm{F}\right)$ to the critical point for the saturated liquid and from $433 \mathrm{~K}\left(320^{\circ} \mathrm{F}\right)$ to the critical point for saturated vapor.

L. A. Weber (National Institute of Standards and Technology, NIST), Vapor Pressures and GasPhase PVT Data for 1,1-Dichloro-2,2,2-Trifluoroethane, Journal of Chemical and Engineering Data, American Chemical Society (ACS), volume 35, number 3, pages 237-240, July 1990 (4 pages with 2 figures and 4 tables, RDB0910)

New data for the and gas-phase PVT surface of $R-123$ in the temperature range $338-453 \mathrm{~K}$ (149$356^{\circ} \mathrm{F}$ ) at densities up to $0.67 \mathrm{~mol} / \mathrm{L}$ are presented. The data have been represented anaIytically to demonstrate the precision and to facilitate calculation of thermodynamic properties.

Genetron(R) 123, technical bulletin 646 (B-525. 646), AlliedSignal Incorporated, Morristown, NJ, February 1993 (4 pages with 3 tables, RDB3452)

This bulletin supplies information on R-123, described as a replacement for $\mathrm{A}-123$ in centrifugal chillers. It provides physical property data, in inch-pound (IP) units, including the chemical formula, molecular weight, atmospheric boiling point, corresponding heat of vaporization, and critical parameters (temperature, pressure, and density). flammability, and ozone depletion potential. It also indicates the liquid density and specific heats of the liquid and vapor at $30^{\circ} \mathrm{C}$ $\left(86^{\circ} \mathrm{F}\right)$. It then presents a tabular comparison of performance for R-11 and R-123. The report provides tabular thermodynamic properties (pressure, density, vapor volume, liquid and vapor enthalpy and entropy, and latent heat of vaporization) for -18 to $71^{\circ} \mathrm{C}$ (0 to $160^{\circ} \mathrm{F}$ ). Formulae are provided to calculate thermodynamic properties including vapor pressure, ideal gas heat capacity, and liquid density correlations. Estimated coefficients are presented for a Martin-Hou equation of state. AlliedSignal's product name for $R-123$ is Genetron(R) 123.

Thermodynamic Properties of HCFC-123 (2,2dichloro-1,1,1-trifiuoroethane), technical information report T-123-ENG (H-47753), DuPont Chemicals, Wilmington, DE, January 1993 (40 pages with 1 figure and 2 tables, available from JMC as RDB. 3422)

This report provides thermodynamic property data for R-123 in inch-pound (IP) units of measure. It provides physical properties including the chemical formula, molecular weight, atmospheric boilling point, and critical parameters (temperature, pressure, density, and specific volume). It then presents a modified BenedictWebb-Rubin (MBWR) equation of state and an ideal gas heat capacity equation at constant pressure. It also gives a Martin-Hou equation of state, fit from MBWR data, and a corresponding ideal gas heat capacity equation at constant vapor. It supplies equations to calculate vapor pressure and density of the saturated liquid. The report provides tabular saturation properties (pressure and llquid and vapor volume, density, enthaipy, and entropy as well as latent heat of vaporization) for -101 to $+183^{\circ} \mathrm{C}(-150$ to $+362^{\circ} \mathrm{F}$ ). A set of tables presents volume, enthalpy, entropy, heat capacity at constant pressure, heat capacity ratio (dimensionless $\mathrm{Cp} / \mathrm{Cv}$ ), and velocity of sound data for superheated vapor at constant pressure for $7-3450$ $\mathrm{kPa}$ (1-500 psia). The new tables are based on experimental data from the National Institute of Standards and Technology, NIST). The report concludes with a pressure-enthalpy diagram. DuPont's product names for R-123 are Suva(R) 123 Refrigerant and Suva(R) Centri-LP Refrigerant.

Thermodynamic Properties of HCFC-123 (2,2dichloro-1,1,1-trifluoroethano), technical information report T-123-SI (H-47754), DuPont Chemicals, Wilmington, DE, January 1993 (32 pages with 1 figure and 2 tables, available from JMC as RDB3423)

This report provides thermodynamic property data for R-123 in metric (SI) units of measure. It provides physical properties including the chemical formula, molecular weight, atmospheric boiling point, and critical parameters 
(temperature, pressure, density, and specific volume). It then presents a modified BenedictWebb-Rubin (MBWR) equation of state and an ideal gas heat capacity equation at constant pressure. It also gives a Martin-Hou equation of state, fit from MBWR data, and a corresponding ideal gas heat capacity equation at constant vapor. It supplies equations to calculate vapor pressure and density of the saturated liquild. The report provides tabular saturation properties (pressure and liquid and vapor volume. density, enthalpy, and entropy as well as latent heat of vaporization) for -100 to $+183^{\circ} \mathrm{C}(-148$ to $+362^{\circ} \mathrm{F}$ ). A set of tables presents volume, enthalpy, entropy, heat capacity at constant pressure, heat capacity ratio (dimensionless $\mathrm{Cp} / \mathrm{Cv}$ ), and velocity of sound data for superheated vapor at constant pressure for 10-3600 $\mathrm{kPa}(1.520 \mathrm{psia})$. The new tables are based on experimental data from the National Institute of Standards and Technology, NIST). The report concludes with a pressure-enthalpy diagram. DuPont's product names for R-123 are Suva(R) 123 Refrigerant and Suva(R) Centri-LP Refrigerant.

\section{R-124}

H. Kubota, Y. Tanaka, T. Makita, H. Kashlwagi, and M. Noguchi, Thermodynamic Propertles of 1 Chloro-1,2,2,2-Tetrafiuoroethane (R-124), International Journal of Thermophysics, Plenum Publishing Corporation, Brugge, Belglum, volume 9. pages 85-101, 1988 (RDB2332)

Thermodynamic Properties of HCFC-124 (2chloro-1,1,1,2-tetrafiuoroethane), technical information report T-124-ENG (H-47755), DuPont Chemicals, Wilmington, DE, January 1993 (36 pages with 1 figure and 2 tables, available from JMC as RDB3424)

This report provides thermodynamic property data for R-124 in inch-pound (IP) units of measure. It provides physical properties including the chemical formula, molecular welght, atmospheric boilling point, and crtical parameters (temperature; pressure, density, and specific volume). It then presents a modified BenedictWebb-Rubin (MBWR) equation of state and an ideal gas heat capacity equation at constant pressure. It also gives a Martin-Hou equation of state, fit from MBWR data, and a corresponding ideal gas heat capacity equation at constant vapor. It supplies equations to calculate vapor pressure and density of the saturated llquid. The report provides tabular saturation properties (pressure and liquid and vapor volume, density, enthalpy, and entropy as well as latent heat of vaporization) for -101 to $+122{ }^{\circ} \mathrm{C}(-150$ to $+252^{\circ} \mathrm{F}$ ). A set of tables presents volume. enthalpy, entropy, heat capacity at constant pressure, heat capacity ratio (dimensionless $\mathrm{Cp} / \mathrm{Cv}$ ), and velocity of sound data for superheated vapor at constant pressure for 7.3450 kPa (1-500 psia). The new tables are based on experimental data from the National Institute of Standards and Technology, NIST). The report concludes with a pressure-enthalpy diagram. DuPont's product name for R-124 is Suva(R) 124 Refrigerant.

Thermodynamic Properties of HCFC-124 (2chloro-1,1,1,2-tetrafluoroethane), technical information report T-124-SI (H-47756), DuPont Chemicals, Wilmington, DE, January 1993 (32 pages with 1 figure and 2 tables, avallable from JMC as RDB3425)

This report provides thermodynamic property data for R-124 in metric (SI) units of measure. It provides physical properties including the chemical formula, molecular weight, atmospheric boiling point, and crttical parameters (temperature, pressure, density, and specific volume). It then presents a modified BenedictWebb-Rubin (MBWR) equation of state and an ideal gas heat capactiy equation at constant pressure. It also gives a Martin-Hou equation of state, fit from MBWR data, and a corresponding ideal gas heat capacity equation at constant vapor. It supplies equations to calculate vapor pressure and density of the saturated liquid. The report provides tabular saturation properties (pressure and liquid and vapor volume, density, enthalpy, and entropy as well as latent heat of vaporization) for -100 to $+122{ }^{\circ} \mathrm{C}(-148$ to $\left.+252^{\circ} \mathrm{F}\right)$. A set of tables presents volume, enthalpy, entropy, heat capacity at constant pressure, heat capacity ratio (dimensionless $\mathrm{Cp} / \mathrm{Cv}$ ), and velocity of sound data for superheated vapor at constant pressure for 10-3600 $\mathrm{kPa}(1-520 \mathrm{psia})$. The now tables are based on experimental data from the National Institute of Standards and Technology, NIST). The report concludes with a pressure-enthalpy diagram. DuPont's product name for R-124 is Suva(R) 124 Refrigerant.

\section{R-125}

Y. Monluc, T. Sagawa, H. Sato, and K. Watanabe (Kelo University, Japan), Thermodynamic Properties of HFC-125, paper B101, Proceedings of the Twellth Japan Symposium on Thermophysical Properties, pages 65-68, 1991 (4 pages with 5 flgures and 1 table, RDB2427) 
This paper reports experimental data for R-125, including vapor pressure and PVT properties in the vapor phase. Vapor pressures were measured for $303-339 \mathrm{~K}\left(86-151^{\circ} \mathrm{F}\right)$ and correlated; the crtical pressure (3.633 $\mathrm{MPa}, 527.3$ psia) also was determined based on a critical temperature previously determined by $M$. $O$. McLinden of $339.4 \mathrm{~K}\left(151.3^{\circ} \mathrm{F}\right)$. PVT properties were measured along five isochores for temperatures of $240-423 \mathrm{~K}\left(-27\right.$ to $\left.302{ }^{\circ} \mathrm{F}\right)$, pressures of $1.5-8.6$ MPa (220-1250 psia), and densities of 97-446 $\mathrm{kg} / \mathrm{m}^{3}(6-28 \mathrm{lb} / \mathrm{cf})$. The experimental approach and regression equation are presented and vapor pressure measurements are tabulated and plotted. The PVT properties for the vapor phase also are plotted and compared to other published data.

\section{R-134a}

R. S. Basu and D. P. Wilson (AlliedSignal Incorporated), Thermophysical Properties of 1,1,1,2Tetrafluoroethane (R-134a), International Journal of Thermophysics, Catherine Press, Limited, Brugge, Belgium, volume 10, number 3, pages 591-603, May 1989 (13 pages, RDB0514)

R. S. Basu, I. R. Shankland, and R. G. Richard (AlliedSignal Incorporated), Thermodynamic and Transport Properties of 1,1,1,2-Tetrafluoroethane (R-134a) - An Alternative CFC Substitute in Refrigeration and Air Condttioning, presented paper (AIChE Winter Annual Moeting, Washington, DC, 1988), Buffalo Research Laboratory, AlledSignal Incorporated, Buffalo, NY, November 1988 (26 pages, RDB0515)

A. R. H. Goodwin and M. R. Moldover (National Institute of Standards and Technology, NIST), Thermophysical Properties of Gaseous Refrigeranis from Speed of Sound Measurementa (Apparatus, Model, and Results for 1,1,1,2-tetrafluoroethane, R-134a). Journal of Chem. Physics, Amercan Institute of Physics, volume 93 , number 4 , pages 2741-2753, 15 August 1990 (13 pages with 10 figures and 4 tables, RDB0919)

The speed of sound in gaseous R-134a has been obtained between 233.16 and $340 \mathrm{~K}$ from measurements of the frequency of the radial acoustic resonances of a gas-filled spherical cavity. Perfect gas heat capacities and second and third acoustic virial coefficients are used to estimate the density virial coefficients $B(T)$ and $\mathrm{C}(\mathrm{T})$ and an effective square-well potential. The estimates of $B(T)$ are consistent with $B(T) d \theta-$ duced from high-quality equation-of-state measurements; those for $C(T)$ are slightly inconsis- tent. The apparatus and its calibration with argon are described.

M. L. Huber and M. O. McLinden (National Institute of Standards and Tochnology, NIST), Thermodynamic Properties of R-134a $(1,1,1,2-T$-Trafluoroethane, Proceedings of the 1992 International Refrigeration Conference - Energy Efficiency and New Refrigerants, edited by D. R. Treo and J. E. Braun, Purdue University, West Lafayette, IN, volume 2, pages 453-462, July 1992 (10 pages with 4 figures and 9 tables, RDB2828)

C.C. Plao, H. Sato, and K. Watanabo (Keio University, Japan), Thermodynamic Charts, Tables, and Equations for HFC-134a, Transactions, American Society of Heating, Refrigerating, and Air-Conditioning Engineers (ASHRAE), Atlanta, GA, volume 97, part 2, 1991; republished in Aternative Refrigerants, technical data bulletin 7(3). ASHRAE, pages 28-44, October 1991 (17 pages with 15 figures and 4 tables, RDB2615)

C-C. Plao, H. Sato, and K. Watanabe (Kelo University, Japan), An Experimental Study for PVT Properties of CFC Alternative Refrigerant 1,1,1,2-tetrafluoroethane (R-1340), CFC Aternatives, technical data bulletin 6(1). American Society of Heating, Refrigerating, and Air-Condtioning Engineers (ASHRAE), Atlanta, GA, pages 1-9, June 1990; republished in Transactions, American Society of Heating, Refrigerating, and Air-Conditioning Engineers, Atlanta, GA, volume 96, 1990 (9 pages with 8 figures and 4 tables, RDB2334)

I. R. Shankland, R. S. Basu, and D. P. Wilson (AlliedSignal Incorporated), Thermal Conductivity and Viscosity of a Now Stratospherically Safe Refrigerant-1,1,1,2-Tetrafluoroethane (R-134a), Status of CFCs - Refrigeration Systems and Refrig. erant Properties (proceedings of the meetings of IIR Commissions B1, B2, E1, and E2, Purdue University, West Lafayette, IN), International Institute of Refrigeration, Paris, France, pages 305-314, July 1988 (9 pages, RDB0516)

L. A. Weber (National Institute of Standards and Technology. NIST), Vapor Pressures and GasPhase PVT Data for 1,1,1,2-Tetrafluoroethane. International Journal of Thermophysics, Plenum Publishing Corporation, Brugge, Belgium, volume 10, number 3, pages 617-627, May 1989 (12 pages. RDB0909)

New data for the vapor pressure and PVT surface of R-134a in the temperature range of 40 . $150{ }^{\circ} \mathrm{C}\left(104-302{ }^{\circ} \mathrm{F}\right)$ are presented. The PVT data are for the gas phase at densities up to one-half critical. Densities of the saturated vapor are dertved at five temperatures from the intersections of the experimental isochores with 
the vapor pressure curve. The data are represented analytically in order to demonstrate experimental precision and to facllitate calculation of thermodynamic properties.

D. P. Wilson and R. S. Basu (AlledSlgnal Incorporated). Thermodynamic Propertles of Now Stratospherically Sate Working Fluld - R-134n, ASHRAE Special Publication, CFCs: Time of Transition. American Society of Heating. Refrigerating. and Air-Conditioning Engineers (ASHRAE), Atlanta, $\mathrm{GA}$, pages $104 \mathrm{ff}, 1989$ (RDB2236)

M-S. Zhu, L-Z. Han, Y.D. Fu, J. WU, and C-X. Lu (Tsinghua Universtty, China), Research on PVT Properties, Vapor Pressure, and Surface Tension of HFC-134a. Procesdings of the 1992 International Refrigeration Conterence - Energy Efficiency and New Refrigerants, edtted by D. R. Tree and J. E. Braun, Purdue University, West Lafayette, IN, volume 2, pages 499-509, July 1992 (11 pages with 5 figures and 8 tables, RDB2833)

Genotron(A) 134a, technical bulletin 645 (B-525645). AlliedSignal Incorporated, Morristown, NJ, February 1993 (4 pages with 3 tables, RDB3453)

This bulletin supplies information on R-134a, described as a replacement for R.12 in automoblle air condtioning; residential, commercial and industrial refrigeration; and in certain centrifugal chiller applications. It provides physical property data, in inch-pound (IP) units, including the chemical formula, molecular wolght, atmospheric boiling point, corresponding heat of vaporization, and crttical parameters (temperature, pressure, and density), flammability, and ozone depletion potentlal. It also indlcates the liquid density and specific heats of the liquild and vapor at $30^{\circ} \mathrm{C}\left(86^{\circ} \mathrm{F}\right)$. It then presents a tabular comparison of performance for R-12, R-22, and R-134a. The report provides tabular thermodynamic properties (pressure, density, vapor volume, liquid and vapor enthalpy and entropy. and latent heat of vaporization) for -29 to $71^{\circ} \mathrm{C}$ $\left(-20\right.$ to $\left.160^{\circ} \mathrm{F}\right)$. Formulae are provided to calculate thermodynamic properties including vapor pressure, llquild density, and ideal gas heat capaclty correlations. Coefficlents are presented for a Martin-Hou equation of state. A. liedSignal's product name for R-134a is Gen. otron(R) 134a.

Thermodynamic Propertles of HFC-1340 $(1,1,1,2$-tetrafluoroothane), technical information repont T-134a-ENG (H-47751), DuPont Chemicals, Wilmington, DE, January 1993 (36 pages with 1 figure and 2 tables, avallable from JMC as RDB3426)

This report provides thermodynamic property data for R-134a in inch-pound (IP) units of measure. It provides physical properties including the chemical formula, molecular weight, atmospheric boiling point, and critical parameters (temperature, pressure, density, and specific volume). It then presents a modfied Benedict. Webb-Rubin (MBWR) equation of state and an Ideal gas heat capaclty equation at constant pressure. It also gives a Martin-Hou equation of state, fit from MBWR data, and a corresponding ideal gas heat capacity equation at constant vapor. It supplies equations to calculate vapor pressure and density of the saturated liquid. The report provides tabular saturation properlies (pressure and llquild and vapor volume, density, enthalpy, and entropy as well as latent heat of vaporization) for $-101^{10}+101^{\circ} \mathrm{C}(-150$ to $+213^{\circ} \mathrm{F}$ ). A set of tables presents volume. enthalpy, entropy, heat capacity at constant pressure, heat capacity ratio (dimensionless $\mathrm{Cp} / \mathrm{Cv}$ ), and velocity of sound data for superheated vapor at constant pressure for 7-3800 kPa (1-550 psia). The new tables are based on experimental data from the National Insttute of Standards and Technology, NIST). The report concludes with a pressure-enthalpy diagram. DuPont's product names for R-1.ta are Suva(P) $134 a$ Refrigerant, Suva(A) Cold-MP Refrigerant, Suva(A) Trans-AC Refrigerant, Formacel(R) Z-4 Blowing Agent, Dymel(R) 1,34.8 Aerosol Propellant, and Dymel(R) 134a/P Aerosol Propellant.

Thermodynamic Propertles of HFC-134a (1,1,1,2-tetrafluoroothano), technical Information report T-134a-SI (H-47752), DuPcint Chemicals, Wilmington, DE, January 1993 (36 pirges with 1 figure and 2 tables, avaliable from JMC as RDB3427)

This repont provides thermodynamic property data for R-134a in metric (SI) units of measure. It provides physical propertios Including the chemical formula, molecular weight, atmospheric bolling point, and critical parameters (temperature, pressure, density, and specific volume). It then presents a modified BenedictWebb-Rubin (MBWP) equation of state and an ideal gas heat capactly equation at constant pressure. It also ghes a Martin-Hou equation of state, fit from MBWR data, and a corresponding ideal gas heat capaclty equation at constant vapor. It supplles equations to calculate vapor pressure and density of the saturated llquid. The report provides tabular saturation properties (pressure and llquid and vapor volume, density, enthalpy, and entropy as well as latent heat of vaporization) for -100 to $+101^{\circ} \mathrm{C}(-148$ to $+213^{\circ} \mathrm{F}$ ). A set of tables presents volume, enthalpy, entropy, heat capacity at constant pressure, heat capacity ratlo (dimensioniess $\mathrm{Cp} / \mathrm{Cv}$ ), and veloctty of sound data for super. heated vapor at constant pressure for 10-4000 $\mathrm{kPa}$ (1-580 psia). The new tables are based on experimental data from the Natlonal Instltute of 
Standards and Technology, NIST). The report concludes with a pressure-enthalpy diagram. DuPont's product names for R-134a are Suva(R) 134a Refrigerant, Suva( $R$ ) Cold-MP Refrigerant, Suva(P) Trans-AC Refrigerant, Formacel(R) Z-4 Blowing Agent, Dymel(R) 134a Aerosol Propellant, and Dymel(R) 134a/P Aerosol Propellant.

\section{R-141b}

A. R. H. Goodwin and M. R. Moldover (National Institute of Standards and Technology, NIST), Thermophysical Properties of Gaseous Refrigerants from Speed of Sound Measurements: II. Results for 1,1-dichloro-1-fluoroethane $\left(\mathrm{CCl}_{2} \mathrm{FCH}_{3}\right)$, Journal of Chem. Physics, American Institute of Physics, volume 95, number 7, pages 5230-5235, 1 October 1991 (6 pages with 5 figures and 4 tables, RDB3105)

R-141b

\section{R-236ea}

N. D. Smith, Thermophysical Properties of HFC. 236ea, Environmental Research Brief EPA-600/S92-066, U.S. Environmental Protection Agency (EPA), Research Triangle Park, NC, October 1992 (5 pages with 5 tables, avallable from JMC as RDB3403)

This synopsis summarizes properties of R-236ea $(1,1,1,2,3,3$-hexafluoropropane), a potential alterinative for R-114. It notes that the thermophysical properties of the fluids closely match, and that modelling indicates acceptable performance. The efficiency of R-236ea is indicated as within $1 \%$ of that of R-114. Tables, in both inch-pound (IP) and metric (SI) units provide the freezing and boiling points, critical properties, heat of vaporization, and llquid specific heat capacity. Measured liquid densities are given at eight temperatures from $2-95^{\circ} \mathrm{C}\left(35-202^{\circ} \mathrm{F}\right)$ and vapor pressures for -14 to $+141^{\circ} \mathrm{C}\left(8-286^{\circ} \mathrm{F}\right)$. Calculated Ilquild and vapor density as well as heat of vaporization are tabulated for -14 to $+141^{\circ} \mathrm{C}\left(8-288^{\circ} \mathrm{F}\right)$ and the equations used are provided. The ideal gas heat capacity is similarly provided for $27.327^{\circ} \mathrm{C}\left(80-620^{\circ} \mathrm{F}\right)$. The methods used and estimated accuracy are indicated.

\section{R-245ca}

N. D. Smith, Thermophysical Properties of HFC245ca, Environmental Research Brlef EPA-600/S92-038, U.S. Environmental Protection Agency (EPA), Research Triangle Park, NC, August 1992 (4 pages with 5 tables, available from JMC as RDB. 3402)

This synopsis summarizes properties of R-245ca $(1,1,2,2,3$-pentafluoropropane), a potentlal alternative for R-11 and R-123. It notes that the thermophysical properties of the fluids closely match, and that modelling indicates acceptable performance. The efficiency of R-245ca is indlcated as $3-4 \%$ less than R-11 and $1-2 \%$ less than R-123. Tables, in both inch-pound (IP) and metric (SI) units provide the melting and boiling points, critical properties, heat of vaporization, and llquid heat capacity. Measured liquid densities are given at six temperatures from 22-140 ${ }^{\circ} \mathrm{C}\left(72-284^{\circ} \mathrm{F}\right)$ and vapor pressures for -39 to 26 ${ }^{\circ} \mathrm{C}$ (-38 to $78^{\circ} \mathrm{F}$ ). Calculated liquil and vapor density as well as vapor pressure and heat of vaporization are tabulated for $5-178{ }^{\circ} \mathrm{C}(41-353$ ${ }^{\circ}$ F) and the equations used are provided. The ideal gas heat capacity is similarly provided for $27.327^{\circ} \mathrm{C}\left(80-620^{\circ} \mathrm{F}\right)$. The methods used and estimated accuracy are indicated.

\section{R-245cb}

R. L. Shank (Union Carbide Corporation), Thermodynamic Properties of 1,1,1,2,2-Pentafluoropropane (Refrigerant 245cb), Journal of Chemical and Engineering Data, American Chemical Society (ACS), volume 12, number 4, pages 474-480, October 1967 (7 pages with 4 figures and 5 tables, RDB2506)

Thermodynamic properties are presented for the saturated liquid and vapor of R-245cb from $-40^{\circ} \mathrm{C}\left(-40^{\circ} \mathrm{F}\right)$ to the critical temperature, $106.96{ }^{\circ} \mathrm{C}\left(224.52{ }^{\circ} \mathrm{F}\right)$; a pressure-enthalpy diagram is included. The crtical properties, coefficients for a Benedict-Webb-Rubin (BWR) equation of state, a vapor-pressure equation, a llquiddensity equation, and a heat-capacity equation are given. Data also are provided for the superheated vapor from the saturation temperature to $371^{\circ} \mathrm{C}\left(700^{\circ} \mathrm{F}\right)$. The properties listed are volume, enthalpy, entropy, heat capacity at constant pressure, and heat capacity ratio as functions of temperature and pressure. Pressurevolume isotherms are plotted for both the highdensity and crtical regions. These properties were calculated from measured volumetric and spectral data; the experimental procedures and calculations are described. 
R-401

Thermodynamic Properties of Suva(A) MP39 Retrigeramt [R-401 (53/13/34)], technical information repon T-MP39-ENG (H-47764), DuPont Chemicals, Wilmington, DE, January 1993 (28 pages with 1 figure and 2 tablos, avallable from JMC as RDB3430)

This report provides thermodynamic property data for $R-401(53 / 13 / 34)$, a blend of R-22, $R$ 152a, and $R-124$ (R-22/152a/124), in inchpound (IP) units of measure. It provides phystcal properties including the chemical formula, molecular weight, atmospheric boiling point, and critical parameters (temperature, pressure, density, and specific volume). It then presents a Peng-Robinson-Stryjek-Vera (PRSV) equation of state and an ideal gas heat capacity equation at constant pressure. It also supplies equations to calculate vapor pressure and density of the saturated liquid. The report provides tabular saturation properties (liquid and vapor pressure, volume, density, enthalpy, and entropy as well as latent heat of vaporization) for -101 to $+99^{\circ} \mathrm{C}$ $\left(-150\right.$ to $\left.+211^{\circ} \mathrm{F}\right)$. A set of tables presents volume, enthalpy, and entropy data for superheated vapor at constant pressure for 7-3800 $\mathrm{kPa}$ (1-550 psia). The report concludes with a pressure-enthalpy diagram. DuPont's product name for $R-401(53 / 13 / 34)$ is Suva(R) MP39.

Thermodynamic Properties of Suva(A) MP39 Refrigerant [R-401 (53/13/34)], technical information report T-MP39-SI (H-47765), DuPont Chemicals, Wilmington, DE, January 1993 (24 pages with 1 figure and 2 tables, avallable from JMC as RDB3431)

This report provides thermodynamic property data for $R-401(53 / 13 / 34)$, a blend of R-22, R152a, and R-124 (R-22/152a/124), in metric (SI) units of measure. It provides physical properties including the chemical formula, molecular weight, atmospheric boiling point, and critical parameters (temperature, pressure, density, and specific volume). It then presents a PengRobinson-Stryjek-Vera (PRSV) equation of state and an ideal gas heat capactly equation at constant pressure. It also supplies equations to calculate vapor pressure and density of the saturated liquid. The report provides tabular saturation propertles (ilquil and vapor pressure, volume, density, enthalpy, and entropy as well as latent heat of vaporization) for -100 to $+99^{\circ} \mathrm{C}$ $\left(-148\right.$ to $\left.+210^{\circ} \mathrm{F}\right)$. A set of tables presents volume, enthalpy, and entropy data for superheated vapor at constant pressure for 10-3800 $\mathrm{kPa}$ (1-550 psla). The report concludes with a pressure-enthalpy dlagram. DuPont's product name for $R-401(53 / 13 / 34)$ is Suva(R) MP39.
Thermodynamic Properties of Suva(R) MP52 Refrigerant [R-401 (33/15/52)], technical information report T-MP52-ENG (H-47769), DuPont Chemicals, Wilmington, DE, February 1993 (28 pages with 1 flgure and 2 tables, avallable from JMC as RDB3428)

This report provides thermodynamic property data for R-401 (33/15/52), a blend of R-22, R152a, and R-124 (R-22/152a/124), in inchpound (IP) units of measure. It provides physical properties including the chemical formula, molecular woight, atmospheric boiling point, and critical parameters (temperature, pressure, density, and specific volume). It then presents a Peng-Robinson-Strylek-Vera (PRSV) equation of state and an ideal gas heat capacity equation at constant pressure. It also supplies equations to calculate vapor pressure and density of the saturated liquid. The report provides tabular saturation properties (liquid and vapor pressure, volume, density, enthalpy, and entropy as well as latent heat of vaporization) for -101 to +104 ${ }^{\circ} \mathrm{C}\left(-150\right.$ to $\left.+220^{\circ} \mathrm{F}\right)$. A set of tables presents volume, enthalpy, and entropy data for superheated vapor at constant pressure for $7-3800$ $\mathrm{kPa}$ (1-550 psia). The report concludes with a pressure-enthalpy dlagram. DuPont's product name for $R-401(33 / 15 / 52)$ is Suva(A) MP52.

Thermodynamic Properties of Suva(P) MP52 Refrigerant [R-401 (33/15/52)], technical information report T-MP52-SI (H-47770), DuPont Chemicals, Wilmington, DE, February 1993 (24 pages with 1 figure and 2 tables, available from JMC as RDB3429)

This report provides thermodynamic property data for R-401 (33/15/52), a blend of R-22, R152a, and R-124 (R-22/152a/124), in metric (SI) units of measure. It provides physical properties including the chemical formula, molecular weight, atmospheric boiling point, and critical parameters (temperature, pressure, density, and specific volume). It then presents a PengRobinson-Stryjek-Vera (PRSV) equation of state and an ideal gas heat capacity equation at constant pressure. It also supplies equations to calculate vapor pressure and density of the saturated liquid. The report provides tabular saturation properties (liquild and vapor pressure, volume, density, enthalpy, and entropy as well as latent heat of vaporization) for -100 to +104 ${ }^{\circ} \mathrm{C}\left(-148\right.$ to $\left.+220^{\circ} \mathrm{F}\right)$. A set of tables presents volume, enthalpy, and entropy data for superheated vapor at constant pressure for $10-4000$ $\mathrm{kPa}$ (1-580 psia). The report concludes with a pressure-enthalpy dlagram. DuPont's product name for $R-401(33 / 15 / 52)$ is Suva(R) MP52.

Thermodynamic Properties of Suva(A) MP68 Refrigerant [R-401 (61/11/28)], technical infor- 
mation report T-MP66-ENG (H-47759), DuPont Chemicals, Wilmington, DE, January 1993 (24 pages with 1 figure and 2 tables, avallable from JMC as RDB3432)

This report provides thermodynamic property data for R-401 (61/11/28), a blend of R-22, R152a, and R-124 (R-22/152a/124), in inchpound (IP) units of measure. It provides physical properties including the chemical formula, molecular weight, atmospheric boilling point, and critical parameters (temperature, pressure, density, and specific volume). It then presents a Peng-Robinson-Stryjek-Vera (PRSV) equation of state and an ideal gas heat capacity equation at constant pressure. It also supplies equations to calculate vapor pressure and density of the saturated liquid. The report provides tabular saturation properties (liquid and vapor pressure, volume, density, enthalpy, and entropy as well as latent heat of vaporization) for -101 to $+97^{\circ} \mathrm{C}$ $\left(-150\right.$ to $\left.+207^{\circ} \mathrm{F}\right)$. A set of tables presents volume, enthalpy, and entropy data for superheated vapor at constant pressure for $7-3800$ $\mathrm{kPa}(1.550 \mathrm{psia})$. The report concludes with a pressure-enthalpy dlagram. DuPont's product name for $R-401(61 / 11 / 28)$ is Suva(R) MP66.

Thermodynamic Properties of Suva(R) MP68 Retrigerant [R-401 (61/11/28)], technical information report T-MP66-SI (H-47760), DuPont Chemicals, Wilmington, DE, January 1993 (24 pages with 1 figure and 2 tables, available from JMC as RDB3433)

This report provides thermodynamic property data for $R-401(61 / 11 / 28)$, a blend of R-22, R152a, and R-124 (R-22/152a/124), in metric (SI) units of measure. It provides physical properties including the chemical formula, molecular weight, atmospheric boiling point, and critical parameters (temperature, pressure, density, and specific volume). It then presents a PengRobinson-Stryjek-Vera (PRSV) equation of state and an ideal gas heat capacity equation at constant pressure. It also supplies equations to calculate vapor pressure and density of the saturated liquid. The report provides tabular saturation properties (ilquid and vapor pressure, volume, density, enthalpy, and entropy as well as latent heat of vaporization) for -100 to $+97^{\circ} \mathrm{C}$ $\left(-148\right.$ to $\left.+207^{\circ} \mathrm{F}\right)$. A set of tables presents volume, enthalpy, and entropy data for superheated vapor at constant pressure for 10-4000 $\mathrm{kPa}(1.580 \mathrm{psia})$. The report concludes with a pressure-enthalpy dlagram. DuPont's product name for R-401 $(61 / 11 / 28)$ is Suva(A) MP66.

\section{R-402}

Thermodynamic Properties of Suva(A) HP80 Refrigerant [R-402 (60/2;38)], technical information report T-HP80-ENG (H-4i766), DuPont Chemicals, Wilmington, DE, January 1993 (24 pages with 1 figure and 2 tables, avallable from JMC as RDB3436)

This report provides thermodynamic property data for R-402 $(60 / 2 / 38)$, a blend of R-125, R290 , and $R-22$ (R-125/290/22), in inch-pound (IP) units of measure. It provides physical properties including the chemical formula, molecular weight, atmospheric boiling point, and critical parameters (temperature, pressure, density, and specific volume). It then presents a Peng-Robinson-Stryjek-Vera (PRSV) equation of state and an ideal gas heat capacity equation at constant pressure. It also supplles equations to calculate vapor pressure and density of the saturated liquid. The report provides tabular saturation properties (liquid and vapor pressure. volume, density, enthaipy, and entropy as well as latent heat of vaporization) for -101 to $+688^{\circ} \mathrm{C}$ $\left(-150\right.$ to $\left.+154^{\circ} \mathrm{F}\right)$. A set of tables presents volume, enthalpy, and entropy data for superheated vapor at constant pressure for 7.3800 $\mathrm{kPa}(1-550 \mathrm{psia})$. The report concludes with a pressure-enthalpy diagram. DuPunt's product name for R-402 (60/2/38) is Suva(R) HP80.

Thermodynamic Propertles of Suva(R) HP8O Refrigerant [R-402 (60/2/38)], technical information report T-HP80-SI (H-47767), DuPont Chemicals, Wilmington, DE, January 1993 (24 pages with 1 figure and 2 tables, available from JMC as RDB3437)

This report provides thermodynamic property data for R-402 (60/2/38), a blend of R-125, R290 , and R-22 (R-125/290/22), in metric (SI) units of measure. It provides physical properties including the chemical formula, molecular weight, atmospheric boiling point, and critical parameters (temperature, pressure, density, and specific volume). It then presents a PengRobinson-Stryjek-Vera (PRSV) equation of state and an ideal gas heat capacity equation at constant pressure. It also supplies equations to calculate vapor pressure and density of the saturated liquid. The report provides tabular saturation properties liquid and vapor pressure, volume, density, enthalpy, and entropy as well as latent heat of vaporization) for -100 to $+68^{\circ} \mathrm{C}$ $\left(-148\right.$ to $\left.+154^{\circ} \mathrm{F}\right)$. A set of tables presents volume, enthalpy, and entropy data for superheated vapor at constant pressure for $10-4000$ $\mathrm{KPa}$ (1-580 psia). The report concludes with a pressure-enthalpy diagram. DuPont's product name for R.402 (60/2/38) is Suva(P) HP80.

Thermodynamic Properties of Suva(P) HP81 Refrigerant [R-402 (38/2/60)], technical information 
report T-HP81-ENG (H-47757), DuPont Chemicals, Wilmington, DE, January 1993 (24 pages with $1 \mathrm{flg}$ ure and 2 tables, avallable from JMC as RDB3434)

This report provides thermodynamic property data for R-402 (38/2/60), a blend of R-125, R. 290 , and R-22 (R-125/290/22), in inch-pound (IP) units of measure. It provides physical properties including the chemical formula, molecular weight, atmospheric bolling point, and critical parameters (temperature, pressure, density, and specific volume). It then presents a Peng-Robinson-Stryjek-Vera (PRSV) equation of state and an ideal gas heat capactty equation at constant pressure. It also supplies equations to calculate vapor pressure and density of the saturated liquid. The report provides tabular saturation properties (liquild and vapor pressure. volume, density, enthalpy, and entropy as well as latent heat of vaporization) for -101 to $+75^{\circ} \mathrm{C}$ $\left(-150\right.$ to $\left.+167^{\circ} \mathrm{F}\right)$. A set of tables presents volume, enthalpy, and entropy data for superheated vapor at constant pressure for $7-3800$ $\mathrm{kPa}(1-550 \mathrm{psia})$. The report concludes with a pressure-enthalpy diagram. DuPont's product name for R-402 $(38 / 2 / 60)$ is Suva(R) HP81.

Thermodynamic Properties of Suva(R) HP81 Refrigerant [R-402 (38/2/60)], technical information report T-HP81-SI (H-47758), DuPont Chemicals, Wilmington, DE, January 1993 (20 pages with $1 \mathrm{flg}$ ure and 2 tables, avallable from JMC as RDB3435)

This report provides thermodynamic property data for R-402 (38/2/60), a blend of R-125, R290 , and R-22 (R-125/290/22), in metric (SI) units of measure. It provides physical properties including the chemical formula, molecular weight, atmospheric boiling point, and critical parameters (temperature, pressure, density, and specific volume). It then presents a PengRobinson-Stryjek-Vera (PRSV) equation of state and an ideal gas heat capacity equation at constant pressure. It also supplies equations to calculate vapor pressure and density of the sat. urated liquid. The report provides tabular saturation properties (liquid and vapor pressure, volume, density, enthalpy, and entropy as well as latent heat of vaportzation) for -100 to $+74^{\circ} \mathrm{C}$ $\left(-148\right.$ to $\left.+165^{\circ} \mathrm{F}\right)$. A set of lables presents volume, enthalpy, and entropy data for superheated vapor at constant pressure for $10-4000$ $\mathrm{kPa}(1.580$ psla). The report concludes with a pressure-enthalpy dlagram. DuPont's product name for R-402 $(38 / 2 / 60)$ is Suva(R) HP81.

\section{Other Zeotropes}

D. R. Defibaugh and G. Morrison (National Institute of Standards and Technology, NIST), Compressed
Liquild Densities, Saturated Liquild Donstties, and Saturation Pressures of Mixtures: Difluoromethane $+1,1,1,2$-Tetrafluoroethane, Difluoromethane + 1,1-Difluoroethane, Proceedings of the 1992 International Refrigeration Conference Energy Efficiency and New Refrigerants, edited by D. R. Tree and J. E. Braun, Purdue Untwersity, West Lafayette, IN, volume 2, pages 473-478, July 1992 (6 pages with 8 figures, RDB2830)

$$
\text { R-32/R-134a, R-32/R-152a }
$$

\section{R-502}

Thermophysical Properties of Refrigerants (R502, Azeotrope of R-22 and R-115), Japanese Association of Refrigeration, Tokyo, Japan, November 1986 (164 pages with 21 figures and 44 tables in both Japanese and English, RDB0405)

This comprehensive volume summarizes crttcal, thermodynamic, transport, physical, chemical, compatibilty, and other data available on $R$ 502, an azeotrope comprising 48.8\% R-22 and $51.2 \%$ R-115 by weight. Included are tabular data and/or plots for PVT properties, enthalpy, entropy, isobaric and isochoric specrific heat capacity, specific heat ratio, isentropic expansion exponent, speed of sound, surface tension, viscosity, kinematic viscosity, thermal conduc. tivity, thermal diffusivity, Prandt number, solubility, refiactive index, and dielectric zonstant. An extended Benedict-Webb-Rubin (BWR) equation of state is presented and compared to other equations and data. Relations also are presented for key equilibrium properties. Data are tabulated for the solubility of water in R-502 and of R-502 in alkylbenzene lubricant. Limited data are provided on the stability of R-502 in the presence of metals and oll and on linear swell for neoprene GN, Buna(TM) $N$, natural rubber. GR-I, GR-S, and polysulfide rubber. Published safety data, including toxicity and flemmability, are summarized. The volume contains an extensive list of references as well as discussion of the ranges and differences among property sources identified. An introductory section outlines conversions among several metric systerns, including SI, and inch-pound units. An appendix addresses compllance with the Japanese Industrial Standards (JIS), noting that the quality of R-502 is not covered; JIS K1528-1982 requirements for the quality of R-22 are summarized. 


\section{Other Azeotrones}

P. B. Logsdon, E. A. E. Lund, I. R. Shankland, and R. R. Singh (AlliedSignal Incorporated), Properties of a Zero ODP Azeotropic Refrigerant Blend, HFC-125/HFC-143a, Proceedings of the International CFC and Halon Alternatives Conference Washington, DC), Allance for Responsible CFC Policy, Arlirigion, VA, pages 47-54, September 1992 (10 pages with 1 figure and 7 tables, RDB2A02)

Genetron(A) AZ-20, technical bulletin 525-652, AlliedSignal Incorporated, Morristown, NJ, January 1993 (4 pages with 3 tables, RDB3219)

This bulletin describes a patented azeotropic blend of R-32 and R-125, specifically R-32/125 $(60 / 40)$, designed to replace R-22 in residential air-conditioning systems. It provides physical property data, in inch-pound (IP) units, including the chemical formula, molecular weight, atmospheric boilling point, corresponding heat of vaporization, and critical parameters (temperature, pressure, and c'ensity), flammability, and ozone depletion potential. It also indicates the liquid density and spocis:- heats of the liquid and vapor at $26.7^{\circ} \mathrm{C}\left(80^{\circ} \mathrm{F}\right)$. It then presents a tabular comparison of performance with R-22, R-32, R125, and R-502. The report provides tatular thermodynamic properties (pressure, liquid density, vapor volume, liquid and vapor enthalpy and entropy, and latent heat of vaporization) for -29 to $+71^{\circ} \mathrm{C}\left(-20\right.$ to $\left.+160{ }^{\circ} \mathrm{F}\right)$. Formulae are provided to calculate thermodynamic properiles including vapor pressure, liquid density, and ideal gas heat capacity correlations. A Martin-Hou equation of state also is presented. AlliedSignal's product name for R-32/125 $(60 / 40)$ is Genetron(R) AZ-20.

Genetron(R) AZ-50, technical bulletin 525-651, AlliedSignal Incorporated, Morristown, NJ, January 1993 (4 pages with 3 tables, RDB3222)

This bulletin describes an azeotropic blend oi $R$ 125 and R-143a, specifically R-125/143a, designed to replace R-502 in low-temperature commercial refrigeration applications. It provides physical property data, in inch-pound (IP) units, including the chemical formula, molecular weight, atmospheric boilling point, corresponding heat of vaporization, and critical parameters (temperature, pressure, and density), flammability, and ozone depletion potentlal. It also indicates the liquid density and specific heats of the liquid and vapor at $26.7^{\circ} \mathrm{C}\left(80^{\circ} \mathrm{F}\right)$. It then presents a tabular compariscn of performance with R-22 and R-502. The report provides tabular thermodynamic properties (pressure, density, vapor volume, liquid and vaper enthalpy and entropy, and latent heat of vaporization) for -40 to $+71^{\circ} \mathrm{C}\left(-40\right.$ to $\left.+160^{\circ} \mathrm{F}\right)$. Formulae are provided to calculate thermodynemic properties including vapor pressure, liquid density, and ideal gas heat capacity correlations. A MartinHou equation of state also is presented. AlliedSignal's product name for R-125/143a is $\mathrm{Ge}$ netron(R) AZ-50.

R-32/125 Azeotrope, technical data sheet 525643, AlliedSignal Incorporated, Morristown, NJ, April 1991 (2 pages with 1 figure and 2 tables, RDB3220)

This data sheet provides information on a patented azeotropic blend, R-32/125 (60/40). It provides physical property data, in inch-pound (IP) units, including the chemical formula, molecular weight, atmospheric bolling point, corresponding heat of vaporization, and critical parameters (temperature, pressure, and density), flammability, and ozone depletion potential. It also indicates the liquid density and specific heats of the liquid and vapor at $26.7^{\circ} \mathrm{C}$ (80 $\left.{ }^{\circ} \mathrm{F}\right)$. It then presents a tabular comparison of performance with R-22, R-32, R-125, and R-502. The document provides a vapor pressure chart for the blend for -40 to $+49\left(-40\right.$ to $\left.+120^{\circ} \mathrm{F}\right)$. AlledSignal's product name for R-32/125 $(60 / 40)$ is Genetron(R) AZ-20.

R-32/125 Azeotrope, technical data sheet 525658, AlledSignal Incorporated, Morristown, NJ, July 1991 (1 page with 1 figure, RDB3221)

This data sheet provides a pressure-enthalpy diagram for a patented azeotropic blend, R$32 / 125(60 / 40)$ in inch-pound (IP) units. AlliedSignal's product name for R-32/125 $(60 / 40)$ is Genetron(R) AZ-20.

\section{Ethers}

D. R. Defibaugh, K. A. Gillis, M. R. Moldover, G. Morrison, and J. W. Schmidt (National Institute of Standards and Technology, NIST), Thermodynamic Properties of $\mathrm{CHF}_{2}-\mathrm{O}_{-} \mathrm{CHF}_{2}$, Bis(difluoromethyl) Ether, Fluid Phase Equilibr:a, Elsevier Science Publishers B.V., Amsterdam, The Netherlands, volume 81, pages 285-305, 1992 (21 pages, RDB3327)

This paper reports on measurements and data reduction to provide thermodynamic property data for E-134, a candidate alternative refrigerant. It summarizes measurements of the refracthe index of the saturated liquid and vapor as well as the sried of sound of the dilute vapor. These measu:-sments provide the normal boiling point, critical parameters (temperature, pressure, and density), and ideal gas heat capacity. Vapor pressure measurements using a high- 
pressure ebulliometer are tabulated; the apparatus is depicted in a figure. Refractive index, speed-of-sound, results of acoustic isotherms, liquid density, and saturation data are tabulated; deviations with other measurements and data fits are plotted. Coefficients of a Carnahan-Starling-DeSantis (CSD) equation of state and a polynomial representation of the ldeal gas heat capacity are derived and presented. The paper notes that samples of E-134 with impurities were found to be unstable during laboratory measurements. It also notes that an azeotrope of $E$. 134 and R-143a was discovered during the investigation. Samples of E-134 were found to be soluble in several elastomers used in the measurement apparatus.

N. D. Smith, Thermophysical Properties of HFE125, Environmental Research Brief EPA-600/S-93001, U.S. Environmental Protection Agency (EPA), Research Triangle Park, NC, February 1993 (4 pages witt: 4 tables, available from JMC as RDB3404)

This synopsis summarizes properties of E-125 (pentafluorodimethylether), a potential alternative refrigerant for low-temperature appllcations. Tables, in both inch-pound (IP) and metric (SI) units provide the freezing and boiling points, critical properties, heat of vaporization, and liquid specific heat capacity. Measured ilquid densities are given at eight temperatures from $10-61^{\circ} \mathrm{C}\left(50-142{ }^{\circ} \mathrm{F}\right)$ and vapor pressures for -104 to $81^{\circ} \mathrm{C}\left(-156\right.$ to $\left.177{ }^{\circ} \mathrm{F}\right)$. Calculated liquid and vapor density as well as heat of vaporization are tabulated for -55 to $81{ }^{\circ} \mathrm{C}$ ( -66 to $177^{\circ} \mathrm{F}$ ) and the equations used are provided. The methods used and estimated accuracy are indicated.

B.H. Wang, J. L. Adcock, S. B. Mathur, and W. A. Van Hook (University of Tennessee), Vapor Pressures, Liquid Molar Volumes, Vapor Non-ldealities, and Critical Properties of Some Fluorinated Ethers: $\mathrm{CF}_{3} \mathrm{OCF}_{2} \mathrm{OCF}_{3}, \mathrm{CF}_{3} \mathrm{OCF}_{2} \mathrm{CF}_{2} \mathrm{H}$, C$\mathrm{CF}_{2} \mathrm{CF}_{2} \mathrm{CF}_{2} \mathrm{O}, \mathrm{CF}_{3} \mathrm{OCF}_{2} \mathrm{H}_{\text {, and }} \mathrm{CF}_{3} \mathrm{OCH}_{3}$, and of $\mathrm{CCI}_{3} \mathrm{~F}$ and $\mathrm{CF}_{2} \mathrm{CiH}$, Journal of Chem. Thermodynamics, Academic Press Limited, volume 23, pages 699-710. December 1991 (12 pages with 8 tables, RDB2505)

Vapor pressures, compressibilities, expansivities, and molar volumes of the liquid phase are presented, based on measurements between room temperature and the crtical temperature. for a series of fluorinated ethers. Critical temperatures and pressures and approximate melting and boiling temperatures are tabulated for perfluorodimethoxymethane, 2-hydryl-F-ethyl F-methyl ether, F-oxetane, and pentafluorodimethyl ether. These ethers are under investigation as potential refrigerants, blowing agents, and cleaning agents based on their physical and chemical similarity to present refrigerants. Equations are presented for determination of these properties. Vapor-phase nonidealities were measured for each compound, but only for samples of high vapor density. Apparatus calibrations were verified with measurements for R-11 and R-22.

\section{R-717 (Ammonia)}

L. Haar and J. S. Gallagher, Thermodynamic Properties of Ammonia, Journal of Physical Chemistry Reference Data, volume 7, number 3, pages $635 \mathrm{ff}, 1978$ (RDB3237)

\section{R-717/R-718 (Ammonia/Water)}

N. C. Goomer et al, Ammonia-Water Systems: Part I, Thermodynamic Properties, Bhabha Atomic Research Center, Bombay, India, 1980 (RDB3235)

\section{R-717, ammonia, absorption}

P. C. Jain and G. K. Gable, Equilibrium Property Data Equations for Aqua-Ammonia Mixtures, paper 2180. Transactions, American Society of Heating, Refrigerating, and Air-Conditioning Engineers, Atianta, GA, volume 77, part 1, 1971 (RDB3233)

\section{R-717, ammonia, absorption}

R. A. Macriss, B. E. Eakin, R. T. Ellington, and J. Huebler, Physical and Thermodynamic Properties of Ammonia-Water Mixtures, research bulletin 34, Institute of Gas Technology (IGT). Chicago, IL. 1964 (RDB3232)

R-717, ammonia, absorption

Y. M. Park (A Joo University, Korea) and R. E. Sonntag (University of Michigan), Thermodynamic Properties of Ammonia-Water Mixtures: A Generalized Equation-of-State Approsch, paper 3319, Transactions, American Society of Heating, Refrigerating, and Air-Conditioning Engineers, Atlanta, $\mathrm{GA}$, volume 96 , part 1,1990 (10 pages with 9 figures and 3 tables, RDB3227)

\section{R-717, ammonia, absorption}

E. P. Perlman, Vapor Pressure of Aqueous Ammonia Solution, Part I, Journal of the Chemical Society, volume 79, pages 718 ff, 1901 (RDB3228)

R-717, ammonia, absorption 
E. P: Pirlman, Vapor Pressure of Aqueous Ammonia Solution, Part II, Joumal of the Chemical Society, volume 81, 1903 (RDB3229)

R-717, ammonia, absorption

G. Scratchard ot al, Thermodynamic Properties Saturated Liquid and Vapor of Ammonia-Water Mixtures, Refrigerating Enginesring. American Society of Refrigerating Engineers (ASRE, now merged into the American Society of Heating, Refrigerating, and Air-Conditioning Engineers, ASHRAE), Atlanta, GA, volume 53, pages 413 ff, 1947 (RDB3231)

S. C. G. Schultz, Equations of State for the System Ammonia-Water for Use with Computers, Proceedings of the International Congress of $R_{\theta}$ frigeration, International Institute of Refrigeration IIR), Paris, France, volume 2, pages 431 ff, 1972 (RDB3234)

\section{R-717, ammonia, absorption}

B. Ziegler and C. Trepp (Swiss Federal Institute of Technology, ETH, Switzerland), Equation of State for Ammonia-Water Mixtures, International Journal of Refrigeration, Paris, France, volume 7, number 2, pages $101 \mathrm{ff}$, February 1986 (RDB3236)

R-717, ammonia, absorption

\section{General and Multiple Fluids}

T. Atwood (AlledSignal Incorporated), Retrigerant Tables and Charts, ASHRAE Handbook - Fundamentals (published in separate editions with inchpound and SI metric units), American Society of Heating, Refrigerating, and Air-Conditioning Engineers (ASHRAE), Atlanta, GA, chapter 17, pages 17.1-17.71, 1989 (71 pages, RDB0037)

This chapter provides pressure-enthalpy (ph) diagrams and tabulates thermodynamic and thermophysical properties for R-11, R-12, R-13, R-13B1, R-14, R-22, R-23, R-50, R-113, R-114, R$142 b, R-152 a, R-170, R-290, R-500, R-502$, R503, R-600, R-600a, R-717, R-744, R-1150, and $\mathrm{R}-1270$. The tabular data include temperature, pressure, vapor volume, llquld density, enthalpy, entropy, viscosity, thermal conductivity, specific heat, and the velocity of sound. Temperatureentropy (ts) dlagrams and properties are provided for cryogenic fluids including R-702, R702p, R-704, R-720, R-728, R-729, R-732, and R740. An enthalpy-concentration diagram and tabular data for the specific volume at saturation are presented for ammonia water for absorption cycles. Enthalpy equillbrium and concentration diagrams are similarly provided for water-lithium bromide solutions.
D. Arnaud, L. Niveau, and S. Wosinski (Atochem Groupe Elf Aquitaine), Comparison of Thermophysical Properties of HFC 125, 32, and 143a, Proceedings of the 1992 International Refrigeration Conference - Energy Efficiency and New Refrigerants, edited by D. R. Tree and J. E. Braun, Purdue University, West Lafayette, IN, volume 2, pages 375-383, July 1992 (9 pages with 4 figures and 4 tables, avallable from JMC as RDB2820)

This paper provides property data for R-32, R125, and R-143a. These data are provided to predict the properties of their mixtures as replacements for R-502, an azeotrope containing R-22 and R-115. Critical properties, solubility, flammability, ozone depletion potential (ODP), and global warming potential (GWP) are compared for the three hydrofluorocarbons (HFCs) to those of R-502. Transport properties, including thermal conductivity, viscosity, surface tension, and specific heat are similarly compared. Tabular data are provided for compatibility with polychloroprene (neoprene), nitrile butyl rubber (NBR), and polyethylene chlorosulfone (DuPont Hypalon(R)) elastomers. Miscibility also is compared for R-502 and the three HFCs with unidentified naphthenic mineral oil and neopentyl polyester and alkylbenzene lubricants in $80 \%$ and $5 \%$ lubricant concentrations. A serles of plots provide the vapor pressure, saturated liquid density, llquid viscosity, and liquid thermal conductivity for -60 to $+60^{\circ} \mathrm{C}\left(-76\right.$ to $\left.140^{\circ} \mathrm{F}\right)$. The paper reviews the design changes required, but concludes that only few adaptations will be needed for either retrofit or new uses of these fluids.

H. D. Baehr (Universität Hannover), New Refrigerants, Research Into Their Thermodynamic Property Data, Proceedings of the 3rd International Energy Agency Heat Pump Conference (Tokyo, Japan, 12-15 March 1990) edited by T. Saito and Y. Igarashi, Pergamon Press, Elmsford, NY, pages 243-251, 1990 (12 pages with 1 figure and 3 tables, RDB0406)

M. Barret and Y. Candau (Université Paris XII - Val de Marne, France). Thermodynamic Properties Computation of Two Possible Substitute Retrigerants, Proceedings of the 1992 International Refrigeration Conference - Energy Efficiency and New Refrigerants, edited by D. R. Tree and J. E. Braun, Purdue University, West Lafayette, IN, volume 2, pages 433-442, July 1992 (10 pages with 3 figures and 7 tables, RDB2826)

N. F. Carnahan and K. E. Starling, Intermolecular Repulsions and the Equation of State for Fluids, AlChE Journal, American Institute of Chemical Engineers (AIChE), New York, NY, volume 18, pages 1184 ff, 1972 (RDB2333) 
H. B. Chae, J. W. Schmidt, and M. R. Moldover (National Institute of Standards and Technology, NIST), Surface Tension of Refrigerants R-123 and R-1348, Journal of Chemical and Engineering Data, American Chemical Society (ACS), pages 68, January 1990 (3 pages with 2 figures and 3 tables, RDB0917)

The surface tensions of two environmentally acceptable refrigerants (R-123 and R-134a) were measured with a differential capillary rise technique. Measurements span the temperature range -25 to $+140^{\circ} \mathrm{C}\left(-13\right.$ to $\left.284^{\circ} \mathrm{F}\right)$ for $\mathrm{R}-123$ and -10 to $+95^{\circ} \mathrm{C}\left(14\right.$ to $203^{\circ} \mathrm{F}$ ) for R-134a.

H. B. Chae, J. W. Schmidt, and M. R. Moldover (National Institute of Standards and Technology, NIST), Alternative Refrigerants R-123a, R-134, R141b, R-142b, and R-152a: Critical Temperature, Refractive Index, Surface Tension, and Estlmates of Liquid, Vapor, and Critical Densities, Journal of Physical Chemistry, pages 8840-8845, 13 December 1990 (6 pages with 6 flgures and 4 tables, RDB0918)

Differential capillary rise and refractlve index data are reported for five alternative refrigerants: $R-123 a, R-134, R-141 b, R-142 b$, and R-152a. This paper explains the selection of these fluids, describes the apparatus and analytical methods, and compares the findings with published reports by others. The data extend from about $25^{\circ} \mathrm{C}\left(77^{\circ} \mathrm{F}\right)$ to the critical point of each fluid and directly yield the critical temperature $T_{c}$ and the temperature-dependent capillary length. The present data were combined with liquid density data (near ambient temperature) to determine the Lorentz-Lorenz constant. The Lorentz-Lorenz relation is used to estimate the liquid, vapor, and critical densities, and the surface tension. R-141b slowly decomposed when maintained near its critical point (in contact with gold, sapphire, stainless steel, and crown glass).

C. L. Gage, Equation-of-State Parameters for Potential CFC and HCFC Replacements, Environmental Research Brlef EPA-600/5-93-003, U.S. Environmental Protection Agency (EPA), Research Triangle Park, NC, February 1993 (2 pages with 2 tables, available from JMC as RDB3406)

This summary presemis coefficients to calculate thermodynamic properties for 11 potential alternative refrigerants. These data are provided for use with for the Carnahan-Starling-DeSantis equation of state. The summary also presents coefficients for a quadratic equation for the ideal gas heat capacity. The chemicals include nine hydrofluorocarbons (HFCs), namely R-227ca, R227ea, R-236cb, R-236ea, R-236fa, R-245ca, R$245 \mathrm{cb}, \mathrm{R}-245 \mathrm{fa}$, and $\mathrm{R}-254 \mathrm{cb}$. They also include two ethers, E-125 and E-143a.
P. A. Domanskl and D. A. Didion, Impact of Refrigerant Property Uncertainties on Prediction of Vapor Compression Cycle Performance, report NBSIR 86-3373, National Institute of Standards and Technology (then the National Bureau of Standards), Gaithersburg, MD, December 1986 (54 pages, RDB0922)

This paper presents a sensitivity study of a vapor-compression cycle in the form of a heat pump operating in the cooling mode. The study was performed with the aid of a detailed simulation model; runs were made for different parametric values and the capacity and power, input were compared with results of a run using an unchanged value of the parameters. The effects on ovaporator and condenser pressures, and refrigerant mass flow rate are given. The independent variables include thermodynamic and transport propertles, as well as the refrigerant flow, heat transfer, and pressure drop coefficients. The parameters which had the most effect on system performance were liquid transport properties, evaporative heat transfer coefficient, and vapor density.

B. R. Fellows, R. G. Richard, and I. R. Shankland (AlliedSignal Incorporated), Electrical Charactertzation of Alternate Refrigerants, paper 45, proceedings of the XVIIIth International Congress of Refrigeration (Montreal, Québec, Canada, August 1991), International Institute of Refrigeration, Paris, France, August 1991 (10 pages with 2 figures and 7 tables, RDB2319)

J. Gallagher, M. O. McLinden, G. Morrison, M. L. Huber, and J. Ely, NIST Thermodynamic Properties of Refrigerants and Refrigeramt Mixtures Database (REFPROP), NIST Standard Reference Database 23 version 3.0, National Institute of Standards and Technology, Gaithersburg, MD, March 1992 (software and documentation avallable from NIST, RDB2430)

Version 3.00 of REFPROP calculates properties for 26 pure refrigerants, as well mixtures of up to five of them. A method to estimate binary interaction parameters is provided for those pairs of fluids for which measurements are not avallable. The refrigerants include $R-11, R-12, R-13, R$ 13B1, R-14, R-21, R-22, R-23, R-113, R-114, R115, $R-123, R-124, R-125, R-134, R-134 a, R-$ $141 b, R-142 b, R-143, R-143 a, R-152 a, R-218, R-$ 290 (propane), R-C270 (cyclopropane), R-C318, and E-134. Fourteen thermodynamic properties can be calculated, in user-selected units of measurement. This update replaces version 2.0 [see RDB1105].

J. Gallagher, M. O. McLinden, and G. Morrison, REFPROP, A Program for the Calculation of the Thermodynamic Properties of Refrigerants and 
Refrigerant Mlxtures, NIST Standard Reference Database 23 version 2.0, National Institute of Standards and Technology, Gaithersburg, MD, March 1991 (software and documentation available from NIST, RDB1105)

Version 2.00 of REFPROP calculates properties for 18 pure refrigerants and 24 binary mixtures of them in user-selected units of measurement. These refrigerants include R-11, R-12, R-13, R13B1, R-14, R-22, R-23, R-113, R-114, R-115, R123, R-124, R-125, R-134, and R-134a, R-142b, $R-152 a$, and R-C270. This version has been superseded; see RDB2430.

J. Gallagher, M. O. McLinden, and G. Morrison, REFPROP, A Program for the Calculation of the Thermodynamic Properties of Refrigerants and Refrigerant Mixtures, NIST Standard Reference Database 23 version 1.02, National Institute of Standards and Technology, Gaithersburg, MD, 28 September 1990 (software and documentation, RDB0916)

Version 1.02 of REFPROP calculates properties for 16 pure refrigerants and 24 binary mixtures of them in user-selected units of measurement. These refrigerants include R-11, R-12, R-13, R13B1, R-14, R-22, R-23, R-113, R-114, R-123, R124, R-125, R-134, and R-134a, R-142b and R152a. This version has been superseded; see RDB2430.

A. R. H. Goodwin and M. R. Moldover (National Institute of Standards and Technology, NIST), Thermophysical Properties of Gaseous Refrigerants from Speed of Sound Measurements: III. Results for 1,1-dichloro-2,2,2-trifluoroethane $\left(\mathrm{CHCl}_{2}\right.$ $\mathrm{CF}_{3}$ ) and 1,2-dichloro-1,2,2-trifluoroethane (CHCIF-CCIF $)$, Journal of Chem. Physics, American Institute of Physics, volume 95, number 7. pages 5236-5242, 1 October 1991 (7 pages with 4 figures and 4 tables, RDB3106)

$$
\text { R-123, R-123a }
$$

$X$. Guozhen, W. Yezheng, D. Kunxuan, and C. Zhong (XI'an Jiaotong University, China), The Relations Used to Analyze tho Phase Equilibrium Properties of Binary Refrigerant Mixtures, Procoodings of the 1992 Intemational Refrigeration Conference - Energy Efficiency and New Refrigerants, edited by D. R. Tree and J. E. Braun, Purdue University, West Lafayette, IN, volume 2, pages 425-432, July 1992 (8 pages with 2 figures and 4 tables, RDB2825)

D. W. Hughes, J. T. McMullan, and R. Morgan, Determination of the Thermodynamic Properties of Refrigerant-Oil Mlxtures, Proceedings of the 1982 Purdue Compressor Conference, Purdue Uni- versity, West Lafayette, IN, pages 214-221, July 1982 (RDB3323)

A. Kamei, C-C. Plao, H. Sato, and K. Watanabe (Keio University, Japan), Thermodynamic Charts and Cycle Pertormance of [H]FC-134a and [H]FC-152a, paper 3318, Transactions, American Society of Heating, Refrigerating, and Air-Conditloning Engineers (ASHRAE), Atlanta, GA, volume 96. part 1, 1990 (9 pages with 13 figures and 5 tables, RDB3110)

thermodynamic properties and cycle performance for R-134a and R-152a

R. F. Kayser (National Institute of Standards and Technology, NIST), Thermophysical Properties, report DOE/CE/23810-8A, Air-Conditioning and Refrigeration Technology Institute (ARTI), Arlington, VA, January 1993 (102 pages, including 13 figures and 32 tables, available from JMC as RDB3201)

This progress report provides an update on a project to provide highly accurate, selected thermophysical properties data for R-32, R-123, $R-124$, and R-125. The report summarizes the work completed in the fourth quarter of a 15month project and includes plots showing the ranges of measured data, deviations from correlations, and comparisons with earlier data. Preliminary tables are appended, in both metric (SI) and inch-pound (IP) units. They relate Burnett measurements of density and pressure to temperature for the vapor phase and vibrating densimeter measurements for the liquid phase for R-32. Burnett and ebulliometric vapor-pressure data are tabulated and extrapolated to provide saturated vapor and liquid densities. Adiabatic calorimeter measurements at constant volume are presented for the liquid and twophase regions. Measurements of thermal conductivity have been delayed by a failure, not yet analyzed, due to corrosion of leads in the transient hot-wire apparatus. Supercritical data, therefore, are not tabulated pending verification and completion, though a preliminary plot is included. Density and pressure measurements versus temperature also are provided for R-124 and R-125 for the liquid phase. Measured pressure and density data also are tabulated for R125 for compressed liquid, and a range of isochores. Ebulliometric vapor-pressure measurements and fits to Antoine equations are given for both R-124 and R-125. Isochoric PVT measurements and both liquid and two-phase heat capacity are tabulated for R-123. Progress in fitting the data to modifled Benedict-WebbRubin (MBWR) equations of state for R-125, both as part of related research and the present project, is cited. Progress on a 32-term MBWR 
equation, based on analysis of thermal conductivity data for R-123, also is described.

R. F. Kayser (National Institute of Standards and Technology, NIST), Thermophysical Propertles, report DOE/CE/23810-4A, Alr-Condtioning and Refrigeration Technology Institute (ARTI), Arlington, VA, October 1992 (222 pages, including a 104-page report with 8 figures and 23 tables, and 4 appended draft papers, available from JMC as RDB2C01)

This progress report provides an update on a project to provide highly accurate, selected thermophysical properties data for R-32, R-123, R-124, and R-125. Pressure-temperature and density-pressure relations are plotted for R-32 based on measurements using a Burnett apparatus. Pressure-volume-temperature relations, determined with a vibrating-tube apparatus and extrapolations, also are plotted. Deviations to measured data, generally within $\pm 0.1 \%$ are plotted and skeleton density data are tabulated. PVT and experimental liquid heat capacity data are tabulated for the 284-340 K (51-153 $\left.{ }^{\circ} \mathrm{F}\right)$. Transient hot-wire measurements of thermal conductivity for $300-340 \mathrm{~K}(80-160$ ' $\mathrm{F}$ ) are presented and viscosity measurements are described. A virial equation and coefficients for the ideal-gas heat capacity of R-124 is summarized. The speed of sound, ideal-gas heat capacity, and acoustic virial coefficients are tabulated for R-125 for $250-400 \mathrm{~K}\left(-10\right.$ to $\left.260^{\circ} \mathrm{F}\right)$. Pressure-temperature and molar heat capacity data are plotted and PVT and heat capacity data are tabulated for R-125. Finally, thermal conductivity data are tabulated for R-123, based on transient hot-wire measurements. Further data are summarized in four appended draft papers entitled "Coexisting Densities, Vapor Pressures, and Critical Densities of Refrigerants $R-32$ and $R-152 a$ at 300 to $385 K_{i}$ " "Coexisting Densities and Vapor Pressures of Refrigerants R-22, $R$ 134a, and $R-124$ at 300 to $395 \mathrm{~K} ; "$ "Critical Densities and Coexisting Density Data: Application to Refrigerants $R-22, R-134 a$, and $R-124 ; "$ and "Measurements of the Viscosities of Saturated and Compressed Fluid 1-chloro-1,2,2,2tetrafluoroethane (R-124) and Pentafluoroethane (R-125) at Temperatures Between 120 and $420 \mathrm{~K}$." [see RDB3201 for update]

R. F. Kayser (Natlonal Institute of Standards and Technology, NIST). Thermophysical Properties, report DOE/CE/23810-3A, Air-Condtioning and Refrigeration Technology Institute (ARTI), Arlington, VA, July 1992 (54 pages including a 6-page report and 2 appended draft papers, avallable from JMC as RDB2801)

This progress report provides an update on a project to provide highly accurate, selected thermophysical properties data for R-32, R-123,
R-124, and R-125. The thermodynamic data also will be fit to modified Benedict-Webb-Rubin (MBWR) and improved Camahan-Starling-DeSantis (CSD), or Carnahan-Starling-DeSantisMorrison (CSDM), equations of state for each fluid. The CSDM equation takes into account the effects of the dipole moment to improve modelling of blends of very polar fluids, such as $R-32 / 134 a$. Viscosity and thermal conductivity data for R-32 and thermal conductivity data for R-123 will be correlated for use in transport property models. Measurements in this reporting period have focused on the PVT behavior, isochoric heat capacity, and transport properties of R-32 and on the thermal conductivity of R-123. Measurements for R-32, based on Burnett apparatus, are described. A draft paper entitled "Ebulliometric Measurement of the Vapor Pressure of Difluoromethane (R-32)," submitted to the Journal of Chemical and Engineering Data, is appended. Measurements of the molar heat capacity using an adiabatic calorimeter, of thermal conducthity using a lowtemperature iransient hot-wire instrument, and shear viscosity using a torsional quartz crystal viscometer are outlined. The pressure and liquid densities of R-32/134a and R-32/152a were determined at the bubble points of these $\mathrm{mix}$ tures in a related project. The thermal conductivity of R-124 was measured in the liquid and vapor phases, and a draft paper entitled Thermal Conductivity of 2-Chloro-1,1,1,2Tetrafluoroethane (R-124)," submitted to the International Journal of Thermophysics, also is appended. Thermal conductlvity measurements of R-125 in the vapor, liquil, and supercritical phases are outlined as are viscosity measurements for both R-124 and R-125. The thermal conductivity measurements of R-123, using lowand high-temperature transient hot-wire instruments, also are described. The agreement between newly acquired property data are compared to those resulting from other identified investigations, generally indlcating more complete and much more precise findings. [see RDB2C01 for update]

R. F. Kayser (National Institute of Standards and Technology, NIST), Thermophysical Properties, report DOE/CE/23810-2A, Alr-Conditioning and Refrigeration Technology Institute (ARTI), Arlington, VA, April 1992 (9 pages with 4 figures, available from JMC as RDB2511)

This interim report introduces a project to provide highly accurate, selected thermophysical properties data for R-32, R-123, R-124, and R125. The thermodynamic data also will be fit to modified Benedict-Webb-Rubin (MBWR) and improved Carnahan-Starling-DeSantis (CSD), or Carnahan-Starling-DeSantis-Morrison (CSDM), 
equations of state for each fluid. The CSDM equation takes into account the effects of the dipole moment to improve modelling of blends of very polar fluids, such as R-32/134a. Viscosity and thermal conductivity data for R-32 and thermal conductwity data for R-123 will be correlated for use in transport property models. Measurements in this reporting period have focused on the PVT behavior and vapor pressure of R-32, thermal conductivity of R-123, and speed of sound in R-124. Plots compare the measured and calculated vapor pressure data for R-32 and measured thermal conductivity of R-123 with similar data from prior studies by other researchers. The report also summarizes ongoing property measurements and modelling for the same fluids in companion research. [See RDB2801 for update]

G. Latini, P. Plerpaoli, and F. Polonara (Università di Ancona, Italy). Dynamic Viscosity and Thermal Conductivity Prediction of Refrigerants and Refrigerant Mixtures, Proceedings of the 1992 International Refrigeration Conference - Energy Efficiency and New Refrigerants, edited by D. R. Tree and J. E. Braun, Purdue University, West Lafayette, IN, volume 2, pages 489-498, July 1992 (9 pages with 7 tables, RDB2832)

R. C. McHarness and D. C. Chapman, Refrigerating Capacity and Performance Data for Various Refrigerants, Azeotropes, and Mixtures, Transactions, American Society of Heating, Refrigerating, and Alr-Conditioning Engineers (ASHRAE). Atlanta, GA, volume 67, 1961 (RDB3213)

M. O. McLinden (National Institute of Standards and Technology, NIST), Thermodynamic Properties of CFC Alternatives - A Survey of Available Data, CFCs: Today's Options - Tomorrow's Solutions (proceedings of ASHRAE CFC Technology Conference, Gaithersburg, MD, 27-28 September 1989). American Society of Heating, Refrigerating. and Air-Conditioning Engineers (ASHRAE), Atlanta, GA, pages 17-31, 1990; republished in International Journal of Refrigeration, Paris, France, volume 13, number 5, May 1990, pages 149-162 (15 pages with 29 figures and 5 tables, RDB0912)

Thermodynamic properties, from a variety of sources including unpubllshed data, are summarized for ten potential substitutes for CFC refrigerants. The fluids include R-22, R-23, R-32, $R-123, R-124, R-125, R-134 a, R-142 b, R-143 a$, and R-152a. The data include triple-point, normal bolling point, and critical point parameters, and the temperature dependence of the vapor pressure, saturated liquid density, and ideal-gas data heat capacity. Also considered are singlephase PVT data. The saturation and ideal-gas data are fit to simple correlations.
M. O. McLinden (National Instltute of Standards and Technology, NIST). Physical Properties of Alternatives to the Fully Halogenated Chlorofluorocarbons, publication unknown, National Institute of Standards and Technology, Boulder, CO, 1989 (RDB0906)

The properties of nine halogenated hydrocarbons are collected from a variety of sources, including unpublished data. These data are evaluated and correlated. Considered are the triple point, normal boiling point, and critical point parameters and the temperature dependence of the vapor pressure, saturated liquid density, solubility in water, and hydrolysis rates. The fluids, which are potential alternatives to the fully halogenated chlorofluorocarbons, are R-22, R-123, R-124, R-125, R-124, R-134a, R-141b, R-142b, and R-152a; also included is the solvent R-140a (methyl chloroform).

M. O. McLinden, J. S. Gallagher, L A. Weber, G. Morrison, D. Ward, A. R. H. Goodwin, M. R. Moldover, J. W. Schmidt, H. B. Chae, T. J. Bruno, J. F. Ely, and M. L. Huber (National Institute of Standards and Technology, NIST), Measurement and Formulation of the Thermodynamic Properties of Retrigerants 1340 (1,1,1,2-Tetrafluoroothane) and 123 (1,1-Dichloro-2,2,2-Trifluoroothano), paper 3282 (RP.588), Transactions, American Society of Heating, Refrigerating, and Air-Conditioning Engineers (ASHRAE), Attanta, GA, volume 95, part 2, pages 263-283, 1989 (21 pages, RDB0913)

Thermodynamic properties of R-134a and R-123 are formulated using a modified BenedictWebb-Rubin (MBWR) equation of state fit to experimental measurements of the critical point, vapor pressure, saturated liquid and vapor volumes, superheated pressure-volume-temperature (PVT) behavior, and second virial coefficients derived from PVT and sound speed measurements. The heat capacity of the ideal gas reference state is determined from sound speed measurements on the low density vapor. Surface tensions are also presented. The experimental methods and results are summarized, compared to the property formulation, and compared to other sources in the itterature. Tables and diagrams of the thermodynamic properties of R-123 and R-134a, prepared using the MBWR equation of state, are presented. While the various measurements cover different ranges of temperature and pressure, the MBWR formulation is applicable in both the liquid and vapor phases at pressures up to $10,000 \mathrm{kPa}$ (1500 psia); the applicable temperature range is 233 to $450 \mathrm{~K}$ ( -40 to $350^{\circ} \mathrm{F}$ ) for R-134a and 255 to $450 \mathrm{~K}$ ( 0 to $350^{\circ} \mathrm{F}$ ) for R-123. This paper summarizes the results of ASHRAE research project RP-588. 
R. C. Miller; A. D. Ceballos, K. R. Hall, and J. C. Holste (Texas A\&M University), Accurate Vapor Pressures for Refrigerants. Proceedings of the 1992 International Refrigeration Conference - Energy Efficiency and New Refrigerants, edited by D. R. Tree and J. E. Braun, Purdue University, West Lafayette, IN, volume 2, pages 479-487, July 1992 (9 pages with 3 flgures and 2 tables, RDB2831)

G. Morrison and J. S. Gallagher (National Institute of Standards and Technology, NIST), REFPROP: A Thermodynamic Properties Software Program for Refrigerants and Their Mixtures, publication unknown, 1990 (12 pages with 2 figures, available from JMC as RDB0914)

This paper introduces REFPROP, a computer software package that produces tables of thermodynamic properties for 15 refrigerants and 20 of their binary mixtures. It addresses the Carnahan-Starling-DeSantis (CSD) equation of state chosen for property calculations, the software subroutines included, and sources used to obtain the incorporated property data. The paper compares output to source data for R-123. (Please see RDB2430 for further information on REFPROP.)

G. Morrison and M. O. McLinden, Application of a Hard Sphere Equation of State to Refrigerants and Refrigerant to Mixtures. NBS Technical Note 1226. National Institute of Standards and Technology (then the National Bureau of Standards), Gaithersburg, MD, August 1986 (156 pages, available from JMC as RDB0911)

The Carnahan-Starling-DeSantis (CSD) equation of state is applied to halogenated hydrocarbon refrigerants and their mixtures. A set of thermodynamic functions is derived from the PVT equation of state and the ideal gas heat capacities. Reference states are discussed for both pure materials and mixtures. Although the model exhibits a critical point, it does not quantitatively represent properties in the critical region. Despite this limitation, this model can represent both liquid and gaseous mixtures away from their own critical points, even at conditions near to and above the critical points of their components. Agorthms and FORTRAN routines for the use of this model are presented along with the numerical coefficlents for 11 pure refrigerants and $7 \mathrm{mbxtures}$. Routines for evaluating the coefficients from saturation data are included. Several examples of the application of this equation of state are presented to demonstrate its versatllity. The average deviation from the tabulated saturation properties of the 11 pure refrigerants is $0.54 \%$ for pressures, $0.09 \%$ for liquid volumes, and $0.50 \%$ for vapor volumes.
G. Morrison and D. K. Ward (National Institute of Standards and Technology, NIST), Thermodynamic Properties of Two Alternative Refrigerants, 1,1-Dichloro-2,2,2-Trifluoroethane (R-123) and $1,1,1,2-$ Tetrafluoroethane (R-134a), publication unknown, undated (38 pages with 11 figures and 7 tables, available from $\mathrm{MMC}$ as RDB0907)

This paper describes property measurements for R-123 and R-134a. A simple variable-volume sapphire cell was used to obtain vapor-liquidequilibrium measurements. Vapor pressures and saturation liquid densities are presented for R-134a from $-5^{\circ} \mathrm{C}\left(23^{\circ} \mathrm{F}\right)$ to the critical temperature, and for R-123 at $30-100^{\circ} \mathrm{C}\left(85-210^{\circ} \mathrm{F}\right)$. Saturation vapor density was also determined for R-134a from $35^{\circ} \mathrm{C}\left(95^{\circ} \mathrm{F}\right)$ to the critical point, where the critical conditions were measured. A mechanical oscillator densimeter was used to provide density measurements of the compressed liquids. These measurements are presented from the saturation pressure to $5.5 \mathrm{MPa}$ (800 psi) for R-134a and to $3.5 \mathrm{MPa}$ (500 psi) for $\mathrm{R}-123$ at $5-95^{\circ} \mathrm{C}\left(40-200{ }^{\circ} \mathrm{F}\right)$. Results are summarized and compared with similar measurements made by other groups.

T. W. Phillips and K. P. Murphy (AlliedSignal Incorporated, then Alled Chemical Corporation), Liquild Viscosity of Halogenated Refrigerants, paper 2152. Transactions, American Society of Heating, Refrigerating, and Air-Conditioning Engineers (ASHRAE), Atlanta, GA, volume 76, part II, pages 146-156, June 1970 (12 pages with 5 figures and 3 tables, RDB2315)

Liquid viscosity data are tabulated for R-11, R12, R-13, R-22, R-114, R-115, R-133a, R-152a, R500, R-502, R-31/R-114, R-115/R-152a, R-503, R-504, and R-32/R-12.

T. W. Phillips and K. P. Murphy (AlliedSignal Incorporated, then Allied Chemical Corporation). Liquid Viscosity of Halocarbons, Journal of Chemical and Engineering Data, volume 15, number 2, pages 304-307, February 1970 (4 pages with 5 figures and 5 tables, RDB2314)

K. Raznjevic, Handbook of Thermodynamic Tables and Charts, Hemisphere Publishing Corporation, Washington, DC, and McGraw-Hill Book Company, New York, NY, 1976 (RDB3211)

J. R. Sand, S. K. Fischer (Oak Rilge National Laboratory, ORNL), and J. A. Jones (Jet Propulsion Laboratory, California Insthute of Technology). Experimentaily Determined and Estimated CSD and LKP Interaction Coefficients for Ozone-Safe Refrigerant Mixtures, International Journal of Refrigeration, Paris, France, in publication (RDB2336)

Estimates of interaction coefficients (ICs) are provided for binary refrigerant blends for both 
the Carnahan-Starling-Desantis (CSD) and LeOKesler-Plocker (LKP) equations of state (EOS). These IC values characterize the non-ideal behavior of mixtures, and are useful in calculating thermodynamic properties. The estimates were determined by least-squares fits of the CSD and LKP equations to previously measured, saturated vapor pressure (bubble point) data. 71 mixtures of 8 different refrigerants in 18 binary combinations were analyzed. The combinations included R-12/R-152a, R-22/R-124, R-22/R-134, R-22/R-134a, R-22/R-142b, R-22/R-152a, R23/R-22, R-23/R-134a, R-124/R-142b, R-134/R124, R-134/R-142b, R-134a/R-124, R-134a/R134, R-134a/R-142b, R-134a/R-152a, R-152a/R124, R-152a/R-134, and 152a/R-142b. The paper describes the use of IC values, experimental apparatus used to measure the data, presents the resulting ICs, and discusses variances found with previously determined values. Good agreement was found for several known blends, but poor agreement resulted for the well characterized R-22/R-142b blend; further experimental verfflcation is recommended. Comparisons between experimental ICs and those calculated from physical properties or critical constants of the components suggest that refinement of the property calculation algorithms may be desirable.

I. R. Shankland, Transport Properties of CFC At ternatives, unpublished presentation (Symposium on Global Climate Change and Refrigerant Properties, AIChE Spring National Meeting, Orlando, FL, 1990), Buffalo Research Laboratory, AlliedSignal Incorporated, Buffalo, NY, March 1990 (31 pages, available from JMC as RDB0517)

R. R. Singh, E. A. E. Lund, and I. R. Shankland, (AlliedSignal Incorporated), Thermophysical Properties of HFC-32, HFC-125, and HFC-32/HFC125, unidentified publication (8 pages with 3 figures and 4 tables, RDB2234)

N. D. Smith, New Chemical Alternatives for CFCs and HCFCs, Environmental Research Brief EPA600/F-92-012, U.S. Environmental Protection Agency (EPA), Research Trlangle Park, NC, 24 March 1992 (2 pages with 2 tables, available from JMC as RDB3405)

This summary outtines efforts to identify alternathe refrigerants. It mentions a panel, convened to assess the potential for finding suitable alternative chemicals. It discusses the trade offs, in replacing one or more chlorine or bromine atoms in familiar refrigerants with hydrogen, between desired environmental characteristics and flammability, toxicity, and loss in efficiency. It reviews a search and cooperattvely funded project, with the Electric Power Research Insti- tute (EPRI), at Clemson University and the University of Tennessee. The goals were to synthesize and determine relevant physical properties of numerous fluorinated propanes, butanes, and ethers. Chemical formulae and normal boiling points are tabulated for $\mathbf{3 4}$ compounds considered. 11 are identified for further characteriza. tion; their chemical names and the refrigerants they might replace are tabulated. Additional testing of these 11 candidates is continuing. This research includes determination of atmospheric stability and tests of acute inhalation toxicity, materials compatibility, vapor thermal conductivity, and refrigeration performance. The 11 selected chemicals include nine hydrofluorocarbons (HFCs), namely R-227ca, R$227 \mathrm{ea}, R-236 \mathrm{cb}, \mathrm{R}-236 \mathrm{ea}, \mathrm{R}-236 \mathrm{fa}, \mathrm{R}-245 \mathrm{ca}, \mathrm{R}-$ $245 \mathrm{cb}, \mathrm{R}-245 \mathrm{fa}$, and R-254cb. They also include two ethers, E-125 and E-143a.

K. Watanabe, H. Sato, and Z-Y. Qian (Kelo University, Japan). Thermodynamic Properties of New Refrigerants - HFC-32 and HFC-125, Proceedings of the 1992 International Refrigeration Conference - Energy Efficiency and New Refrigerants, edited by D. R. Tree and J. E. Braun, Purdue University, West Lafayette, IN, volume 2, pages 443452, July 1992 (10 pages with 9 figures, RDB2827)

L A. Weber (National Institute of Standards and Technology, NIST), Criteria for Establishing ACcurate Vapor Pressure Curves, Proceedings of the 1992 International Refrigeration Conference Energy Efficiency and New Refrigerants, edited by D. R. Tree and J. E. Braun, Purdue Unlversity, West Lafayette, IN, volume 2, pages 463-471, July 1992 (9 pages with 4 figures, RDB2829)

L. A. Weber (National Institute of Standards and Technology, NIST), Thermophysical Properties of Some Selected Alternative Retrigeramts, presentation at the 1990 USNC/IIR-Purdue Refrigeration Conference and ASHRAE-Purdue CFC Conference (Purdue University, West Lafayette, IN, July 1990); published in the Proceedings of the 1992 International Refrigeration Conference - Energy Efficiency and New Refrigerants, edited by D. R. Tree and J. E. Braun, Purdue University, West Lafayette, IN, volume 2, pages 703-712, July 1992 (10 pages with 8 figures and 1 table, available from JMC as RDB0908)

Research on thermophysical propertles for six candidate alternatve refrigerants is summarized. Properties measured include gas- and liquid-phase PVT, vapor pressure, surface tension, index of refraction, dielectric constant, gas-phase speed of sound, critical parameters and materials compatibility. Results have been obtained for R-123, R-125, R-134, R-134a, and 
R-141b; some properties have been obtained for E-134.

E. G. Wright (E. I. DuPont de Nemours and Company, Incorporated). Prediction of Refrigerant Ternary Mixture Properties Using the RedlichKwong-Soave Equation of State, Advances in Nonazeotropic Mixture Refrigerants for Heat Pumps, technical data bulletin, American Society of Heating, Refrigerating, and Air-Conditioning Engineers (ASHRAE), Atlanta, GA, pages 37-52, June 1985 (RDB2331)

ASHRAE Thermodynamic Properties of Refrigerants, inch-pound (IP) version, American Society of Heating, Refrigerating, and Air-Conditioning Engineers (ASHRAE), Atlanta, GA, 1986 (508 pages, RDB3208)

ASHRAE Thermodynamic Properties of Refrigerants, metric (SI) version. American Society of Heating, Refrigerating, and Air-Conditioning Englneers (ASHRAE), Atlanta, GA, 1986 (472 pages, RDB3209)

\section{Please see RDB3208 for abstract}

Gas Heat Capacity, preliminary information bulletin, Buffalo Research Laboratory, AlledSignal Incorporated, Buffalo, NY, 23 May 1990 (1 page with 1 table, available from JMC as RDB0506)

An equation is provided to calculate the gas heat capacity of refrigerants in Btu/lb. $\mathrm{R}$ as a function of temperature in ${ }^{\circ} R$. Coefficients are provided for R-123, R-123a, R-124, R-125, R134, $R-134 a$, and $R-143 a$. The information presented is preliminary and estimated.

Liquid Density, preliminary information bulletin, Buffalo Research Laboratory, AlliedSignal Incorporated, Buffalo, NY, 1 May 1990 (1 page with 1 table, available from JMC as RDB0507)

An equation is provided to calculate the liquid density of refrigerants in $\mathrm{lb} / \mathrm{cf}$ as a function of critical properties. Coefficients are provided for $R-123, R-123 a, R-124, R-125, R-134, R-134 a$, and R-143a. The information presented is preliminary and estimated.

Revision of the ASHRAE Thermophysical Properties of Refrigerants", research project 558-RP, American Society of Heating, Refrigerating, and AirConditioning Engineers (ASHRAE), Atlanta, GA, December 1987 - ongoing (ASH0558)

The objective of this project is to update a standard reference on refrigerant properties. The work comprises a therature search, data analysis, development of empirical or semi-empirical property equations, and preparation of tables. The fluids addressed include R-11, R-12, R-13,
R-13B1, R-14, R-22, R-50 (methane), R-113, R114, R-115, R-142b, R-152a, R-170 (ethane), R290 (propane), R-C318, R-500, R-502, R-503, R600 (butane), R-600a (Isobutane), R.702 (hydrogen), R-702a (p-hydrogen), R-704 (hellum), R-717 (ammonia), R-718 (water), R-720 (neon), R-728 (nitrogen), R-729 (air), R-732) oxygen), R-740 (argon), R-744 (carbon dioxide), R-1150 (ethylene), and R-1270 (propylene). The contractor is Purdue University, led by P. E. Lilley and P. D. Desal; it is sponsored by ASHRAE Technical Committeo 3.1, Refrigerants and Brines.

Liquid Viscosity Corrolation, preliminary information bulletin, Buffalo Research Laboratory, AN. liedSignal Incorporated, Buffalo, NY, 23 May 1990 (1 page with 1 table, available from JMC as RDB0508)

A correlation is provided to calculate the viscosity of refrigerants, in $\mathrm{lb} / \mathrm{hrft}$, in their liquid state as a function of temperature, in ${ }^{\circ} R$. Coefficients, based on measurements in the range of -20 to $+80^{\circ} \mathrm{C}\left(-4\right.$ to $\left.+176{ }^{\circ} \mathrm{F}\right)$, are provided for R-123, R-123a, R-124, R-125, and R-134a. An equation is included to estimate the viscosity of R-134a in its vapor state. The information presented is preliminary and estlmated.

Liquid Thermal Conductivity Correlation, preliminary information bulletin, Buffalo Research Laboratory, AlliedSignal Incorporated, Buffalo, NY, 23 May 1990 (1 page with 1 table, avallable from JMC as ROB0509)

A correlation is provided to calculate the thermal conductivity of refrigerants, in Btu/hrtt. $\mathrm{F}$, in their liquid state as a function of temperature, in ${ }^{\circ} \mathrm{F}$. Coefficients, based on measurements in the range of $25.70^{\circ} \mathrm{C}\left(77.1588^{\circ} \mathrm{F}\right)$, are provided for R-123, R-123a, R-124, R-125, and R-134a. The information presented is preliminary and estimated.

Martin-Hou Equations of State, preliminary information bulletin, Buffalo Research Laboratory, AliedSignal Incorporated, Buffalo, NY, May 1990 (3 pages with 2 tables, available from JMC as RDB0505)

The Martin-Hou equation of State and related equations to calculate the enthalpy and entropy of refrigerants are presented. Reference points and coefficients are provided, in consistent inchpound units, for R-123, R-123a, R-124, R-125, R134, R-134a, and R-143a. The Information presented is preliminary and estimated.

Pressure-Enthalpy Graphs for the Atternative Retrigerants R-32, R-123, R-125, R-134a, and R141b, research project 743-RP, American Society of Heating, Refrigerating, and Air-Conditioning En- 
gineers (ASHRAE), Atlanta, GA, April 1992 - October 1992 (ASH0743)

The contractor for the project is University of Idaho, led by S. G. Penoncello; it is sponsored by ASHRAE Technical Committeo 3.1, Refrigerants and Brines.

REFPROP, A Program for the Calculation of the Thermodynamic Properties of Refrigerants and Refrigerant Mixtures, description, National Institute of Standards and Technology, Gaithersburg, MD, January 1990 (4 pages, RDB1104)

REFPROP calculates thermodynamic properties of refrigerants, both single component and mixtures. Tables produced by REFPROP can be used in estimating the efficiency and capability for a wide range of equipment with conventional and alternative refrigerants. This userfriendly package generates saturation property tables at desired temperatures or pressures, as well as tables of properties with the independent variables chosen from pressure, volume, temperature, entropy, and enthalpy. Dependent variables include those mentioned plus constant-pressure and constant-volume heat capacities, and velocities of sound. Version 1.0 of REFPROP calculates properties for 15 pure refrigerants and 20 binary mixtures. The calculations are based on wide-ranging measurements, including new data for refrigerants R-123, R-124, R-134, and R-134a, as well as revised correlations for R-11, R-13, R-13B1, R-14, R-22, R-23, R-113, R-114, R-142b and R-152a. The Carnahan-Starling-DeSantis (CSD) equation of state and ideal gas heat capactiles are used. REF. PROP runs on IBM-compatible personal computers. Future upgrades will include additional refrigerants and ternary blends. (Please see RDB2430 for further information on REFPROP.)

Selected Physical Properties of HCFC-123, HCFC-123a, HCFC-124, HFC-125, HFC-134, HFC-134a, and HFC-143a, preliminary information bulletin, Buffalo Research Laboratory, AlliedSignal Incorporated, Buffalo, NY, May 1990 (1 page with 1 table, avallable from JMC as RDB0504)

The critical temperature in ${ }^{\circ}$, critical pressure in psia, crtical density in Ib/cf, boiling point temperature in ${ }^{\circ} \mathrm{F}$, and molecular weight (relative mole jular mass) are tabulated for R-123, R12́3a, R-124, R-125, R-134, R-134a, and R-143a. The information presented is preliminary and estimated.

Thermodynamic Propertles of Refrigerants 125 and 1416, research project 654-RP, American Society of Heating, Refrigerating, and Air-Conditioning Engineers (ASHRAE), Atlanta, GA, September 1990 - December 1992 (ASH0654)
This study will determine the liquid densities, vapor densitles, vapor pressures, PVT properties, enthalpy, entropy, specific heat, and sound velocities of R-125. Vapor specific heat and PVT will be determined for R-141b. Critical temperatures and pressures will be determined for each substance. . The contractor for the project is Texas A\&M University led by J. C. Holste; it is sponsored by ASHRAE Technical Committee 3.1, Refrigerants and Brines.

Thermophysical Properties of Environmentally Acceptable Fluorocarbons - HFC-134a and HCFC-123, Japanese Association of 'Refrigeration and Japan Fon Gas Assoclation, Tokyo, Japan, 1991 (304 pages with 83 figures and 99 tables in both Japanese and English, RDB2235)

This comprehensive volume summarizes critical, thermodynamic, transpon, physical, chemical, compatibility, and other data available on $R$ 123 and R-134a. Included are tabular data and/or plots for solubility, refractive index, dielectric constant, dielectric strength, PVT properties and equations of state, enthalpy, entropy, isobaric and isochoric specific heat capacity, isentropic expansion exponent, speed of sound, surface tension, viscosity, kinematic viscosity, and thermal conducthity. Data on thermal and chemical stabilty are summarized, including weight and length changes with polypropylene, polystyrene, polyethylene, polyvinyichloride, polyamide, polyimide, chlorinated and chlorosulfonated polyethylene, nitrile butadiene rubber, Butyl(TM) rubber, fluorocarbon rubber, ethylene propylene diene terpolymer (EPDM), urethane rubber, and polychloroprene. Safery data, including toxicity and flammability, are summarized. The volume contains an extensive list of references as well as discussion of the ranges and differences among property sources identified. An introductory section outtines conversions among several metric systems, including SI, and inch-pound units. It also reviews the environmental concerns with chlorofluorocarbon (CFC) refrigerants.

Thermophysical Propertios of Pure Substances and Mixtures for Refrigeration, proceedings of the meeting of IIR Commissions B1 (Herzlia, Israel, March 1990), International Institute of Refrigeration, Paris, France, 1990 (278 pages with 33 papers, RDB1103)

Thermophysical Properties of Retrigerants, American Society of Heating, Refrigerating, and AirConditioning Engineers (ASHRAE), Atlanta, GA, 1976 (252 pages with 42 tables, RDB3210)

This reference provides viscosity, thermal conductuity, and specitic heat data, along with empirical or semi-empirical property equations, for 
refrigerants in inch-pound (IP) units. Conversion tables are provided for other units of measure. The fluids addressed include R-11, R-12, R-13, R-13B1, R-14, R-21, R-22, R-23, R-40 (methyl chloride), R-50 (methane), R-113, R-114, R-115, R-142b, R-152a, R-170 (ethane), R-290 (propane), R-C318, R-500, R-502, R-503, R-504, R-600 (butane), R-600a (isobutane), R-702 (hydrogen), R-702a (p-hydrogen), R-704 (hellum), R-717 (ammonia), R-718 (water), R-720 (neon), R-728 (nttrogen), R-729 (air), R-732) oxygen), R-740 (argon), R-744 (carbon dioxide), R1150 (ethylene), and R-1270 (propylene). More than 1000 references are cited.

Thermophysical Properties of Retrigerants 123 and 134a, proposed research project 655A-TRP, American Society of Heating, Refrigerating, and AirConditioning Engineers (ASHRAE), Atlanta, GA, in planning (ASH0655A)

This project is sponsored by ASHRAE Technical Committee 3.1, Refrigerants and Brines.

Thermophysical Properties of Rolrigerants 125 and 141b, proposed research project 655B-TRP, American Society of Heating, Refrigerating, and AirConditioning Engineers (ASHRAE), Atlanta, GA, in planning (ASH0655B)

This project is sponsored by ASHRAE Technical Committee 3.1, Refrigerants and Brines.

Transport Properties of Suva(A) Refrigerants: Suva(R) Cold-MP (HFC-134a), Suva(R) Trans A/C (HFC-134a), and Suva(R) Centri-LP (HCFC-123), product information report ART-1 (H-43855-1), DuPont Chemicals, Wilmington, DE, September 1992 (24 pages with 18 figures, available from JMC as RDB3438)

This report provides plots and equations for estimation of the transport properties of R-123 and R-134a. Liquid viscosity, liquid thermal conductivity, saturated liquid heat capacity, vapor viscosity at atmospheric pressure, vapor thermal conductivity at atmospheric pressure, vapor heat capacity, and vapor heet capacity ratio $\left(C_{p} / C_{y}\right)$ are addressed. Corresponding data are plotted for R-11 and R-12 for all but the vapor heat capacity data for comparison. The plots and equations are repeated in inch-pound (IP) and metric (SI) units. The equations are based on curve fits of measured data.

Transport Properties of Suva(R) Refrigerants: Suva(A) MP39, Suva(P) MP52, and Suva(A) MP66, product information report ART-10 (H-45949), DuPont Chemicals, Wilmington, DE, January 1993 (32 pages with 24 figures, available from JMC as RDB3440)
This report provides plots and equations for estimation of the transport properties of R-401 (33/15/52), R-401 (53/13/34), and $R-401$ $(61 / 11 / 28)$. These three refrigerants are $200-$ tropic blends of R-22, R-152a, and R-124 (R$22 / 152 a / 124)$. Saturated liquid viscosity, thermal conductivity, and heat capacity; vapor viscosity at atmospheric pressure; vapor thermal conductivity at atmospheric pressure; vapor heat capacity; and vapor heat capacity ratio $\left(\mathrm{C}_{\mathrm{p}} / \mathrm{C}_{\mathrm{v}}\right)$ are addressed. Plots provide correction factors for vapor viscosity at higher pressures for vapor densities to $110 \mathrm{~kg} / \mathrm{m3}(7 \mathrm{lb} / \mathrm{cf})$. The plots and equations are repeated in inchpound (IP) and metric (SI) units. The equations are based on curve fits of measured data. DuPont's product names for R-401 (33/15/52), $R-401(53 / 13 / 34)$, and $R-401(61 / 11 / 28)$ are Suva(R) MP52, Siva(P) MP39, and Siva(R) MP66 respectlvely.

Vapor Thermal Conductivtty Correlation, preliminary information bulletin, Buffalo Research Laboratory, AlliedSignal Incorporated, Buffalo, NY, 23 May 1990 (1 page with 1 table, available from JMC as RDB0510)

A correlation is provided to calculate the thermal conductivity of refrigerants, in Btu/hrtt. ${ }^{\circ} \mathrm{F}$, in their vapor state as a function of temperature, in - $F$. Coefficients, based on measurements in the range of $25-70^{\circ} \mathrm{C}\left(77-158{ }^{\circ} \mathrm{F}\right)$, are provided for R-123, R-123a, R-124, and R-134a. The information presented is preliminary and estimated.

Vapor Pressure, preliminary information bulletin, Buffalo Research Laboratory, AlliedSignal Incorporated, Buffalo, NY, 1 May 1990 (1 page with 1 table, available from JMC as RDB0511)

An equation is provided to calculate the vapor pressure of refrigerants in psia as a function of temperature in ${ }^{\circ} \mathrm{R}$. Coefficients are provided for R-123, R-123a, R-124, R-125, R-134, R-134a, and R-143a. The information presented is preliminary and estimated.

\section{APPLICATION DATA}

\section{Heat Transfer}

K. I. Bell, G. F. Hewitt, and S. D. Morris, Nucleate Pool Boiling of Refrigeramt-Oll Mixturee, Experimental Heat Transfer, volume 1, number 1, 1987 (RDB2402) 
B. Bella, A. Cavallini, G. A. Longo, and L. Rossetto (Universita dl Padova, Italy), Pure Refrigerant Condeneation on a Singlo Integral Finned Tubs: Vapor Velocity Effects, Proceedings of the 1992 International Refrigeration Conference - Energy Efficiency and Now Refrigerants, edited by D. R. Tree and J. E. Braun, Purdue University, West Lafayette, IN, volume 1, pages 177.186, July 1992 (10 pages with 7 figures and 2 tables, RDB2719)

D. B. Bivens and A. Yokozekl (DuPont Chemicals), Heat Transfer of Retrigerant Mixtures, Proceed. ings of the 1992 International Refrigeration Conference - Energy Efficiency and Now Refrigerants, edited by D. R. Tree and J. E. Braun, Purdue University, West Lafayette, IN volume 1, pages 141. 148. July 1992 (8 pages with 5 figures and 1 table, RDB2715)

J. B. Chaddock and H. K. Varma (Duke Untversity), An Experimental Investigation of Dry-Out with R22 Evaporating in a Horizontal Tube, Transactions. American Society of Heating, Refrigerating, and Air-Conditioning Engineers (ASHRAE), Atlanta, GA, volume 85, part 2, 1979 (RDB3321)

S. Chongrungreong and $H$. J. Sauer, Jr. (University of Missouri at Rolla). Nucleate Boiling Performance of Refrigerants and Refrigerant Oll Mixtures, Journal of Heat Transfer, American Society of Mechanical Engineers (ASME), New York, NY, volume 102, number 4, pages 701.704, 1980 (RDB. 2401)

J. C. Conklin and E. A. Vineyard (Oak Ridge National Laboratory, ORNL), Flow Boiling Enhancement of R-22 and a Nonazeotropic Mixture Using Perforated Foils, paper BA-92-4-3 (Annual Meeting. Baltimore, MD, June 1992), Transactions, American Soclety of Heating, Refrigerating, and AirConditioning Engineers (ASHRAE), Atlanta, GA, volume 98, part 2, pages 402-410, 1992 (9 pages with 12 figures, RDB2611)

J. C. Conklin (Oak Ridge National Laboratory, ORNL) and E. Granryd (Royal Institute of Technology, Sweden), Thermal Performance Analysis for Heat Exchangers Having a Variable Overall Heat Transfor Coefficlent, paper 91-WA-NE-7 (ASME Winter Annual Meeting, Atlanta, GA), American Soclety of Mechanical Engineers (ASME), New York, NY, December 1991 (6 pages with 5 figures and 4 taties, RDB2341)

J. C. Conklin and E. A. Vineyard (Oak Ridge Natlonal Laboratory, ORNL), Tubeside Condensation of Nonazeotropic Refrigerant Mixtures for Two Enhanced Surfaces, Proceedings of the ASME/JSME Thermal Engineering Joint Conference, American Society of Mechanical Engineers (ASME), Now York, NY, USA, Japan Society of Mo- chanical Engineers (JSME), Tokyo, Japan, volume 3. pages 251-256, 1991 (6 pages with 9 figures, RDB2410)

J. C. Conklin and E. A. Vineyard (Oak Rldge National Laboratory, ORNL). Tubeside Evaporation of Nonazeotropic Rofrigeramt Mixtures from Two Enhanced Surfaces, paper 90-WA-HT-8 (ASME Winter Annual Meeting, Dallas, TX), American Society of Mechanical Engineers (ASME). New York, NY, November 1990 (7 pages with 9 figures, RDB2342)

S. J. Eckels and M. B. Pate (lowa State University of Science and Technology), In-Tube Evaporation and Condensation of Refrigerant-Lubricant Mixtures of HFC-134a and CFC-12, Transactions, American Society of Heating, Refrigerating, and AirConditloning Engineers (ASHRAE), Atlanta, GA, volume 97, part 2, 1991; republished in Alternative Refrigerants, technical data bulletin 7(3), ASHRAE, pages 1-9, October 1991 (9 pages with 15 figures and 2 tables, RDB2612)

S. J. Eckels and M. B. Pate (lowa State University of Science and Technology). Evaporation and Condensation of HFC-134a and CFC-12 in a Smooth Tube and a Micro-Fin Tube, Transactions, American Society of Heating. Refrigerating, and Alr-Conditioning Engineers (ASHRAE), Atlanta, GA, volume 97, part 2, 1991; republlshed in Alternative Refrigerants, technical data bulletin $7(3)$, ASHRAE, pages 10-20, October 1991 (11 pages with 14 flgures and 7 tables, RDB2613)

S. J. Eckels and M. B. Pate (lowa State Untversity of Science and Technology). An Experimental Comparison of Condensation Heat Transfer $\mathrm{Co}$ efficients for HFC-134a and CFC-12, International Journal of Refrigeration, Paris, France, volume 13, number 11. November 1990; republished in Pro. ceedings of the 1990 USNC/IIR -Purdue Refrigeration Conference and ASHRAE-Purdue CFC Conference, edited by D. R. Tree, Purdue University, West Lafayette, IN, July 1990 (RDB2238)

S. J. Eckels and M. B. Pate (lowa State University of Science and Technology). A Comparison of R$134 a$ and R-12 In-Tube Heat Transfer Coefficlents Based on Exlsting Correlations, CFC Atternatives, technical data bulletin 6(1). American Society of Heating, Refrigerating, and Alr-Conditioning Engineers (ASHRAE), Atlanta, GA, pages 25-34, June 1990; republished in Transactions, American Society of Heating, Refrigerating, and Air-Conditioning Engineers, Atlanta, GA, volume 96, part 1, 1990 (10 pages with 16 figures and 2 tables, RDB2239) 
D. Gorenflo, P. Blein, G. Herres, W. Rott, H. Schomann, and P. Sokol (Untversităt Padertorn, Germany). Heat Transfer at Pool Bolling of Mixtures with R22 and R114, International Journal of Refrigeration, Paris, France, volume 11, number 7 , pages 257-263, July 1988 (7 pages with 9 figures and 2 tables, RDB3449)

E. Granryd (Royal Institute of Technology. Sweden). Heat Transfer in Flow Evaporation of Nonazeotropic Refrigerant Mixtures - a Theoretical Approsech, paper 251, proceedings of the XVIIIth International Congress of Refrigeration (Montreal, Québec, Canada, August 1991), International Institute of Refrigeration, Paris, France, August 1991 (12 pages with 6 figures, RDB2409)

E. Granryd (Royal Institute of Technology, Sweden) and J. C. Conklin (Oak Ridge National Laboratory, ORNL), Thermal Performance Analysls for Heat Exchangers Using Nonazeotroplc Refrigeramt Mixtures, Heat Transfer in Advanced Energy Systems. American Society of Mechanical Engineers (ASME), New York, NY, Heat Transfer Dlvision volume 151 and Advanced Energy Systems Division volume 18, pages 25-32, November 1990 (8 pages with 10 figures, RDB2330)

N. S. Gupte (Carrier Corporation) and R. L. Webb (Pennsytvania State University), Convective Vaporization of Refrigerants in Tube Banks, paper BA-92-4-4 (Annual Meeting, Baltimore, MD, June 1992), Transactions, American Society of Heating, Refrigerating, and Alr-Conditioning Engineers (ASHRAE), Atlanta, GA, volume 98, part 2, pages 411-424, 1992 (14 pages with 27 figures and 2 tables, RDB2607)

S. Ha (Goldstar Company Limited, Korea) and A. E. Bergles (Rensselaer Polytechnic Institute), The Influence of Oil on Local Evaporation Heat Transfer Inside a Micro-Fin Tube, paper CH-93-14-5 (Winter Meeting. Chicago, IL. January 1993), Transactions, American Society of Heating, Refrigerating, and Air-Conditioning Engineers (ASHRAE), Atlanta, GA, volume 99, pan 1, 1993 in publication (12 pages with 17 figures and 1 table, ROB3113)

D. L. Hinton (Tennessee State University), J. C. Conklin, and E. A. Vineyard (Oak Ridge National Laboratory, ORNL), Evaporation of an R143a and R124 NARM Inside Smooth and Corrugated Tubes, paper 92-WA/HT-5, American Society of Mechanical Engineers (ASME), New York, NY, November 1992 (6 pages with 8 figures, RDB3339)

D. L. Hinton (Tennessee State University), J. C. Conklin, and E. A. Vineyard (Oak Ridge National Laboratory, ORNL), Evaporation Charncteristlcs of R-22 Flowing Inside a Corrugated Tube, Enhanced Heat Transfer (proceedings of the 28th Na- tlonal Heat transfer Conference, San Dlego, CA), edited by M. B. Pate and M. K. Jensen, American Society of Mechanical Engineers (ASME), New York, NY, Heat Transfer Division volume 202, pages 127-132, August 1992 (6 pages with 12 figures, available from JMC as RDB2902)

This paper compares the boiling performance of R-22 for two tubes, one smooth and one with corrugated (also called spirally indented) heat transfer enhancement. The imvestigation serves as the reference case for future work on zeotropic mixtures. The experimental apparatus and instrumentation are described; the former comprises a variatí-speed compressor, variable-ortice flow-metering device, and two sets of counterflow, concentric-tube heat exchangers with different tube-side surfaces. The measurements reflect use of an alkybenzene lubricant, with an estimated circulation concentra. tlon of the order of $1 \%$. Two temperature levels were investigated, corresponding to those for the heating and cooling modes of air-source heat pumps at standard rating conditions. The measured heat transfer coefficient (HTC) for evaporation is compared to predictions, based on corretations from prior studies. HTC is then plotted versus heat flux and quality; both HTC and pressure drop are plotted against mass flux. The paper concludes that the corrugated tube geometry does entrance heat transfer over a wide range of mass and heat fluxes, with the most significant increase occurring at low qualltles. The paper discusses suppression of nucleate boiling in the corrugated tube at lower mass fluxes; it suggests that evaporator designs be split to use corrugated lubes where the heat transfer is highest, at low qualitles, and some other qeometry for the intermediate and high quality, egions.

D. W. Hughes, J. T. McMullan, K. A. Mawhinney, and $R$. Morgan, Influence of Oil on Evaporator Heat Transfer (Results for R-12 and Shell Clavus 68), International Journal of Refrigeration, Paris France, volume 7 , number 3 , pages $150-158$, May 1984 (10 pages, RDB0923)

Experiments to investigate the influence of lubricating oll on heat transfer and refrigerant flow in evaporators are described. R-12 and Shell Clavus 68 oil were used. Efforts were made to model actual operation as closely as possible. The oil was found to have a significant effect on refrigerant flow and pressure drop. Measurements made on the heat transfer coefficient indicated that the oll had different effects depending on the fluid flow regime. No effect was apparent for annular-wavy regimes, but the presence of oil significantly reduced the heat transfer coefficlent for annular-film flows. 
D. L. Jackman and M. K. Jensen, Nucleate Pool Boiling of Retrigerant-Oil Mixtures, paper 82 . WA/HT-45, American Society of Mechanical Englneers (ASME), New York, NY, 1982 (RDB2403)

D. Jung and R. Radermacher (University of Maryland), Prediction of Heat Transfer Coefficienis oi Various Retrigerants During Evaporation, paper 3492. Transactions, American Soclety of Heating, Refrigerating, and Air-Conditloning Engineers (ASHRAE), Atlanta, GA, volume 97, part 2, pages 48-53, 1991 (6 pages with 7 figures and 3 tables, RDB2347)

D. Jung (University of Maryland), M. O. McLinden (National Institute of Standards and Technology, NIST), R. Radermacher (University of Maryland), and D. A. Didion (NIST), A Study of Flow-Boiling Heat Transfer with Refrigerant Mixtures, International Journal of Heat and Mass Transfer, volume 32. number 9, pages 1751.1764, September 1989 (RDB2348)

D. Jung (University of Maryland), M. O. McLinden (National Instltute of Standards and Tochnology, NIST), R. Radermacher (University of Maryland), and D. A. Didion (NIST), Horizontal Flow Boilling Heat Transfer Experiments with a Mixture of R22/P-114, International Journal of Heat and Mars Transfer, volume 32, pages 131-145, 1989 (RDB2903)

D. Jung (National Institute of Standards and Technology, NIST), Horizontal-Flow Boiling Heat Transfer Using Refrigerant Mixtures, report ER6364. Electric Power Research Institute (EPRI), Palo Alto, CA, May 1989 (236 pages wirn 62 figures, 14 tables, and two appendices, RDB2BOC)

This report documents a study of horizontal, conve.tive, boiling heat transfer, including experiments to ineasure two-phase heat transfer cuefficients of refrigerant mixtures. The report reviews the properties of mixtures, including those unique to azeotropes, and associated heat transfer. It then describes experin: apparatus designed to simulate evaporator conditions in heat: pump and refrigeration systems. Measursenerint approaches are presented both for heat traissfer and composition determination. Measured data are summarized for zeotropic mixtures of R-12 and R-114, both an azeotropic and zeotropic mixtures R-12 and R152a, and their pure components for ranges of heat flux and mass flow rates. Differences in bubble growth are discussed between pure and mixed fluids. The results indicate two distinct regions of heat transfer, namely partial boiling and convective evaporation, the former governed by suppression of nucleate boiling. The report re' 'ews analytical studies to predict the transition quality. Measured, local heat transfer coefficients were as much as $36 \%$ lower than the weighted average of the components for mixtures in the convective region. The study attributes this reduction to observed differences in composition in the annular liquid film for mixtures with large difference in component volatilities, such as R-22/114. An approach is proposed to account for mixture effects based on phase-equilibrium information.

M. A. Kadzierskl and M. P. Kaul, Horizontal Nucleate Flow Boilling Heat Transfer Coefficient Measurements and Visual Observations for R12, R134a, and R134a/Ester Lubricant Mixtures, report NISTIR 5144, National Institute of Standards and Technology, Gaithersburg, MD, March 1993 (36 pages with 10 figures and 1 table, available from NTIS, RDB3418)

This report presents a calorimetric and visual investigation of nucleate flow boiling of R-12 and R-134a inside horizontal tubes. Mixtures of R134a with $0.9 \%$ polyol ester lubricant (Castrol Icematic(R) SW100) and 0.9 and $2.3 \%$ neopentyl polyol ester (ICl Emkarate(TM) 213b, a developmental lubricant) also were investigated. The report documents both calorimetric measurements of the local two-phase heat transfer coefficients and simultaneous visual measurements, using high-speed photography. Derived bubble diameters and densities are presented. The test apparatus, instrumentation procedures, and calorimetric and visual results are described. Plots are provided of the heat transfer coefficient measurements for a range of heat fluxes for Reynolds numbers of zero to approaching 10,000 . Good agreement was achieved with the Borishanskil-Minchenko equation. For both R. 12 and R-134a, an increase in either the heat flux or Reynolds number of the flow increases the heat transfer coefficient, though the former has a larger effect. Visual observations of the bubble density and size are used tc explain the heat transfer trends. Faster bubble formation by R-134a correlated with superior heat transfer. The authors offer a probable explanation for observed heat transfer enhancement of neopentyle polyol ester mixture over pure R-134a. They attribute it to canceling effects of drastic reduction in bubble diameters and significant increase in site density. Boilling appeared to occur from lubricant-rich clouds, acting like porous surfaces, on the heater portion of the tube.

M. A. Kedzlerskl, Simultaneous Visual and Calorimetric Measurements of R-11, R-123, and R-123/Alkylbenzene Nucleate Flow Bolling, report NISTIR 4948, National Institute of Standards and Technology, Gaithersburg, MD, October 1992 (60 pages with 50 figures and 2 tables, available from NTIS at price code A04, RDB2B07) 
J. Ogata, Y. Iwatujl, Y. Shimada (Mitsubishi Heavy Industries, Limited), and T. Yamazakl (Tokyo Electric Power Company), Bolling Heat Transfer Enhancement in Tube-Bundle Evaporators Utillzing Electric Field Effects, paper BA-92-5-2 (Annual Meeting, Baltimore, MD, June 1992), Transactions, American Society of Heating, Refirigerating, and AlrConditioning Engineers (ASHRAE), Atlanta, GA, volume 98, part 2, pages 435-444, 1992 (10 pages with 10 figures and 3 tables, RDB2609)

M. M. Ohadi, R. A. Papar, T. L Ng, M. A. Faani, and $R$. Radermacher (University of Manyland), EHD Enhancement of Shell-Side Bolling Heat Transfer Coefficients of R-123/Oil Mixture, paper BA-92-51 (Annual Meeting, Baltimore, MD, June 1992), Transactions, American Society of Heating, Refrigerating, and Air-Conditioning Engineers (ASHRAE), Atlanta, GA, volume 98 , part 2, pages 427-434, 1992 (8 pages with 10 figures and 1 table, RDB2608)

C. Pais and R. L. Webb (Pennsylvania State University). Literature Survey of Pool Bolling on Enhanced Surfaces, technical paper 3444, Transactions, American Society of Heating, Refrigerating. and Air-Conditioning Engineers (ASHRAE), Atlanta, GA, volume 97, part 1, 1991 (RDB2405)

M. B. Pate, Evaporation and Condensation Heat Transfer Coefficients for HCFC-124/HCFC22/HFC-152a, Proceedings of the 1990 USNC/IIRPurdue Refrigeration Conference and ASHRAEPurdue CFC Conference, edited by D. R. Tree, Purdue University, West Lafayette, iN, July 1990 (RDB2240)

R. A. Papar, M. M. Ohadi, A. Kumar, and A. I. Ansari (University of Maryland), Effect of Electrode $\mathrm{Go}$ ometry on EHD-Enhanced Boiling of R-123/Oil Mixture, paper $\mathrm{CH}-93-14-4$ Winter Meeting, Chicago, IL, January 1993), Transactions, American Society of Heating, Refrigerating, and Air-Conditioning Engineers (ASHRAE), Atlanta, GA, volume 99, part 1,1993 in publication (11 pages with 5 figures, RDB3112)

P. Rohlin (The Royal Instlute of Technology, Sweden), Coefficients of Performance and Local Heat Transfer Coofficients for Flow Boiling Inside Horizontal Tubes with Nonazeotropic Refrigerant Mixtures in a Small Exhaust Alr Heat Pump, Proceedings of the 1992 International Refrigeration Conference - Energy Efficiency and New Refrigerants, edited by D. R. Tree and J. E. Braun, Purdue University, West Lafayette, IN, volume 1, pages 157-166, July 1992 (10 pages with 8 figures and 1 table, RDB2717)

Test results are presented for three refrigerant blends in an exhaust-air heat pump, with a heating capacity of 1050-1450 W (3600-4950
$B t u / h)$. Such heat pumps are used, widely in Sweden, to recover heat from exhaust air to heat service hot water, particularly for large multifamily residential buildings. Heatinc coefficlents of performance (COPs), capacities, and local heat transfer coefficients in the evaporator are compared to those for R-12. Data for R22/R-152a/R-124 (36/24/40) and two blends of R-22/R-142b (45/55 and 60/40) are plotted and discussed. The experiments indicate that use of these zeotropic mixtures can increase both the COP and capacity despite a large reduction in the local heat transfer coefficient. The reduction is large with the binary mixtures and is compounded by suppression in nucleate boiling. also observed by other referenced investigations. Both the experimental apparatus and analytical methods used are described.

S. M. Sami, J. Schnotale (University of Moncton, New Brunswick, Canada), and J. G. Smale (DuPont Canada, Incorporated). Prediction of the Heat Transfer Characteristics of R-22/R-152a/R-114 and R-22/R-152a/R-124, paper 3602 (Annual Meeting, Baltimore, MD, June 1992), Transactions, American Society of Heating, Refrigerating, and AirConditloning Engineers (ÁSHRAE), Atlanta, GA, volume 98, part 2, pages 51-58, 1992 (8 pages with 10 figures and 1 table, RDB2601)

L. M. Schlager, M. B. Pate, and A. E. Bergles, Oil Quantity Measurements in Smooth and MicroFin Tubes During Evaporation and Condensation of Refrigerant-Oll Mixtures (RP-469), Transactions, American Society of Heating, Refrigerating, and Air-Conditioning Engineers (ASHRAE), Atlanta, GA, volume 97, part 1, 1990 (RDB2241)

L. M. Schlager, M. B. Pate, and A. E. Bergles, Porformance Predictions of Refrigerant-Oil Mixiures in Smooth and Internally Finned Tubes, 2 papers, Transactions, American Society of Heating, Refrigerating, and Air-Conditloning Engineers (ASHRAE), Atlanta, GA, volume 96, part 1, 1990 (RDB2242)

L. M. Schlager, M. B. Pate, and A. E. Bergles, Performance of Micro-Fin Tubes with Refrlgerant 22 [R-22] and Oil Mixtures, ASHRAE Journal, American Society of Heating, Refrigerating, and Air-Conditioning Engineers (ASHRAE), Atlanta, GA, pages 17-28, November 1989 (RDB2243)

L. M. Schlager, M. B. Pate, and A. E. Bergles, Heat Transfer and Pressure Drop During Evaporation and Condensation of R-22 in Horizomtal MicroFin Tubes, International Journal of Refrigeration, Paris France, volume 12, number 1, pages 6-14, January 1989 (9 pages, RDB2244) 
L. M. Schlager, M. B. Pate, and A. E. Bergles, Heat Transfer and Pressure Drop Performance of Smooth and Internally Finned Tubes with Oll and Retrigerant 22 [R-22] Mixtures, Transactions, American Society of Heating, Refrigerating, and AlrConditioning Engineers (ASHRAE), Atlanta, GA, volume 95, part 2, 1989 (RDB2245)

L. M. Schlager, M. B. Pate, and A. E. Bergles, Evaporation and Condensation of RefrigerantOil Mixtures in a Low-Fin Tube, Transactions, American Society of Heating, Refrigerating, and AirCondhitioning Engineers (ASHRAE), Atlanta, GA, volume 94, part 2, pages 1176-1194, 1989 (RDB2343)

B. K. Sthapak, H. K. Varma, and C. P. Gupta, Heat Transfer Coefficients in the Dry-Out Region of a Horizontal-Tube, Water-Heated, R-12 Evaporator, Transactions, American Society of Heating, Refrigerating, and Air-Conditioning Engineers (ASHRAE), Atlanta, GA, volume 82, part 2, 1976 (RDB3320)

M. W. Spatz and J. Zheng (AlliedSignal Incorporated), An Experimental Evaluation of the Heat Transfer Coefficients of R-134a Relative to R-12, Proceedings of the 1990 USNC/IIR-Purdue Refrigeration Conference and ASHRAE-Purdus CFC Conference, edited by D. R. Tree, Purdue University, West Lafayette, IN, pages 225-233, July 1990 (9 pages with 8 figures, RDB0501)

K. E. Starner, Summary of Pool Boilling Test Results for R-134a, R-22, and R-12 with Oils, York International Corporation, York, PA, 22 July 1992 (1 page, available from JMC as RDB2808)

This document summarizes tests to compare heat transfer characteristics of R-12, R-22, and R-134a, with and without lubricants, for Wolverine Turbo- $B(R)$ enhanced-surface tubes. Turbo$B(R)$ tube is enhanced on both the inside and outside surfaces to increase the overall heat transfer coefficient; its primary use is as a boiling tube for evaporators in chillers. Quantitative results are presented for a heat flux of 17.3 $\mathrm{kW} / \mathrm{m}^{2}(5500 \mathrm{Btu} / \mathrm{htt} 2)$ for nominal $19 \mathrm{~mm}$ $\left(3 / 4^{\prime \prime}\right)$ outside-dlameter tubes in a $60 \mathrm{~cm}\left(2^{\prime}\right), 8$ tube bundle at $4.4^{\circ} \mathrm{C}\left(40^{\circ} \mathrm{F}\right)$. Differences are presented between the wall temperature and the refrigerant saturation temperature at the measured pressure. Results are compared between refrigerant-lubricant mixtures, with $1.5 \%$ mineral oil by volume, and those for pure refrigerants. Additional data are provlded for R-134a with miscible lubricants, including an unidentifled polyalkylene glycol (PAG) and ester. For pure refrigerants, the measured temperature difference is $0.14^{\circ} \mathrm{C}\left(0.25^{\circ} \mathrm{F}\right)$ lower for R-22 and 0.06 ${ }^{\circ} \mathrm{C}\left(0.1^{\circ} \mathrm{F}\right)$ higher for R-12 compared to that for $\mathrm{R}-134 \mathrm{a}$. The document reports penalties, com- pared to pure refrigerants, of $0.53,0.31,2.78$, 0.19 , and $0.33{ }^{\circ} \mathrm{C}(0.95,0.55,5.00,0.35$, and $0.60^{\circ} \mathrm{F}$ ) for mixtures with $1.5 \%$ lubricant for $R-12$ with mineral oll, R-22 with mineral oll, R-134a with mineral oil (nonmiscible), R-134a with PAG, and R-134a with ester, respectively. Additional penalties of 0.17 and $0.39^{\circ} \mathrm{C}\left(0.30\right.$ and $\left.0.70{ }^{\circ} \mathrm{F}\right)$ are reported for mixtures of 0.08 and $0.15 \%$ mineral oil with $1.5 \%$ ester-based lubricant above that for the refrigerant-ester mixture alone.

K. Stephan and M. Körner (Technical University of Berlin, Germany). Calculation of Heat Transfer for Vaporizing Binary Mixtures, summary translation by AlliedSignal Incorporated from German text published in Chem. Ing. Tech., volume 41, number 7. pages 409-417, 1968; includes notes on the document prepared by R. R. Singh, AlliedSignal Incorporated, 22 October 1990 (8 pages with 5 figures, available from JMC as RDB0905)

K. Stephan (Technical University of Berlin, Germany), Influence of Oil on Heat Transfer of Boiling Refrigerant 12 and Refrigerant 22, Proceedings of the XIth International Congress of Refrigeration, International Instituie of Refrigeration IIR), Paris, France, 1963 (RDB3420)

H. Takamatsu, S. Momokl, and T. Fujil, A Comparison of Evaporation Heat Transfer Coefficients and Pressure Drop in a Smooth tube for HFC-134a and CFC-12, Proceedings of the XVIIIth International Congress of Refrigeration (Montreal, Québec, Canada, August 1991), International Institute of Refrigeration, Paris, France, volume II, pages 444-448, August 1991 (5 pages, RDB3419)

K. Torikoshi, K. Kawabata, and T. Ebisu (Daikin Industries, Limited, Japan), Heat Transfer and Pressure Drop Characteristics of HFC-134a in a Horizontal Heat Transfer Tube, Proceedings of the 1992 International Refrigeration Conference Energy Efficiency and New Refrigerants, edited by D. R. Tree and J. E. Braun, Purdue University, West Lafayette, IN volume 1, pages 167-176, July 1992 (10 pages with 15 figures and 1 table, RDB2718)

R. L. Webb and W. F. McQuade (Pennsylvania State University), Pool Boilling of R-11 and R-123 Oil-Refrigerant Mixtures on Plain and Enhanced Tube Geometries, paper CH-93-14-3 Minter Meeting. Chicago, IL, January 1993), Transactions, American Society of Heating, Refrigerating, and AirConditioning Engineers (ASHRAE), Atlanta, GA, volume 99, part 1, 1993 in publlcation (12 pages with 18 figures and 4 tables, RDB3111)

R. L. Webb and C. Pais (Pennsylvania State University). Nucleate Pool Boiling Data for Five Refrigerants on Three Tube Geometries, technical pa- 
per 3443, Transactions, American Society of Heating, Refrigerating, and Air-Conditloning Engineers (ASHRAE), Attanta, GA, volume 97, part 1, 1991 (RDB2404)

J. G. Withers and E. P. Habdas (UOP Wolverine Tube Division), Heat Transfer Characteristics of Helical-Corrugated Tubes for Intube Boiling of Refrigerant R-12, AIChE Symposium Series 138, American Institute of Chemical Engineers (AIChE), New York, NY, volume 70, pages 98-106, 1974 (9 pages with 13 figures and 1 table, RDB2904)

This paper revlews experimental measurements of heat transfer in copper, helical-corrugated tubes for full vaporization of oil-free R-12. The experimental apparatus and procedure as well as the data reduction methods are described. A series of runs to determine the optimum tube configuration, leading to a geometrical characterizing parameter referred to as the severity, is outlined. The boiling capacity of the tube, logmean temperature difference (LMTD), pressure drop, and average inside heat transfer coefficient (HTC) are plotted as functions of the severity. Heat transfer and pressure-drop data are presented for selected corrugated tubes for convective boilling at -1 to $10^{\circ} \mathrm{C}$ ( 30 to $50{ }^{\circ} \mathrm{F}$ ). The study found that integral, internal helical ridging enabled doubling or tripling of the intube heat transfer compared to that for plain tubes. The internal configuration enabled an increase of up to $200 \%$ over the peak (burn-out) heat flux. The external configuration of the corrugated tubes also doubled the water-side HTC, with concentric tube arrangements, by increasing the turbulence of the water in the annulus.

A. Yabe, T. Taketanl (Mechanical Engineering Laboratory, Japan), H. Makl, K. Takahashl, and Y. Nakadal (University of Tokyo, Japan), Experimental Study of Electrohydrodynamically (EHD) Enhanced Evaporator for Nonazeotropic Mixtures, paper BA-92-5-4 (Annual Meeting, Baltimore, MD, June 1992). Transactions. American Society of Heating, Refrigerating, and Air-Conditioning Englneers (ASHRAE), Atlanta, GA, volume 98, part 2, pages 455-461, 1992 (6 pages with 10 figures, RDB2610)

S. Yoshida, T. Matsunaga, H-P. Hong, and M. Miyazaki (Kyushu Universty, Japan), An Experimental Investigation of Oil Infiuence on Heat Transfer to a Refrigeramt Inside Horkzomtal Evaporator Tubes, Transactions of the Japanese Society of Mechanical Engineers (JSME), series B, volume 55, number 513, pages 1410-1416, 1989 (in Japanese); republished in Heat Transfer - Japanese Research, Scripta Technica, Incorporated (Wiley Company), volume 20, number 2, pages 113-129, May 1991 (in English, 17 pages with 14 figures, RDB2905)
Condensing Refrigerants in Horizontal and Inclined Tubes, research project 1-RP, American Society of Heating, Refrigerating, and Air-Conditioning Engineers (ASHRAE), Atlanta, GA, April 1966 (ASHOOO1)

This research developed correlations for heat transfer in smooth tubes, both horizontal and inclined, for condensing of R-12. Annular, dispersed and annular-dispersed, and wave and wave-annular flow regimes were identified. The heat transfer equations developed are applicable to condensation within the annular-flow regime. The contractor for the project was Kansas State University, led by R. G. Nevins; it was sponsored by ASHRAE Technical Committee 1.3, Heat Transfer and Fluid Flow.

Experimental Determination of Heat Transfer in Water-Cooled Condensers and Direct Expansion Water Coolers Using Brazed Plate Heat Exchangers, proposed research project 752-TRP, American Society of Heating, Refrigerating, and AirConditioning Engineers (ASHRAE), Atlanta, GA, in planning (ASH0752)

This project will determine average heat transfer coefficients for R-22 and R-134a for counterflow plate heat exchangers. Two or more commerclally-available, brazed-plate heat exchangers will be tested. Heat transfer coefficients will be measured for the refrigerants for condensing at $41^{\circ} \mathrm{C}\left(105^{\circ} \mathrm{F}\right)$ and evaporating at $2{ }^{\circ} \mathrm{C}\left(35^{\circ} \mathrm{F}\right)$. Water-side coefficients also will be determined. The coefficients and associated pressure drops will be presented as functions of the mass flow rates, which will be varied over the full range of commercial applications. Superheating and subcooling effects also will be investigated. The overall goal is to provide basic information to permit potential users to evaluate counterflow, brazed-plate heat exchangers as refrlgerant evaporators and condensers. This project is sponsored by ASHRAE Technical Committeo 8.5, Liquid to Refrigerant Heat Exchangers. Proposals were due at ASHRAE Headquarters on 1 June 1992 and are being evaluated; further information is avallable from the ASHRAE Manager of Research $(+1-404 / 636-8500)$.

Experimental Determination of the Effect of Oil on Heat Transfer in Flooded Evaporators with Refrigerants HCFC-123, HFC-134a, and HCFC22, research project 751-RP. American Society of Heating, Refrigerating, and Air-Conditioning Englneers (ASHRAE), Atlanta, GA, 1993 - ongoing (ASH0751)

This project will determine average shell-side boiling coefficients for R-22, R-123, and R-134a with compatible lubricants for finned and enhanced tube surfaces, as used in flooded evaporators. The work will expand on that ad- 
dressed in ASHRAE 392-RP, by covering the influences of the lubricants. Heat flux, mass flux, and vapor quality will cover typical conditions for air conditioning and refrigeration for lubricant concentrations of $0-10 \%$ at evaporator temperatures of approximately $4^{\circ} \mathrm{C}\left(40^{\circ} \mathrm{F}\right)$. The contractor is the Northern IIIInois University; it is sponsored by ASHRAE Technical Committee 8.5. Liquid to Refrigerant Heat Exchangers.

Experimental Determination of Shell-Side Condenser Bundle Heat Transfer Design Factors for Refrigerants R-123 and R-134a, research project 676-RP, American Soclety of Heating, Refrigerating. and Air-Conditioning Engineers (ASHRAE), Atianta, GA, June 1991 - December 1993 (ASH0676)

This research will determine the heat transfer coefficients (HTC) for R-123 and R-134a in condensers for the refrigerant-side (outside) of tubes. Limited measurements also will be made for R-11 and R-12 for comparison. Four or more different geometries for tube bundles, with at least two finned and two enthanced tubes types, will be examined Correlations or charts will be developed for use in heat exchanger design. The contractor for the project is lowa State University of Science and Technology led by M. B. Pate; it is sponsored by ASHRAE Technical Committeo 8.5, Llquid-to-Refrigerant Heat Exchangers.

Heat Transfer and Fluid Flow in Spray Evaporators with Application to Reducing Relrigerant inventory, research project 668-RP. American Society of Heating, Refrigerating, and Alr-Conditioning Engineers (ASHRAE), Atlanta, GA, June 1991 - December 1993 (ASH0668)

This research addresses the heat transfer and fluid flow for R-22, R-123, and R-134a in fallingfilm (spray) evaporators with horizontal tubes. The work includes performance of a literature search, experimental measurement of heat transfer on both single tubes and tube bundles. Both plain and enhanced tube surfaces will addressed under varied temperature and flow to determine the optimum conditions. Correlations or charts will be developed for use in heat exchanger design. A goal is to enable design of equipment for comfort cooling using reduced inventories of refrigerants. An overall goal is to provide basic information to permit potential users to evaluate counterflow, brazed-plate heat exchangers as refrigerant evaporators and condensers. The contractor for the project is lowa State University of Science and Technology led by $M$. B. Pate; it is sponsored by ASHRAE Technical Committee 1.3, Heat Transfer and Fluid Flow.
Heat Transtor and Fluld Flow Study of Ammonia Spray Evaporators, research project 725-RP, American Society of Heating, Refingerating, and AlrConditioning Engineers (ASHRAE), Atlanta, GA Aprll 1992 - April 1994 (ASH0725)

This research addresses heat transfer and fluid flow for ammonia in falling-film (spray) evaporators with horizontal tubes. The work includes performance of a literature search, experimental measurement of heat transfer on both single tubes and tube bundles. Both plain and enhanced tube surfaces will addressed under varied temperature and flow to determine the optimum conditions. Correlations or charts will be developed for use in heat exchanger design. A goal is to enable design of equipment for comfort cooling using reduced inventories of ammonia. An overall goal is to provide basic in formation to permit potentlal users to evaluate counterflow, brazed-plate heat exchangers as refrigerant evaporators and condensers. The contractor for the project is the Texas Technological University, led by M-C. Chyu; th is sponsored by ASHRAE Technical Committee 1.3, Heat Transfer and Fluid Flow.

Heat Transfer and Pressure Drop During Condensation and Evaporation of R-134a/OII Mixtures in Smooth and Micro-Fin Tubes, research project 630-RP. American Society of Heating, $R_{\theta}$ frigerating, and Air-Conditioning Engineers (ASHRAE), Atlanta, GA, Aprl 1990 - November 1992 (ASH0630)

This project is investigating heat transfer and pressure drop for in-tube evaporation and condensation for R-134a. The effects of lubricants also will be examined. Existing correlations will be evaluated and modified. The contractor for the project is lowa State University of Science and Technology led by M. B. Pate; it is sponsored by ASHRAE Technical Committeo 1.3, Heat Transfer and Fluid Flow.

Heat Transfer and Pressure Drop in the Dry-Out Region of In-Tube Evaporation with RefrigerantLubricant Mixtures, proposed research project 800-TRP, American Soclety of Heating, Refrigerating, Air-Conditioning Engineers (ASHRAE), Atlanta, $\mathrm{GA}$, in planning (ASH0800)

This research will focus on heat transfer in the final stage of in-tube evaporation, where the annular liquid film thins and dries out. The work will formulate a generallzed heat transfer coefficlent in this dry-out region, where significant area is required to achieve desired levels of superheating. Unusual behavior or refrlgerant-lubricant mixtures also may occur in this region. Heat transfer and pressure drop will be measured in both smooth and enhanced tubes with R-22 and R-134a, or an appropriate alternative, 
as a function of lubricant content. Mlxtures containing $0,1,2,3$, and $5 \%$ lubrlcant will be tested, for conditions determined through a literature search and examination of the energy transfer process in qualities exceeding $90 \%$. This project is sponsored by ASHRAE Technical Committeo 1.3. Heat Transfer and Fluid Flow. Proposals are due at ASHRAE Headquarters on 28 May 1993; further Information is avallable from the ASHRAE Manager of Research (+1404/636-8500)

Heat Transfer Rates from a Submerged Rotating Cylindrical Heater to an Evaporating Fluid, research project 14-RP. American Society of Heating. Refrigerating, and Air-Conditloning Engineers (ASHRAE), Atlanta, GA, July 1962 - July 1963 (ASH0014)

The contractor for the project was the University of Kentucky, led by M. Baker; it was sponsored by ASHRAE Technical Committee 1.3, Heat Transfer and Fluid Flow.

Performance of Turbo-B(R) Enhanced Boiling Tubes in CFC-11 and HCFC-123, E. I. DuPont de Nemours and Company, Incorporated, Wilmington, DE, and Wolverine Tube, Incorporated, Decatur, AL, 17 December 1990 (9 pages with 2 figures and 2 tables, available from JMC as RDBOCO2)

This document compares the performance of a commercially-avallable, enhanced heat transfer tube with R-11 and R-123. By varying the temperature of water flowing through a tube positioned in a refrigerant bath, the overall heat transfer coefficient and heat flux capability of the copper tube were determined. Tabular data and overall heat transfer coefficient and heat flux plots are presented. The heat transfer coefficient for R-123 was 3-6\% lower than that for R11.

Performance of Turbo- $B(R)$ Enhanced Boiling Tubes in CFC-12 and HFC-134a, E. I. DuPont de Nemours and Company, Incorporated, Wilmington, $D E$, and Wolverine Tube, Incorporated, Decatur, AL, 17 December 1990 (6 pages with 2 figures and 2 tables, available from JMC as RDBOCO3)

This document compares the performance of a commerclally-avallable, enhanced heat transfer tube with R-12 and R-134a. By varying the temperature of water flowing through a tube positioned in a refrigerant bath, the overall heat transfer coefficient and heat flux capability of the copper tube were determined. Tabular data and overall heat transfer coefficient and heat flux plots are presented. The heat transfer coefficient for R-134a was 4-30\% higher than that for R-12.
Oll Quantity Measurements in Smooth and ML cro-Fin Tubes During Evaporation and Condensation in Refrigerant-Oil Mixturts, research project 469-RP, American Society of Heating, Refrigerating, and Air-Conditloning Engineers (ASHRAE), Atlanta, GA (ASH0469)

The contractor was lowa State University of Science and Technology led by M. B. Pate.

Heat Transfer and Fluid Flow in a Finned-Tube Flooded Evaporator, research project 392-RP, American Soclety of Heating, Refrigerating, and AlrConditioning Engineers (ASHRAE), Atlanta, GA, phase III: September 1989 - October 1992 (ASH0392)

The objective of this project is to develop data to improve designs of flooded evaporators. Heat transfer coefficients are being measured for different finned-tube geometries. The first two phases entalled a literature search and addressed modelling and simulation, respectively. Phase III is collecting and analyzing data on pool and forced-convection bolling. The contractor is Pennsytvania State University, led by R. L. Webb and C. Pais; it is sponsored by ASHRAE Technical Committee 8.5, Liquid to Refrigerant Heat Exchangers. [see RDB2404 and RDB2405 for findings]

\section{Plpe Slzing and Flow}

T. Atwood (AlliedSignal Incorporated), Pipe Sizing and Pressure Drop Calculations for HFC-134a, ASHRAE Journal, American Soclety of Heating, Refrigerating, and Air-Conditioning Engineers (ASHRAE), Atlanta, GA, pages 62-66, April 1990 (5 pages, RDB0513)

N. E. Hopkins, Rating the Restrictor Tube, Refrigerating Engineering, American Society of Refrigerating Engineers (ÁSRE, now merged into the American Society of Heating, Refrigerating, and AlrConditioning Engineers, ASHRAE), Atlanta, GA, pages $1087 \mathrm{ff}$, November 1950 (RDB3417)

S. J. Kuehl (Whirlpool Corporation) and V. W. Goldschmidt (Purdue University), Flow of R-22 Through Short-Tube Restrictors, paper 3603 , Transactions, American Society of Heating, Refrigerating, and Air-Conditioning Engineers (ASHRAE), Atlanta, $G A$, volume 98 , part 2, pages 59-64, June 1992 (RDB3215)

S. J. Kuehl and V. W. Goldschmidt (Purdue University), Modeling of Steady Flows of R-22 Through Capillary Tubes, Transactions, American Society of Heating, Refrigerating, and Air-Conditioning En- 
gineers (ASHRAE), Atlanta, GA, volume 97, part 1, pages 139-148, January 1991 (RDB3414)

H. A. Whitesel, Caplliary Two-Phase Flow, Part I, Refrigerating Englneering. American Soclety of Refrigerating Engineers (ASRE, now merged into the American Society of Heating, Refrigerating, and Air-Conditioning Engineers, ASHRAE), Atlanta, GA, pages 42 fi, April 1957 (ROB3415)

H. A. Whitesel, Capillary Two-Phase Flow, Part II, Refrigerating Engineering. American Society of Refrigerating Engineers (ASRE, now merged into the American Soclety of Heating. Refrigerating, and Air-Condtioning Engineers, ASHRAE), Atlanta, GA, pages 35 ff, September 1957 (RDB3416)

H. Wilaya (AlledSignal Incorporated), Adlabatic Capillary Tube Test Data for HFC-134a, Proceedings of the 1992 International Refrigeration Conference - Energy Efficiency and Now Refrigerants, edted by D. R. Tree and J. E. Braun, Purdue University, West Lafayette, IN, volume 1, pages 6371 . July 1992 (9 pages with 9 figures and 3 tables, RDB2714)

Capillary Tube Performance with Alternative Refrigerants, proposed research project 762-TRP, American Society of Heating, Refrigerating, and AlrConditioning Engineers (ASHRAE), Atlanta, GA, in planning (ASH0762)

This project will develop a methodology to allow users to predict refrigerant mass flow rate through a straight, adiabatic capillary tube, based on tube geometry, refrigerant properties, and operating conditions. The goal is a method applicable to any refrigerant, single component or thand, to replace existing charts, developed primarily for R-12 and R-22. The work will include both a theoretical analysis and laboratory effort to validate the rating method developed. It is sponsored by ASHRAE Technical Committee 8.8, Refrigerant System Controls and Accessories. Proposals are due at ASHRAE Headquarters by 28 May 1993; further Information is available from the ASHRAE Manager of $R_{\theta}$ search $(+1-404 / 636-8500)$.

Charge Invemery Calculations for Evaporating and Condenaing Refrlgerants Inside Tubes, proposed research project 758-TRP, American Society of Heating, Refirgerating, and Air-Conditioning Engineers (ASHRAE), Atlanta, GA (ASH0758)

This research project is sponsored by ASHRAE Technical Committeo 8.4, Air-to-Refrigerant Heat Transfer Equipment.

Fundamental Study of Refrigeramt Line Transients, research project 736-RP. American Society of Heating, Refrigerating, and Air-Condtioning Engineers (ASHRAE), Atlanta, GA, 1993 - ongoing (ASH0736)

This research project will identify causes and consequences of pressure transients, induced by condensation during hot-gas defrost, in $r \theta$ frigerant piping. The undertying goal is to develop means to prevent their occurrence, either by appropriate design or operation. The problem induces hydraullc shock and vapor-propelled liquid slugging. The work will involve a literature search, documentation of critical flow regimes, and analysis of both condensation-induced hydraulic shock and vapor-propelled liquid slugs. The contractor is the University of IIInols; it is sponsored by ASHRAE Technical Committeo 10.3, Refrigerant Piping.

Measurement of Two-Phase Rotrigerant LiquidVapor Mass Flow Rate, research project 722-RP, American Soclety of Heating, Refrigerating, and AirCondtioning Engineers (ASHRAE), Atlanta, GA, April 1992 - April 1994 (ASH0722)

The contractor for the project is McMaster University, les by M. Shoukri; it is sponsored by Technical Committee 1.2, Instruments and Measurements.

Pressure Drop in Refrigerant Suction Lines at High Refrigeramt Flux with Oll in Circulation, proposed research project 731-TRP, American Society of Heating, Refrigerating, and Air-Conditioning Engineers (ASHRAE), Atlanta, GA (ASH0731)

This research project is sponsored by ASHRAE Technical Committee 10.3, Refrigerant Piping.

\section{Recycling, Reclamation, and Disposal}

J. P. Doyle (National Refrigerants, Incorporated, NRI), Refrigerant Management: Conserving a Valuable Resource, Hoating/Piping/Air Conditioning, Penton Publishing, Chicago, $I L$, volume 65 , number 3, pages 59-62, March 1993 (4 pages with 2 figures and 2 tables, RDB3413)

R. E. Kauffiman (University of Dayton Research Institute), Chemical Analysis and Recycling of Used Refrigerant from Field Systems, paper 3555 (RP-601) Winter Moeting, Anaheim, CA, January 1992), Transactions, American Society of Heating, Refrigerating, and Alr-Conditioning Engineers (ASHRAE), Atlanta, GA, volume 98, part 1, pages 128-136, 1992 (9 pages with 4 figures and 1 table, RDB2429)

This paper summartzes research to identify and quantify the typical contaminant levels in used 
refrigerants. A total of 39 samples were taken from both normally operating and falled air-conditioning and refirgerating systems. These samples included R-11 from centrifugal chillers, R-12 from commerclal refrigeration systerns, $R$ 22 from unitary heat pumps and air conditioners, and R-502 from low-temperature frozen food cases. Results are summarized for measurement of water content (Kart Fisher technique), acid content (ASTM 664 tests), lon content (ion-specific electrode), high-bolling content (gravimetric technique, gas chromatography, and mass spectrography), particulate content (direct-current plasma emission spectrometer and scanning electron microscope), and volatlle impurtty content (gas chromatography and mass spectrometry). The contaminamt levels found exceeded those of new refrigerants, but the types and concentrations varied by refrigerant, application, and whether a system burnout had occurred. Laboratory tests evaluated a recycling scheme based on oil separation followed by water and acid removal, by an alumina/molecular sleve filter/dryer. The preliminary study showed that this recycling procedure is effective in removing acids, but has insignificant effects on volatile impurities and high-boiling residue. The effects of noncondensable gases were not addressed.

Chemical Analysis and Recycling of Used Rofrigerant from Fleld Systems, research project 601-RP, American Society of Heating, Refrigerating, and Air-Conditioning Engineers (ASHRAE). Atlanta, GA, March 1989 - January 1991 (ASH0601)

This study identified and quantified typical contaminant levels in refrigerants from both normally operating and falled air-conditioning and refrigerating systems. These samples included R-11 from centrifugal chillers, $R-12$ from commercial refrigeration systems, $\mathrm{R}-22$ from unitary heat pumps and air conditioners, and R-502 from low-temperature frozen food cases. The principal investigator was R. E. Kaufman at the University of Dayton Research Insthute. The project was sponsored by ASHRAE Technical Committeo 3.3, Contaminant Control in Refrigerating Systems. [see RDB2429 for findings]

Containers for Recovered Fluorocarbon Retrigerants, ARI Guideline K-1990, Alr-Conditioning and Refrigeration Institute (ARI), Arlington, VA, 1990 (10 pages, avallable from ARI for $\$ 15.00$, RDB3102)

This document provides recommendations for voluntary use by those who supply, use, store, or transport containers for recovered fluorocarbon refrigerants. It is intended as a guide of good practice to facilitate recovery, recycling, and reclamation of refrigerants, to in turn reduce environmental impacts. The need for containers designed and identified specifically for these uses stems from practical and safety considerations. The guideline identifies mandatory federal requirements in the United States, but it is nelther an exhaustive listing nor does it address lo. cal requirements. It covers cylinders and ton tanks for R-12, R-22, R-114, R-500, and R-502 as well as drumis for R-11 and R-113.

Performance of Refrigerant Recovery, Recycling, and/or Reclaim Equipmemt. ARI Standard 740-1991. Air-Conditioning and Refrigeration Institute (ARI), Arlington, VA, 1991 (12 pages, avallable from ARI for \$10.50, RDB3104)

This standard establishes uniform methods of testing for rating and evaluating performance of equipment for refrigerant recovery, recycling, and/or reclaim. It addresses contaminant or purity levels, capacity, speed, and purge loss, the last to minimize emission into the atmosphere of refrigerants. The standard is intended for guidance of the industry, including manufacturers, refrigerant reclaimers, repackagers, distributors, installers, servicemen, contractors, and consumers. The refrigerants covered include R-11, R-12, R-13, R-22, R-113, R-114, R$500, R-502$, and R-503. It does not apply to ze0tropic mixtures of these or other refrigerants. The standard covers general equipment requirements, specifies a standard sample for testing, and outlines test apparatus. It prescribes a performance testing procedure, sampling and chemical analysis methods, performance calculations and rating, tolerances, and product labeling. The rating sample characteristics include contents of moisture, particulates, acids, mineral oil, and noncondensable gases. Conformance with the standard is voluntary, but conformance may not be claimed unless all requirements of the standard are met.

Sealed-Tube Tests of Refrigerants from Field Systems Before and After Recycling, research project 683-RP. American Society of Heating, Refrigerating, and Alr-Conditioning Engineers (ASHRAE), Atlanta, GA, April 1991 - ongoing (ASH0683)

This project will quantify typical contaminant levels in refrigerants after oil separation, filtering, and drying. It also will determine the effects of contaminants at the concentrations found. The focus is on R-11 from centrifugal chillers, R-12 from commerclal refrigeration systems, R-22 from unitary heat pumps, and R-502 from lowtemperature commercial refrigeration systems. The work is an extension of ASHRAE research project RP-601 and is being performed by the same contractor, the University of Dayton Research Institute led by R. E. Kaufman. It is sponsored by ASHRAE Technical Committee 
3.3, Contaminant Control in Refrigerating Sys. tems.

State of Knowledge Summary of Chlorofluorocarbon Handling Technologles: Destruction, Recycling, and Encapsulation, draft report for U.S. Department of Energy. E. A. Mueller Consulting Engineers, Baltimore, MD, May 1989 (65 pages, RDB1107)

Reducing Emission of Fully Halogenated Chiorofluorocarbon (CFC) Refrigeramts in Refrigeretion and Air-Conditioning Equipment Applications. ASHRAE Guideline 3-1990 plus addendum ASHRAE Guldeline 3a-1992, American Society of Heating, Refrigerating, and Alr-Conditloning Englneers (ASHRAE), Atlanta, GA, 1990 and 1992 (30 pages with 5 tables, RDB2911)

This guideline covers all refrigeration and airconditioning equipment and systems that use fully halogenated CFC refrigerants. It recommends practices and procedures to reduce inadvertent release of CFC refrigerants during manufacture, installation, testing, operation maintenance, and disposal of refrigeration and air-conditioning equipment and systems. It also covers refrigerant recovery, recycling, reclaim, and disposal.

\section{Retrofit and Conversion}

Retroft Guldellnes for Suva(P) $134 a$ (Suva(A) Cold MP, document ART-16 (H-47761), DuPont Chemicals, Wilmington, DE, January 1993 (8 pages with 1 table, available from JMC as RDB3447)

\section{Appliances}

\section{Chillers}

A. M. Bell (SnyderGeneral Corporation), How to Convert CFC-12 Chillers to HFC-134a, Heating/ Piping/Air Conditioning, Penton Publishing, Chicago, IL volume 65, number 4, pages 39-42, April 1993 (4 pages wth 3 figures, RDB3457)

W. A. Phillips (York International Corporation), Refrigerant Retrofits: An Overview, Heating/Piping/ Air Conditioning, Penton Publishing, Chicago, IL, volume 65, number 4, pages 33-37, April 1993 (5 pages with 7 figures, RDB3456)

B. Seibert (The Trane Company), How to Convert CFC-11 Chillers to HCFC-123, Heating/ Piping/Air Conditioning, Penton Publishing, Chicago,
IL, volume 65, number 4, pages 45-50, April 1993 (6 pages with 5 figures, RDB3458)

Retrofitting CFC-12 Chillors with Suva(R) Cold MP, document ARTD-26 (H-31752), DuPont Chemicals, Wilmington, DE, undated circa 1992 (4 pages with 1 table, avallable from JMC as RDB3450)

Thls bulletin briefly reviews considerations for retrofit decisions for chillers, noting that altemathe refrigerants cannot be simply "dropped into" a system designed for chlorofluorocarbon (CFC) refrigerants. It notes that requirements may range from a minimum effort, such as lubricant replacement, to significant changes, such as replacing gears, impellers, or materials of construction. The document introduces a retrofit program, with four chiller manufacturers, to convert large chillers from CFCs to alternative refrigerants. A table compares the boiling point, flammability, toxicity, ozone depletion potential (ODP) and global warming potentlal (GWP) of $R-12$ and R-134a. The discussion notes differences between these fluids including separation of pressures as temperatures drop, a higher isentroplc head for R-134a, and immiscibility with conventional mineral oils. The document then revlews field experience with a $2462 \mathrm{~kW}$ (700 ton) York International TurboPak(R) centrifugal chiller converted to R-134a in 1989 and an unidentified 300 SUS polyalkyiene glycol (PAG) lubricant. Subsequent inspections and a second retrofitting of the dive gear are described, indicating satisfactory operation with a decrease in efficiency of up to $7 \%$ and an increase in capacity of up to $9 \%$. The document also discusses a second conversion, of a SnyderGeneral McQuay PEHO48 centrtfugal chiller. With a change in gear set, the unit showed a $4.1 \%$ improvement in efficlency and a $0.8 \%$ increase in capacity using R-134a and mineral oll. A test to simulate an o-ring failure in the compressor shaft seal is described, in which oil placed in the evaporator did not return to the compressor due to poor miscibility. A second PEH048 chiller using R-500 and mineral oll was converted to R-134a with a Mobll ester-based lubricant. The unit showed a $0.1 \%$ decrease in efficiency and $1.3 \%$ decrease in capacity. The o-ring fallure simulation was repeated with normal lubricant retum to the sump. The report concludes by identifying several general considerations including proper system operation, component compatibility, and safety and handling procedures.

Suva(A) 134a (Suva Cold MP, HFC-134a) in Chillers, document ART-3 (H-42444), DuPont Chemicals, Wilmington, DE. October 1992 (6 pages with 5 tables, available from JMC as RDB3443) 


\section{Commerclal Reírigeration}

S. Corr ( $\mathrm{ICl}$ Chemicals and Polymers, Limited), T. W. Dekleva, and A. L Savage (ICl Americas, Incor. porated), Retrofitting Large Refrigeration Systems with HFC-134a, ASHRAE Journal, American Society of Heating, Refrigerating, and Alr-Condltioning Engineers (ASHRAE), Atlanta, GA, pages 29-33, February 1992 (5 pages with 3 figures and 2 tables, RDB3303)

S. Corr, R. D. Gregson, G. Tompsett (ICl Chemicals and Polymers, Limited), A. L. Savage and J. A. Schukraft (ICl Americas, Incorporated), Retroffting Large Retrigeration Systems with R-134a, Proceedings of the 1992 International Refrigeration Conference - Energy Efficiency and New Refrigerants, edited by D. R. Tree and J. E. Braun, Purdue University, West Lafayette, IN, volume 1, pages 221-230, July 1992 (10 pages with 7 flgures and 1 tables, reprint available from JMC as RDB2724)

J. P. Davey and C. C. Mulliss (Rhône-Poulenc Chemicals Limited, UK), Field Experience in Retrofitting isceon 1340 and isceons 62-S and 69-L. CFC Alternatives: User Experience and Update. Institution of Mechanical Engineers and Institute of Refrigeration, London, UK, 11 November 1992 (13 pages with 1 figure and 7 tables, RDB3331)

Retroft Guidelines for Suva(A) HP80, document ART-9 (H-45947), DuPont Chemicals, Wilmington, DE, November 1992 (8 pages with 1 table, avallable from JMC as RDB3445)

Retroft Guidelines for Suva(R) HP81, document ART-15 (H-47763), DuPont Chemicals, Wilmington, $D E$, January 1993 (10 pages with 2 tables, available from JMC as RDB3446)

Retrofit Guidelines for Suva(R) MP39 and Suva(R) MP66, document ART-5 (H-42446), DuPont Chemicals, Wilmington, DE, August 1992 (10 pages with 4 tables, avallable from JMC as RDB3444)

\section{Heat Pumps for District Heating}

$T$. Widgren with preface by $L$ Petersson, Conversion to HFC-134a in a 25 MW Heat Pump, Hammarby, Sweden, report RT-IST-51/92, ABB STAL AB, Finspång. Sweden, September 1992 (28 pages with 13 figures and 2 tables, RDB2B10)

This report summarizes conversion of a large heat pump, for district heating, from R-500 to use of R-134a and the first subsequent year of operating experience. The report reviews both use of large heat pumps in Sweden and corre- sponding use of refrigerants. It then reviews specific considerations for this conversion, including a description of the heat pump and its two-stage, centrifugal compressor. The thermophysical properties of alternative refrigerants are outlined, with emphasis on projected performance with R-134a. Equipment modifications for the conversion are described, including a summary of compatibility considerations with the new refrigerant and polyalpha oleofin lubricant. The conversion, start up, and added refrigerant leak monitors are reviewed. Operational experience for 1991/1992 is discussed, including capacity, efficlency, avallablity, refrigerant and lubricant sampling, sealants, and leakage. The report concludes that the conversion was successful. The heat pump ran for 6,641 hours of operation and $148 \mathrm{GWh}$ (0.5 trillion Btu) of production at output temperatures sometimes exceeding $90^{\circ} \mathrm{C}\left(194^{\circ} \mathrm{F}\right)$. There were no unplanned outages. Peak capacity is 2-4\% lower with R-134a than with R-500, leading to an annual reduction in output of $1.4 \%$. Efficlency is essentially the same. This conversion is believed to be the largest single use of R-134a to date.]

\section{Mobille Air Conditioners}

S. Corr, E. Goodwin, R. D. Gregson, A. Halse, A. Lindley (ICl Chemicals and Polymers, Limited), S. H. Colmery, T. W. Dekleva, and R. Yost (ICl Americas, Incorporated), Ester Lubricants for Use with HFC-134a Retroff Applications, seminar presentation at the Society of Automotive Engineers (SAE) International Congress and Exposition (Detroit, MI), ICl Americas Incorporated, Now Castle, DE, USA, 25 February 1992 (22 pages with 23 charts, RDB2619)

This document provides the presentation charts and text for an update on retroft of moblle air air-conditioning (MAC) systems. The presentation reviews the basis for selection of R-134a including consideration of performance, avoidance of ozone depletion, and safety. The lubricant used is identffied as a fundamental issue in retrofitting MAC systems with R-134a. Properties of two candldate esters and sealed-tube test results, including both mineral cil and R-12 as contaminants, are reviewed. One finding is that the lubricants impact the materials examined more than the refrigerants. Volume change (swell) is plotted for R-12 with mineral oll, the same pair followed by R-134a with a polyol ester, and R-134a with the ester alone for nine elastomers. They include chlorosulfonated PE, EPDM, EPDM-O, EPDM-S, fluoropolymer, HNBR, natural rubber, neoprene, and nitrile. Compressor tests to examine the suitability of 
the fluids are summarized; the tests Included high contaminant levels to approximate those expected in retrofits. A rating system to gauge wear is outlined. Fleet trlals conducted in Australla are summarized, noting anecdotal suggestions that R-134a may provide Improved performance. While much more study is needed, the esters tested appear promising for use with R-134a in MAC system retroft.

S. Corr, E. Goodwin, R. D. Gregson, A. Halse, A. Lindley (ICl Chemicals and Polymers, Limited), S. H. Colmery, T. W. Dekleva, and R. Yost (ICl Americas, Incorporated), Retroftting Mobile AlrConditioning Systems with HFC-134a, seminar presentation at the Society of Automotive Englneers (SAE) Passenger Car Moeting and Exposition (Nashville, TN), ICl Americas Incorporated, New Castle, DE, USA, 18 September 1991 (22 pages with 27 charts, RDB2618)

This document provides the charts and text for a presentation on retrofth of mobile air air-condltloning (MAC) systems. The need for a service refrigerant, aftermarket logistics, and requirements of the Clean Air Act Amendments of 1990 are introduced. The reasons for selecting R$134 a$ as a retrofit refrigerant are discussed. Retrofit solutions may lle between simple replacement of the refrigerant and lubricant and the need to flush the system and also replace certain components. The rationale for esters as the lubricant is presented. Ten ester candidates are summarized and data are provided on vis. cosity, miscibility, and wear tests. Compatibility findings are presented for EPDM, HNBR, neoprene, nitrile, nylon, and fluoroelastomer (DuPont Viton(R)) with mineral oll, a polyalkylene glycol (PAG), an end-capped PAG, and an ester. Mutual compatibility and thermal stability data are discussed for the lubricants. A finding on chlorinated impurities (e.g., residual R-12 or flushing solvents) is reviewed, indicating that its nature is more important than its concentration. Sealed-tube test results are reviewed for R-12 and R-134a with mineral oil, PAG, and ester lubricants with contaminants. The data include changes in color, viscosity, acid number, and metal content as well as copper plating and metal impacts; no detrimental effects from residual R-12 and mineral oll were observed with R-134a and the esters. Hydrolytic stability tests point to greater stability with polyol esters than PAGs. The stability analyses and a compressor test program are outlined. [see RDB2913 for update]

S. Corr, R. D. Gregson, A. Halse, A. Lindley (ICl Chemicals and Polymers, Limited), and T. W. Dekleva (ICl Americas, Incorporated), Retrofitting Mobile Air-Conditioning Systems: The First Alter- native, Part I, seminar presentation at the Society of Automotlve Engineers (SAE) International Congress and Exposition (Detrolt, MI), ICl Americas Incorporated, New Castle, DE, USA, 26 February 1991 (14 pages with 17 charts, RDB2616)

S. Corr, R. D. Gregson, A. Halse, A. Lindley (ICI Chemicals and Polymers, Limited), and T. W. Dekleva (ICl Americas, Incorporated), Retrofitting Mobilo Air-Condtiloning Systems: The First Alternative, Part 2, seminar presentation at the Society of Automothe Engineers (SAE) International Congress and Exposition (Detrolt, MI), ICI Americas Incorporated, New Castle, DE, USA, 26 February 1991 (14 pages with 16 charts, RDB2617)

T. W. Dekleva, S. H. Colmery (ICl Americas, Incorporated), J. Bresnahan (ICl Australia Operations Pty Limited), S. Corr, and A. Lindley (ICl Chemicals and Polymers, Limited), Retrofitting Mobile AirCondhioning Systems with HFC-134a - An Update, Proceedings of the International CFC and Halon Alternatives Conference (Washington, DC), Alliance for Responsible CFC Pollcy, Arlington, VA, pages, 697-706, September 1992 (10 pages with 1 table, RDB2914)

This paper focuses on procedures and system performance for retroftt of mobile air alr-conditioning (MAC) systems with R-134a. The paper outlines the need for retrofit, pointing to the hundreds of millions of vehicles that use R-12 and anticipated shortfall to meet service needs after recycling and recovery. The paper briefly notes acthities underway to prepare guidelines for refrigerants, procedures, and fittings; qualify suitabis lubricants; and identify acceptable practices. $\mathrm{ICl}$ is pursuing ester lubricants, but the paper notes that others are investigating use of polyalkylene glycols (PAGs). The paper reviews a number of retroft procedures and the labor requirements for them. Two categories are contrasted, with and without flushing to remove mineral oll. The paper reviews the time and impacts of R-12 recovery, system flushing, removal and draining of the compressor, addition of lubricant, system reassembly, evacuation, and recharging with R-134a. Specific flushing agents including per- and trichloroethylene (PCE and TCE), are discussed. Fleet trlals to gauge the performance and compressor durability consequences of retrofit, with different procedures and compressor types, are reviewed; these tests are underway in Australia, the Untted States, and eisewhere. R-134a may require $10-20 \%$ extra condenser capacity at idle conditions or high ambient temperatures. No performance penalties have been associated with flushing or not flushing. The paper concludes that R-134a combined with ester lubricants appears to offer acceptable levels of per- 
formance and systems compatibllity, but more work is required.

\section{Safety}

Absorption of Ammonis into Water, research project 591-RP, American Society of Heating, Refrigerating, and Air-Conditioning Engineers (ASHRAE), Atlanta, GA, September 1988 - June 1990 (ASH0591)

The contractor for the project was Kansas State University at Manhattan, lod by D. L. Fenton and R. L Gorton; it was sponsored by ASHRAE Technical Committee 10.1, Custom Engineered Refrigeration Systems.

Number Designation and Safoty Classiffeation of Refrigerants, ANSI/ASHRAE Standard 34-1992. American Society of Heating, Refrigerating, and AlrConditioning Engineers (ASHRAE), Atlanta, GA, February 1992 (16 pages with 1 figure and 5 tables, RDB2909)

This voluntary, consensus standard describes a shorthand way of naming refrigerants and classifies them according to potential hazands. It is intended to establish a simple means of referring to common refrigerants, instead of using the chemical name, formula, or trade name. It also establishes a uniform system for assigning unambiguous reference numbers, compositiondesignating prefixes for refrigerants, and safety classifications based on toxicity and flammability. This standard is widely cited in construction codes and provides the classiflcations used in ASHRAE Standard 15-1992, Safety Code for Mechanical Refrigeration, to specify safety requirements for refrigerant use. This version supersedes ANSI/ASHRAE Standard 34-1989 and earlier editions.

Safety Code for Mechanical Refrigeration, ASH. RAE Standard 15-1992, American Society of Heating, Refrigerating, and Alr-Condtiloning Engineers (ASHRAE), Atlanta, GA, July 1992 (RDB2910)

This voluntary, consensus standard specifies reasonable safeguards of life, limb, health, and property; defines practices that are inconsistent with safety, and prescribes safety standards. It applies to mechanical refrigerating systems and heat pumps used in identified occupancies as well as to components replaced atter adoption. The purpose is to promote the safe design, construction, and operation of covered systems. This standard is widely cited and elther incorporated by reference or directly quoted in construction codes. It prescribes the maximum quantities of indwidual refrigerants that may be used for specific bullding occupancies as well as component, equipment, and Installation requirements. Minimum safety devices, marking, and tests also are specified. This verslon supersedes ANSI/ASHRAE Standard 15-1989, including its addendum (ANSI/ASHRAE Standard 15-1991) and earlier editions.

Safety of Suva(R) Refrigerante, document AS-1 (H-27350-2), DuPont Chemicals, Wilmington, DE, undated clrca 1992 (6 pages with 1 table, RDB3451)

\section{Flammabillity}

R. G. Richard and I. R. Shankland (AlledSignal Incorporated). Flammabllity of Alternative Refrigerants. ASHRAE Journal, American Society of Heating, Refrigerating, and Air-Conditioning Engineers (ASHRAE), Atlanta, GA, volume 34, number 4. pages 20 ard 22-24, April 1992 (RDB2525)

This article reports data for refrigerant flammability measurements using the ASTM E-681 test piocedure. Lower and upper flame limits (LFL and UFL) are tabulated for R-11, R-22, R-30 (methylene chloride), R-32, R-5C (methane), R113, R-123, R-123a, R-124, R-125, R-134, R134a, R-140a, R-141b, R-142b, R-143, R-143a, R-152, R-152a, R-161, R-218, R-290 (propane), R-C318, R-600 (butane), R-600a (isobutane), R611 (methyl formate), R-717 (ammonia), dimethyt ether, and sulfur hexafluoride. The flammability test procedure and apparatus are discussed, including attention to the Ignition source, based on recommendations of ASHRAE Standard 341992. Flammability limits are compared for R$32, R-141 b$, and R-142b, to illustrate the influence of alternative ignition sources and condltions. Critical flammability ratios are presented for selected mixtures.

$H$. Shaoqiang, $L$ Xiaoping, and $X$. Chunfol Wanbao Refrigerator Industrial Corporation, China), Retrigerant HFC-152a Flammability Test Results, publication unknown, undated circa 1991 (4 pages with 1 table, avallable from JMC as RDB2512)

This paper assesses the flammability risk of $R$. 152a, which is reported as flammable in concentrations of $4.7-16.8 \%$ by volume in air. The authors hypothesized that the highest probabllity of fires and explosions will occur when enough refrigerant leaked from the freezer evaporator into the fresh-food compartment, with ignition caused by an arc or spark from the thermostat. Concentrations of $5,10,15$, and $20 \%$ R-152a were tested using an electric pulse spark. Ignition was found to be unlikely in the model tested (BCD-158), because of incomplete mixing and the location of the thermostat. The 
risk would be high in a frost-free refrigerator, requiring an explosion-proof thermostat. The paper concludes that the most likely scenario for a fire is when the concentration reaches $12 \%$ and is exposed to an open flame. A person standing near the iefrigerator could be injured by a blow from the door opened by fire or explosion, by flames, or both. No deformation or damage to the refrigerator cabinet was observed from test fires.

Combustion of Ammonia With and Whthout Oll Vapor, research project 682-RP, American Society of Heating, Refrigerating, and Air-Conditioning Engineers (ASHRAE), Atlanta, GA, September 1991 . September 1993 (ÁSH0682)

This project will redetermine the flammability limits of ammonia (R-717) in air as well as the combustibility of air-ammonia-oil and air-ammonia-methane mixtures, in concentrations of $100-250,000 \mathrm{ppm}$. It also will examine the geometric configurations for release that facilitate combustion, in order to improve discharge designs for flaring. The contractor for this research is Kansas State University, led by $D$. $L$. Fenton and K. S. Chapman; it is sponsored by ASHRAE Technical Committeo 10.1, Custom Engineered Refrigeration Systems.

Flammability Characteristics of lsotron 141b. preliminary information bulletin. Elf Atochem North America, incorporated (provided by the former Penmwalt Corporation), King of Prussla, PA, May 1989 (1 page, available from JMC as RDB0521)

Lower and upper flammability limits (LFL and UFL), as a volume percentage of refrigerant in humid air, are given for R-141b based on ASTM E681 tests. The limits cited are 7.4-15.5\% at 21 ${ }^{\circ} \mathrm{C}\left(70^{\circ} \mathrm{F}\right)$ and $5.8-16.5 \%$ at $120^{\circ} \mathrm{C}\left(250^{\circ} \mathrm{F}\right)$. The maximum explosion pressure and maximum rate of pressure rise are tabulated for the same temperatures. Flammability characteristics of ethyl alcohol and R-290 (propane) are presented for comparison. A higher concentration of $R-141 \mathrm{~b}$ is required for flammability. Additionally, R-141b exhiblts significantly lower rates of pressure rise and lower heats of combustion.

Results of Testing: Limits of Flammability for Isotron 141b, preliminary Information bulletin, Elf Atochem North America, incorporated (provided by the former Pennwalt Corporation), King of Prussia. PA, May 1989 (4 pages with 5 flgures and 1 table, available from JMC as RDB0522, picture missing)

Lower and upper flammability limits (LFL and UFL), as a volume percentage of refrigerant in humid air, are given for R-141b based on ASTM E681-85 tests. The limits cited are 7.4-15.5\% at $21^{\circ} \mathrm{C}\left(70^{\circ} \mathrm{F}\right)$ and $5.8-16.5 \%$ at $120^{\circ} \mathrm{C}\left(250^{\circ} \mathrm{F}\right)$. Comparative data are presented for $\mathrm{R}-600 \mathrm{a}$ (iso- butane) and othanol, 1.86-8.5\% and 3.46-18.4\% respectively. A modified test procedure and the method of determining flammabilly limits are presented. Additionally, the effects of humidity, temperature, and Ignition source on flammability testing are discussed.

Results of Testing: Flashpoint of lsotron 141b, preliminary information bulletin. Elf Atochem North America, Incorporated (provided by the former Pennwalt Corporation), King of Prussla, PA, May 1989 (1 page, avallable from JMC as RDB0523, picture missing)

The procedure and results of measuring the flash point of R-141b are summarized based on ASTM D1310 tests using a Fisher/Tag open cup apparatus. No flash point was observed for this fluld even though it has lower and upper flammability limits. The nature of the liquid is such that it does not produce a vapor layer that will flash according to the standard test method. The document notes that similar behavior has been observed for chlorinated solvents such as R-30 (methylene chloride) and R-140a (methyl chloroform).

Results of Testing: Maximum Rate of Pressure Rise - Maximum Explosion Pressure of lsotron 141b, preliminary information bulletin, Elf Atochem North America, Incorporated (provided by the former Pennwalt Corporation), King of Prussia, PA. May 1989 (2 pages with 1 table, available from JMC as RDB0524, picture missing)

The procedure and results of measuring the maximum rate of pressure rise and maximum explosion pressure of R-141b are summarized. The rate of pressure rise is reported as 262 and $220 \mathrm{kPa} / \mathrm{s}(38$ and $32 \mathrm{psi} / \mathrm{s})$ at $21^{\circ} \mathrm{C}\left(70^{\circ} \mathrm{F}\right)$ and $120^{\circ} \mathrm{C}\left(250^{\circ} \mathrm{F}\right)$, respectively, in a $0.37 \mathrm{~m}^{3}(13.1$ cf) vessel. The maximum pressure is reported as 78 and 57 psig at corresponding conditions. A comparison of normalized rates of pressure rise (the $\mathrm{Kg}$ ) shows R-141b to be approximately 230 times less severe than R-290 (propane) and 50 times less severe than ethanol.

Flammability Characteriatics of Isotron 142b, preliminary information julletin, Eff Atochem North America, Incorporated (provided by the former Pennwalt Corporation), King of Prussia, PA, May 1989 (1 Puge, available from JMC as RDB0525)

Lower and upper flammability limits (LFL and UFL), as a volume percentage of refrigerant in humid air, are given for R-142b based on ASTM E681 tests. The LFL clted is $7.8 \%$ at $21^{\circ} \mathrm{C}(70$ $\left.{ }^{\circ} \mathrm{F}\right)$ using a fuse wire as the ignition source. The cited LFL and UFL, using a match as the Ignition source, are 6.9-17.0\% at $21^{\circ} \mathrm{C}\left(70^{\circ} \mathrm{F}\right)$ and 6.1$17.8 \%$ at $120^{\circ} \mathrm{C}\left(250^{\circ} \mathrm{F}\right)$. The maximum explosion pressure and maximum rate of pressure 
rise are tabulated for the same temperatures. Flammability characterlatics of ethyl alcohol and R-290 (propane) are presented for comparison. A higher concentration of R-142b is required for flammability. Addhionally, R-142b exhiblts significantly lower rates of pressure rise and lower heats of combustion.

Results of Testing: Limits of Flammabiltty for Isotron 142b, preliminary information bulletin, Elf Atochem North America, Incorporated (provided by the former Penmwalt Corporation). King of Prussla, PA, May 1989 (4 pages, avallable from JMC as RDB0526, picture missing)

Lower and upper flammability limits (LFL and UFL), as a volume percentage of refrigerant in humid air, are given for R-142b based on ASTM E681 tests. The LFL ctted is $7.8 \%$ at $21^{\circ} \mathrm{C}(70$ of using a fuse wire as the ignition source. The cited LFL and UFL, using a match as the ignition source, are $6.9-17.0 \%$ at $21^{\circ} \mathrm{C}\left(70^{\circ} \mathrm{F}\right)$ and 6.1. $17.8 \%$ at $120^{\circ} \mathrm{C}\left(250^{\circ} \mathrm{F}\right)$. Comparative data are presented for R-600a (isobutane) and ethanol, $1.86-8.5 \%$ and $3.46-18.4 \%$ respectively. A modified test procedure and the method of determining flammability limits are presented. Addltionally, the effects of humidity, temperature, and ignition source on flammability testing are discussed.

Results of Testing: Flashpoint of Isotron 142b. preliminary information bulletin, Elf Atochem North America, Incorporated (provided by the former Pennwalt Corporation), King of Prussla, PA, May 1989 (1 page with 1 figure, avallable from JMC as RDB0527, picture missing)

The procedure and results of measuring the flash point of R-142b are summarized based on ASTM D1310 tests using a Fisher/Tag open cup apparatus. No flash point was observed for this fluid. An upward extension of a test flame was observed when passed over a sample of the refrigerant. The extension grow with increasing temperature of the refrigerant, but the vapor space above the llquid nelther flashed nor burned away from the test flame.

Results of Testing: Maximum Rate of Pressure Rise - Maximum Explosion Pressure of Isotron 142b, preliminary information bulletin, Ef Atochem North America, Incorporated (provided by the former Pennwalt Corporation), KIng of Prussia, PA, May 1989 (2 pages with 1 table, avallable from JMC as RDB0528, plcture missing)

The procedure and results of measuring the maximum rate of pressure rise and maximum explosion pressure of R-142b are summarized. The rate of pressure rise is reported as 606 and $634 \mathrm{kPa} / \mathrm{s}$ (88 and $92 \mathrm{psi} / \mathrm{s})$ at $21^{\circ} \mathrm{C}\left(70^{\circ} \mathrm{F}\right)$ and $120^{\circ} \mathrm{C}\left(250^{\circ} \mathrm{F}\right)$, respectively, in a $0.37 \mathrm{~m}^{3}(13.1$ cf) vessel. The maximum pressure is reported as 88 and 68 psig at corresponding conditions. A comparison of normalized rates of pressure rise (Kg) shows R-142b to be approximately 100 times less severe than R-290 (propane) and 23 times less severe than ethand.

\section{Toxicity}

Clement Associates, Incorporated Health Effects Assessment for Ammonia, The ':ertilizer Institute, Washington, DC, February 1990 (148 pagpo, RnA. 1106)

This document revlews data relevant to assessing the health effects of inhalation exposure to ammonia. The focus is on chronic exposures; information on subchronic and acute exposures also is reviewed to acquire a complete picture of the toxicity of ammonia. Physical and chemical propertles, sources, environmental fate, environmental effects, and other related toplcs are discussed to provide context and perspective.

D. L. Holness, J. T. Purdham, and J. R. Nethercott, Acute and Chronic Respiratory Effects of Occupational Exposure to Ammonia, Journal of the American Industrial Hygiene Association, volume 50, number 12, pages 646-650, December 1989 (4 pages with 7 tables, RDB3238)

Meridian Research, Incorporated, Results of Employee Exposure Monthoring for HCFC-123 at Centrifugal Chiller Installations, U.S. Environmental Protection Agency (EPA), Washington, DC, 26 November 1991 (82 pages, RDB2529)

J. Parsnow, Monitoring Instruments for HCFC123, publication 819-060, Carrier Corporation, Syracuse, NY, April 1992 (8 pages with 2 figures and 1 table, RDB2915)

H. W. Sibley, A Study for Determining Refrigeramt Exposure Levels While Servicing an HCFC-123 Centrifugal Chiller, publication 819-061, Carrier Corporation, Syracuse, NY, April 1992 (8 pages with 4 figures and 1 table, RDB2916)

1990-1991 Threshold Limit Values for Chemical Substances in the Work Environment, 1990-1991 Threshold Limit Values for Chemical Substances and Physical Agents and Biological Exposure Indices. The American Conference of Government Industrial Hyglenists (ACGIH), Cincinnati, $O H_{1}$ 1990, pages $1-49$ and notes (55 of 132 pages with 2 tables and 4 appendices, RDB2B05)

This book provides data for use as guldelines or recommendations in the control of potentlal hizards. Threshold limit values (TLVs) are tab. ulated for airborne concentrations of chemical 
substances to which workers may be exposed. These chemicals include common refrigerants based on both chronic and acute effects. The TLV data refer to concentrationis under which it is belleved that nearly all workers may be repeatedly exposed without adverse health effects subject to identffied considerations. The TLVs are categorized as time-weighted average (TWA or TLV-TWA), s.iurt-term exposure limit (STEL or TLV-STEL), and ceiling (TLV-C). Notes are provided for interpretation, but the information is not intended for use without training in industrial hygiene. The document also lists intended changes and provides appendices addressing carcinogens, substances of variable composition, mixtures, and sampling criteria for airborne particulate matter.

Report on Testing and Analysis of the Concentration of HCFC-123 in Field Installations with General Machinery Rooms Containing Hermetic Centrifugal Chillers, report CFC-1, The Trane Company, La Crosse, WI, October 1991 (34 pages with 14 figures and 15 tables, RDB2246)

This report provides measured data on R-123 concentrations in equipment rooms housing hermetic centrifugal chillers. Twelve sites, representing a broad range of applications, were tested during normal operation. Additional data were taken at two sites during refrigerant transfers. Measurements were made by gas chromatography, both on site and using actlvated charcoal tubes (subsequently analyzed in labc ratories). All of the sites except one were determined to have concentratlons substantially less than $1 \mathrm{ppm}$, if any. Concentrations above minimum quantifiable levels, $0.33-0.56 \mathrm{ppm}$, were detected in only two cases. Leakage from empty, but improperly sealed, refrigerant drums was identified as the probable cause for one site. The sources in the other were improperly sealed drums and a leak from the purge vent line. The latter was ascribed to improper field installation and use of incompatible piping materials. A retest of this site, after corrections, found concentrations in line with the others. Reports on the individual sites and summary discussion describe the tests and safety considerations for refrigerants. The findings em. phasize the importance of following proper refrigerant handling and storage procedures as well as installation recommendations.

Report of Worker Exposure to HCFC-123 During Servicing of Hermetic Centrifugal Chillers, report CFC-2, The Trane Company, La Crosse, WI, May 1992 (16 pages with 3 figures and 9 tables, RDB2908)

This report addresses the safety aspects of exposure of service personnel to R-123 during the full range of service procedures for centrifugal chiller applications. Earlier toxicity findings and Implications are reviewed as background. The report then documents the measured concentrations during refrigerant transfer, routine maintenance, and major service from three different installations. Chronic (long-termi), acute (short-term intermittent), and emergency acute exposure considerations are outlined. The measurement procedures are described; they used actlvated charcoal tubes subsequently analyzed by gas chromatography in laboratories, and on-site infrared vapor analyzers. Timeweighted average (TWA) exposures are tabulated for the chronic exposures, ranging from less than the limit of quantification (LOQ) to 1.9 ppm. Peak concentrations and durations are tabulated for the intermittent, acute exposures. Test reports are included to describe each site and provide detalled measured data. The report concludes that the long-term concentrations observed were more than five times below the allowable expcsure level (AEL) of $10 \mathrm{ppm}$. The instantaneous concentrations were well within the $30-50 \mathrm{ppm}$ limits based on guidelines developed by the American Conference of Government Industrial Hygienists (ACGIH). The findings emphasize the importance of following proper handling and storage procedures for refrigerants and installation recommendations of ASHRAE Standard 15R [now 15-1992].

\section{Other}

G. C. Hourahan (Air-Conditioning and Refrigeration Institute). Planning for the Use of Alternative Ro frigerants in Alr Conditioning and Refrigeration, presented at the Seventh Annual Conference Washington, DC), Defense Fire Protection Association, 29 April 1993 (6 pages with 7 flgures and 2 tables, avallable from JMC as RDB3502)

This paper illustrates options for equipment planners to alleviate confusion for use of alternattve refrigerants in air conditioning and refrigeration. It briefly outlines the phase out of chloroflisiocarbon (CFC) and hydrochlorofluorocarion (HCFC) refrigerants as well as the tradeoffs between ozone depletion and global warming among alternatives. It summarizes a study by the Congressional Research. Service, which predicts a state of chaos and shortages in late 1995 and subsequent several years. A figure indicates the number of CFC chillers that manufacturers expect to corvert or replace before 1993 and in 1993-1995. It addresses new alternatives, concluding that there are "no magic compounds around the comer" and new candidates will require 8-12 years to enter full-scale 
production. Two figures summarize crtterla for selection of altemattve refrigerants and chiller options by type and refrigerant. Refrigerant containment, equipment conversion, and equipment replacement options are outlined. Recommendations are noted, including designation of a refrigerant manager and development of a management plan. Two tables summarize estimated refrigerant inventories and service needs by equipment category and alternative refrigerants by applications.

G. Mozzon and P. Sansalvadore (Aspera-Whirlpool SpA, Italy), Reliability of Hermetic Compressors for R-134a Appliances, paper 4.4, Proceedings of the International Seminar on New Technology of Alternative Refrigerants - Lubricants and Materials Compatibility (Tokyo, February 1983), Japanese Association of Refrigeration (JAR), Tokyo, Japan, pages 77-82, February 1993 (6 pages with 2 figures and 6 tables, RDB3316)

R. C. Niess, CFCs and Electric Chillers - Selection of Large-Capacity Water Chillers in the 1990s, report TR-100537, Electric Power Research Institute (EPRI), Palo Alto, CA, March 1992 (188 pages with 3 flgures and 34 tables, RDB2A18)

CFCs and Electric Chillers - Selecting Large Water Chillers as CFCs are Phased Out, brochure CU.2039R.7.92, Electric Power Research Institute (EPRI), Palo Alto, CA, July 1992 (6 pages with 4 figures, RDB3454)

CFCs and Electric Utilities - Making the Transition to a Safer World, report CU-7027 (project RP2792-12), Electric Power Research Institute (EPRI), Palo Alto, CA, October 1990 (76 pages with 29 figures, RDB3455)

This report provides an illustrated narrative, based on a series of slide presentations, to review the phase out of chlorofluorocarbon (CFC) refrigerants, their use in electric-powered equipment, and estimates of phaseout impacts. The tie between the chemical composition of refrigerants and stability, flammability, and toxicity is illustrated. Data on the ozone-depletion potential (ODP), global warming potential (GWP) and atmospheric lifetime also are indicated. The report reviews data on use of refrigerants by application and resultant electric utility loads and revenues. The report notes that utility income from these sources is more than double that recelved by other industry participants. Likely alternative refrigerants as well as their impacts on equipment cost, efficiency, resultani energy consumption, and loads are projected.

DuPont HFC-134a: Properties, Uses, Storage, and Handling, bulletin P134a (H-45945), DuPorit Chemicals, Wilmington, DE, November 1992 (32 pages with 10 flgures and 20 tables, available from JMC as RDB3439)

This document provides extensive application information for R-134a. It reviews identifiers and potential uses, shows an infrared spectrum for laboratory analyses, compares theoretical performance to R-12, and-summarizes physical properties as well as flammability, environmental, and toxicity indices. Plots of solubility in water, pressure-temperature relationships, and vapor thermal conductivity are included. Pressure-enthalpy diagrams, in both inch-pound (IP) and metric (SI) units, are provided. The bulletin reviews chemical and thermal stability data, including thermal decomposition, stability with metals and refrigeration lubricants, stability with foam chemicals, and concerns if mixed with R12. It then addresses compatibility with plastics, elastomers, desiccants, and refrigeration lubricants. A table summarizes compatibility with plastics including ABS polymer (Kralastic(R)), acetal (DuPont Delrin(R)), acrylic (Lucite(R)), cellulosic (Ethocel(R)), epoxy, polytetrafluoroethylene (PTFE, DuPont Teflon(R)), ETFE (Tefzel(R)), PVDF, ionomer (Surtyn(P)), nylon 6/6 polyamide (DuPont Zytel(R)), polyarylate (Arylon(R)), polycarbonate (Tuffak(R)), polybutylene terephthalate (PBT, GE Valox(R)), polyethylene terephthalate (PET, DuPont Rynite(R)), polyetherimide (GE Ultem(R)), polyethylene-HD (Alathon(R)), polyphenylene oxide (PPE, GE Noryl(A)), polyphenylene sulfide (Ryton(R)), polypropylene, polystyrene (Styron(R)), polysulfone (Polysufone(R)), and polyvinyi chloride (PVC and CPVC). Tabular summaries also are provided for R-134a compatibility with a urethane rubber (Uniroyal Adiprene(R) L), Buna N, Buna S, buty rubber, synthetic rubber (DuPont Hypalon(R) 48), natural rubber, neoprene $W$, hydrocarbon rubber (DuPont Nordel(R)), silicone rubber, polysulfide rubber (Thiokol(R) FA), and fluoroelastomer (DuPont Viton(R) A). These summaries indicate changes in length, weight, Shore $A$ hardness, elasticity, and appearance after exposures at $25^{2}$ and $80^{\circ} \mathrm{C}$ (77 and $176^{\circ} \mathrm{F}$ ). A table summarizes permeation through elastomeric hoses made of nylon, Hypalon 48, and two nitriles with identified liners, reinforcement, and covers. Solubility data are provided for R-134a in unidentified naphthenic mineral oil, dlalkylbenzene, alkylbenzene, polyalkylene glycol (PAG), and ester lubricants. Safety data are then presented including a review of inhalation toxicity, cardiac sensitization, responses to spills or leaks, and skin and eye contact. Flammability data and recommended practices for leak testing, bulk delivery, storage, charging, and recovery are reviewed. Monitors and leak detection are discussed as are storage, handling, and shipping. The bulletin concludes with discus- 
sion of recovery, reclamation, recycling, and disposal.

DuPont Suva(R) HP Retrigeramt Blends: Properties, Uses, Storage, and Handling, bulletin P.HP (H-47122), DuPont Chemicals, Wilmington, DE, January 1993 (24 pages with 2 figures and 7 tables, available from JMC as RDB3442)

This document provldes extensive application information for R-402, a blend of R-125, R-290, and $R-22$ (R-125/290/22), including $R-402$ $(38 / 2 / 60)$ and $R-402(60 / 2 / 38)$. It also addresses a blend of R-125, R-143a, and R-134a, specifically R-125/143a/134a $(44 / 52 / 4)$. It reviews identfiers, the blend compositions, and potential uses. The bulletin then summarizes physical properties as well as flammability, environmental, and toxicity indices. The bulletin reviews chemical and thermal stability data, including thermal decomposition. A table provides representative data on stablity with metals (copper, iron, and aluminum) based on sealedtube tests of mixtures of R-402 (38/2/60) with mineral oll (Witco Suniso(F) 3GS), alkylbenzene (Shrieve Zerol(A) 150 TD), and a branched acids polyol ester (Castrol Icematic(R) SW32) lubricants. Results also are provided for R$125 / 143 a / 134 a(44 / 52 / 4)$ with the same lubricants and a mixed acids ester (Mobil EAL(R) Arctic 22). The report reviews compatibility of the refrigerant blends with R-502, noting chemical compatibility but separation difficulty leading to a need for disposal by incineration. It then addresses compatibility with elastomers; a tabular summary is provided for five polymers with combinations of the cited lubricants and R-502, R-402 (38/2/60), and R-125/143a/134a. The compounds tested were polytetrafluoroethylene (PTFE, DuPont Teflon(R) in commercial grade sheet from Tex-O-Lon Manufacturing), Buna $\mathrm{N}$ nitrile butadiene (NBR, Parker Seal), hydrogenated NBR (HNBR, Parker Seal N1195), chloroprene (CR, Precision Rubber neoprene $W$, and EPDM (Kirkhill Rubber). Compatibility data also are discussed fC. polyethylene terephthalate (PET, DuPont Mylar(R) film), polyesterimide motor wire with amide-imide overcoating, and Dacron/Mylar/Dacron(R) lead wire (Belden) as well as for molecular sieve desiccants (UOP 4A-XH-5 and XH-9). Miscibility is summartzed for R-502 and the three zeotropes with mineral oll, alkylbenzene, and polyol ester lubricants. Safety data are then presented including a review of inhalation toxicity, cardlac sensitization, responses to spills or leaks, skin and eye contact, and flammability. Monitors and leak detection are dlscussed as are storage, handling, and shipping. The bulletin concludes with discussion of recovery, reclamation, recycting, and disposal. DuPont's pruduct names for $\mathbf{R}-402(38 / 2 / 60), \quad \pi-402$
$(60 / 2 / 38)$, and $R-125 / 143 a / 134 a(44 / 52 / 4)$ are Suva(A) HP81, SUva(P) HP80, and SUva(P) HP62 respectively.

DuPont Suva(P) MP Refrigeram Blonds: Propertles, Uses, Storage, and Handiling, bulletin P-MP $(\mathrm{H}-45944)$, DuPont Chemicals, Wilmington, DE, December 1992 (36 pages with 14 figures and 13 tables, available from JMC as RDB3441)

This document provides extensive application information for R-401 (33/15/52), R-401 $(53 / 13 / 34)$, and $R-401(61 / 11 / 28)$. It reviews identfiers, the blend compositions, potential uses, compares theoretical performance to R. 12, and discusses temperature glides. Using R$401(53 / 13 / 34)$ as an lllustration, it presents tabular data on the theoretical effect of leakage on performance. The bulletin then summarizes physical properties as well as flammabllity, environmental, and toxicity indices. Plots of pressure-temperature relationships and pressure-enthalpy dlagrams, in both inch-pound (IP) and metric (SI) units, are provided. The bulletin reviews chemical and thermal stabllity data, including thermal decomposition. A table provides representative data on stability with metals (copper, iron, and aluminum) and refrigeration lubricants; comparative information is given for R-12 with two mineral olls. The lubricants addressed include alkylbenzenes (Shrieve Zerol(R) $150 \mathrm{DL}, 300$, and 500T), branched acids polyol esters (Castrol Icematic(R) SW22, SW32, SW68, and SW100), mbxed acids polyol esters (Mobil EAL(R) Arctic 68), Henkel Emery(R) ISO 10 and 100, and Lubrizol ISO 150. It then addresses compatibility with elastomers; a tabular summary is provided for R-401 (36/24/40), Zerol(R) 500 , and a 50/50 mbxture with 11 polymers including natural rubber (NR), butyl rubber (IIR). EPDM (DuPont Nordel(R)), chlorof rene (CR, DuPont Neoprene(A) W, styrene-butadiene copolymer (SBR, Buna-S), Buna N nitrile (NBR, Polysar Krynac(R)), hydrogenated NBR (HNBR, Polysar Tornac(P)), chlorosulfonated polyethylene (CSM, DuPont Hypalon(F) 48), fluoroelastomer (FKM, DuPont Viton(F)), sillcone rubber (SI, Dow Sllastic(R)), opichlorohydrin homopolymer (CO, Goodrich Hydrin(A) 100), eplchlorohydrin copolymer (ECO, Goodrich Hydrin(F) 200), urethane (Uniroyal Adiprene(R)), and polysulfide rubber (T. Thiokol(R) FA). A separate table summarizes the compatibility of R-401 (33/15/52), a mixture of this refrigerant with Zerol(A) $500 T$ and a mineral of (BVM $100 \mathrm{~N}$ ), and Zerol(R) 500T alone with 5 polymers; they include CR (DuPont Neoprene(R)), NBR nitrite, HNBR, CO, and ECO. Compatibility data also are provided for poly. ester insulation material for motors and for molecular sleve desiccants (UOP 4A-XH-5 and XH-9). Misclbility data are provided for 30,60 , 
and $90 \%$. weight lubricant mbxtures with $R-401$ $(61 / 11 / 28)$ and naphthenic mineral oil, paraffinic mineral oil, alkylbenzenes, polyol esters, and the latter two also with mineral oils. Hose permeation rates are presented for nylon-lined and nitrile hoses. Safety data are then presented including a review of inhalation toxicity, cardiac sensitization, responses to spills or leaks, skin and eye contact, and flammability. Monitors and leak detection are discussed as are storage, handling, and shipping. The bulletin concludes with discussion of recovery, reclamation, recycling, and disposal. DuPont's product names for $R-401$ (33/15/52), $R-401$ $(53 / 13 / 34)$, and $R-401(61 / 11 / 28)$ are Suva(R) MP52, Suva(R) MP39, and Suva(R) MP66 respectively.

Freon(A) Fluorocarbons Properties and Applications, bulletin B-2E, E. I. DuPont de Nemours International S.A., Geneva, Switzerland, undated circa 1984 (12 pages with 1 figure and 10 tables, RDB2433)

This brochure summarizes physical, thermodynamic, safety, and application data for $R-11, R$ 12, R-13, R-1381, R-14, R-22, R-23, R-113, R$114, R-115, R-116, R-152 a, R-500, R-502$, and R503. Stability and decomposition data are provided for R-11, R-12, R-13, R-22, R-113, R-114, R-115, and R-502. Hydrolysis data with water, alone and in the presence of steel, are presented for R-11, R-12, R-22, R-30 (methylene chloride), R-40 (methyl chloride), R-113, R-114, and R-502. Swell data with elastomers are tabulated for R-11, R-12, R-13, R-13B1, R-22, R-30, R-40, R-113, R-114, R-115, R-140a (methyl chloroform), and R-502 with neoprene GN, butadiene acrylonitrile (Buna(TM) N), butadiene styrene (Buna(TM) S), isoprene isobutylene (Butyl(TM)), and polysulfide and natural rubbers. Compatibility data are discussed with lubricants, plastics, and metals.

Pilot Survey of Refrigerant Use and Emissions from Retail Food Stores, research project 691-RP, American Society of Heating, Refrigerating, and AirConditioning Engineers (ASHRAE), Atlanta, GA, September 1991 - ongoing (ASH0691)

The contractor for the project is the Radian Cor. poration, led by T. J. Nelson; it is sponsored by the ASHRAE Task Group on Halocarbon Emissions

Survey of the Use and Emission of Chlorofluorocarbons from Large Chillers, research project 603-RP, American Society of Heating, Refrigerating, and Alr-Conditioning Engineers (ASHRAE), Atlanta, GA, March 1989 - February 1991 (ASH0603)

The contractor for the project is the Radian Corporation, led by T. J. Nelson; it is sponsored by the ASHRAE Task Group on Halocarbon Emissions

\section{TEST AND ANALYSIS METHODS}

G. Angelino and C. Invernizzi, General Method for the Thermodynamic Evaluation of Heat Pump Working Fluids, International Journal of Refrigeration, Paris, France, volume 11, pages 16-25, 1988 (RDB3338)

T. O. Armstrong, Chloride Analyses as a Measure for the Evaluation of Sealed Tube Tests, Transactions, American Society of Heating, Refrigerating, and Air-Conditloning Engineers (ASHRAE), Atlanta, GA, volume 71, part 1, pages $150 \mathrm{ff}, 1965$ (RDB2325)

J. J. Baustian, M. B. Pate, and A. E. Bergles, Messuring the Concentration of a Flowing Oil-Retrigerant Mixture with a Bypass Viscometer, Transactions, American Soclety of Heating, Refrigerating, and Air-Conditioning Engineers (ASHRAE), Atlanta, GA, volume 94, part 2, 1988 (RDB2406)

J. J. Baustian, M. B. Pate, and A. E. Bergles, Measuring the Concentration of a Flowing Oil-Refrigerant Mixture with a Vibrating U-Tube Densimeter, Transactions, American Society of Heating, Refrigerating, and Air-Conditloning Engineers (ASHRAE), Atlanta, GA, volume 94, part 2, 1988 (RDB2407)

J. J. Baustian, M. B. Pate, and A. E. Bergles, Measuring the Concentration of a Flowing Oll-Refrigerant Mixture with an Acoustic Velocity Sensor, Transactions. American Society of Heating, Refrigerating, and Air-Conditioning Engineers (ASHRAE), Atlanta, GA, volume 94, part 2, 1988 (RDB2408)

J. J. Baustian, M. B. Pate, and A. E. Bergles, Measuring the Concentration of a Flowing Oll-Refrigerant Mixture: Instrumentation Test Facility and Initial Results, Transactions, American Society of Heating, Refrigerating, and Alr-Conditioning Engineers (ASHRAE), Atlanta, GA, volume 94, part 1. pages 167-177, 1988 (RDB2247)

M. Benedict, G. B. Webb, and L. C. Rubin, An Empirical Equation for Thermodynamic Properties of Light Hydrocarbons and Their Mixtures, Journal of Chem. Physics, American Institute of Physics, volume 8, pages 334 ff, 1940 (RDB2350) 
T. J. Bruno, Chemical Analyals Protocol for At ternative Refrlgerants - Part 1: Spectroscopic Methods, paper 3618 (Annual Meeting, Battimore, MD, June 1992), Transactions, American Society of Heating, Refrigerating, and Air-Conditioning Englneers (ASHRAE), Atlanta, GA, volume 98, part 2 , pages 204-209, 1992 (6 pages with 2 figures and 1 table, RDB2603)

T. J. Bruno, Chemical Analyais Protocol for Alternative Refrigerants - Part 2: Separation Methods, paper 3619 (Annual Meeting, Baltimore, MD, June 1992), Transactions, American Society of Heating, Refrigerating, and Alr-Conditioning Englneers (ASHRAE), Atlanta, GA, volume 98, part 2 , pages 210-215, 1992 (6 pages with 7 figures, RDB2604)

T. J. Bruno, Spectroscopic Library for Alternative Retrigerant Analysis, report NIST Special Publication 794, National Institute of Standards and Technology, Boulder, CO, August 1990 (192 pages, available from Superintendent of Documents, U.S. Government Printing Office, Washington, DC 20402 . USA; order by stock number 003-00303036-8 for $\$ 12.00$ prepald, RDB2250)

This report assembles infrared and mass spectra on a range of ethane and ethylene compounds relevant to research of alternative refrigerants. Limited physical property and safety data also are included. Some compounds addressed are not sulted for refrigerant use, but could be found as impurities or as reaction/decomposition products in refrigerant tests. This publication provides an information source to aid in identification of such compounds. The ethane compounds addressed include R-112, R-112a, R-113, R-113B2, R-113a, R-114, R-114a, R-114B2, R-115, R-116, R-121, R122, R-123, R-123B1, R-123B2, R-123aB1, R124, R-125, R-131, R-131a, R-132b, R-132bB2, R-133a, R-133aB1, R-134, R-134a, R-141, R141b, R-142B1, R-142b, R-143, R-143a, R151B1, R-152a, and R-161. Ethylene compounds covered include R-1110, R-1111, R1112a, R-1112aB2, R-1113, R-1114, R-1120, R1121, R-112281, R-1123, R-1130, R-1130, R1130a, R-1131a, R-1132a, and R-1141.

H. A. Connon (E. I. DuPont de Nemours and Company), A Generalized Computer Program for Analysis of Mixture Refrigerntion Cycles, Transactions, American Soclety of Heating, Refrigerating, and Air-Conditioning Engineers (ASHRAE), Atlanta, GA, volume 90, part 2, pages 628-639, 1984 (RDB3214)

G. C. Doderer and H. O. Spauschus (General Electric Company). A Sealed Tube - Gas Chromatograph Method for Measuring Reaction of Refrigerant 12 with Oil, Transactions, American Society of Heating, Refrigerating, and Air-Conditioning Engineers (ASHRAE), Atlanta, GA, volume 72, part II, pages IV.4.1-IV.4.5, 1966 (RDB2326)

P. A. Domanski and M. O. McLinden (National Institute of Standards and Technology, NIST), A Simplified Cycle Simulation Model for the Performance Rating of Refrigerants and Refrigerant Mixtures, International Journal of Refrigeration, Parls, France, volume 15, number 2, pages 81-88, February 1992 (8 pages with 6 figures and 1 table, RDB3448)

P. A. Domanski and M. O. McLinden (National Institute of Standards and Technology, NIST), A Simplified Cycle Simulation Model for the Performance Rating of Refrigerants and Refrigerant Mixtures, Proceedings of the 1990 USNC/IIR-Purdue Refrigeration Conference and ASHRAE-Purdue CFC Conference, edited by D. R. Tree, Purdue University, West Lafayette, IN, pages 466-475, July 1990 (10 pages with 6 figures and 1 table, available from JMC as RDB2C05)

[see RDB3448 for corrected and updated version]

S. R. Dunne and T. J. Clancey, Methods of Teating Desiccants for Refrigerant Drying. Transactions, American Society of Heating, Refrigerating, and Air. Conditloning Engineers (ASHRAE), Atlanta, GA, volume 90, part 1, 1984 (RDB2431)

H. M. Elsey, Small Sealed Tube Procedure for Quality Control of Refrigeration Oils, Transactions, American Society of Heating, Refrigerating, and Air-Conditioning Engineers (ASHRAE), Atlanta, GA, volume 71, part I, pages 143 ff, 1965 (RDB2328)

H. M. Elsey, L. C. Flowers, and J. B. Kelley, A Method of Evaluating Refrigerator Oils, Refrigerating Engineering, American Soclety of Refrigerating Engineers (ASRE, now merged into the American Society of Heating, Refrigerating, and Air-Conditioning Engineers, ASHRAE), Atlanta, GA, volume 60, number 7, pages 737 ff, July 1952 (RDB2321)

V. Z. Geller and M. E. Paulattis (University of Delaware), The Calculation and Prediction of Transport Properties for New Refrloerants and Blends in Refrigeration Application, Proceedings of the International CFC and Halon Alternatives Conference (Washington, DC), Alliance for Responsible CFC Pollcy, Artington, VA, pages 115124. September 1992 (10 pages with 6 figures and 3 tables, RDB2A07)

D. F. Huttenlocher (General Electric Company), Bench Scale Teat Procedure for Hermetic Compressor Lubricants, ASHRAE Journal, American 
Society of Heating, Refrigerating, and Alr-Condltioning Engineers (ASHRAE), Atlanta, GA, volume 11, number 6, pages 85-89, June 1969 (RDB2421)

R. E. Kauffiman (University of Dayton Research Institute), Accelerated Screening Methods for Dotermining Chemical and Thermal Stability of Refrigerant-Lubricant Mixtures, Part I: Mothod Assessment, final report DOE/CE/23810-10, AlrConditioning and Refrigeration Technology Institute (ARTI), Arlington, VA, April 1993 (42 pages with 2 figures and 1 table, available from JMC as RDB3501)

This report presents the results of a literature search. It addresses analytical techniques sultable for development into accelerated screening tests, to evaluate the chemical and thermal stabilities of refrigerant-lubricant combinations. The search focused on chemical stability data for R-12, R-22, R-134a, and other refrigerant candidates as well as thermal analytical techniques. The computerized search sources and approaches are summarlzed. Identified literature and prepared abstracts are categorized as analyses of chlorine-free refrigerants, analyses of chlorinated refrigerants, and accelerated thermal analytical techniques. Other documents are listed in an appendix. Evaluation criteria for candidate compatibility tests are indicated. Identified methods are discussed, and two differential thermal analytical (DTA) techniques are outlined for further development. Intial results are presented for one method for separate combinations of R-12 and R-22 with mineral oil. The candidate techniques will be evaluated in a second phase of the project, for which completion is projected in February 1994.

D. E. Kvalnes, The Sealed Tube Test for Retrigeration Oils, Transactions, American Society of Heating, Refrigerating, and Air-Conditioning Engineers (ASHRAE), Atlanta, GA, volume 71, part I, pages $138 \mathrm{ff}, 1965$ (RDB2324)

B. I. Lee and M. G. Kesler (Mobil Research and Development Corporation), A Generalized Thermodynamic Correlation Based on Threa-Parameter Corresponding States, AJChE Journal, American Institute of Chemical Engineers (AIChE), New York, NY, volume 21, number 3, pages 510-527, May 1975 (RDB3341)

J. Y. Lin and M. B. Pate (lowa State University of Science and Technology), A Thermal Conductivity Prediction Method for Refrigeram Mixtures in the Liquid Phase, Proceedings of the 1992 International Refrigeration Conference - Energy Efficiency and New Refrigerants, edited by D. R. Tree and J. E. Braun, Puidue University, West Lafayette,
IN, volume 2, pages 365-374, July 1992 (10 pages with 8 figures and 1 table, RDB2819)

M. O. McLinden (National Institute of Standards and Technology, NIST), Thermodynamic Evaluation of Refrigerants in the Vapor Compression Cycle Using Reduced Properties, International Journal of Refrigeration, Paris, France, volume 11, pages 134-143, 1988 (RDB3212)

D. A. Nissen and D. C. Macmillan, Apparatus for the Measurement of the Physical Properties of Liquids at Elevated Temperature and Pressure, Review of Scientific Instrumentation, volume 54, number 7, pages $861 \mathrm{ff}, 1983$ (RDB2818)

D. A. Nissen, A Single Apparatus for the Preciae Measurement of the Physical Properties of Liquids af Elevated Temperature and Pressure, report SAN080-8034, Sandia National Laboratory, Albuquerque, NM, 1980 (30 pages with 9 figures and 7 tables, available from JMC or NTIS, RDB2248)

This report describes an instrument designed for measuring the viscosity, surface tension, and density of liquids at elevated temperature (900 ${ }^{\circ} \mathrm{C}, 1650^{\circ} \mathrm{F}$ ) and pressure (10 atm, 147 psia). The theoretical principles, detalls of construction and operation, and response of the instrument are discussed in detail. The thermodynamic properties of a molten salt mixture was measured for $250-450^{\circ} \mathrm{C}\left(482-842{ }^{\circ} \mathrm{F}\right)$ to test its accuracy. The results are shown to be in excellent agreement with published data from prior studies.

U. Plöcker, H. Knapp, and J. Prausnitz, Calculation of High-Pressure Vapor-Liquid Equilibria from a Corresponding-States Correlation with Emphasis on Asymmetric Mixtures, Ind. Eng. Chem. Process Des. Dev., volume 17, number 3, pages 324-332, 1978 (RDB2337)

U. Plöcker, Berechnung von Hochdruck-Phasengleichgewichten $\mathrm{mit}$ einer Korrespondenzmethcide unter besonderer Berücksichtigung asymmetrischer Gemische (Calculation of HighPressure Phase Equilibria by Means of a Correspondence Method Under Special Consideration of Asymmetric fiixtures), doctoral dissertation, Technischen Universităt Berlin, Berlin, FRG, 1977 (in German, 181 pages, RDB3342)

see RDB3343 for translation

U. Plöcker (Technischen Universităt Berlin, Germany), Berechnung von Hochdruck-Phasengleichgewichten mit einer Korrespondenzmethode unter besonderer Berucksichtigung asymmetrischer Gemische (Calculation of HighPressure Phase Equilibria by Means of a Corre- 
spondence Method Under Special Consideration of Asymmetric M(xtures), translation of doctoral clissertation, Oak Ridge National Laboratory, Oak Ridge, TN, undated circa 1992 (RDB3343)

see RDB3342 for original language version

N. D. T. Rohatgl and H. O. Spauschus (Spauschus Associates, Incorporated), Method for Determining Flexural Property Changes of Polymeric Materials upon Accelerated Aging in Refrigerant-Lubricant Mixtures, Proceedings of the 1992 International Refrigeration Conference - Energy Efficiency and New Refrigerants, edited by D. R. Tree and J. E. Braun, Purdue University, West Lafayette, IN, volume 2, pages 395-403, July 1992 (9 pages with 6 figures and 6 tables, RDB2822)

This paper describes a test method to determine changes in flexural properties of small samples of polymeric materials after aging in refrigerants and/or lubricants. The method uses linear stress versus strain curves and calculated flexural modulus of materials. Changes after thermal aging are used to indicate whether a material becomes more flexible (due to absorption of liquid lubricant or refrigerant-fubricant mixture) or less flexible (due to possible extraction of material from the polymeric matrix by the liquid phase). The effects of aging time and temperature also are addressed. The procedure provides quantitative measurements which, along with visual observations, linear swelling and changes in hardness, are necessary to interpret compatibility results from sealed-tube tests. Results are reported for glass-reinforced nylon 6/6, flexible nylon alloy, plasticized nylon coploymers, and polyamide 1212 in R-12 with mineral oil and in R-134a with an unidentified polyalkylene glycol (PAG) lubricant. Density, Shore durometer $D$ hardness, flexural modulus, visual observations, and dimensional changes are tabulated. Stress versus strain curves are plotted both before and after aging.

S. M. Sami (University of Moncton, Canada) and T. N. Duong (University of Sherbrooke, Canada), Dynamic Performance of Heat Pumps Using Refrigerant R-134a, Transactions, American Society of Heating, Refrigerating, and Air-Conditioning Engineers (ASHRAE), Atlanta, GA, volume 97, part 2, 1991; republished in Alternative Refrigerants, technical data bulletin 7(3), ASHRAE, pages 21-27, October 1991 (7 pages with 15 figures, RDB2614)

K. S. Sanvordenker and W. Gram (Tecumseh Products Company), Laboratory Testing Under Controlled Environment, Using a Falex Mlachine, Proceedings of the 1974 Purdue Compressor
Technology Conference, Purdue University, West Lafayette, IN, pages $67 \mathrm{ff}$, July 1974 (RDB2527)

K. S. Sanvordenker and M. W. Larime (Tecumseh Products Company), Screening Tests for Hermetic Magnet Wire Insulation, paper 71 C38EI-39, Proceedings of the Tenth Electrical Insulation Conference, Institute of Electrical and Electronic Engineers (IEEE), New York, NY, pages 122-126, September 1971 (5 pages with 3 figures and 5 tables, RDB2424)

This paper examines both the test methods and results of testing, for magnet wire insulation for hermetlc compressors using R-22. Abrasion results (average cycles to fallure) are tabulated and plotted as recelved and following exposures for 7-10 days, one month, and three months. The insulations examined included two batches of urethane modified polyvinyl formal (FU), two batches of polyester-imide (PEI), dual coat amide-imide topcoat on a polyester base (AI/PE), dual coat polyester (PE/PE), and polyimide (PI). The temperature and elapsed time for burnout are tabulated, for these flve types of insulations, and compared between environments of R-22 and air. Data on retained dielectric strength are presented for FU, PEI, $A l / P E, P E / P E$, and for Formvar urethane and polyesteramide imide (PEAl); blister, resistance is tabulated for all but PE/PE. Because the interactions of enamels and R-22, the paper suggests that the rate of R-22 absorption be determined and exposures adjusted for complete saturation. Tests after saturation provide a cornmon basis for comparisons and suitable screening approach for structurally-different enamels.

H. O. Spauschus (Spauschus Assoclates, Incorporated), G. Freeman, and T. L. Starr (Georgla Tech Research Institute), Surtace Analysis of Glass from Sealed Tubes After Aging with HFC-134a, presentation charts (ASHRAE Annual Meeting, Baltimore, MD, June 1992), Spauschus Associates, Incorporated, Atlanta, GA, USA, June 1992 (21 pages with 7 figures and 2 tables, avallable from $J M C$ as RDB2729)

This presentation reported findings of an irivestigation of the sealed-tube test procedure. The study examined whether fluoride decomposition products, formed in aging hydrofluorocarbons (HFCs) at high-temperature, react with the glass surface. The undentying concems are that such reactions might destroy evidence of other chemical reactions and might also weaken the tubes, posing a safety risk. These concerns challenge the suitability of the ANSI/ASHRAE Standard 97-1989 test procedure for HFCs, and other refrigerants. The charts of 3 ine prior 
studies for and against fluoride attack of glass and an experiment to investigate the issue. Glass shards from sealed tubes, used in thermal aging tests, were examined by photoelectron spectrometer. No fluoride was detected from any tube except one treated with hydrofluoric acid (HF). The study concluded that R-134a undergoes neither thermal decomposition nor reactions with lubricants, metals, or glass at temperatures as high as $200^{\circ} \mathrm{C}\left(392{ }^{\circ} \mathrm{F}\right)$. No evidence was found of fluoride formation in the absence of catalysts, such as molecular sieves. The study also concluded that borosillicate glass tubes are suited as reaction vessels for sealedtube tests. (See RDB2217, RDB2326, RDB2327, RDB2329, and RDB2526 for related papers)

H. O. Spauschus and D. R. Henderson (Spauschus Associates, Incorporated). New Methods of Determining Viscosity and Pressure of PefrigerantLubricant Mixtures, Proceedings of the 1990 USNC/IIR-Purdue Refrigeration Conference and ASHRAE-Purdue CFC Conference, edited by D. R. Tree, Purdue University, West Lafayette, IN, pages 173-176, July 1990 (4 pages with 7 figures, 6 page preprint available from JMC as RDB2249)

This paper describes new methods for measuring viscosity and vapor pressure of refrigerantlubricant mixtures for compositions of $0-100 \%$ and temperatures from -40 to $150^{\circ} \mathrm{C}$ ( -40 to 300 $\left.{ }^{\circ} \mathrm{F}\right)$. The equipment and methods also can be applied to fluids for absorption systems. Automatic data acquisition, data reduction, and computer generated graphics are utilized. Typical viscosity-pressure-temperature-composition data are presented to illustrate engineering applicability. The method uses a new viscometer, based on electromagnetic forces and the time required for a metallic piston to traverse a known distance through the fluid.

H. O. Spauschus and D. R. Hurst, Now Stability Test Methods for Alternative Hefrigerants and Mixtures, presentation slides and abstract (seminar on Ozone/CFC - Alternative Studies Update), ASHRAE 1989 Annual Meeting (Nancouver, BC, Canada) Spauschus Associates, Atlanta, GA, June 1989 (15 pages as RDB0544)

H. O. Spauschus and G. C. Doderer (General Electric Company), Reaction of Refrigerant 12 with Petroleum Oils, ASHRAE Journal, American Society of Heating, Refrigerating, and Air-Conditioning Engineers (ASHRAE), Atlanta, GA, volume 3, number 2, pages 65-69, February 1961 (RDB2526)

H. Wijaya and H. M. Hughes (AlliedSignal Incorporated), A Proposed Procedure for Qualifying Halogen Leak Detectors, Proceedings of the International CFC and Halon Alternatives Conference
(Baltimore, MD), Allance for Responsible CFC Pollcy, Arlington, VA, November 1990 (9 pages with 10 figures and 3 tables, RDB2316)

$X$. XU and D. Clodic (École des Mines de Paris, France), Exergy Analysis on a Vapor-Compresslon Refrigerating System Using R-12, R-134a, and R-290 as Refrigerants, Proceedings of the 1992 International Refrigeration Conference - Energy Efficiency and New Refrigerants, edited by D. R. Tree and J. E. Braun, Purdue University, West Lafayette, IN, volume 1, pages 231-240, July 1992 (10 pages with 3 figures and 8 tables, RDB2725)

Measurement of Two-Phase Refrigerant LiquidVapor Mass Flow Rate, research project 722-RP. American Society of Heating, Refrigerating, and AirCondtioning Engineers (ASHRAE), Atlanta, GA, April 1992 - October 1993 (ASH0722)

This project is developing a meter to measure instantaneous mass flow of two-phase refrigerants for use in laboratories, rating procedures, and field monitoring. The contractor for the project is McMaster University (Canada) led by M. Shoukri and J. S. Chang; it is sponsored by ASHRAE Technical Committee 1.2, Instruments and Measurements.

Retrigerant Extraction Test, Copeland Corporatlon, Sidney, $\mathrm{OH}$, undated clrca 1989 (4 pages with 1 table, available from JMC as RDB0005)

This procedure outlines a test to determine the amount of extractable residue in materials that are used in hermetic refrigerant system when exposed to refrigerant environments. Extractables are determined as the fraction of weight loss after exposure to evaporating refrigerant at elevated temperature and pressure. Charging data are provided for R-12, R-22, and R-502.

Refrigerant-Lubricant Soak Test, Copeland Corporation, Sidney, OH, undated circa 1989 (3 pages, available from JMC as RDB0007)

This procedure outlines a test to determine the effect of materials exposed to a refrigerant-lubricant mixture at operating conditions. The parameters determined are dimensional, including swell, and weight change; visual observations of decomposition also are addressed. The procedure described is based on thermal-aging in a pressure vessel, preceded and followed by measurements.

Sealed Glass Tube Method for Determining the Stability of Materials Used within Refrigeration Systems, product engineering specification ES23138, Copeland Corporation, Sidney, OH, 11 May 1987 (10 pages with 1 figure and 2 tables, available from JMC as RDB0006) 
This procedure outlines a sealed-tube test to rate the quality of lubricants with R-12. It is based on visual Inspection of the oil and metal (steel and copper) test strips and the amount of reacthity, determined by gas chromatography, after thermal aging at $175^{\circ} \mathrm{C}\left(347^{\circ} \mathrm{F}\right)$ for 3 - and 14-day periods.

Sealed Tube Method to Test the Chemical Stability of Material for Use within Refrigeration Systems, standard ANSI/ASHRAE 97-1989, American Society of Heating, Refrigerating, and Air-Conditioning Engineers (ASHRAE), Atlanta, GA, 1989 (RDB2251)

Test Method for Inorganic Acid Removal Capacity of Desiccants Used in Liquid Line Filter Driers, proposed research project 793-TRP, American Society of Heating, Refrigerating, Alr-Conditioning Engineers (ASHRAE), Atlanta, GA, in planning (ASH0793)

This research will develop a method of testing desiccants, at liquid-line conditions, for inorganic acld removal capacity from circulating refrigerant. It then will demonstrate the consistency of the method with different desiccants and refrigerants. UOP molecular sieve $4 A X-H 6$ (8x12), Rhóne-Poulenc activated alumina grade A $(3-5 \mathrm{~mm})$, and Davison Chemical sillca gel grade 407 (8-20 mesh) will be tested. It also will determine the solubility of hydrochloric acid (HCl) in R-:2 and R-22 at specified temperatures. The work is needed to assist component manufacturers in design of filter driers with maximum performance. The need is heightened by increased refrigerant recycling and recovery. This proposed project is sponsored by ASHRAE Tochnical Committeo 3.1, Contaminant Control in Refrigeration Systems. Further information is available from the ASHRAE Manager of Research (+1-404/636-8500).

\section{IMPACTS}

L. J. M. Kuljpers (Phillips Research Laboratories) and S. M. Miner (Consultant), The CFC Issue and the CFC Forum at the 1988 Purdue IIR Confer. ence, International Journal of Refrigeration, Paris, France, volume 12, number 3, pages 118-124, May 1989 (8 pages with 4 figures and 2 tables, RDB. 1108)

L J. M. Kuilpers et al, Retrigeration, Air Condltloning, and Heat Pumps (Technical Options Report), Technical Progress on Protecting the Ozone Laver, report RWR-570-LK-91423-al, United
Nations Environment Programme, Paris, France, December 1991 (RDB2318)

L. J. M. Kuijpers et al, Rotrigeration, Air Condr tioning, and Heat Pumps (Technical Options Report). Technical Progress on Protecting the Ozone Layer, United Nations Environment Programme, Paris, France, 30 June 1989 (172 pages with 13 figures and 24 tables, available from JMC as RDB2317)

This report is one of five prepared to assess the status of technologies impacted by the Montreal Protocol and to identify options for achieving compliance. The report was prepared by an international panel of 48 individuals, pursuant to Article 6 of the Protocol. It addresses the Protocol and reassessment procedure, refrigerants, domestic refrigeration (including refrigerators and other appllances), retail refrigeration (including commercial uses), transport refrigeration, cold storage, industrial refrigeration, comfort air conditioning, mobile air conditioning, heat pumps, and refrigerant recycling.

\section{Costs and Performance}

J. C. Bare (Environmental Protection Agency, EPA), Simulation of Performance of Chlorine-Free Fluorinated Ethers and Fluorinated Hydrocarbons to Replace CFC-11 and CFC-114 in Chillers, paper 3661 Winter Meeting, Chicago, IL, January 1993). Transactions, American Society of Heating, Refrigerating, and Air-Conditioning Engineers (ASHRAE), Atlanta, GA, volume 99, part 1, in publication (RDB3407)

M. H. Blatt (Electric Power Research Institute, EPRI), Electric Chillers: Cost-Effective Choice for the Future, Heating/Piping/Air Conditioning, Penton Publishing, Chicago, IL, volume 65, number 3. pages 75-82, March 1993 (6 pages with 4 figures and 2 tables, RDB3412)

S. Corr, P. D. Guy, F. T. Murphy, G. Tompsett (ICI Chemicals and Polymers, Limited), and T. W. Dekteva (ICl Americas, Incorporated), Performance Characteristics of R-1344 and Afternative Lubricants, seminar presentation at the ASHRAE Winter Meeting, (New York, NY), ICl Americas Incorporated, New Castle, DE, USA, 22 January 1991 (26 pages with 19 charts, RDB2522)

S. W. Crown, H. N. Shapiro, M. B. Pate (lowa State University of Sclence and Technology). A Comparison Study of the Thermal Performance of R12 and R-134a, Proceedings of the 1992 Interna. tional Refrigeration Conference - Energy Efficiency 
and New Refrigerants, edited by D. R. Tree and J. E. Braun, Purdue University, West Lafayette, IN, volume 1, pages 187-196, July 1992 (10 pages with 11 figures and 2 tables, RDB2720)

This paper compares the performance of a 10 $\mathrm{kW}$ (3 ton) refrigeration system with R-134a to R-12. The equipment tested, instrumentation, and test conditions are described. Both the capacity and coefficient of performance (COP) are plotted as functions of the condenser water temperature for representative evaporator tem. peratures. COP and capacity ratios for R-134a to R-12 are similarly plotted with varying R-134a charges. System performance was shown to be less sensitive to the charge for R-12. Experimental results show that R-134a yielded higher efficiency and cooling capacity for almost all tests, especially with subcooling of $5.6-7.5^{\circ} \mathrm{C}$ $\left(10-15^{\circ} \mathrm{F}\right)$. COPs are compared to pressure ratios for the two refrigerants, leading to a conclusion that the system can operate at a higher pressure ratlo with $R-134 a$ and yet have a higher COP than with R-12. The effects of operating conditions are presented in detail.

R. El-Bourini, K. Hayashi, and T. Adachi (Calsonic Corporation), Automotive Air Conditioning System Performance with HFC-134a Refrigerant, paper 900214 (SAE International Congress and EXposition, Detroit, MI, 26 February - 2 March 1990), Society of Automotive Engineers (SAE), Warrendale, PA, February 1990 (12 pages with 14 figures and 3 tables, RDB2252)

S. K. Fischer and F. A. Creswick, Energy-Use Impact of Chlorofluorocarbon Alternatives, report ORNL/CON-273, Oak Ridge National Laboratory, Oak Ridge, TN, February 1989 (138 pages, available from NTIS, RDB0924)

This study estimates energy-use impacts of phase out of chlorofluorocarbon (CFC) refrigerants under the Montreal Protocol. Major energy-related applications of the fully halogenated CFCs (R-11, R-12, R-113, R-114, and R115) were identified. Four groups of alternattve refrigerants then were considered: 1) chemicals with very similar properties (near drop-in substitutes); 2) a fallback scenario relying on available compounds with more product development; 3) a worst case in which no new chemicals become available, chlorine-containing compounds (e.g., R-22) cannot be used, and fiberglass insulation is used in place of CFCblown foams; and 4) an advanced technology using highly efficient insulation and refrigeration systems. Energy use will not increase significantly if near drop-in compounds (principally $R$. $134 a, R-123$, and $R-141 b$ ) are used. If they do not become available, national energy use will increase by 1.2 quad (1015 Btu) per year. Development of advanced technologies could reduce annual energy use by about 0.83 quad. The major impacts are in applications using foam insulations blown with CFCs (e.g., refrigerators, freezers, water heaters, roofs of commercial buildings, and insulated bullding foundations). The penalty associated with refrigeration equipment is smaller, but is contingent upon attaining the high compressor efficiencies for alternative refrigerants that are available for CFCs.

H. B. Ginder, R-123 versus R-11 Pertormance Test, York International Corporation, York, PA, 19 July 1989 (2 pages with 1 table, available from JMC as $\mathrm{RDB0008)}$

The performance of a 200-ton chiller, designed for R-11 operation, is compared at nominal rating conditions for R-123 and R-11 with a naphthenic oil. The chiller employs a single-stage centrifugal compressor with an open drive and air-cooled motor. The results at full load indlcate a $16.3 \%$ reduction in capacity and an increase of $9.2 \%$ in $\mathrm{kW} /$ ton ( $8 \%$ lower efficiency. Although testing at loads of $20-100 \%$ capacity and varied evaporator and condenser conditions are indicated, part-load performance is not reported.

P. E. Hansen (Danfoss-Flensburg GmbH, Germany) and $L$. Finsen (Danfoss $A / S$, Denmark), Lifetime and Reliability of Small Hermetic Compressors Using a Ternary Blend HCFC-22/HFC1528/HCFC-124, Proceedings of the 1992 International Refrigeration Conference - Energy Efficiency and New Refrigerants, edited by D. R. Tree and J. E. Braun, Purdue University, West Lafayette, IN, volume 2, pages 641-649 July 1992 (9 pages with 6 figures and 2 tables, RDB2839)

E. Heinzelmann and M. S. Ussyk (Empresa Brasileira de Compressores S/A, Embraco), Hermetic Refrigerating Compressors and CFC Substitution, International Journal of Refrigeration, Parls, France, volume 14, number 1 , pages 10-15, January 1991 (6 pages with 11 figures, RDB1201)

This paper presents a basic methodology for screening substitutes for R-12 in refrigerating compressors. Simple analysis of refrigerant thermodynamic properties are presented within the ranges of evaporating and condensing temperatures in which small refrigerating systems operate. Comparisons of vapor pressure, coefficients of performance (COPs), compression ratio, final isentropic compression temperature, and volumetric refrigerant effect are presented for R-12, R-22, R-134a, and R-152a. Additionally, a procedure for developing compressors for use with alternative refrigerants is presented. 
Material compatibillty, performance, reliabllity, and means of production are considered. The differences between developed and developing countries are noted, using Brazll as an example.

E. D. Lawler, HFC-134a vo R-12 Contrifugal Chiller Performance Comparison, SnyderGeneral Corporation, Staunton, VA, 22 August 1990 (1 page with 1 table, avallable from JMC as RDBO801)

The performance of a 100-ton, single-stage, hermetic centrtugal water chiller is compared for R-12 and R-134a. Both tests were run at standard rating conditions (ARI Standard 55088) with the chiller operating at its maximum capacity. The compressor gears were changed to increase the impeller speed to accommodate the greater isentropic head isse required with R134a. The low-pressure cut-out switch and thermostatic expansion valve were adjusted after changing refrigerants, but other hardware and control settings were the same for both tests. The capacity and efficiency increased with R$134 a$, by 0.8 and $4 \%$, respecthely.

E. D. Lawier, HFC-134a ve R-500 Centrifugal Chiller Pertormance Comparison, SnyderGeneral Corporation, Staunton, VA, 29 August 1990 (1 page with 1 table, avallable from JMC as RDB0802)

The performance of a 112-ton, single-stage, hermetic centrfugal water chiller is compared for R-500 and R-134a. Both tests were run at standard rating condltions (ARI Standard 55088) with the chiller operating at its maximum capacity. The chiller initlally was tested with R500 as a baseline and then recharged with R134a. The lubricant was changed from a naphthenic mineral ofl (Witco Suniso(R) 4GS) to an ester (Mobil XRL 1681-1). The low-pressure cutout switch and thermostatic expansion valve were adjusted after changing refrigerants, but other hardware and control settings were the same for both tests. A third test was run with the impeller replaced to provide higher flow. The compressor gears were changed for a fourth test to increase the impeller speed. The capactty with R-134a decreased by 9.9, 1.3, and $4.1 \%$ for the three tests and the efficiency decreased by 2.8 and $0.5 \%$ for the second and fourth tests, but increased by $0.1 \%$ for the third.

$X-Z$. Leng (Belling Research Institute of Household Electric Appliances, China). Testing Study About HFC.152a and the Mixture of HFC-152a with HCFC-22, publication unknown, clrca 1991 (8 pages with 8 figures and 1 table, available from JMC as RDB2513)

This paper analyzes use of R-152a and blends of R-152a with R-22, as substitutes for R-12 for domestlc refrigerator/freezers. The freezer and food-section temperatures, suction and dis- charge pressures, run time, power, and energy use are compared for R-12, R-152a and three compostitions of R-22/152a, namely 14, 22, and $33 \%$ by mass. These data were measured using an instrumented refrigerator/freezer (Hang-Tlan model BCD-177A), reported as having the highest efficiency in the Chinese market. A blend containing approximately $14 \%$ R-22 by mass offered the lowest energy use, 8.2\% less than whth R-12; R-152a alone resulted in a savings of $1.0 \%$. The study found that the freezer evaporator needs to be enlarged to use R-152a. Additional tests were performed changing the lubricant from mineral oll to an alkyibenzene, resulting in slightly higher energy use; compatibility was not addressed. The impacts of leakage were assessed based on compllance with the Chinese requirement (standard GB 8059.1. 3.86) that refirgerant losses not exceed $0.5 \mathrm{~g} / \mathrm{yr}$ $(0.02 \mathrm{oz} / \mathrm{yr})$. Assuming that all refrigerant lost is R-22, an R-22/1528 (30/70 by mass) blend would fractlonate to $25.3 \%$ R-22, improving performance slightly. The paper concludes that R-22/152a results in lower energy use than for R-12 withoust change in construction or performance.

E. E. A. Lund, R. G. Richard, and I. R. Shankland (AlliedSlgnal incorporated). A Perlormance Evaluation of Envtroamentally Accoptable Foam Blowing Agonts, Polyurethanes 88 (proceedings of the 31st SPI Annual Technical and Marketing Conference), pages 290-296, 1988 (7 pages, RDB0502)

M. O. McLinden (National Institute of Standards and Technology, NIST) and R. Radermacher (University of Maryland), Mothods for Comparing the Pertormance of Pure and Mbxed Refrigerants in the Vapor Compreasion Cycle, Intemational Journal of Refrigeration, Paris, France, volume 10, number 6, pages 318-325, November 1987 (8 pages with 8 figures and 2 tables, RDB2508)

M. O. McLinden (National Institute of Standards and Technology, NIST), Optimum Rofrigerants for Nonideal Cycles - An Anatyels Employing Corresponding States, Proceedings of the 1990 USNC / IIR Purdue Refrigeration Conference and ASHRAE-Purdue CFC Conference, edited by D. R. Tree, Purdue University, West Lafayette, IN, pages 69-79, July 1990 (11 pages with 7 figures, RDB0920)

The principle of corresponding states is used to evaluate the effects of the thermodynamic characteristics of working fluid performance in refrigeration cycles. Desired characteristics, expressed in terms of the crtical temperature and ideal gas heat capacity using propane as the reference fluld, are examined for vartous de- 
partures from the theoretical (ideal) vapor-compression cycle. The baseline cycle for the comparisons include compressor efficlency and heat transfer limitations in the condenser and evaporator. The paper addresses the modffied Benedict-Webb-Rubin (MBWR) equation of state chosen for property calculations, the cycle analysis simulation model, and the application of the model to the selection of alternative refrigerants. The results indicate that modifications to the basic vapor-compression cycle should be considered for refrigerants with two or more carbon atoms to achieve maximum energy efficiency.

J. Pannock, D. A. Didion (National Institute of Standards and Technology, NIST), and R. Radermacher (University of Maryland), Performance Evaluation of Chlorine-Free Zeotropic Refrigerant Mixtures in Hear Pumps - Computer Study and Tests, Proceedings of the 1992 International Refrigeration Conference - Energy Efficiency and New Refrigerants, edited by D. R. Tree and J. E. Braun, Purdue University, West Lafayette, IN, volume 1, pages 2534, July 1992 (10 pages with 8 figures and 2 tables, RDB2710)

J. Pannock and D. A. Didion (National Institute of Standards and Technology. NIST), The Performance of Chlorine-Free Binary Zeotropic Refrigerant Mixtures in a Heat Pump, report NISTIR 4748, National Institute of Standards and Technology, Gaithersburg, MD. December 1991 (78 pages with 50 figures and 2 tables, avallable from NTIS at price code A05, RDB2507)

This report examines zeotropic mixtures to replace R-22. 15 binary blends of R-23, R-32, R125, R-134a, R-143a, and R-152a (all hydrofluorocarbons, HFCs) were evaluated using the CYCLE11 simulation program. The rationale for selecting these component fluids is outlined. Efficiency, volumetric capacity, suction pressures, discharge temperatures, and discharge pressures are analyzed and compared. The most promising candidates, R-32/134a and R$32 / 152 a$, were tested in a breadboard heat pump. A series of tests to evaluate use of a llquid-line heat exchanger also was performed. The findings indicate that these two zeotropes may be sultable as replacements for R-22, but that multiple tradeoffs exist in performance for different compressor speeds and mixture compositions. Performance improvements of 2 and $14 \%$ were found for R-32/R-152a for the lowtemperature heating and high temperature cooling modes, respectlvely. The ozone depletion potential of this mixture is zero and the global warming potential is approximately onefourth that of R-22, but the mixture is flammable in the entire composition range. R-32/R-134a mixtures, containing more than $35 \%$ A-32 by mass, ylelded slightly improved performance for cooling and slightly lower for heating. Gains of $5 \%$ for cooling and $2 \%$ for low-temperature heating were measured and compared to R-22 for the equivalent speed and capacities. These results were achleved using the same test apparatus, without optimization for each fluid. Comparative efficiencies and capacities are plotted for the full range of mass fractions at selected operating conditions. An uncertainty analysis is presented in an appendix, but the test results confirm the validity of the modelling approach used.

S. M. Saml (University of Moncton, Canada) and T. N. Duong (University of Sherbrooke, Canada), Dynamic Pertormance of Heat Pumps Using R134a, paper 3491, Transactions, American Society of Heating, Refrigerating, and Air-Condtioning Engineers (ASHRAE), Atlanta, GA, volume 97, part 2, pages 41-47, 1991 (7 pages with 15 figures, RDB2346)

J. R. Sand, E. A. Vineyard, and R. J. Nowak (Oak Ridge Natlonal Laboratory, ORNL). Comparable Refrigerant Performance Data, Oak Ridge $\mathrm{Na}$ tional Laboratory, Oak Ridge, TN, July 1989 (8 pages with 1 figure and 5 tables as RDB0543)

performance comparisons for R-12, R-22, R-32, R-114, R-124, R-125, R-134, R-134a, R-142b, R143, R-143a, R-152a, R-218, and R-C318 at four standard heat pump rating conditions

M. W. Spatz (AllledSignal Incorporated), Pertormance of Alternative Refrigerants from a System's Perspective. Proceedings of the International CFC and Halon Alternatives Conference (Baltimore, MD), Alliance for Responsible CFC Policy, Arlington, VA, pages 352-361, December 1991 (10 pages with 5 figures and 3 tables, RDB2253)

The modeled coefficients of performance (COPs), capacities, and discharge temperatures

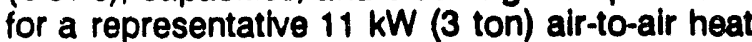
pump are presented for R-22, R-32/R-125 $(60 / 40), R-134 a$, and R-152a - all HFCs. The analyses were made with a modified version of the Oak Ridge National Laboratory (ORNL) Mark III Heat Pump System Design Model. Calculated COPs are tabulated both with simple replacement of R-22 and with reoptimization of the expansion device, heat exchangers, and tubing sizes. Calculations based on a simple (saturated) thermodynamic cycle indicate $8 \%$ lower, $1 \%$ lower, and $4 \%$ higher efficiency for R32/R-125, R-134a, and R-152a, respectively, compared to R-22. The magnitude of these differences shrink when subcooling and superheating are introduced. With reoptimization, the differences range from -0.3 to $+3.2 \%$ for a sys- 
tem optimized for both the heating and cooling modes and -0.9 to $+0.6 \%$ for cooling only, depending on the refrigerant. The paper, therefore, concludes that while these three alternative refrigerants could be used without significant energy penalty, other factors need to be addressed. The approximately $50 \%$ higher condensing pressure of R-32/R-125 could Increase costs. Changes in compressor displacement, increased for R-134a and decreased for R-32/R125, also offect system costs. The flammability of R-152a would either eliminate it from consideration or impact costs by requiring additional safety controls.

T. G. Statt (U.S. Department of Energy, DOE), Energy Impllacations of Global Climate Change, presentation charts, 1989 ASHRAE Annual Meeting (Vancouver, BC, June 1989), U.S. Department of Energy, Washington, DC, June 1989 (16 pages, RDB1109)

E. A. Vineyard (Oak Ridge National Laboratory, ORNL), Laboratory Testing of a Heat Pump System Using an R-1381/R-152a Refrigerant Mixture, paper 3130, Transactions, American Society of Heating, Refrigerating, and Air-Conditioning Engineers (ASHRAE), Atlanta, GA, volume 94, part 1, 1988 (11 pages with 8 figures and 4 tables, RDB2329)

J. Zheng and J. W. Pelava (AlledSignal Incorporated). Performance Test of R-12 Alternates in a Hermetlc Compressor, paper 149, proceedings of the XVIIIth International Congress of Refrigeration (Montreal, Québec, Canada, August 1991), International Institute of Refrigeration, Paris, France, August 1991 (11 pages with 3 figures and 4 tables, RDB2254)

This paper presents measured results of calorimeter tests of replacements for R-12 at -23 to $+1{ }^{\circ} \mathrm{C}\left(-10\right.$ to $\left.+30^{\circ} \mathrm{F}\right)$ evaporating and 38 and $49^{\circ} \mathrm{C}\left(100\right.$ and $\left.120^{\circ} \mathrm{F}\right)$ condensing. The fluids tested included R-134a with a polyalkylene glycol lubricant and four zeotropes with alkylbenzene lubricants. The blends included R-22/R124 (55/45 and $43 / 57 \%$ by woight) and $R-22 /$ $R-152 a / R-124(50 / 20 / 30$ and $36 / 24 / 40)$. The compressor discharge temperature, compression ratlo, cooling capacity, and efficiency are compared to those of R-12.

L. Zhigang, L Xlanding, Y. Jlanmin, T. Zhoufang, J. Pingkun (Xl'an Jlao Tong University, China), C. Zhohua, L. Dairu, R. Mingzhl, Z. Fan, and W. Hong (Sha'an XI Refrigerator Factory, China), Applicathon of HFC-152a/HCFC-22 Blends in Domestlc Refrigerators, publication unknown, circa 1992 (7 pages with 3 tables, partially illegible and incomplete copy available from JMC as RDB2514)
This paper documents a study of substltutes for R-12 In refrigerators. Analytical data are tabulated for ozone depletion potentlal, global warming potentlal, condensing pressure, evaporating pressure, pressure ratio, compressor discharge temperature, capacity, and coefficient of performance (COP) for nine pure refrigerants. They include R-12, R-22, R-123, R-124, R-125, R134a, R-142b, R-143a, and R-152a. Based on both capacity and COP, only R-134a and $R$ $152 \mathrm{a}$ were found sultable, and R.134a was $r \theta-$ jected on the basis of lower efficiency. The paper concludes that the blend of R-22/152a is more promising than pure R-152a: This finding is based on tests that show that addition of small amounts of R-22 to R-152a can reduce its flammability, but still result in a vapor pressure curve (vapor pressure and temperature relation) similar to that of R-12. Tests of a selected refrigerator using three different compressors are summarized to compare the performance of $R$ 12 with two composttions of R-22/152a. The blend requires a change in magnet wire for the motors in hermetic compressors, but suitable enamels have been identified.

Impact of a CFC Ban on the Cost and Pertormance of Household Roirigerators, Centrifugal Chillers, and Commercial/Industrial Systems, technical memorandum to U.S. Department of Energy, Arthur D. Little, Incorporated, Cambridge, MA, August 1989 (82 pages, RDB1110)

This report assesses the potential response of and impacts on the refrigeration industry to a regulatory ban on the production of CFC working fluids by the year 2000 . The primary focus is on the most likely alternatives, in each application category, and their Impact on the design and performance of new equipment.

Potential Costs of Restricting Chlorofluorocarbon Use, report SR/ESD/89-01, Energy Information Administration, U.S. Department of Energy, Washington, DC, August 1989 (88 pages with 33 figures, 10 tables, and 2 appendices, RDB1111)

This report analyzes economic costs for the United States to phase out production of chlorofluorocarbons (CFCs) by the year 2000. CFCs are divided into two groups for the study, one comprising foams, solvents, and fire extinguishants and one for application in refrigeration and air condtioning. The latter is addressed by analyzing the phase out costs for new equipment, impacts on energy efficiency and the economy, and premature obsolescence of existing equipment. The report reviews CFC uses, substitutes, problems assoclated with phase out, the assessment of impacts, and comparison whth a separate but related study. The report concludes that substltutes will increase costs by $2 \%$ 
in new equipment, equating to an increase of $\$ 6.4-12.5$ billion in 1989 dollars. It also found a $1.2 \%$ decrease in energy efficiency, leading to 30-90 TWh (0.1-0.3 quadrillion Btu) higher primary energy use. The largest impact would result from premature obsolescence costs, as high as $\$ 13-2$ billion with $75 \%$ attributable to automobile air conditioners.

Report to the Secretary of Energy on Ozone-Depleting Substances, U.S. Department of Energy, Washington, DC, October 1989 (63 pages, RDB1112)

analysis of the energy and economic effects of phasing out certain organic chlorine and bromine products

\section{Environmental}

J. G. Anderson, D. W. Toohey, and W. H. Brune, Free Radicals Whin the Antarctic Vortex: The Role of CFCs in Antarctic Ozone Loss, Science, volume 251, pages 39-46, 4 January 1991 (8 pages with 6 figures, RDB1202)

This article describes experiments and observations linking chlorine and bromine concentrations with ozone depletion in the antarctic vortex. It briefly reports the findings of the National Science Foundation Ozone Experiment (NOZE 1) expedition in the austral spring of 1986. It describes in greater detall the high-alttude mission and in situ measurements of the subsequent Airborne Antarctic Ozone Experiment. Mathematical equations defining the mechanisms of ozone depletion are presented for chlorine and bromine. What sets Antarctic ozone depletion apart in the context of global change is both the severity of the phenomenon and the unusual decoupling of physical and chemical time constraints that control transformation rates in a specific region of the atmosphere. The article concludes that the dramatic reduction in ozone over the antarctic continent would not have occurred had CFCs not been released to the atmosphere.

J. M. Calm (Engineering Consultant), Global Warming Impacts of Chillars, Hoating/Piping/Air Conditioning, Penton Publishing, Chicago, 11 , volume 65, number 2, pages 28-39, February 1993 (9 pages with 9 figures and 1 table, available from JMC as RDB3304)

This paper summarizes a study of comparative impacts of chillers on global warming, including both direct (chemical) and indirect (energy-related) effects. It summarizes refrigerant options for chillers and uses of alternative refrigerants to replace chlorofluorocarbons (CFCs). It then reviews the greenhouse gas impacts of refrigerant emissions, and compares them to other warming sources. It discusses both global warming potential (GWP) values and their variation with the integration time horizon (ITH) selected for analysis. GWPs are plotted for CFC and atternative refrigerants and as a function of ITH. The paper then summarizes prior analyses of chiller warming impacts, and introduces a recent study performed for EPRI. It summarizes information used to calculate historical and projected carbon dloxide factor (CDF) values, ratios of carbon dioxide amount produced per unit of energy used. The paper outlines regional varlations in fuels used to generate electricity as well as generation and load proflles. It presents calculated warming findings on both a national and regional bases, noting that the regional data can be extrapolated to impacts for other locations or countries with similar generation mixes. The paper concludes that once high-GWP CFCs are eliminated, global warming will be more readily influenced through efficiency improvement and emission reduction than by refrigerant substlutions. It reaffirms the findings of prior studles that indirect effect dominates over direct, including the combined impacts leakage, service, and ultimate disposal losses. It also notes that direct effect is equivalent to less than a 0.1 to $1.1 \%$ change in efficiency, depending on the refrigerant used, once service and disposal losses are reduced and CFCs eliminated. Three figures show comparative warming on a national and regional basis for chillers using R-11, R-12, R-22, $R-123$, and $R-134 a$ as well as direct-fired, $a b-$ sorption chillers (double-effect, water/lithiumbromide). A final plot shows the progressive reduction in total equivalent warming impact (TEWI) for R-11 and R-123 for 1985-1995 based on emission reductions and efficiency improvemonts.

G. J. Epstein and S. P. Manwell (Xenergy Incorporated), Environmental Tradeoffs Between CFCs and Alternative Rofrigerants, ASHRAE Journal, American Society of Heating, Refrigerating, and AirConditioning Engineers (ASHRAE), Atlanta, GA, volume 35, number 1, pages 38-44, January 1993 (7 pages with 1 figure and 5 tables, RDB3225)

D. A. Fisher, C. H. Hales, W-C. Wang, M. K. W. Ko, and N. D. Sze, Model Calculations of the Relative Effects of CFCs and Their Replacements on Global Warming, Nature, volume 344, pages 513 516, 5 Aprll 1990 (4 pages, RDB3328)

S. K. Fischer (Oak Ridge Natlonal Labcratory, ORNL) and M. McFarland (DuPont Chemicals), Alternatives to CFCs and Global Warming: Systems Approach to Evaluating Net Contribu- 
tions, MRS Bulletin, Materlals Research Society, volume XVII, number 3, pages 39-42 (4 pages with 2 figures and 1 table, RDB2413)

S. K. Fischer, P. J. Hughes, P. D. Fairchild (Oak Ridge National Laboratory, ORNL), C. L. Kusik, J. T. Dieckmann, E. M. McMahon, and N. Hobday (Arthur D. Little, Incorporated, ADL), Energy and Global Warming Impacts of CFC Alternative Technologies, Alternative Fluorocarbons Environmental Acceptability Study (AFEAS) and U.S. Department of Energy (DOE), Washington, DC, December 1991 (602 pages with 98 figures and 40 tables plus supporting figures and tables in appendices, RDB2432)

This report documents detailed analyses of global warming for options to replace chlorofluorocarbons (CFCs) in energy-related applications. The study addressed both direct and indirect effects, namely greenhouse gas impacts of chemical emissions and carbon dioxide emissions from associated energy use. The report compares impacts, for alternative technologies, on the basis of total equivalent warming impact (TEWI). Domestic refrigerator-freezers, commercial refrigeration, commercial chillers, residential and commercial unitary heating and cooling equipment, automobile air conditioning, building insulation, and solvents for metal and electronic cleaning were examined on an international basis. The refrigerants addressed for household refrigeration included R-12, R-134a, R-22/152a/124, R-22/142b; absorption and Stirling cycles also were assessed. R-12, R-22, R-134a, R-502, and R-717 (ammonia) were examined for commercial refrigeration. R-11, R-12, R-22, R-123, R-134a, and R717 were addressed for commercial air conditioning along with water-lithium bromide absorption cycles. R-22, R-134a, and ammoniawater absorption were analyzed for unitary air conditioners. R-12, R-134a, R-152a, R-290 (propane), and $R-22 / 152 a / 124$ were evaluated for automotive air conditioning along with Brayton and Stirling cycles.

K. Hearle, F. Riza, A. Whitfield, J. Hemby, J. S. Hoffman, and S. Seidel, Analysis of the Environmental Implications of the Future Growth in Demand for Partially-Halogenated Chlorinated Compounds, report EPA 400/1-90-001, U.S. Environmental Protection Agency (EPA), Washington, DC, January 1990 (304 pages, RDB1113)

M. C. MacCracken et al, (Lawrence Livermore National Laboratory). Energy and Climate Change (Report of the DOE Multi-Laboratory Climate Change Committee), Lewis Publishers, Chelsea, MI, USA, February 1990 (182 pages, RDB2313)
M. J. Molina and F. S. Rowland (University of Californla - Irvine), Stratospheric Sink for Chlorofluoromethanes: Chlorine Atom Catalysed Destruction of Ozone, Nature, volume 249, pages 810-812 (3 pages, RDB0928)

S. L. Roan, Ozone Crisis: The 15-Year Evolution of a Sudden Global Emergency, John Wiley and Sons, Incorporated, NY, New York, 1989 (292 pages, RDB 1208)

This book reviews the 15-year history of action and reaction to the ozone-depletion problem. The text specifically addresses the intervention of politics, and the control both it and economic pressures had over the scientific community.

F. S. Rowland (University of California - Inine), The CFC Controversy: Issues and Answers, ASHRAE Journal, American Society of Heating, Refrigerating, and Air-Conditioning Engineers (ASHRAE), Atlanta, GA, volume 34, number 12, pages 20-27, December 1992 (6 pages with 4 tables, RDB3223)

F. S. Rowland and M. J. Molina (University of Callfornia - Irvine), Chlorofluoromethanes in the Environment, Reviews of Geophysics and Space Physics, American Geophysical Union, Washington, DC, volume 13, number 12, pages 1191-1192, 1975 (2 pages, RDB0927)

M. R. Schoebert and D. L. Hartmann, The Dynamics of the Stratospheric Polar Vortex and its $R_{\theta}$ lations to Springtime Ozone Depletions, Science, volume 251, pages 46-52, 4 January 1991 (7 pages with 5 figures, RDB1203)

S. Solomon and D. L. Albritton (National Oceanic and Atmospheric Administration), Time-Dependent Ozone Depletion Potentials for Short- and Long-Term Forecasts, Nature, volume 357, pages 33-37, 7 May 1992 (5 pages with 3 figures and 2 tables, RDB2A15)

S. Solomon, M. Mills (National Oceanic and Atmospheric Administration), L. E. Heidt, W. H. Pollock (National Center for Atmospheric Research), and A. F. Tuck (National Oceanic and Atmospheric Administration), On the Evaluation of Ozone Depletion Potentials, Journal of Geophysical Research, volume 97, number D1, pages 825-842, 20 January 1992 (18 pages with 12 figures and 5 tables, RDB2A16)

Assessment of the Impacts Associated with a Total CFC Phase Out, final report, Putnam, Hayes and Bartlett, Incorporated, Washington, DC, July 1989 (60 pages, RDB1118)

IEA Heat Pump Center Newsletter, issue on Heat Pumps and the Environment, International Energy Agency (IEA) Heat Pump Center (HPC), Sittard, 
The Netherlands, volume 7, number 2, June 1989 (64 pages, RDB0925)

This issue focuses primarlly on refrigerant environmental impacts of refrigerants.

Newly Found Viruses Might be the Key to Controlling Seas, R\&D Magazine, Des Plaines, IL, volume 32, number 12, December 1990, page 86 (1 page, RDB1114)

This news brief announces the discovery of a group of unspecified aquatic viruses that may aid in reducing global warming. These viruses encourage reproduction of a class of phytoplankton that absorb carbon dioxide. Other aquatic viruses could control reproduction of oxygen-absorting phytoplankton that kill marine life by robbing water of oxygen. Additional research is required to better understand these viruses and their affect on marine life.

Possible Environmental Effects of Chlorofluorocarbons, position statement and paper, American Society of Heating, Refrigerating, and Air-Condltioning Engineers (ASHRAE), Atlanta, GA, 2 February 1989 (12 pages, RDB1115)

Scientific Assessment of Ozone Depletion: 1991, chaired by $D$. L . Albritton (Natlonal Oceanic and Atmospheric Administration, NOAA) and R. T. Watson (National Aeronautics and Space Administration, NASA), report 25, World Meteorological Organization (WMO), Global Ozone Research and Monitoring Project, Geneva, Switzerland, 1991. (340 pages, available from WMO; also available from JMC as RDB2701)

This definitive work updates the assessment used in governmental and international decision-making on protection of the stratospheric ozone layer and climate change. The volume addresses source gases including concentrations, emissions, and trends; ozone and temperature trends; heterogeneous processes including laboratory, field, and modeling studies; both stratospheric and tropospheric processes including observations and Interpretations; ozone depletion and chlorine loading potentials (ODP and CLP values); radiative forcing of climate; future chlorine and bromine loading and ozone depletion; aircraft, rocket and space shuttle effects on stratospheric ozone; and ultraviolet radlation changes. The study was prepared by eleven international panels and subjected to peer reviews.

Scientifle Assessment of Stratospheric Ozone: 1989, report 20, World Meteorological Organization, Geneva, Switzerland, 1989, program description, volume I (534 pages, avallable from GPO as report 1990-259-707:83731; RDB1116)
Scientific Assessment of Stratospheric Ozone: 1989 (Appendix: AFEAS Report), report 20, World Meteorological Organization, Geneva, Switzertand, 1990, program description, volume II (536 pages, available from AFEAS; also available from JMC as RDB1117)

The Impact of Heat Pumps on the Greenhouse Effect, report HPC-ASR1, International Energy Agency (IEA) Heat Pump Center (HPC), Sittard, The Netherlands (64 pages, RDB2C08)

This report summarizes analyses to determine how different types of heat pumps can contribute to reduction of giobal warming. It focuses on heating-only heat pumps for space and service-water heating. Some discussion is included of dual-mode (heating and cooling) and cooling-only devices. The report revlews the international status of heat pump use, the environmental concerns with stratospheric ozone depletion and global warming, and acthities in selected countries to address these issues. The analyses were based on separate studies conducted in member countries of the IEA and by various international organizations. Of the 41 national studies, 32 examine heat pump roles in reducing emissions of greenhouse gases. Eight address heat pumps relathe to reductions in electricity or fossil-fuel use. One examines the effects of alternative technologies on heat pump energy use and greenhouse gas emissions. The report reviews the efficiency levels of different types of heat pumps, opportunities to reduce carbon dioxide emissions, and direct warming effects resulting from emissions of working fluids or methane fuel. The report concludes that the greatest reduction in warming impact can be achieved by changing to working fluids with a lower global warming potential. Additional reductions can be achieved by reducing losses during equipment operation, through use of hermetic designs and recycling of fluids upon retirement. The report notes that sealing is essential for rellability and because working fluids are frequently flammable and/or toxic. Addressing the future of heat pumps, the report notes the need to optimize the full energy system including improvement of power plant efficiency and use of ccgenerationbased power production.

The Impact of Ozone-Layer Depletion, document 7. Global Environment Monitoring System (GEMS), United Nations Environment Programme (UNEP), Nairobi, Kenya, 1992 (40 pages whit 17 figures and 1 table, available from JMC as RDB2704)

This report is one in a series that summarize scientific and engineering assessments for those without technical qualifications. It deals with the effects of ozone depletion on human 
health and the environment, and outlines ways of reducing damage to the ozone layer. This publication reviews the scientific background for ozone depletion, including observations of the Antarctic ozone hole, mid-latitude ozone-layer depletion, and Arctic ozone-layer depletion. It then addresses the effects of ultraviolet radiation - specifically the UV-B wavelengths - on immune systems, skin cancer, and increasing eye damage. It also discusses impacts on the oceans and aquatic ecosystems, land plants, air pollution, and damage to materials. The document then discusses ozone-frlendly technologies for refrigeration, air conditioning, and other uses. It stresses the importance of global cooperation and the need for recycling and destruction of chlorofluorocarbons (CFCs) and halons. The report discusses future policy options and lists several information sources.

The Ozone Layer, document 2, Environment Monitoring System (GEMS), United Nations Environment Programme (UNEP), Nairobi, Kenya, 1987 (RDB2703)

\section{REGULATORY ACTIONS}

\section{International}

S. C. MCDonald, International Aspects of Restrictions on Ozone-Depleting Substances, report PNL-7163, Pacific Northwest Laboratory, Richland, WA, October 1989 (72 pages with 7 tables, available from NTIS, RDB2B06)

This report summarizes international efforts related to protection of stratospheric ozone as well as implications for the United States. It includes a discussion of activities in other countries to meet restrictions in production and use of ozone-depleting substances (ODSs). Data are presented on use of controlled ODSs in these countries. The document concludes with presentation of trade and international competitiveness issues relating to transition to alternatwes to the regulated chlorofluorocarbons and halons. Information is provided on foreign chemical manufacture and the search for alternatives to regulated substances. Appendices identify participants in the Vienna Convention and Montreal Protocol, a draft declaration from the Helsinkl meeting in May 1989 of parties to the Montreal Protocol, and the 1987 text of the Protocol itself.
Handbook for the Montreal Protocol on Substances That Deplete the Ozone Layer, United Nations Environment Programme, Ozone Secretariat, Nairobi, Kenya, second edition, October 1991 (104 pages including 2 page errata, available from JMC as RDB2702)

This document contains the complete text of the Montreal Protocol, originally adopted in 1987 as adjusted and amended in June 1990 and further amended in June 1991. The decisions of the Parties to the Montreal Protocol, that relate to its interpretation, at meetings in Helsinkl in (May 1989), London (June 1990), and Nairobi (June 1991) appear as footnotes to the Articles to which they pertain. The handbook also includes the following appendices: the He/sinki Declaration on Protection of the Ozone Layer (2 May 1989); declarations by Australia, Austria, Belglum, Canada, Denmark, Finland, Germany, Liechtenstein, Netherlands, Now Zealand, Norway, Sweden, and Switzerland on phase out of CFCs not later than 1997 (June 1990); resolution by represented parties on more stringent measures (June 1990); statements by Austria, Denmark, Germany, Finland, Nonway, Sweden, and Switzerland on more stringent measures (June 1991); status of ratification (September 1991, now supersoded); list of relevant publications; nonconfidential production and consumption data regarding controlled substances; Criteria for Projects under the Multilateral Fund; names and address of assessment panel chairmen; annotated Vienna Convention for the Protection of the Ozone Layer; status of ratification of the Vienna Convention (September 1991; now superseded); and the Rules of Procedure. The Vienna Convention was adopted in Vienna on 22 March 1985 and entered into force on 22 September 1988. The Montreal Protocol was adopted in Montreal on 16 September 1987 and entered into force on 1 January 1989; the Amendment was adopted in London on 29 June 1990 and entered into force on 10 August 1992.

Handbook for the Montreal Protocol on Substances That Deplete the Ozone Layer, document UNEP/Oz1.Pro.3/7, United Nations Environment Programme, Ozone Secretarlat, Nairobi, Kenya, May 1991 (130 pages, RDB2349)

This version has been superseded; see RDB2702.

Montreal Profocal on Subatances That Deplete the Ozone Layer, working version, United Nations Environment Programme, June 1990 (28 pages, RDB1119)

This text is an unofficial composite version of the Montreal Protocol as amended in London in June 1990. This version has been superseded; see RDB2702. 


\section{National}

Code of Practice for the Reduction of Chlorafluorocarbon Emisslons from Refrigeration and Air Conditioning Systems, document EPS1/RA/1, Environment Canada, Ottawa, Ontarlo, Canada, March 1991 (27 pages, RDB3218)

Measures of Rationalization of Use and Control of Emission for Specified CFCs, interim report, Ozone Layer Committee, Chemical Product Council, Ministry of International Trade and Industry, Tokyo, Japan, 26 October 1988 (34 pages, RDB1131)

Refrigeration Equipment and Heat Pumps Using CFCs/HCFCs: The Retrigerants Order and Comments, Swedish National Environmental Protection Agency, Stockholm, Sweden, 1988 (71 pages, RDB1130)

Refrigeration Safory Regulation, translated by the Japan Refrigeration and Air Conditioning Industry Association, Tokyo, Japan (36 pages, RDB1132)

\section{SUBSTITUTE REFRIGERANTS}

J. L. Adcock, S. B. Mathur, W. A. Van Hook, H. Q. Huang, M. Narkhede, and B-H. Wang (University of Tennessee), Fluorinated Ethers - A New Series of CFC Substitutes, Proceedings of the International CFC and Halon Alternatives Conference (Baltimore, MD). Allance for Responsible CFC Polisy, Arlington, VA, pages 386-395, December 1991 (10 pages with 6 tables, RDB2255)

A. Advani (Safeway Incorporated), Alternate Refrigerants and Energy Savings in Supermarkets, ASHRAE Journal, American Society of Heating, Refrigerating, and Air-Conditioning Engineers (ASHRAE), Atlanta, GA, volume 34, number 12, pages 40-42, December 1992 (3 pages whth 4 figures, RDB3224)

J. Allcott (McQuay Refrigeration, SnyderGeneral Corporation, UK), HFC-134a and Centrifugal Compressors, CFC Alternatives: User Experience and Update, Insttution of Mochanical Engineers and Institute of Refitgeration, London, UK, 11 November 1992 (9 pages with 4 figures and 5 tables, RDB3336)

D. Arnaud, S. Macaudiere, J. C. Tanguy, and P. F. Radice (Elf Atochem S. A., France), Properties of Blends Which Can Be Used as R-502 Substitutes in Refrigeration. Proceedings of the International
CFC and Halon Alternatives Conference Washington, DC). Alliance for Responsible CFC Policy, Arlington, VA, pages 105-114, September 1992 (10 pages with 3 flgures and 6 tables, RDB2A06)

P. K. Bansal, T. Dutto, and B. Hivet, Performance Evaluation of Environmentally Benign Refrigerants in Heat Pumps: A Simulation Study, Inter. national Journal of Refrigeration, Paris, France, volume 15 , number 6 , June 1992, pages 340-348 (RDB2CO3)

K. Beermann and $H$. Kruse (Universität Hannover, Germany). Experiences with the Refrigerant R134 as a "Drop-In" Replacement in a Large Water-Water Heat Pump, Proceedings of the $1992 \mathrm{In}$ ternational Refrigeration Conference - Energy EFficiency and New Refrigerants, edited by D. R. Tree and J. E. Braun, Purdue University, West Lafayette, IN, volume 1, pages 211-219, July 1992 (9 pages with 4 figures and 4 tables, RDB2723)

A. L. Beyertein, D. D. DesMarteau, S. H. Hwang (Clemson University). N. D. Smith (Environmental Protection Agency, EPA), and P. Joyner (Electric Power Research Institute, EPRI), Physical Properties of Fluorinated Propane and Butane Derivatives as Alternative Refrigerants, paper 3658 Winter Meeting, Chicago, IL, January 1993), Transactions, American Society of Heating, Refrigerating, and Air-Conditioning Engineers (ASHRAE), Atlanta, GA, volume 99, part 1, in publication (12 pages with 10 tables, RDB3408)

A. L. Beyertein, D. D. DesMarteau, S. H. Hwang (Clemson University), N. D. Smith (Environmental Protection Agency, EPA), and P. Joyner (Electric Power Research Institute, EPRI), Physical Property Data on Fluorinated Propanes and Butanes as CFC and HCFC Alternatives, Proceedings of the International CFC and Halon Alternatives Conference (Baltimore, MD). Alliance for Responsible CFC Policy, Arlington, VA, pages 396-405, December 1991 (10 pages with 5 tables, RDB2256)

E. C. Berlinck, C. A. T. Uriu, T. B. Herbas, and J. A. R. Parise (Pontiflcia Universidade Católica do Rio de Janeiro, Brazil), Performance Analyuis of Domestic Heat Pump Units Running on CFC Substitutes, presented at the 1990 USNC/IIR-Purdue Refrigeration Conference and ASHRAE-Purdue CFC Conference (Purdue University, West Lafayette, IN, July 1990); published in the Proceedings of the 1992 International Refrigeration Conference - Energy Efficiency and Now Refrigerants, edited by D. R. Tree and J. E. Braun, Purdue University, West Lafayette, IN, volume 2, pages 693702, July 1992 (10 pages with 5 figures, RDB2843) 
D. J. G. Butler (Building Research Establishment, UK), Summary of Trials with New Retrigerants in Air Conditioning, CFC Alternatives: User Experience and Update, Institution of Mechanical Engineers and Insttute of Refrigeration, London, UK, 11 November 1992 (10 pages with 2 figures and 3 tables, RDB3334)

J. M. Calm (Engineering Consultant), Alternative Refrigerants: Challenges and Opportunities, Heating/Piping/Air Conditioning, Penton Publishing. Chicago, IL, volume 64 , number 5 , pages 38 49. May 1992 (8 pages with 5 figures and 1 table, available from JMC as RDB2621)

This article reviews the status and options available for refrigerants in chillers, with emphasis on use of R-22, R-123, R-134a, R-717 (ammonia), and absorption cycles. The efficiency, globalwarming potential (GWP), ozone-depletion potential (ODP), flammability, toxicity, and cost of refrigerants are discussed; quantitative data are tabulated. A figure shows the capacity ranges and types of equipment available by refrigerant. Comparattve ODP, GWP, efficiency, and capacity are plotted for R-123 and R-11, R-134a and R-12, and R-134a and R-500. Cost projections (with excise taxes) are plotted for the refrigerants reviewed. Options are discussed for existing equipment, including continued use, retrofit, and replacement. Safety and other considerations are reviewed for the alternative refrigerants. The paper concludes that good options are available provided that sound engineering is used.

R. Camporese, B. Boldrin, M. Scattolini (Consiglio Nazionale della Ricerche, Italy), and G. Cordella (Università di Udine, Italy), Improvement of R134a Performance by Addition of R-290, Proceedings of the 1992 International Refrigeration Conference - Energy Efficiency and New Refrigerants, edited by D. R. Tree and J. E. Braun, Purdue University, West Lafayette, IN, volume 1, pages 4552. July 1992 (8 pages with 9 figures and 3 tables, RDB2712)

L. Canren, Y. Zhao, and M. Yital (Tianjin University, China), Investlgation of Using the Ternary Mixture as the Alternative for R-12, Proceedings of the 1992 International Refrigeration Conference Energy Efficlency and New Refrigerants, edited by D. R. Tree and J. E. Braun, Purdue University, West Lafayette, IN, volume 2, pages 661-667, July 1992 (7 pages with 3 figures and 2 tables, RDB2841)

N. E. Carpenter (ICl Chemicals and Polymers, Limited), An Overview: Options for the Supply of Alternative Refrigerants, CFC Alternatives: User EXperience and Update, Institution of Mechanical Engineers and Institute of Refrigeration, London, UK,
11 November 1992 (12 pages with 9 tables, RDB3329)

T. W. Dekleva, R. Yost (ICl Americas, Incorporated), S. Corr, R. D. Gregson, G. Tompsett (ICl Chemicals and Polymers, Limited), T. Nishizawa, and $Y$. Obata ( $\mathrm{Cl}$ Japan), Investigations into the Potential Effects of Process Chemicals and Materials on the Long-Term Performance of Home Appliances, Proceedings of the International CFC and Halon Alternatives Conference Washington, DC), Alliance for Responsible CFC Policy, Arling: ton, VA, 29 September 1992 (17 pages with 4 figures and 7 tables, RDB2913)

S. Devotta and S. Gopichand (National Chemical Laboratory, India), Comparative Assessment of Some Flammable Refrigerants as Alternatives to CFC-12, Proceedings of the 1992 International Refrigeration Conference - Energy Efficiency and New Refrigerants, edited by D. R. Tree and J. E. Braun, Purdue University, West Lafayette, IN, volume 1, pages 249-257, July 1992 (9 pages with 4 figures and 1 table, RDB2727)

This paper reviews the need for assessment of flammable refrigerants and the implications of using such fluids as alternatives to R-12. Because of the complexities and potential adverse findings in qualifying alternative refrigerants, there may not be adequate time for developed countries to fully evaluate new fluids. Developing countries such as India and China, which are seif-reliant in the manufacture of refrigerants and equipment, are short of funds and cannot afford to introduce transition fluids, such as HCFCs and possibly HFCs, and then change again. Global environmental concern requires that flammable fluids also be considered, some of which were used in the past even in home refrigerators. Flammability is considered to pose a lower risk than toxicity. The paper reviews the theoretical performance and flammability of $R$ 142b, R-152a, R-C270 (cyclopropane), R-290 (propane), R-600 (butane), R-600a (isobutane). The pressure ratios, specific compressor displacements, theoretical efficiency, and specific shaft power are plottod for these refrigerants as functions of the evaporating temperature for a range of -35 to $+5{ }^{\circ} \mathrm{C}\left(-31\right.$ to $\left.+41^{\circ} \mathrm{F}\right)$ for a $50^{\circ} \mathrm{C}$ $\left(122{ }^{\circ} \mathrm{F}\right)$ condensing temperature. The performance, flammability and environmental data, and fundamental properties are tabulated and compared to those of R-12. Means to reduce leaks and charge quantities are discussed as ways to reduce the risks. R-C270 would require smaller compressors and may offer superior performance. R-152a may be preferred based on its lower flammability and experience with it. 
D. A. Didion (National Institute of Standards and Technology, NIST) and D. B. Bivens (DuPont Chemicals), Role of Refrigerant Mixtures as Alternatives to CFCs, International Journal of Refrigeration, Paris, France, volume 13, 1990 (RDB2C04)

D. A. Didion (National Institute of Standards and Technology, NIST), R. Cohen, and D. R. Tree (Purdue University), The Role of R-22 in Retrigerating and Air-Conditioning Equipment, International Colloquium on Refrigeration and CFCs (Brussels, Belgium, March 1990), International Institute of Refrigeration, Paris, France, to be published (18 pages with 6 figures and 3 tables, RDB0921)

D. A. Didion, Energy Performance Potential of the Alaskan Air Conditioning Company's Refrigerant Mixture ["R-176"], National institute of Standards and Technology (then the National Bureau of Standards), Gaithersburg, MD, July 1984 (RDB2320)

P. A. Domanskl and D. A. Didlon (Natlonal Institute of Standards and Technology, NIST), Theoretical Evaluation of R22 and R512 Alternatives, report $\mathrm{DOE} / \mathrm{CE} / 23810-7$. Air-Conariboning and Refrigeration Technology Instltute (ARTi), Arlington, VA, January 1993 (32 pages with 19 figures and 7 tables, available from JMC as RDB3305)

This report evaluates performance of candidate refrigerants to replace R-22 and R-502. The alternatives compared to R-22 include R-32/R-125 $(60 / 40)$. R-32/R-125/R-134a (10/70/20), R$32 / R-125 / R-134 a(30 / 10 / 60), R-32 / R-125 / R$ 290/R-134a (20/55/5/20), R-32/R-134a (25/75), R-32/R-134a (30/70), R-32/R-227ea $(35 / 65), R-134 a$, and R-290 (propane). The analyses are based on a semi-theoretical model, CYCLE-11, with cross-flow heat transfer in the evaporator and condenser. Thermodynamic properties were calculated using the CarnahanStarling-DeSantis (CSD) equation of state. The conditions examined approximate outdoor rating conditions for residential heat pumps, namely 27.8 and $35^{\circ} \mathrm{C}\left(82\right.$ and $95^{\circ} \mathrm{F}$ ) for cooling and -8.3 and $8.3^{\circ} \mathrm{C}\left(17\right.$ and $\left.47^{\circ} \mathrm{F}\right)$. Calculated volumetric capacities, coefficients of performance (COPs), pressure lift, and compressor discharge temperatures and pressures are Wotted. The analyses are presented for "dropin" conditions (constant heat exchanger s), constant heat exchanger loading, and with addition of a liquid-suction heat exchanger. The alternatives compared to R-502 are R-32/125/143a $(10 / 45 / 45)$, R-125/R-143a (45/55), and R125/R-143a/R-134a (44/52/4). These fluids are examined at typical conditions for commercial refrigeration, namely -23.3 and $35^{\circ} \mathrm{C}(-10$ and 95 ${ }^{\circ} \mathrm{F}$ ) for the fluld entering the evaporator and condenser, respectively. Simulation cases and results similar to those for the R-22 alternatives are presented. Summary fluid properties and results for the constant exchanger loading cases are tabulated. They indicate efficiency losses of 1-16\% for the R-22 alternatives and 3$7 \%$ fo: the R.502 alternatives. Corresponding changes in volumetric capacity range from $31 \%$ lower to $55 \%$ higher and from $8 \%$ lower to $13 \%$ higher than R-22 and R-502, respectlvely. The report notes, however, that these findings would change with consideration of differences in transport properties. The report abstractly discusses the influence of critical temperature on performance and unavoidable trade off between COP and volumetric capacity. It also reviews the impacts of heat capacity, liquid thermal conductivity, and liquid viscosity; neither these transport properties nor toxicity and flammability were otherwise addressed. Two appendices summarize the nomenclature used in the report and describe the CYCLE-11 model. A third tabulates vapor heat capacity, liquid and vapor thermal conducthity, and liquid and vapor viscosity for the fluids addressed.

R. E. Ertinger (Carrier Corporation), HCFC-22: Requirements for Unitary Products, Proceedings of the International CFC and Halon Alternatives Conference (Baltimore, MD). Alliance for Responsible CFC Policy, Arlington, VA, pages 340-347, December 1991 (8 pages with 3 figures, RDB2257)

This paper estimates the annual quantity of R-22 required internationally for unitary equipment through the year 2000 . Based on its properties, including efficiency, low cost, and safety, R-22 is the most widely used refrigerant. The paper estimates its 1990 use to be 160 million $\mathrm{kg}$ (352 million (bs), of which $14 \%$ was used for equipment other than unitary (e.g., existing and new chillers). For the unitary portion, $24 \%$ was used in new products and $76 \%$ to service existing equipment. Two parametric scenarios are presented: (1) 3,5 , and $7 \%$ growth in demand for unitary products with no change in service practices, and (2) recovery increasing to 40,60 , or $80 \% / \mathrm{yr}$ by 2000 . Based on assumptions for usage in room air-conditioners, duct-free split systems, ducted systems, and commercial unitary systems, the paper projects a range of 77149 million $\mathrm{kg}$ (169-327 million Ibs), depending on recovery levels, to be required in 2000 at the $5 \%$ annual new-product growth rate.

S. K. Fischer (Oak Ridge National Laboratory, ORNL). An Analytical Screening of Allernatives for R-502 in Low-Temperature Refrigerating Applications, paper 3617 (Annual Meeting, Baltimore, MD, June 1992), Transactions, American Society of Heating, Refrigerating, and Air-Conditioning Engineers (ASHRAE), Atlanta, GA, volume 98, part 2 , 
pages 188-203, 1992 (15 pages with 9 figures and 11 tables, RDB2602)

J. N. Friedman, Experimental Evaluation of Alaskan Air Condttioning Company's Mixed Refrigerant R-176, Carrier Corporation, Syracuse, NY, 17 August 1984 (13 pages with 2 figures and 4 tables, available from JMC as RDB1B01)

The measured performance of a zeotropic ternary blend, R-12/R-22/R-142b (15/25/60) is compared to that of R-22 for two residential heat pumps. The units tested included an air-to-water heating-only model and an air-to-air heatingand-cooling model. The charge and expansion device orifice (Accurator( $(\mathcal{A})$ piston size) were optimized for capacity and efficiency. The heating capacity and coefficient of performance (COP) were approximately 52 and $15 \%$ lower, respectively, with the refrigerant blend than with R-22 in the air-to-water heat pump. The heating and cooling capacities were approximately 35 and $46 \%$ lower, respectively, in the air-to-air heat pump, but the efficiency increased by approximately $10 \%$ in the cooling mode and was nearly the same for heating. The test procedures and conditions are described in the report. The study concluded that the mixture is not a viable replacement in Carrier heat pump systems operating in the heating mode. Addltional testing is recommended to determine if increases in efficiency can be achieved with the mixture in the cooling mode, based on further capillary tube and refrigerant charge optimization, despite the decreased cooling capacity.

C. L. Gage (U.S. Environmental Protection Agency, EPA) and G. S. Kazachki (Acurex Environmental Corporation), Predictions of Azeotropes Formed from Fluorinated Ether, Ethane, and Propane Azeotropes, Proceedings of the 1992 International Refrigeration Conference - Energy Efficiency and New Refrigerants, edited by D. R. Tree and J. E. Braun, Purdue University, West Lafayette, IN, volume 2, pages 611-, July 1992 (9 pages with 6 figures and 3 tables, RDB2836)

K. D. Gerdsmeyer (Danfoss GmbH, Germany), R134a in Small Commercial Retrigeration Systems: Some Practlcal Aspects, Proceedings of the 1992 International Refrigeration Conference Energy Efficlency and New Refrigerants, edited by D. R. Tree and J. E. Braun, Purdue University, West Lafayette, IN, volume 1, pages 197-202, July 1992 (10 pages with 4 figures, RDB2721)

This paper present findings with R-134a in commercial refrigeration equipment for evaporating temperatures of -15 to $+15^{\circ} \mathrm{C}\left(5-59{ }^{\circ} \mathrm{F}\right)$ with small hermetic compressors (with displacements volumes up to $20 \mathrm{~cm}^{3}, 1.2 \mathrm{in} 3$ ).
Emphasis is placed on beverage coolers, cooling units for electronics, commercial refrigerators, and heat pump water heaters (HPWHs). Cooling capacities are plotted for R-12 and R$134 a$ based on calorimetric tests of a compressor, showing that the capacity of R-12 and R$134 a$ are similar, but slightly greater for R-12 at low evaporating temperatures and for R-134a at high temperatures. Coefficients of performance (COP) are similarty plotted, showing no penalty with R-134a in compressors optimized for R-12. Tests of a HPWH showed reduced operating time with R-134a due to its higher capacity. More favorable results with systems optimized for R-134a are suggested. The relattve miscibility of mineral oll in R-12 and esters in R-134a are discussed, noting higher concern with design for oil return for the latter. The paper notes that new ester lubricants have the advantage of being biodegradable. Moisture implications and the need for higher drying with ester lubricants are discussed. Residual chlorine from retrofits leads to increased wear with R-134a and esters. The paper argues against conversion from R-12 to R-134a for small refrigeration systems, but concludes that R-134a can be successtully used in new systems.

G. H. Goble (Peoples Welding Supply), A Drop-In CFC-12 Replacement for Automotive Air Condrtioning. Proceedings of the 1992 International Refrigeration Conference - Energy Efficiency and New Refrigerants, edited by D. R. Tree and J. E. Braun, Purdue University, West Lafayette, IN, volume 2, pages 607-609, July 1992 (3 pages, RDB2835)

This paper presents a ternary zeotropic blend, proposed as a transition fluid, to replace R-12 in automotive air conditioners. The blend is R$22 / R-600 a / R-142 b(55 / 8 / 37)$, which offers an ozone depletion potential of 0.05 and compatibility with mineral oils. It has been tested in approximately 150 vehicles, two since August 1990. Only one fallure has resulted, but it was not attributed to the refrigerant change. Colder air dellvery than for R-12 was found; the condensing temperature is higher, though still low enough to prevent refrigerant-oil breakdown. The isobutane content makes the blend miscible in standard mineral oils, including Witco Suniso(R) $3 G S$ and 5 GS naphthenic olls and Virginia KMP 150 paraffinic oil. The flammability, both as compounded and after fractionation from leakage, is reviewed. Testing of a silane-based, desiccant and sealant additive are described to reduce refrigerant leaks. The paper notes that the blend composition can be customized for hot climates. 
L. R. Grzyll and C. F. Parish (Mainstream Englneering Corporation), An Innovative Approach for the Screening and Development of CFC Afternatives, Proceedings of the 1992 International Refrigeration Conference - Energy Efficiency and New Refrigerants, edited by D. R. Tree and J. E. Braun, Purdue University, West Lafayette, IN, volume 2, pages 415-424, July 1992 (10 pages with 6 figures and 4 tables, RDB2824)

L-Z. Han, M-S. Zhu, and Z-Z. Lin (Tsinghua University, China), Experimental Study on Blend HCFC22/HFC-152a as a Refrigerant in Refrigerator, Proceedings of the International CFC and Halon Alternatives Conference (Baltimore, MD), Allance for Responsible CFC Pollcy, Arlington, VA, pages 494-501, December 1991 (8 pages with 4 figures and 1 table, RDB2311)

G. G. Haselden and L. Klimek, An Experimental Study of the Use of Mixed Retrigerants for Nonisothermal Refrigeration, Proceedings of the $\mathrm{In}$ stitute of Refrigeration, pages 129-148, 1957 (20 pages with 10 figures and 1 table, RDB2C02)

H. T. Haukàs (Nonweglan Institute of Technology, Nonway). Practical Performance of Alternatives to R-12 and R-502 in Retrigerators and Freezers, CFC Alternatives: User Experience and Update, institution of Mechanical Engineers and Institute of Refrigeration, London, UK, 11 November 1992 (7 pages with 9 figures and 2 tables, RDB3333)

X. He, U. C. Spindler, D. Jung, and R. Radermacher (University of Maryland), Investigation of R-22/R142b Mixture as a Substitute for R-12 in SingleEvaporator Domestic Refrigerators, paper 3557 (Winter Meeting, Anaheim, CA, January 1992), Transactions, American Society of Heating, Refrigerating, and Air-Conditioning Engineers (ASHRAE), Atlanta, GA, volume 98 , part 1 , pages 150-159, 1992 (10 pages with 10 figures and 1 table, RDB. 2340)

R. D. Heap (Shipowners Refrigerated Cargo Research Association, UK), Practical Application of Alternative Refrigerants in Refrigerated Transport, CFC Alternatives: User Experience and Update, Institution of Mechanical Engineers and Institute of Refrigeration, London, UK, 11 November 1992 (7 pages with 3 tables, RDB3332)

K. E. Hickman (York International Corporation), Refrigerants After CFCs - What Aro tho Choices, Technical Papers of the 15th Annual Meeting (2124 March 1993, Vancouver, BC. Canada), International Institute of Ammonia Refrigeration (IIAR), Washington, DC, March 1993 (30 pages with 2 figures and 2 tables, RDB3409)

This paper reviews refrigerants to replace R-12, R-22, and R-502. It summarizes the phase out schedule of the Montreal Protocol and identifies alternative refrigerants that are available. The paper addresses R-134a, R-401 (R$22 / 152 a / 124)$ blends, R-152a/227ea (80/20), and $R-134 a / 152 a(85 / 15)$ as alternatives for $R$ 12 as well as $R-402(R-125 / 290 / 22)$ blends, $R$ $290 / 22 / 218$ blends, and R-22 as alternatives for R-502. It then discusses longer-range options, specifically those under investigation in the Al. ternative Refrigerants Evaluation Program (AREP). They include R-32/125 (60/40), R$32 / 134 a(25 / 75)$ and $(30 / 70), R-32 / 125 / 134 a$ $(10 / 70 / 20)$ and $(30 / 10 / 60)$, R$32 / 125 / 290 / 134 a(20 / 55 / 5 / 20)$, R-32/227ea (35/65), R-134a, R-290 (propane), and R-717 (ammonia) as R-22 replacements and $R$. 125/143a (45/55), R-125/R-143a/R-134a $(44 / 52 / 4)$, and R-32/125/134a (10/45/45) as replacements for R-502. Two tables summarize near term and longer-range alternatives and identify their compositions, characteristics, and for some potential applications. The paper outlines ongoing research of these fluids, including determination of properties and investigation of materials compatibility. It suggests potential changes in equipment design, particularly for zeotropes, for the neve fluids. They include considerations for temperature glides, influences of composition change on heat transfer, counterflow heat exchangers, composition maintenance in charging and servicing, and requirements for testing and fleld dlagnosis. Two figures illustrate the temperature glide for zeotropes. The paper then surveys requirements and complextties for service including prohibitions against venting, labeling needs, and composition maintenance for blends. It briefly mentions considerations for retrofit conversions. The paper concludes that new refrigerants are likely to be more expensive than those they replace, design emphasis is required for charge reduction and leak avoidance, and that work is needed to examine changes to improve perfor. mance with refrigerant blends. It also notes that propane and ammonia are likely to recelve fresh consideration in the turmoil created by changes.

H. M. Hughes (AlliedSignal Incorporated), NonOzone Depleting Refrigerants for Centrifugal Compressors, Proceedings of the International CFC and Halon Alternatives Conference Washington, DC). Alliance for Responsible CFC Pollcy, Arlington, VA, pages 41-46, September 1992 (6 pages with 4 figures, RDB2A01)

This paper reviews the characteristics sought in a replacement for R-11 and R-123, as well as reasons for their widespread use and the longterm need for a replacement. R-245ca, with a boiling point of $25.5^{\circ} \mathrm{C}\left(79.9^{\circ} \mathrm{F}\right)$ and a molecular mass of 134.0 , is identified as a candidate. It is 
reported to be nonflammable and have a global warming potentlal (GWP) comparable to that of R-134a. The paper presents the results of cycle comparisons based on modelling. These results include figures comparing the capacity and coefficient of performance (COP) for R-11. R-123, and R-245ca. An investigation of multistage systems is outlined. The results, excluding interstage losses, indicate that R-245ca matches R-11's efficiency with three stages and becomes more efficient with four or more. Moreover, anticipation of better heat transfer characteristics is noted, based on the higher molecular weight of R-245ca. Little is known of the toxicity of this fluid, though most HFCs tend to have low toxicity. Potential obstacles such as lubricant identification and materials compatibilthy are discussed.

J. A. Jones and A. Lund, Low-Ozone Damaging Fluid Mix Substitutes for Refrigerant 12, Jet Propulsion Laboratory, California Institute of Technology, Pasadena, CA 1989 (RDB2338)

B. D. Joyner, Retrigerants 69-S and 69-L, "DropIn" Replacements for R-502, Proceedings of the International CFC and Halon Alternatives Conference (Baltimore, MD), Allance for Responsible CFC Pollcy, Arlington, VA, December 1991 (RDB2303)

H. Jürgensen (AEG Hausgerăte AG, Germany). Messungen an Haushaltskühlgeräten mit brennbaren Kältemitteln (Measurements of Residential Refrigerators with Flammable Refrigerants), DKV Jahrestagung, Bremen, FRG, 17 November 1992 (15 pages with 5 figures and 5 tables, RDB3108)

$H$. Jürgensen (AEG Hausgeräte AG, Germany), Messungen an Haushaltskühlgeräten mit brennbaren Kaltemitteln (Measurements of Residential Refrigerators with Flammable Refrigerants), presentation charts, DKV Jahrestagung, Bremen, FRG, 17 November 1992 (18 pages, RDB3109)

G. S. Kazachkl (Acurex Environmental Corporation) and C. L. Gage (U.S. Environmental Protection Agency, EPA), Thermodynamic Evaluation of Predicted Fluorinated Ether, Ethane, and Propane Azeotropes. Proceedings of the 1992 International Refrigeration Conference - Energy Efficiency and Now Refrigerants, edited by D. R. Tree and J. E. Braun, Purdue University, West Lafayette, IN, volume 2, pages 595-605, July 1992 (11 pages with 10 figures and 4 tables, RDB2834)

This paper summarizes thermodynamic analyses of seven predicted azeotropes of fluorinated ethers, ethanes, and propanes. They include $E$ 125/R-C270, E-125/R-134a, E-143a/R-134, R134a/E-143a, E-143a/R-152a, R-134/R-245cb, and R-245cb/R-227ea. Their performance was evaluated using basic thermophysical property data and the results used to rank the azeotropes among other refrigerants.

K. Kim, U. C. Spindler (University of Maryland), D. Jung (Inha University, Korea), and R. K. Radermacher (University of Maryland), R-22/R-152a MIXtures and Cyclopropane (R-C270) as Substitutes for R-12 in Singlo-Evaporator Refirigerators: Simulation and Experiments, paper $\mathrm{CH}-93-20-2$ (Winter Meeting, Chicago, IL, January 1993), Transactions. American Society of Heating, Refrigerating, and Air-Conditioning Engineers (ASHRAE), Atlanta, $\mathrm{GA}$, volume 99 , part 1, 1993 in publication (8 pages with 4 figures and 3 tables, RDB3114)

T. S. Kim, J. Y. Shin, S. D. Chang, M. S. Kim, and S. T. Ro (Seoul National University, Korea), Cycle Performance and Heat Transfer Characteristics of a Heat Pump Using R-22/R-142b Retrlgerant Mixtures, Proceedings of the 1992 International Refrigeration Conference - Energy Efficiency and New Refrigerants, edited by D. R. Tree and J. E. Braun, Purdue University, West Lafayette, IN, volume 1, pages 53-62, July 1992 (10 pages with 14 figures, RDB2713)

D. L. Klug (DuPont Chemicals), Near- and LongTerm Alternatives for Hydrochlorofluorocarbon 22 (HCFC-22), paper 1.2, Proceedings of the International Seminar on New Technology of Alternative Refrigerants - Lubricants and Materials Compatibility (Tokyo, February 1983), Japanese Association of Refrigeration (JAR), Tokyo, Japan, pages 9-14, February 1983 (6 pages with 3 figures and 1 table, RDB3307)

K. Koike (Ebara Corporation, Japan), HCFC-123 Centrifugal Retrigeration Machine, paper 4.3, Proceedings of the International Seminar on New Technology of Alternative Refrigerants - Lubricants and Materials Compatibility (Tokyo, February 1983), Japanese Association of Refrigeration (JAR), Tokyo, Japan, pages 67-76, February 1993 (10 pages with 7 figures and 3 tables, RDB3315)

S. N. Kondepudi (Drexel University), Experimental Investigation of R-22 Replacement Retrigerants in a Split-System Residential Air Condhioner, report EPA/430/R-92/007, U.S. Environmental Protection Agency (EPA), Washington, DC, September 1992 (30 pages with 4 figures and 12 tables, RDB2B09)

This report summarizes capacity and efficiency tests of five zeotropic blends in a Lennox, 2 ton, split-system air conditioner. The refrigerants included three mixtures of R-32 and R-134a, with 20,30 , and $40 \%$ R-32 by mass, and two of R-32 and R-152a, with 30 and $40 \%$ R-32. The five 
blends were selected as candidate R-22 replacements based on prlor studies. Testing was performed by ETL Testing Laboratorles, and confirmed by independent tests by Lennox Industries; both were performed in accordance with standard rating test procedures. The fluids were tested under near "drop-in" conditions, without equipment modification except for substitution of a manual expansion device and replacement of the refrigerant and lubricant. An unidentified polyol ester lubricant was used. The report summarizes the need for R-22 alternatives, candidates identifled in prior and ongoing studles, testing and equipment details, and measured results. It also compares the findings to simulations. Measured capacity and efficiency fell below simulated results, but the test system had not been optimized for the alternative refrigerants. The blends tested generally showed steady-state efficlency to be within $2 \%$ of that of R-22, but offered lower capacity. R-32/134a $(40 / 60)$ was identified as a promising retrofit fluid since it yielded steady state efficiency and capacity $1 \%$ higher than R-22, though the seasonal performance (SEER) was $1 \%$ lower.

W. L. Kopko (York International Corporation), Extending the Search for Now Refrigerants, International Journal of Refrigeration, Paris, France, volume 13, number 3, March 1990, pages 79 if (RDB2304)

H. Kruse and F. Rinne (Universität Hannover, Germany). Performance and Leakage Investigations of Refrigeration and Air-Conditioning Systems Using Refrigerant Mixtures as Working Fluids, Proceedings of the 1992 International Refrigeration Conference - Energy Efficiency and New Refrigerants, edited by D. R. Tree and J. E. Braun, Purdue University, West Lafayette, IN, volume 2, pages 621-630, July 1992 (10 pages with 10 figures, RDB2837)

$H$. Kruse and U. Hesse (Untversitắt Hannover, Germany), Possible Substitutes for Fully Halogenated Chlorofluorocarbons Using Fluids Already Marketed, Status of CFCs - Refrigeration Systems and Refrigerant Properties (proceedings of the meetings of IIR Commissions 81, B2, E1, and E2, Purdue University, West Lafayette, IN), International Institute of Refrigeration, Paris, France, July 1988; republished in the International Journal of Refrigeration, Paris, France, volume 11, number 4, pages 276-283, 1988 (RDB2305)

H. Kruse (Universităt Hannover, Germany), The Advantages of Zeotropic Retrigerant Mixtures for Heat Pump Applications, International Journal of Refrigeration, Paris, France, volume 4, pages 119-125, 1981 (RDB3216)
L. J. M. Kullpers (Phillips Research Laboratories), J. A. De Witt, and M. J. P. Janssen, Possibilities for the Replacement of CFC 12 in Domestic Equipment, International Journal of Refrigeration, Paris, France, volume 11, number 4, pages 284-291, 1988 (RDB2258)

J. W. Linton, W. K. Snelson, P. F. Hearty, and A. R. Triebe (National Research Council, Canada), The Potential of HFC-134a and HFC-152a to Replace CFC-12 in Medium Temperature Heat Pump Applications, Proceedings of the 1992 International Refrigeration Conference - Energy Efficiency and New Refrigerants, edited by D. R. Tree and,J. E. Braun, Purdue University, West Lafayette, IN, volume 1, pages 203-209, July 1992 (7 pages with 8 figures, RDB2722)

A. Lorenz and K. Meutzner, On Application of Nonazeotropic Two Component Refrigerants in Domestic Refrigerators and Home Freezers, proceedings of the XIVth International Congress of Refrigeration (Moscow, USSR, August 1975), International Institute of Refrigeration, Paris, France, August 1975 (RDB3217)

S. Madigan (Danfoss), Compressor Manufacturer's Experiences with R-134a Applications, Proceedings of the International CFC and Halon Alternatives Conference (Washington, DC), Allance for Responsible CFC Policy, Anlington, VA, pages 153-155, September 1992 (3 pages with 4 figures and 1 table, available from JMC as RDB2A14)

This paper outlines factors requiring attention when substituting R-134a for R-12 in systems with capillary tubes and Danfoss LBP compressors. Pressure-enthalpy diagrams show that the latent heat of vaporization is significantly higher for R-134a than for R-12, requiring lower mass flow for the same capacity. A table compares the enthalpy and design parameters for the two fluids. The paper notes that capittary tubes must be reselected with the refrigerant change to adapt for the differences in pressure and mass and volume flow. Compatibility is noted as good with substitution of polyol ester lubricants, to account for miscibility; valve coking is not anticipated. The dependence on a filter drier, with Union Carbide $\mathrm{XH} 7$ recommended as the desiccant, is outlined based on the moisture content of the lubricant and the difficulty of drying it. A set of housekeeping rules is outlined.

M. O. MCLinden and D. A. Didion (Natlonal Institute of Standards and Technology, NIST), Quest for ALternatives, ASHRAE Journal, volume 29, pages 32 42. December 1987; republished in ASHRAE Special Publication, CFCs: Time of Transition, American Society of Heating, Refrigerating, and Air-Conditioning Engineers (ASHRAE), Atlanta, GA, pages 
69-78, 1989 (6 pages with 9 figures and 1 table, RDB2259)

This article reviews the criteria required of refrigerants and the reasons chlorofluorocarbons (CFCs) were originally investigated. A systematic examination, based on molecular structure, reveals a range of compounds that should be environmentally acceptable and still retain desired attributes. 860 compounds were screened, resulting in 51 fluids warranting further examination. The article notes that the number of compounds from which to choose alternatives is limited; the chlorofluorocarbon family - including fluorocarbons and hydrocar. bons - remains the clear choice by virtue of stability, thermodynamic properties, health and safety characteristics, and familiarity. Some compromise with traditional criteria (e.g., capacity, flammability, and efficiency) will be needed. Present refrigerants resulted from more than 30 years of research and development. Careful scientific and technological planning are required to effect a significant change, and to avoid a new solution that introduces more problems than it solves.

A. Meyer, The Success of Hydrocarbons in Domestic Refrigeration. DKK Scharfenstein $\mathrm{GmbH}$, Scharfenstein, Germany, December 1992 (11 pages with 4 figures and 1 table, RDB3226)

R-290, R-600a, R-290/600a (50/50), refrigerators, refrigerator/freezers

S. M. Miner (Engineering Consultant), An Appraisal of Ammonia as an Alternative Refrigerant in Light of the CFC and GWP Situation, Technical Papers of the 14th Annual Meeting (22-25 March 1992, Mlami, FL), International Institute of Ammonia Refrigeration (IIAR), Washington, DC, pages 231-250, March 1992 (20 pages with 4 figures and 5 tables, RDB2912)

This paper reviews the history of ammonia refrigeration and the impediments - real and percelved - to its brcader use. Safety issues and environmental benefits associated with ammonia are identified. Current developments and research efforts related to ammonia use are summarized. The paper then outlines several applications of ammonia as examples and concludes with sources of further information.

S. Morlkawa (Asahi Glass Company, Limited, Japan), Recent Development of CFC Alternatives, Catalysis Society of Japan, volume 34, number 7, pages 458-463, 1992 (6 pages, RDB3325)

D. Naito (Dalkin Industrles, Limited), Alternatives to CFC Refrigerants. Proceedings of the 3rd In- ternational Energy Agency Heat Pump Conference (Tokyo, Japan, 12.15 March 1990), edited by T. Salto and $Y$. Igarashl, Pergamon Press, Elmsford, NY, pages 713-720, 1990 (8 pages, RDB0407)

A. D. Nickens, G. F. Brunner, and D. L. Hamilton, Navy Investigations of HFC-134a as a Replacement for CFC-12 in Shipboard Applications, Naval Engineers Journal, pages 98-103, May 1992 (6 pages with 4 figures and 4 tables, available from JMC as RDB2706)

This article reviews research and development efforts by the U.S. Navy to qualify R-134a as the retrofit replacement refrigerant for $R-12$ and for future air-conditioning applications on ships and submarines. The article recaps fleet use of R-12 for air-condltioning and refrigeration, compares the properties of R-134a to those of R-12, and outlines the Navy's review of toxicity data and risk affects. Unique considerations for submarine use are summarized, including potential interactions with life-support and contaminant removal systems, in the event of refrigerant leaks. These systems include burners to oxidize carbon monoxide and hydrogen as well as carton dioxide scrubbers. The article reviews tests of R-134a in 25 and 80 ton shipboard air-condltioning plants. Initial retrofit tests using R-134a with a polyalkylene glycol (PAG) lubricant resulted in $5 \%$ improvements in both capacity and efficiency. Inspection after 5100 hours of operation, however, revealed extensive copper plating and severe damage to one piston, wrist pin, and connecting rod. Damage to other parts, including a chipped oil ring, worn piston rings, and broken or collapsed suction valve springs also were noted. These findings led to a judgement that PAG lubricants are unsatisfactory for shipboard reciprocating compressors for air conditioning. While a molecular-sieve drier had been used for a portion of the cited tests, initial operation was without a drier. The paper reviews a subsequent test of an 80 ton plant with R-134a and a proprietary polyol ester (POE) lubricant, provided by the Carrier Corporation. A lubricant analysis after two hours of operation revealed approximately $15 \%$ residual mineral oil, which was reduced to approximately $3 \%$ after a second oil change. Cooling capacity increased by $1 \%$ and efficiency dropped by $2 \%$ using R134a. Although minor copper plating was evident after 2000 hours of operation, particularly on the suction valves, no measurable decomposition was detected in the R-134a. No measurable wear was found on any component to date, and the extended operation test is continuing. Onboard demonstration and fleet retrofit plans are summarized. 
G. J. O'Neill and R. S. Holdsworth W. R. Grace and Company). Bls (Difluoromethyl) Ether Retrigerant, patent 4,961,321, 9 October 1990 (4 pages, RDB1133)

This patent describes the use of E-134 as a refrigerant, either as a single component or in a blend. The refrigerant is described as environmentally safe, nontoxic, and nonflammable and as having the desired physical, chemical, and thermodynamic properties necessary for a refrigerant.

M. A. Palmer (W. S. Atkins Limited, UK), Better Ways of Using Ammonia, CFC Alternatives: User Experience and Update, Instltution of Mechanical Engineers and Institute of Refrigeration, London, UK, 11 November 1992 (4 pages with 4 figures, RDB3335)

S. F. Pearson, (Star Refrigeration Limited), The Development of a Drop-In Replacement for R-502, paper 92.4, Proceedings of the Institute of Refrigeration, London, UK, January 1992 (9 pages with 15 figures and 1 table, RDB2306)

This paper describes the development, performance testing, flammability considerations, charging, and separation of two ternary zeotropes developed as replacements for R-502. Both are blends of R-22, R-218 (octafluoropropane), and R-290 (propane). One containing $39 \%$ R-218 results in marginally lower discharge temperatures; the other containing 20\% R-218 offers discharge temperatures between those of R-502 and R-22. These R-290/22/218 mixtures are nonfiammable and of low toxicity. They exhibit ozone depletion potentials (ODPs) of 0.037 and 0.028 and nearly the same refrigerating effect as R-502. Measured coefficients of performance (COPs) with these blends were higher than for R-502 under comparable conditions. The paper describes the choice of components, including initial consideration of blends containing R-125 and R-1270. The test rig, results, and effects of diffusion and replacement of lost refrigerants also are discussed. Extensive international field testing is mentioned, but not described.

S. F. Pearson, (Star Refrigeration Limited), Development of a Substifute for R-502, paper 162 , proceedings of the XVIIIth International Congress of Refrigeration (Montreal, Québec, Canada, August 1991), International Institute of Refrigeration, Paris, France, August 1991 (RDB2425)

S. F. Pearson, (Star Refrigeration Limited), Refrigeration after CFCs, proceedings of the Low Temperature Engineering and Cryogenics Conference, Southampton, 1990 (RDB2237)
R. L. Powell (ICl Chemicals and Polymers, Limited), Long Term Replacements for R-22 and R-502: The Next Challenge, unpublished presentation (International CFC and Halon Alternatlves Conference, Baltimore, MD), avallable from ICl Americas Incorporated, New Castle, DE, USA, December 1991 (16 pages with 4 figures and 3 tables, RDB2519)

This paper identifles a number of substitute candidates for R-22 and R-502, and describes the advantages and disadvantages of each. Options addressed include R-32, R-125, R-134a, $R-143 a, R-152 a$, as well as nine binary and ten ternary blends of them. Selection of candibates is limited to fluorocarbons, because only these compounds exhlbit the low boiling points needed for refrigeration, especially at temperatures needed for commercial frozen-food storage. Chlorinated compounds are excluded bocause of their potentlal for ozone depletion. Perfluorocarbons, such as R-218, are unlikely since their high-fluorine content, and resultant long atmospheric lifetimes, are expected to lead to high direct global warming potentials (GWPs). Similar properties to the fluids being replaced, to minimize equipment development requirements, and avoidance of subatmospheric operation are further goals. Flammability and toxicity limit some choices, such as R-290 (propane) and R-717 (ammonia). The paper raises avoidance of high GWPs, flammable ranges, high discharge superheat, high fractionation potentlal in leakage, and maintenance or improvement of efficiency to further narrow the list. The paper recommends mixtures or $R$ 32 and R-134a, modified where necessary with R-125 to suppress the flammability of R-32 and reduce discharge temperatures, as the preferred solutions.

R. Radermacher and D. Jung (University of Maryland), Theoretical Analysis of Replacement Refrigerants for R-22 for Residential Uses, report EPA/400/1-91/041, U.S. Environmental Protection Agency (EPA), Washington, DC, December 1991 (77 pages with 10 figures and 10 tables, avallable from JMC as RDB2509)

This report examines the need and candidate replacements for R-22. The simulation programs (HAC1 for single fluids and binary mixtures and HACT1 for ternary mixtures) and data used for the study are summarized. Hydrofluorocarbon (HFC) refrigerants $R-32, R-125, R-134$, R-134a, R-143a, and R-152a and hydrochlorofluorocarbon (HCFC) R-124 were selected for analyses. Results are presented for R-32/124, R-32/134, R-32/134a, R-32/152a, R-125/124, R125/134a, R-125/152a, R-143a/124, R143a/134a, and R-143a/152a. Results also are provided for three ternary blends, investigated 
to reduce flammablity, namely R-32/152a/124, R-32/152a/134, and R-32/152a/134a. Coeffclents of performance (COPs) and seasonal performance factors (SPFs) were calculated. The report also reviews the design modfications considerat and discusses requirements for future research. No single-component refrigerant was found acceptable as a substitute, but binary and ternary blenos appear promising. The ternary mixture of R-i? $/ 152 a / 124$ showed the best performance, with a COP increase of 13.7\% over R-22. Chlorine-fiee R-32/152a/134 yielded a $12.6 \%$ increase, but no manufacturer has indicated intent to produce R-134. R$32 / 134 a$ shows an improvement of $6 \%$ and may not be flammable since it contalns $70 \%$ R-134a. The report notes that significant design changes, such as use of counter-flow heat exchangers, will be necessary to achieve these gains. A caveat incicates that the ranking of substitutes may change, due to the influence of transport propertles and other variables not considered. (This report replaces the published draft, see RDB1134.)

F. Radermachei and D. Jung (University of Maryland), Replacement Refrigerants for R-22, published draft report, U.S. Environmental Protection Agency (EPA), Washington, DC, November 1990 (80 pages with 24 exhibits, RDB1134)

This peer-review draft examines alternative refrigerants for R-22. The report summarizes the simulation programs used, HAC and HACT, to examine candidate refrigerants. Coefficients of performance (COPs) and seasonal performance factors (SPFs) were calculated for a number of mixtures. The report also reviews the design modifications considered and discusses requirements for future research. No single-component refrigerant was found sultable as a substitute, but binary and ternary blends appear promising. The R-32/152a blend was identified as the most promising option, with an estimated COP increase of $11 \%$. A further increase by $4 \%$ was estimated with use of a suction gas heat exchanger. Addition of a third, nonflammable cimponent is suggested to reduce flammability. (This published draft was replaced by RDB2509.)

R. Radermacher (University of Maryland) and J. Lavelle (Elf Atochem North America, incorporated), Comparison of R-12 with the Blend of R-22/R142b. Proceedings of the ASME Winter Annual Meeting. American Society of Mechanical Engineers (ASME). New York, NY, pages 22-30, 1988 (RDB2339)

C. K. Rice and J. R. Sand (Oak Ridge National Laboratory, ORNL), Compressor Calorimeter Per- formance of Retrigerant Blends - Comparative Methods and Results for a Refrigerator Freezer Application, paper CH-93-20-3 Winter Meeting, Chicago, IL, January 1993), Transactions, American Society of Heating, Refrigerating, and Air-Conditioning Engineers (ASHRAE), Atlanta, GA, volume 99, part 1, 1993 in publication (19 pages with 7 figures and 5 tables, RDB3115)

M. L. Robin, Y. likubo (Great Lakes Chemical Corporation), G. de Souza Damasceno, J. N. Dubrouillet, V. W. Goldschmidt, and D. R. Tree (Purdue University), Performance of Alternative Refrigerants: Refrigerator-Freezer Energy Testing with HFC1528 / HFC-227ea Mixtures, Proceedings of the International CFC and Halon Alternatives Conference (Washington, DC), Alliance for Responsible CFC Policy, Arlington, VA, pages 99-104, September 1992 (6 pages with 2 tables, RDB2A05)

This paper presents measured performance data for blends of R-152a and R.227ea tested in an unmodifled home refrigerator. Physical and thermodynamic properties as well as flammability data and ozone depletion potentials (ODPs) are tabulated for R-12, R-152a, and R-227ea for comparison. The energy measurements were based on ANSI/AHAM Standard HRF-1-1988, with an increased number of thermocouples. An unidentified polyol ester (POE) was used as the lubricant for the R-152a/227ea mixtures. R$152 a / 227$ ea $(80 / 20)$ offered slightly reduced energy consumption and $5 / / 50$ and $20 / 80$ mixtures increased energy consumption by 4.3\%. The paper concludes that the R-152a/ 227 ea blends may offer significantly improved performance compared to R-12 in an optimized system. Recommendations are provided for further work.

R. J. Rose (University of Maryland), D. Jung (Inha University, Korea) and R. Radermacher (University of Maryland), Testing of Domestic Two-Evaporator Refrigerators with Zeotropic Refrigerant Mixtures, paper 3620 (Annual Moeting, Baltimore, MD, June 1992), Transactions, American Society of Heating, Refrigerating, and Air-Conditioning En/jineers (ASHAAE), Atlanta, GA, volume 98, part 2, pages 216-226, 1992 (10 pages with 7 flgures and 3 tables, RDB2605)

S. M. Sami, J. Schnotale (University of Moncton, Canada), and J. G. Smale (DuPont Canada, Incorporated). An Investigation of Ternary Blends Performance Proposed as Substitutes for CFC12. Proceedings of the 1992 International Refrigeration Conference - Energy Efficiency and New Refrigerants, edted by D. R. Tree and J. E. Braun, Purdue University, West Lafayette, IN, volume 2, pages 651-660, July 1992 (10 pages with 9 figures, RDB2840) 
J. R. Sand, E. A. Vineyard, and V. D. Baxter (Oak Ridge National Laboratory, ORNL), Laboratory Evaluation of an Ozone-Sate Nonazeotroplc Refrigerant Mixture in a Lorenz-Meutzner Refrigerator Freezer Desion, paper CH-93-20-4 Winter Meeting, Chicago, IL January 1993), Transactions, American Society of Heating, Refrigerating, and AirConditioning Engineers (ASHRAE), Atlanta, GA, volume 99, part 1, 1993 in publication (14 pages with 8 figures and 12 tables, RDB2412)

J. R. Sand, S. K. Fischer (Oak Ridge National Laboratory, ORNL), Modeled Performance of Nonchlorinated Substitutes for CFC-11 and CFC-12 in Centrifugal Chillers, International Journal of Refrigeration, Paris, France, in publication (6 pages, RDB2411)

J. R. Sand, S. K. Fischer (Oak Ridge National Laboratory, ORNL), and P. A. Joyner (Electric Power Research Institute, EPRI), Modeled Performance of Nonchlorinated Substttutes for CFC-11 and CFC-12 in Centrifugal Chillers, Proceedings of the International CFC and Halon Alternatives Conference (Baltimore, MD), Alliance for Responsible CFC Policy, Arlington, VA, pages 406-415, December 1991 (10 pages with 2 tables, RDB2260)

J. R. Sand and E. A. Vineyard, Report of Foreign Travel: 2-5 May 1989 [Zeotropic Blends in Refrigerators], ORNL/FTR-3251, Oak Ridge National Laboratory, Oak Ridge, TN, 18 May 1989 (14 pages, RDB1135)

This informal report summarizes meetings on refrigerator/freezer testing with zeotropic blends of refrigerants (nonazeotropic mixtures of refrigerants or NARMs) at the Universităt Hannover (Hannover, FRG). The research investigated a freezer, modified with a polystyrene block to form separate freezer and fresh-food compartments, operating with an R-22/142b refrigerant blend. The simulation program, testing protocol, instrumentation, and plans for testing other blends were reviewed. Also addressed is a visit to AEG GmbH (Kassel, FRG), a major manufacturer of domestic appliances, to discuss research on alternattve refrigerants. Compressor componente were reviewed after 1000 hours accelerated iffe testing in R-134a and in R22/R-142b. Parts from the R-134e compressor looked very good, whereas parts from the $R$ $22 / R-142 b$ test unit showed much more thermal breakdown. Some AEG engineers favor R-152a, or blends of R-152a with R-22 or R-134a, as an alternatve to $R-12$.

K. S. Sanvordenker (Tecumseh Products Company). Compressor Manufacturer's R-134a Applications, Proceedings of the International CFC and Halon Alternatives Conference Washington, DC). Alliance for Responsible CFC Policy, Arting- ton, VA, pages 157-164, September 1992 (8 pages with 3 figures and 3 tables containing corroctions to the copy in the proceedings, available from JMC as RDB2901)

This paper highlights the efforts of a compressor manufacturer to implement research data into R-134a applications for hermetic units. Comparattve capacity and performance data, based on calorimeter tests, are tabulated for compressors representative of those used in refrigerator/freezer applications. The capacity is approximately $10 \%$ lower with $\mathrm{R}-134 \mathrm{a}$ at rating conditions, but the efficiency stays the same. Further data show that the relative capaicities and efficiencies of R-12 and R-134a may be lower or higher depending on the application conditions. Sound levels are plotted for tradltional R-12 and redesigned, high-efficiency R134a compressors; the overall sound level is lower for the latter. Materials compatibility issues are reviewed, noting the advantages and acceptance of polyol ester (POE) lubricants as the consensus selection for R-134a. The paper discusses lubricant stability, chemical reactwity, miscibility, solubility, and lubricity. A plot compares the solubility of R-12 and R-134a in two POEs to R-12 in mineral oll. The discussion suggests that a bigger motor, with a small potential penalty in efficiency, may be required for R-134a due to the impact on equalization pressure and the required starting torque. A need is noted for new test methods for lubricity. The impacts on motor insulation and uncertainties regarding contaminants are covered briefly. The paper concludes that there are no technical barriers to conversion from R-12 to R-134a, but that information dissemination and the cost of the refrigerant and lubricant remain factors in the rate of conversion.

K. S. Sanvordenker (Tecumseh Products Company), R-152a versus R-134a in Domestic Refrigerator-Freezer - Energy Advantage or Energy Penaltyl, Proceedings of the 1992 International Refrigeration Conference - Energy Efficiency and New Refrigerants, edited by D. R. Tree and J. E. Braun, Purdue University, West Lafayette, IN, volume 1, pages 259-263, July 1992 (5 pages with 4 tables, RDB2728)

This paper presents now laboratory data for $R$ $12, R-134 a$, and $R-152 a$ in domestlc refrigeratorfreezer applications. It responds to assertions and reported findings that R-152a would offer higher efficiency, noting an error in the published thermodynamic data used. The paper reviews reports of R-152a advantages and impllcations. It also provides capacity and efficiency data, based on calorimeter tests, for six compressors for R-12, R-134a, and R-152a with a

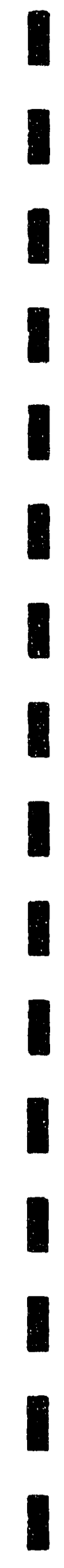

I 
polyol ester lubricant. These tests were run at $23^{\circ} \mathrm{C}\left(-10^{\circ} \mathrm{F}\right)$ evaporator temperature and both 43 and $54^{\circ} \mathrm{C}\left(110\right.$ and $\left.130^{\circ} \mathrm{F}\right)$ condenser tem. peratures. The test method, ASHRAE Standard 23 , and associated peculiartiles are reviewed. R-152a consistently yielded a $10 \%$ lower capacity than R-134a, which in turn showed a $10 \%$ drop compared to R-12. The energy efficiencies were nearly the same at the higher condensing temperature, but R-152a suffered a $6.5 \%$ penalty at the more representative lower condensing temperature. The data are briefly related to analyses by other investigators, which corroborate the findings. The paper concludes that use of R-152a instead of R-134a may yield a significant energy penalty rather than advantage.

I. R. Shankland (AlliedSignal Incorporated), CFC Alternatives for Thermal Insulation Foams, CFCs: Today's Options - Tomorrow's Solutions (proceedings of ASHRAE's CFC Technology Conference, National Institute of Standards and Technology, Gaithersburg, MD, September 1989), American Society of Heating, Refrigerating, and AirConditioning Engineers (ASHRAE), Atlanta, GA, pages $87-95,1990$ (9 pages, RDB0518)

M. B. Shiflet, A. Yokozeki, and P. R. Reed (DuPont Chemicals), Near-Azeotropic Refrigerants as Alternatives for R-502, ASHRAE Journal, American Society of Heating, Refrigerating, and Air-Condltioning Engineers (ASHRAE), Atlanta, GA, pages 24-28, February 1992 (5 pages with 2 figures and 3 tables, RDB3302)

M. B. Shiflet, A. Yokozekl, and P. R. Reed (DuPont Chemicals), Property and Porformance Evaluation of "SUVA" HP Retrigerants as R-502 Alternatives, Proceedings of the 1992 international Re. frigeration Conference - Energy Efficiency and New Refrigerants, edited by D. R. Tree and J. E. Braun, Purdue University, West Lafayette, IN, volume 1, pages 15-24, July 1992 (10 pages with 10 figures and 2 lables, RDB2709)

M. B. Shiflet, A. Yokozekl, and D. B. Bivens (DuPont Chemicals), Retrigerant Mixtures as HCFC-22 Alternatives, Proceedings of the 1992 International Refrigeration Conference - Energy Efficiency and New Refrigerants, edted by D. R. Tree and J. E. Braun, Pundue University, West Lafayette, IN, volume 1, pages 35-44, July 1992 (10 pages with 8 figures and 2 tables, RDB2711)

M. B. Shiflet and P. R. Reed (DuPont Chemicals), Alternative Low-Temperature Refrigerants, paper 163 , proceedings of the XVIIlth International Congress of Refrigeration (Montreal, Québec, Canada, August 1991), Internatlonal Institute of Refrigeration, Paris, France, August 1991 (RDB2307)
J. G. Smale (DuPont Canada, Incorporated), Now Refrigerants and Mixtures. for Heat Pump Opportunities in Canada, Proceedings of the 3 rd International Energy Agency Heat Pump Conference (Tokyo, Japan, 12.15 March 1990), edited by T. Saito and Y. Igarashi, Pergamon Press, Elmsford, NY, 1990 (10 pages with 5 figures and 11 tables, RDB2A13)

L. Snitkjær and F. K. Eggert (Danfoss-Flensburg GmbH, Germany). Use of a Ternary Blend in Existing Domestic CFC-12 Appllances, Proceedings of the 1992 International Refrigeration Conference - Energy Efficiency and New Refrigerants, edited by D. R. Tree and J. E. Braun, Purdue University, West Lafayette, IN, volume 2, pages 631. 640 July 1992 (10 pages with 5 figures and 4 tables, RDB2838)

T. G. Statt (U.S. Department of Energy), An Overview of Ozone-Safe Retrigerants for Centrifugal Chillers, CFC Alternatives, technical data bulletin 6(1). American Society of Heating, Refrigerating, and Air-Conditioning Engineers (ASHRAE), Atlanta, GA, pages 35-39, June 1990; republished in Transactions, American Society of Heating, Refrigerating, and Air-Condtiloning Engineers, Attanta, $G A$, volume 96, part 1, 1990 (5 pages with 2 figures and 5 tables, RDB2335)

R. A. Struss, J. P. Henkes, and L. W. Gabbey (Modine Manufacturing Company). Performance Comparison of HFC-134a and CFC-12 with Vartous Heat Exchangers in Automotive Air-Condttioning Systems, paper 900598 (SAE International Congress and Exposition, Detroit, MI, 26 February 2 March 1990), Society of Automotive Engineers (SAE), Warrendale, PA, February 1990 (12 pages with 13 figures and 7 tables, RDB2A17)

This paper reviews vehicular wind tunnel tests that were carried out on two automotive airconditioning systems. The test data compare performance of R-12 and R-134a with various heat exchangers. The vehicles, heat exchangers, test facilities, approach, and findings are reviewed. R-12 was tested with a 525 SUS viscosity mineral oil. R-134a was tested with a proprietary polyalkylene glycol, supplied by DuPont Chemicals. The seat exchangers included both a serpentine and a parallel flow designs. Refrigerant chirge requirements were determined by comparative tests. R-134a resulted in higher head pressures, but the same compartment temperatures as with R-12. Heat exchanger selection was found to influence charge levels, indicated as important with use of the more expensive R-134a. An appendix describes the wind tunnel used.

S. G. Sundaresan (Copeland Corporation), Commercial Refrigeration: The Challenge and the ls- 
sues Regarding the Retrofft and New Equlpment, paper 4.2, Proceodings of the International Seminar on Now Tochnology of Alternative Refrigerants - Lubricants and Materials Compatibility (Tokyo, February 1983), Japanese Association of Refrigeration (JAR), Tokyo, Japan, pages 57-66, February 1993 (6 pages with 1 figure and 6 tables, RDB3314)

S. G. Sundaresan (Copeland Corporation), Aspects of Lubrication, Fractionation, and Rellability of Compressors with new Refrigerants for Commercial Refrigeration, CFC Alternatives: User Experience and Update, Institution of Mechanical Engineers and Institute of Refrigeration, London, UK, 11 November 1992 (12 pages with 1 figure and 7 tables, RDB3330)

S. G. Sundaresan (Copeland Corporation), Near Azeotrope Retrigerants to Replace R-502 in Commercial Retrigeration, Proceedings of the 1992 International Refrigeration Conference - En. ergy Efficiency and New Refrigerants, edited by $D$. R. Tree and J. E. Braun, Purdue University, West Lafayette, IN, volume 1, pages 1-13, July 1992 (13 pages with 11 figures and 7 tables, RDB2708)

S. G. Sundaresan (Copeland Corporation), Alternate Refrigerants and Lubricants for Refrigeration Compressors, paper 151, proceedings of the XVIIIth International Congress of Refrigeration (Montreal, Québec, Canada, August 1991), International Institute of Refrigeration, Paris, France, August 1991 (RDB2308)

T. Takaichi (Showa Denko K.K., Japan), Current Status of R\&D for CFC Alternatives, paper 1.1, Proceedings of the International Seminar on New Technology of Alternative Refrigerants - Lubricants and Materia/s Compatibility (Tokyo, February 1983). Japanese Association of Refrigeration (JAR), Jokyo, Japan, pages 3-8, February 1983 (6 pages with 5 figures and 4 tables, RDB3306)

The paper briefly surveys research and development efforts to identify alternatwes for chlorofluorocarbon (CFC) refrigerants. It recaps the introduction of CFCs, discovery of their ozonedepletion role, and both measured concentra. tions in the atmosphere and ozone decline. It then reviews the 1992 revisions to the Montreal Protocol, international production of CFCs and R-22, and 1991 CFC consumption by application in Japan. The paper discusses interest in hydrochlorofluorocarbon (HCFC) and hydrofluorocarbon (HFC) alternatives and provides a tabular summary of candidate fluids. A figure indicates the chernical paths to produce the primary alternative fluorocarbons. It then reviews the Program for Alternattve Fluorocarbons Toxicity Testing (PAFT) and outlines the five programs underway. It also summarizes efforts under the Alternative Fluorocarbons Ervironmental Acceptability Study (AFEAS) to assess candidate HCFCs and HFCs. It mentions a fiveyear cooperative program by the Japanese $R \theta-$ search institute of Innovative Technology for the Earth (RITE), Ministry of International Trade and Industry (MITI). New Energy Development Organization (NEDO), National Chemistry Laboratory for Industry (NCLI), and ten chemical producers to develop a new generation refrigerant. This "third generation" fluid would be ozone safe, have low global warming effect, and have a new molecular structure consisting of oxygen and other elements in addition to carbon, fluorine, and hydrogen. While this paper does not address any of these subjects in depth, it provides a sweeping overview of efforts to introduce alternattve refrigerants.

T. Takaichl (Showa Denko K.K., Japan), Development of Alternatlve Fluorocarbons, Petrotech, volume 14, number 6, pages 513-518, 1991 (6 pages, RD83324)

N. Tanaka (Mitsubishi Electric Corporation, Japan), Trends of Alternative Refrigerants, paper 4.1, Proceedings of the International Seminar on New Technology of Alternative Refrigerants - Lubricants and Materials Compatibitity (Tokyo, February 1983). Japanese Association of Refrigeration (JAR), Tokyo, Japan, pages 51-56. February 1993 (6 pages with 5 figures and 2 tables, RDB3313)

D. W. Treadwell (Lennox Industries Incorporated), Application of Propane (R-290) to a Single Packaged Unitary Air-Conditioning Product, Proceedings of the International CFC and Halon Atternatives Conference (Baltimore, MD). Allance for Responsible CFC Policy, Arlington, VA, pages 348351. December 1991 (4 pages with 1 table, available from JMC as RDB2261)

This paper discusses the safety considerations and two tests of propane (R-290) as a refrigerant in a single-package, unitary air conditioner. Advantages cited include lower discharge temperature and pressure compared to R-22, both favorable to compressor life, as well as higher efficiency (by 1-2\%) and materials compatibility. The low cost, avallability, and favorable environmental attributes (no ozone-depletion potential and near zero global warming potential) are contrasted to its flammability. The paper estlmates the charge quantity required to be less than half that of R-22, and concludes that the probability of reaching the lower flammability limit in a house - under identified leak assumptions - is remote. The paper indicates that the potential risks should be evaluated in light of the environmental and other advantages. 
S. Uemura, S. Inagaki, N. Kobayashi, T. Teraoka, and $M$. Noguchl (Dalkin Industries, Limited), Characteristics of HFC Refrigerants, Proceedings of the 1992 Intemational Refrigeration Conference Energy Efficiency and New Refrigerants, edted by D. R. Tree and J. E. Braun, Purdue University, West Lafayette, IN, volume 2, pages 385-394, July 1992 (10 pages with 13 figures and 5 tables, available from JMC as RDB2821)

E. A. Vineyard, J. R. Sand (Oak Ridge National Laboratory, ORNL), and T. G. Statt (U.S. Department of Energy, DOE), Selection of Ozone-Safe, Nonazeotropic Refrigerant Mixtures for Capacity Modulation in Residential Heat Pumps, paper 3199, Transactions, American Society of Heating, Refrigerating, and Alr-Conditioning Engineers (ASHRAE), Atlanta, GA, volume 95, part 1, 1989 (12 pages with 4 figures and 4 tables, RDB1136)

M. Yital, W. Jie, Y. Zhao, W. Hualxin, and L. Canren (Tianjin University, China), Investigation of Using Nonazeotropic Refrigerant Mixture as the Rt. placement of R-12, Proceedings of the 1992 international Refrigeration Conference - Energy Efficiency and New Refrigerants, edited by D. R. Tree and J. E. Braun, Purdue University, West Lafayette, IN, volume 2, pages 669-676, July 1992 (8 pages with 6 figures and 3 tables, RDB2842)

M-S. Zhu, L-Z. Han, Z-Z. Lin (Tsinghua University, China) B. Lu, D. Liu, and L. Yang (Beiling Snow Flake Electrical Appliance Group Corporation, China), Experimental Researches on Domestlc Refrigerators Using HFC-134a as Refrigerant, Proceedings of the 1992 International Refrigeration Conference - Energy Efficiency and New Refrigerants, edited by D. R. Tree and J. E. Braun, Purdue University, West Lafayette, IN, volume 1, pages 241-247, July 1992 (7 pages with 1 figure and 5 tables, RDB2726)

M-S. Zhu, L-Z. Han, and Z-Z. Lin (Tsinghua University, China), Researches of CFC Alternatives in Tsinghua University, Proceedings of the International CFC and Halon Alternatives Conference (Baltimore, MD), Alliance for Responsible CFC Pollcy, Arlington, VA, pages 484-493, December 1991 (10 pages with 6 tables, RDB2312)

Alternative Rofrigerant Research for Residential Refrigerator-Freezers, research project 614-RP, American Society of Heating, Refrigerating, and AirConditloning Engineers (ASHRAE), Atlanta, GA, April 1989 - June 1991 (ASH0614)

The contractor for this project was Oak Ridge National Laboratory, led by $E$. Vineyard; it was sponsored by ASHRAE Technical Committees 3.1, Refrigerants and Brines, and 7.1, Residential Refrigerators and Food Freezers. [see RDB2412 for findings!
As Easy as 123, E. I. DuPont de Nemours and Company, Incorporated, Wilmington, $\mathrm{DE}$; The Trane Company, La Crosse WI; and York International Corporation, York, PA; October 1990 (12. minute videotape, RDB1137)

This video explains how R-123 was developed to replace R-11 by balancing ozone-depletion. global-warming, and energy-efficiency considerations.

CFCs: Time of Transition, American Society of Heating, Refrigerating, and Alr-Conditioning Engineers (ASHRAE), Attanta, GA, 1989 (274 pages with 32 papers, RDB1138)

CFCs: Today's Options - Tomorrow's Solutions. proceedings of 1989 ASHRAE CFC Technology Conference (Gaithersburg, MD, September 1989), American Society of Heating, Refrigerating, and AirConditioning Engineers (ASHRAE), Attanta, GA, 1990 (128 pages with 13 papers, RDB1139)

Development of an Advanced Refrigerant for Compression Heat Pump, Research Institute of Innovative Technology for the Earth (RITE), December 1991 (RDB3326)

Proceedings of the 1990 USNC/IIR-Purdue Retrigeration Conference and ASHRAE-Purdue CFC Conference, edited by D. R. Tree, Ray W. Herrick Laboratories, Purdue University, West Lafayette, IN, July 1990 (526 pages with 56 papers, RDB1 140)

Progress in Japan with Substitutes for CFC Rofrigerants: Report on Trip to Japan (17 November - 2 December 1989), Air-Condtioning and Refrigeration Institute (ARI), Arlington, VA, 1989 (17 pages including 2 tables, ROBOCO4)

This report summarizes observations made during a trip to Japan to investigate progress with substitutes for chlorofluorocarton refrigerants, with emphasis on materials compatibility and lubricant research issues. The report summarizes status of refrigerants, research, and testing techniques; an itinerary and list of contacts are included. The substitutes being addressed match those being pursued in the United States, but the effort and depth of analysis are greater.

Research Needs for Energy Efficlent Alternatives to Chlorofluorocarbons, request for proposals DE-RP01-89ER30155, U.S. Department of Energy (DOE), Washington, DC, August 1989 (170 pages, RDB1141)

Report of the ARI Delegation to Japan on Alternative Refrigerants, report DOE/CE/23810-12, Air-Conditioning and Refrigeration institute (ARI), 
Arlington, VA, February 1993 (20 pages including 2 appendices, avallable from JMC as RDB3401)

This document reports on a trip, by an ARI delegation, to exchange information on alternative refrigerants and to review methods to screen alternatives to chlorofluorocarbons (CFCs) and hydrochlorofluorocarbons (HCFCs). Five representatives travelled to Japan to participate in the International Seminar on New Technology of Alternative Refrigerants - Lubricants and Materials Compatibility. They subsequently visited seven manufacturers and the Ministry of International Trade and Industry (MITI). Techniques for materials compatibility screening, lubricant testing, and flammability studies were of specific interest. This report provides an overview of Japanese phase-out strategies, identffies research into alternattve refrigerants and lubricants for them, and reviews the screening methods used. It discusses the status of retrofits and system design. The conference agenda and lists of both the ARI delegates and companies visited are provided in appendices. The report notes that the leading replacement refrigerant is R-134a. Efforts with hydrochlorofluorocarbon (HCFC) alternatives are limited since companies expect to move away from such fluids by the year 2000 . R-32/134a $(30 / 70)$ is considered a candidate to replace $R$ 22, though the Japanese view this zeotrope as not flammable, unlike in the U.S., based on testing under different conditions. More than 50 compounds have been synthesized and are under investigation as alternatives for R-502. Polyol ester (POE) lubricants are the prime focus for hydrofluorocarbons (HFCs), except in automothe air conditioning where polyalkylene glycols (PAGs) are used. The report discusses specific fluids, lubricants, test procedures, and regulatory actions and expectations for several application areas. Observations regarding use of absorption chillers as alternatives, government incentives, CFC taxes, safety standards, and a CFC destruction technology also are mentioned.

Status of CFCs - Refrigeration Systems and Refrigerant Properties, proceedings of the meetings of IIR Commissions B1, B2, E1, and E2 (Purdue University, West Lafayette, IN), International Institute of Refrigeration, Paris, France, July 1988 (438 pages with 51 papers, RD81142)

\section{ABSORPTION AND ADSORPTION}

M. R. Ally, Computer Simulation of Absorption Heat Pump Using Aqueous Lithium Bromide and Ternary Nitrate Mixtures, report ORNL/TM-10392, Oak Ridge National Laboratory, Oak Ridge, TN, June 1988 (52 pages, available from NTIS, RDB1143)

This report presents the results of a computer simulatio.i study aimed at comparing the potential performance of lithium bromide (LiBr) and ternary nitrate aqueous mixtures in a heat pump. The falling-film heat transfer coefficient for the ternary nitrate mixture is estimated to be lower than that for $\mathrm{LiBr}$ by about one-third. Due to a lack of measured thermophysical properties, the estimates relied on extrapolations. The results show that the ternary nitrate mixture may be operated up to $260^{\circ} \mathrm{C}\left(500^{\circ} \mathrm{F}\right)$ boost temperature, which is approximately $80^{\circ} \mathrm{C}\left(176^{\circ} \mathrm{F}\right)$ higher than what has been demonstrated with LiBr. In higher temperature regimes, the nitrates show the potential for $10 \%$ higher COPs and a marginally greater absorber capacity than LiBr. Experimental measurements of the falling film heat transfer coefficient, subcooling, and thermophysical properties are required to make a more definithe investigation.

S. C. Bhaduri (Indian Institute of Technology), Thermodynamic Criterion for Selection of Refrigerant-Absorbent Pairs for Vapor Absorption Refrigeration System, Proceedings of the International CFC and Halon Alternatives Conference (Washington, DC), Alliance for Responsible CFC Policy, Arlington, VA, pages 83-98, September 1992 (16 pages with 5 figures and 1 table, RDB2A04)

R. L. Cox, Improvements and Enhancements of the ABSORB Computer Program for Modeling Chemical Absorption Heat Pump Systems, re port ORNL/TM-9957, Oak Ridge National Laboratory, Oak Ridge. TN, July 1986 (56 pages, avallable from NTIS, RDB1144)

This report provides documentation for updates to $A B S O R B$, a simulation program for modeling chemical absorption heat pump systems of varying configuration. A number of improvements and enhancements have been incorporated to improve the robustness, flexibility, and applicability of this code; these modffications include: 1) a revised strategy of solving the system equations, 2) increased modularization of the program, and 3) the first efforts to employ the code to determine an optimum economic design of a heat pump system. A llsting of the FORTRAN source code for ABSORB is included as an appendix. The listing excludes the optlmizing package NPSOL, which is proprietary 
and must be separately obtained. User documentation to run ABSORB is published separately in report ORNL/Sub/43337/2.

R. C. DeVault, Advanced Absorption Cycles: System Development and Supporting Research, Oak Ridge Natlonal Laboratory (ORNL), Oak Ridge, TN, March 1990 (48 pages, RDB1145)

G. Grossman and E. Michelson, Absorption Heat Pump Simulation and Studies, Part I: A Modular Computer Simulation of Absorption Systems, report ORNL/Sub/43337/2, Oak Ridge National Laboratory, Oak Ridge, TN (avallable from NTIS, RDB0926)

B. H. Jennings and F. P. Shannon, The Thermodynamics of Absorption Refrigeration, Refrigerating Engineering. American Society of Refrigerating Engineers (ASRE, now merged into the American Society of Heating, Refrigerating, and Air-Conditioning Engineers, ASHRAE), Atlanta, GA, volume 35, pages $333 \mathrm{ff}, 1938$ (RDB3230)

R. A. Macriss and T. S. Zawacki, Absorption Fluids Data Survey 1989 Update, report ORNL/ Sub/8447989/4, Oak Ridge Natlonal Laboratory, Oak Ridge, TN, 1989 (52 pages with 21 tables, available from NTIS, RDB1146)

This document updates the serles of reports on absorption fiuids and data, ORNL/Sub/8447989/1,2,3, with data developed and published primarily between 1985-1988, and by citation of 44 additional references. Seventy-four worldwide publications containing data relating to properties of binary, ternary, and multicomponent absorption fluids are identified. The fluids discussed include combinations of 9 different refrigerant compounds, as well as 30 single, 7 binary, and 1 ternary absorbent compounds.

M. R. Patterson, R. N. Crosswhite, and H. PerezBlanco, A Menu-Driven Program for Determining Properties of Aqueous Lithium Bromide Solutions, report Oh.NI./TM-11331, Oak Ridge National Laboratory, Oak rilige, TN, January 1990 (38 pages with program diskette, available from NTIS, RDB1147)

This report contains a description of and user's guide for the computer program LIMENU for calculating the thermodynamic and transport properties of aqueous solutions of lithium bromide ( $\mathrm{LiBr}$ ).

Thermophysical Property Data for Water-Lithlum Bromide at High Temperatures and Concentrations, research project 527-RP, American Society of Heating, Refrigerating, and Air-Conditioning Engineers (ÁSHRAE), Atlanta, GA, July 1987 - June 1991 (ASH0527)
The contractor is the Georgia Tech Research Institute, led by $A$. S. Teja; the project was sponsored by ASHRAE Technical Committee 8.3, Absorption and Heat-Operated Machines.

Working Fluids and Transport Phenomena in Advanced Absorption Heat Pumps, report HPTC30.2 , edited by $T$. Saito, Heat Pump Technology Center of Japan, Tokyo, Japan, volume II, March 1990 (362 pages, RDB1148)

This report summarizes the findings of the International Energy Agency (IEA) research project on Working Fluids and Transport Phenomena in Advanced Absorption Heat Pumps'(Annex XIV).

\section{RESEARCH PROGRAMS}

G. C. Hourahan and M. S. Menzer (Air-Conditioning and Refrigeration Institute), Research Needs in Air-Conditioning and Refrigeration, Proceodings of the ASME National Heat Transfer Conference (Atlanta, GA, August 1993), American Society of Mechanical Engineers (ASME), New York, NY, 1993 (8 pages with 5 flgures and 1 table, avallable from JMC as RDB3421)

This paper outlines research needs stemming from introduction of alternatlve refrigerants and the concurrent desire to maintain or increase equipment efficiency. Its purpose is to seed interest in and identify sponsorship opportunities for necessary research. The paper briefly reviews potential impacts of refrigerants on ozone depletion and global warming. It then discusses vapor-compression and absorption cycles and equipment. Starting with their components, it identifies research needs to utilize alternative refrigerants. Research of heat exchanger enhancement, fundamental bolling heat transfer, considerations for glide utilization for zeotropes, and influences of lubricants are among the topics addressed. Design issues for compressurs, both positive displacement and centrifugal, are surveyed with emphasis on discharge valve requirements, impeller improvement, oll-free possibilitles, and seal refinement. Research needs are cited for materials compatibility and lubricants, composition management for zeotropic blends, and leak sensor requirements. The paper then discusses opportunities for not-in-kind technologies including absorption, adsorption (or desiccant), Stirling, and other cycles. It also mentions needs relating to distribution systems, training of service personnel, and conversions to alternative fluids. The paper mentions ongoing research by the Air-Conditioning and Refrig- 
eration Technology Institute (ARTI) and provides a tabular summary of agencles funding research of air conditioning and refrigeration. They include the ARTI, American Soclety of Heating Refrigerating and Alr-Conditioning Engineers (ASHRAE), Electric Power Research Institute (EPRI), Gas Research Institute (GRI), U.S. Department of Energy (DOE), and U.S. Environmental Protection Agency (EPA).

M. O. McLinden, W. M. Haynes (National Institute of Standards and Technology, NIST, USA), J. T. R. Watson (National Engineering Laboratory, UK), and K. Watanabe (Keio University, Japan), A Survey of Current Worldwide Research on the Thermodynamic Properties of Alternative Refrigerants, report NISTIR 3969, National Institute of Standards and Technology, Boulder, CO, June 1991 (84 pages, available from NTIS, RDB2262)

A survey of research on thermophysical properties of alternative refrigerants is presented in tabular form. Research acthitles throughout the world, concerned with either measurements or correlations of properties, are summarized. The fluids include R-22, R-23, R-32, R-123, R-123a, R-124, R-125, R-134, R-134a, R-141b, R-142b, R143a, R-152a, E-134 (bis-difluoromethylether), fluoroethers, and hydrofluoroethers along with mixtures containing at least one of these. The properties addressed are thermodynamic, transport, phase equilibria, dielectric constant, and refractive index. The report provides summary information about each research actwity, including the ranges of data, estimated accuracy, and references. The organizations and investigators involved as well as apparatus and techniques employed are tabulated by country. Neither actual property data nor correlating equations are presented. The objectives were to assist in coordination of research programs, to expedite acquisition of required property data, and to serve as a guide for planning future research. The collaborative effort to compile this information was undertaken under Annex 18. Thermophysical Properties of the Environmentally Acceptable Refrigerants, of the Advanced Heat Pump Programme of the International Energy Agency.

K. Watanabe (Kelo University, Japan), Current Status of Thermophysical Properties Research on CFC Alternatives, Proceedings of the 3rd International Energy Agency Heat Pump Conference (Tokyo, Japan, 12-15 March 1990) edited by T. Saito and Y. Igarashi, Pergamon Press, Elmsford, NY, pages 263-282, 1990 (22 pages, RDB0408)

\section{AFEAS}

Alternative Fluorocarbons Environmental ACceptability Study, program description, AFEAS, Washington, DC, April 1990 (4 pages, RDB1149)

AFEAS was initiated in December 1988, as a consortium of 12 chemical producers, to assess the potential impacts of chlorofluorocarbon refrigerant alternatives on the environment. Results were presented at the United Nations Environment Programme (UNEP) meeting in Nairobl in August 1989, and were incorporated as an appendix to the Sclentific Assessment under the Montreal Protocol on Substances that Déplete the Ozone Layer. The study is being expanded to conduct further related research. This brochure introduces AFEAS.

Alternative Fluorocarbons Environmental ACceptability Study (AFEAS) Summary Leaflets, Alternative Fluorocarbons Environmental Acceptabillty Study, Washington, DC, 31 May 1990. (10 pages, RDB1150)

This series of five leaflets summarize key AFEAS findings. They address Atmospheric Fluorocarbons and Stratospherte Ozone, Breakdown Products of Alternatives, UV-B Radiation Measurements, Alternative Fluorocarbons and Global Warming, and a Glossary of Terms.

\section{ARI}

G. C. Hourahan and D. S. Godwin (Air-Conditioning and Refrigeration Institute), ARI's R-22 Alternative Refrigerants Evaluation Program (AREP), Proceedings of the International CFC and Halon Alternatives Conference (Washington, DC), Alliance for Responsible CFC Policy, Arlington, VA, pages 5564 , September 1992 (10 pages with 3 figures and 3 tables, available from JMC as RDB2906)

This paper summarizes a program to evaluate candidate fluicis to replace R-22, establish test protocols to evaluate them, conduct the tests, and present the results. The overall objectlve is to perform a broad screening of alternative candidates, while eliminating unnecessary duplication of work and wasting of limited resources. The paper outlines the AREP organization, including its Task Force (chaired by D. M. Goldberg) and Technical Committee (chaired by $E$. B. Muir); both their members and participating international organizations are named. The document reviews considerations for ten candldates selected for initial examination from nearly 30 nominations. They include R-32/R-125 (60/40), R-32/R-134a (25/75), R-32/R-125/R134a (10/70/20), R-290 (propane), R-134a, R- 
717 (ammonla), R-32/R-125/R-290/R-154a (20/55/5/20), R-32/R-125/R-134a (30/10/60), R-125/R-143a (45/55), and R-125/R-143a/R$134 a(45 / 50 / 5)$; the list notes changes in selected blend compositions from earler AREP documents. The last two are of primary interest as potential replacements for R-502. Procedures and conditions for compressor calorimeter and heat transfer test are outlined. The Electric Power Research Institute (EPRI) is funding the heat transfer segment. Planned drop-in tests, system simulations, and system tests are outlined. Results of the work will be disseminated through technical publications and through the Refrigerant Database. A Gantt chart shows the schedule for introduction of R22 replacements. Additional figures indicate the AREP testing plan and detail the heat transfer testing protocol.

Participants' Handbook: R-22 Alternative Refrigerants Evaluation Program (AREP), Air-Conditioning and Refrigeration Instltute (ARI), Arlington, $V A, 2$ November 1992 (44 pages, available from JMC as.RDB2B03)

This document outlines an ARI program to evaluate candidate alternatives for R-22 and R-502, the latter an azeotrope of R-22 and R-115, for unitary alr conditioners, heat pumps, chillers, refrigeration equipment, and lce-making machines. This cooperatlve program seeks to accelerate introduction of alternatives by focusing research efforts and avoiding dupllcattve work. The document outlines the AREP organization, including its Task Force (chaired by D. M. Goldberg), Technical Committee (chaired by E. B. Muir), and Heat Transfer Subcommittee. It identifies cooperating organization, including the European Committee of Manufacturers of Refrigeration Equipment (CECOMAF) and the Electric Power Research Institute (EPRI). EPRI is funding, coordinating, and managing the heat transfer segment, an integral part of the program. The document identifies the nomination process and resultant candidate refrigerants, which have changed since the prior version of this document. They Include R-32/R-125 (60/40), R-32/R-134a (30/70), R-32/R-125/R134a (10/70/20), R-290 (propane), R-134a, R717 (ammonia), R-32/R-125/R-290/R-134a (20/55/5/20), R-32/R-125/R-134a (30/10/60), R-32/R-134a (25/75), R-32/R-227ea (35/65), R125/R-143a (45/55), R-125/R-143a/R-134a (44/52/4), and R-32/R-125/R-143a (10/45/45). The last three are of primary interest as potential replacements for R-502. Procedures and conditions for compressor calorimeter and heat trans. fer test are specified for participants. Results of the work will be disseminated via the Refrigerant Database. Related research on toxiclty and en. vironmental assessments of the candidate fluids and components will be coordinated and shared. Appendices to this program handbook Identify committee members, participation commitments, international organizations conducting similar research, and pertinent comblnations of refrigerants and heat exchanger types. This handbook prescribes common terminology and definitions to be used as well as formats and contents to be provided for the program.

ARI Research Plan, Air-Conditioning and Refrigeration Institute, Artington, VA, 10 March 1992 (58 pages, available from JMC as RDBOC01)

This plan documents research needs for airconditioning and refrigeration, with primary focus on refrigerants, energy conservation, and building environment. It provides industry guidance for public-sector research organizations and sponsors. it also may be useful to individual companies in planning proprietary research and development or cooperative programs. A specific plan for materials compatibility and lubricant research, the basis for the Alr-Conditioning and Refrigeration Technology Institute (ARTI) Materials Compatibility and Lubricant Research (MCLR) Program, is included as an appendix. A second appendix provides a serles of charts, to show the status of alternative refrigerants and projectlons for their commerclalization. The charts also list announced production plants. Charts are included for $R-32, R$ 123, R-124, R-125, R-134a, R-142b, R-143a, R$152 a$, and E-134. $A$ third appendix provides elaborations for selected research recommendations including objectives, rationale, suggested approaches, and estimated or recommended budgets and time requirements. This version updates and replaces those published on 6 November 1989, 30 April 1990, 19 December 1990, and 25 September 1991.

\section{ARTI}

G. C. Hourahan and S. R. Szymurski, Materials Compatibility and Lubricants Research on CFCRefrigerant Substltutes, report DOE/CE/23810-8, Air-Conditioning and Refrigeration Technology Institute (ARTI). Arlington, VA, January 1993 (38 pages with 12 figures and 9 tables, avallable from JMC as RDB3204)

This progress report summarizes the goals and status of the Materlals Compatibility and Lubricant Research (MCLR) Program, jointly funded under a grant from the Department of Energy and cost sharing by the air-conditioning and refrigeration industry. The 36-month program 
supports critical research to accelerate introduction of substltutes for chlorofluorocarbon (CFC) refrigerants. The report reviews projects to measure thermophysical properties, model the performance and key operating parameters of 12 potential alternathes for $R-22$ and $R-502$, test the chemical and thermal stability of refrigerant-lubricant mbxtures with metals, and measure the miscibility of lubricants with refrigerants. It outlines projects to provide information on the compatibility of refrigerants and lubricants with motor materials, elastomers, and engineering plastics. The report identifies the objectives and contractors for three new projects to develop accelerated screening and test methods to predict lubricant performance in compressors, the life of motor materials exposed to refrigerant-lubricant mixtures, and chemical and thermal stability of refrigerant-lubricant mixtures. Other projects introduced will measure the viscosity, density, and solubility for refrigerant blends in selected lubricants, electrohydrodynamic (EHD) enhancement of heat exchangers for alternathe refrigerants, and the compatibility of desiccants with refrigerants and lubricants. An ongoing project to collect and facilitate dissemination of data, through development and administration of a refrigerant database, is cited. The scope of the program, objectives of the individual projects, and significant interim findings are presented. This program summary also identifles reports resulting from the indwidual projects, including three final reports on "Theoretical Evaluations of R-22 AVternative Fluids," "Chemical and Thermal Stability of Refrigerant-Lubricant Mixtures with Metals," and "Miscibility of Lubricants with Refrigerants." Elght figures summarize progress in measuring thermophysical properties of R-32, $R-123, R-124$, and $R-125$. Three figures provide Daniel and density plots for R-12 and R-22 with mineral oil and R-134a with penta erythritol ester mixed acid. A table summarizes measured elastomer swelling in refrigerants and lubricants.

G. C. Hourahan and S. R. Szymurskl, Materials Compatibility and Lubricants Research on CFC. Retrigerant Substitutes, report DOE/CE/23810-4, Air-Conditioning and Refrlgeration Technology Institute (ARTI), Arlington, VA, October 1992 (16 pages with 10 tables, avallable from JMC as RDB2B02)

This progress report summarizes the goals and status of the Materials Compatibility and Lubricant Research (MCLR) Program, Jointly funded under a grant from the Department of Energy and cost sharing by the air-condtitioning and refrigeration industry. The 36-month program supports critical research to accelerate introduction of substitutes for chlorofluorocarbon (CFC) refrigerionts The program comprises projects to measure thermophysical properties, model the performance and key operating parameters of nine potential alternatives for R-22, test the chemical and thermal stability of refrigerant-lubricant mixtures with metals, and mea. sure the miscibility of lubricants with refrigerants. Three projects are providing information on the compatibility of refrigerants and lubricants with motor materials, elastomers, and engineering plastics. An eighth prolect collects and facilitates dissemination of data through $\mathrm{de}-$ velopment and administration of a refrigerant database. The second phase of the project commenced in October 1992 and will continue through September 1994. The scope of the program, objectives of the individual projects, and significant interim findings are presented. This program summary also identfiles reports resulting from the indlvidual projects, including three new final reports on "Theoretical Evaluations of R-22 Alternative Fluids," "Chemical and Thermal Stability of Refrigerant-Lubricant Mixtures with Metals," and "Miscibility of Lubricants with Refrigerants." Ten tables summarize the miscibility of alternative refrlgerants in seven tested lubricants.

M. S. Menzer (Air-Conditioning and Refrigeration Technology Institute, ARTI), ARTI Preliminary Rasults of Materials Exposed to Refrigerants and Lubricants, Proceodings of the 1992 International Refrigeration Conference - Energy Efficlency and New Refrigerants, edited by D. R. Tree and J. E. Braun, Purdue University, West Lafayette, IN, volume 2, page 677, July 1992 (1 page, available from JMC as RDB2812)

This synopsis introduces the Materlals Compatibility and Lubricant Research (MCLR) Program, an effort to investigate the properties and compatibilities of alternative refrigerants. The goal of this program is to accelerate commercialization of chlorofluorocarbon (CFC) and hydrochlorofluorocarbon (HCFC) substitutes in air-conditioning and refrigeration applications. The funding and program management are indicated. Seven research projects exceeding $\$ 1.2$ million in total are identffied for the first phase. The program includes projects to measure thermodynamic and heat transport properties of refrigerants, test the chemical and thermal stability of refrigerant-lubricant mixtures with metals, and measure the misclbillty of refrigerants and lubricants. Three additional projects will provide information on the compatibility of refrigerants and lubricants with motor materials, elastomers, and engineering plastics. The seventh project faciltates dissemination of data through development and administration of a refrigerant database. The second phase also is introduced. It includes projects to 
measure the solubility and viscosity of refrigerant-fubricant mixtures, their compatibility with desiccants, and development of screening and test methods. This summary serves as a preface for five presentations from the program.

S. R. Szymurski (Alr-Condltioning and Refrigeration Technology Institute, ARTI), Materials Compatibility and Lubricant Research on CFC-Refrigerant Substitutes - Research Update, Proceodings of the International CFC and Halon Alternatives Conference (Washington, DC) Alllance for Responsible CFC Policy, Arlington, VA, pages 73-82, September 1992 (10 pages, RDB2A03)

This paper provides an update on the goals and status of the Materials Compatibility and Lubricant Research (MCLR) Program, jointly funded under a grant from the Department of Energy and cost sharing by the air-conditioning and refrigeration industry. The program addresses critical research to accelerate the introduction of substtutes for chlorofluorocarbon (CFC) refrigerants. The program comprises projects to measure thermophysical properties, test the chemical and thermal stability of refrigerant-lubricant mixtures with metals, and measure the miscibility of lubricants with refrigerants. One project is modelling the performance and key operating parameters of alternatives for R-22. Three projects will provide information on the compatibility of refrigerants and lubricants with motor materials, elastomers, and engineering plastics. An eighth project collects and facilltates dissemination of data through development and administration of a refrigerant database. The scope of the program, objectives of the projects, and significant preliminary findings are presented.

S. R. Szymurskl, Materials Compatibility and Lubricants Research on CFC-Refrigerant Substitutes, report DOE/CE/23810-3, Air-Conditioning and Refrigeration Technology Institute (ARTI), Arlington, VA, July 1992 (13 pages, available from JMC as RDB2809)

This progress report summarizes the goals and status of the Materials Compatibility and Lubricant Research (MCLR) Program, Jointly funded under a grant from the Department of Energy and cost sharing by the air-conditioning and refrigeration industry. The program addresses crtical research to accelerate the introduction of substitutes for chlorofluorocarbon (CFC) refrigerants. The program comprises projects to measure thermophysical properties, test the chemical and thermal stability of refrigerant-Iubricant mixtures with metals, and measure the miscibility of lubricants with refrigerants. One project is modelling the performance and key operating parameters of alternatlves for R-22.
Three projects will provide information on the compatlbility of refrigerants and lubricants with motor materlals, elastomers, and engineering plastics. An eighth project collects and facilltates dissemination of data through development and administration of a refrigerant database. The scope of the program, objectives of the projects, and significant preliminary findings are presented. [seo RDB2B02 for update]

S. R. Szymurski, Materials Compatibility and Lut bricants Research on CFC-Refrigerant Substttutes, report DOE/CE/23810-1. Alr-Conditioning and Refrigeration Technology Instltute (ARTI), Arlington, VA, January 1992 (6 pages, available from JMC as RDB2414)

This interim report summarizes the progress of the Materials Compatibility and Lubricant Research (MCLR) Program. It is jointly funded under a grant from the Department of Energy and cost sharing by the air-conditioning and refrigeration Industry. The program addresses refrigerant and lubricant properties, materlals compatibility, and lubricants for alternative refrigerants. The program comprises projects to measure thermophysical properties, test the chemical and thermal stability of refrigerant-tubricant mixtures with metals, and measure the miscibility of lubricants with refrigerants. Three projects will provide information on the compatibility of refrigerants and lubricants with motor materials, elastomers, and engineering plastics. A seventh project will collect and facilitate dissemination of data through development and administration of a refrigerant database. The scope of the program, objectives of the seven initial projects, and highlights of the first quarter are presented. Ine primary effort focused on solicitation, evaluation, and negotiation of proposals for the cited projects. A grant proposal for the second phase was completed and submitted to the DOE. [see RDB2809 and RDB2B02 for update]

Materials Compatiblitty and Lubricant Research Presentation Slides, report DOE/CE/23810-9, AirConditioning and Refrigeration Technology Institute (ARTI), Arlington, VA, February 1993 (98 pages, available from JMC as RDB3206)

This report contains prints of the charts used by five researchers for a seminar on Materials Compatibility and Lubricant Research as part of the 1993 American Society of Heating, Refrigerating, and Air-Conditioning Engineers (ASHRAE) Winter Meeting, held in Chicago in January 1993. This session was sponsored by ASHRAE Technical Committees 3.2 (Refrigerant System Chemistry), 3.3 (Contaminant Control in Refrigerating Systems), and 3.4 (Lubrication). The presentations included were by $D$. F. Hutten- 
locher (Spauschus Assoclates, Incorporated) on "Chemical and Thermal Stability of RefrigerantLubricant Mixtures with Metals," S. C. Zoz (lowa State University of Science and Technology) on "Miscibility of Lubricants with Refrigerants," G. R. Hamed (The University of Akron) on "Competibility of Refrigerants and Lubricants with Elastomers," R. C. Cavestrl (Imagination Resources, Incorporated) on "Compatibility of Refrigerants and Lubricants with Plastics," and R. G. Doerr (The Trane Company) on "Compatibility of Refrigerants and Lubricants with Motor Materia/s." The research projects covered are funded by ARTI under a grant from the U.S. Department of Energy. (Presentation slides are not reviewed by ASHRAE except for commercialism; no endorsement should be inferred.)

\section{ASHRAE}

1993-1994 Research Plan, American Society of Heating, Refrigerating, and Air-Conditioning Englneers (ASHRAE), Atlanta, GA, 1 January 1993 (40 pages, RDB3118)

This list of prospective research subjects identifles 238 proposed projects, 72 designated as priority status. The projects are grouped into nine project classifications, based on approved funding guidellines. Projects relating to refrigerants fall in several of these categories, including the highest priority topic, Environmentally-Safe Materials (CFC, etc.). The research areas were proposed by ASHRAE Technical Committees, Task Groups, and other committees; they were prioritized by ASHRAE's Research and Technical Committee. The highest priority group (three stars) includes research of "Thermophysical Properties of Alternative Refrigerants." The next classification includes "Cascado Refrigeration System to Replace CFC and HCFC Refrigerants Below $-60^{\circ} \mathrm{F}^{\prime \prime}\left[-51^{\circ} \mathrm{C}\right]$. The one-star priority group includes development of "A Uniform Equation of State for Alternatives to CFC Refrigerants." It also includes "Dispersion of Ammonia Plumes in the Atmosphere" and research to "Dovelop Solubility and Viscosity Data for Various Oll-Refrigeramt Mlxtures at High Discharge Temperatures and Pressures." Among nonpriority projects are those addressing "Mixtures of Alternative Refrigerants and Lubricating Oils Properties and Effects on Heat Transfer," "Develop Corrosion Data with Materials of Construction and Now Refrigerant-Lubricants at Various Moisture Levels," "Develop RefrigerantLubricant-Desiccant Molsture Equilibrium Data with New HFC Refrigerants and Relevant Lubricants," and "Measurement of R-22 and Alternative Refrigerant Leakage Rates from Open-Shatt
Compressors." Further projects will examine 'Double-Walled Heat Exchangers for Class 2 Refrigerants," "Heat and Mass Transfer Additives in Aqua-Ammonia Systems," "Impacts of Lubricants on the Segregation of Nonazeotropic Refrigerant Mixtures," "Impacts of Lubricants on the Segregation or Fractionation of Refrigerant Mixtures." "This plan summarizes anticipated funding and procedures for implementing the research identfiled; it replaces ver. sions published for preceding years [see RDB2426].

1992-1993 Research Plan, American Society of Heating, Refrigerating, and Alr-Conditioning Engineers (ASHRAE), Atlanta, GA, 1 January 1992 (25 pages, RDB2426)

This list of prospective research subjects identlfles 182 high-priority projects, grouped into eight project classifications based on approved funding guldelines. Projects relating to refrigerants fall in several of these categorles, including the highest priority topic, Environmentally Safo Materials (CFC, etc.). The research areas were proposed by ASHRAE Technical Committees, Task Groups, and other committees; they were prioritized by ASHRAE's Research and Technical Committee. The highest priorty group (three stars) includes research of thermophysical properties of R-123, R-125, R-134a, and R$141 \mathrm{~b}$, as well as measurement of two-phase refrigerant liquid-vapor mass flow rates. The next classification includes real-time determination of the lubricant concentration dissolved in alternative refrigerants, evaluation of leak detection methods for non-CFC refrigerants, and flow regime mapping of R-134a/lubricant mixtures in smooth and internally enhanced tubes. It also includes experimental determination of heat transfer with R-134a and R-22 refrigerants in water-cooled condensers and direct-expansion water coolers using brazed plate heat exchangers. The one-star priority group includes research of alternattves to replace R-22 and R502 , development of a unlform equation of state for alternative refrigerants, and determination of properties and heat transfer effects for mixtures of alternative refrigerants and lubricants. $R \theta$ search of ammonia (R-717) dispersion in the atmosphere also is included. This plan summarizes anticipated funding and procedures for implementing the research identifled; it replaces the versions published for preceding years.

\section{DOE}

Refrigeration Systems Program Summary, report DOE/CH10093-120, U.S. Department of Energy 
(DOE), Washington, DC, December 1991 (24 pages, avallable from NTIS as GPO \#573. $122 / 40020$ at price code A03, RDB2263)

This document summarizes results, current acthities, and objectives of the U.S. Department of Energy (DOE) for research of refrigerators, alr conditioners, heat pumps, chillers, and supermarket systems. Key acthities include investigation of alternative refrlgerants and refrigeration cycles, developing advanced technologies for future air-conditioning and refrigeration equipment designs, and developing advanced insulation for appliances. The program structure and opportunitles for collaboration with industry are outlined.

\section{EPA}

W. R. Rhodes (U.S. Environmental Protection Agency, EPA), Stratospheric Ozone Protection: An EPA Engineering Perspectlve, Journal of the Air and Waste Management Association, volume 41, number 12, pages 1579-1584, December 1991 (6 pages with 2 tables, avallable from JMC as RDB2707)

\section{JRAIA}

S. Uemura (Daikin Industries, Limited, Japan), Basic Requirements and Future Solutions of AirConditioning Units with alternative Refrigerants - 1, paper 5.2, Proceedings of the International Seminar on New Technology of Alternative Refrigerants - Lubricants and Materials Compatibility (Tokyo, February 1983), Japanese Association of Refrigeration (JAR), Tokyo, Japan, pages 89-94, February 1993 (6 pages with 9 figures and 6 tables, RDB3317)

H. Wakabayashl (Matsushita Electric Industrial Company, Limited, Japan), Basic Requirements and Future Solutions of Air-Conditioning Units with alternatlve Refrigerants - 2, paper 5.3, Proceedings of the International Seminar on New Technology of Alternative Refrigerants - Lubricants and Materials Compatibility (Tokyo, February 1983), Japanese Associatlon of Refrigeration (JAR). Tokyo, Japan, pages 95-100, February 1993 (6 pages with 6 figures and 4 tables, RDB3318)
PAFT

Program for Alternative Fluorocarbon Toxicity Testing, program description, PAFT, Bristol, United Kingdom, May 1990 (4 pages, RDB1151)

\section{MISCELLANEOUS DOCUMENTS}

T. Atwood (AlliedSignal Incorporated), The Need for Standardized Nomenclature for Refrigerants, ASHRAE Journal, American Society of Heating, Refrigerating, and Air-Conditioning Engineers (ASH$\mathrm{RAE}$ ). Atlanta, $\mathrm{GA}$, volume 31 , number 11 , pages 44-47, November 1989 (3 pages with 1 table, RDB. 0545)

V. D. Baxter, Report of Forelgn Travel: Q-11 May 1990 [Application of Zeotropic Mixture Refrigerants in Refrigerators and Use of the Lee-Kesler-PIocker Equation of State], ORNL/FTR-3611, Oak Ridge National Laboratory, Oak Rildge, TN, 14 May 1990 (20 pages, RDB1153)

This Informal report summarizes the final working meeting of the International Energy Agency (IEA) research project on State and Transport Properties of High-Temperature Working Fluids and Nonazeotropic Mixtures (Annex XIII). It also addresses research at the Universität Hannover, funded by the U.S. Environmental Protection Agency (EPA), on application of refrigerant blends in refrigerators and separate work to use the Lee-Kesler-Plöcker equation of state to predict refrigerant properties.

J. M. Calm (Engineering Consultant), Refrigerant Database, report DOE/CE/23810-11D. Air-Condltioning and Refrigeration Technology Institute (ARTI), Artington, VA, April 1993 (126 pages, available from JMC as RDB3459)

This document provides bibllographic citations for 692 publications that may be useful in research, design, and application of air-conditioning and refrigeration equipment. Synopses of the content, materials addressed, and key conclusions are provided for approximately half of these documents. The database identifles sources of specific information on R-32, R-123, R-124, R-125, R-134, R-134a, R-141b, R-142b, R143a, R-152a, R-245ca, R-290 (propane), R-600 (butane), R-600a (Isobutane), R-717 (ammonia), ethers, and others as well as azeotropic and zeotropic blends of these fluids. It addresses mineral oil, alkylbenzene, polyalkylene glycol (PAG), polyol ester, and other lubricants. It also references documents on compatibility of re- 
frigerants and lubricants with metals, plastics, clastomers, motor insulation, and other matertals used in refrigerant circults. The database is available in both a computerized version and as a listing in report form. The computerized version includes the same citations and abstracts as the report version plus 22 additional citations, for superseded and historical documents, and data summaries for 90 Indwidual refrigerants and blends. It is accompanied by retrieval sottware to faciltate searches for specific information; the software enables searches for user-selected terms, or combinations of terms. It offers several automated features to simplify searches including optional prompting by search category, an automated "thesaurus" of synonyms and related terms, chain searches to broaden or narrow prior searches, and a "wildcard" capability to allow entry of word segments. The software also enables printing of selected citations, abstracts, and refrigerant summaries as well as preparation of a document order lists. Both versions of the database include instructions to obtain cited documents or subscriptions for updates to the database. Whereas prior releases of the database have focused primarlly on the information needs of manufacturers and researchers, attention is being increased to the requirements of refrigerant users, beginning with this release.

J. M. Calm (Engineering Consultant), Refrigerant Database. Proceedings of the International CFC and Halon Alternatives Conference Washington, DC). Alliance for Responsible CFC Policy, Arlington, VA, pages 55-72, September 1992 (8 pages with 4 figures, avallable from JMC as RDB2907)

This paper reviews the history of the Refrigerant Database, including initial efforts by the AirConditioning and Refrigeration Insthute (ARI) and National Institute of Standards and Technology (NIST). The database currently is sponsored by the Alr-Conditioning and Refrigeration Technology Institute (ARTI), as part of the Materials Compatibility and Lubricant Research (MCLR) Program, under a gram from the U.S. Department of Energy (DOE). The paper outlines the contents and focus of the database, and describes the search and retrieval functions available in a computerized version. Sample searches are llustrated along with the results obtained. Opttons to spectify search terms are summarized; they include toplcal prompts, combinations of search crterla (using Boolean logical operators), and chained searches to refine or broaden earlier searches. The procedures to obtain the database and documents ctted by $t \mathrm{t}$ are indicated.

J. M. Calm (Air-Condtiloning and Refrigeration Institute, ARI), Composition Designations for Ro- trlgeramts, ASHRAE Joumal, American Soclety of Heating, Refrigerating, and Air-Conditioning Englneers (ASHRAE), Atlanta, GA, volume 31, number 11, pages 48-51, November 1989 (3 pages, avallable from JMC as RDB0546)

This paper provides recommendations for consistent use of preflxes for refrigerant designallons. The need for uniform nomenclature and a survey, performed for the Technology Councll and the Research and Tochnical Committee (R\&T) of the American Society of Heating, Refrigerating, and Air-Conditioning Engineers (ASHRAE), are summarized. The requirement surfaced with increasing regulatory and legislathe actions to limit production, use, and emission of refrigerants of environmental concern. A variety of composition-designating Identfiers were introduced to distingulsh between refricerants, but nonuniform usage resulted in contusion rather than clartfication. [The recommendations of this paper were incorporated into ASHRAE Standard 34-1992, seo RDB2909]

E. Johnson and J. Noble, A Survey of Alternatives to Ozone-Destroying Technologies, Greenpeace Internationat, Washington, DC, June 1990 (35 pages, RDB1 154)

This report is a survey of innovations old and new that could provide the goods and services currently dependerit on ozone-destroying chemicals. It is represented as an attempt to show the range of technologies that could be used as replacements without adverse impact on the ozone layer. The survey notes that the HCFC and HFC alternatives have not been proven to be harmless to the ozone layer, but are greenhouse gases and have serious toxicity problems.

P. I. Rothfleisch and D. A. Dldion (Natlonal Institute of Standard's and Technology, NIST), A Pertormance Evaluation of a Varlable Speed, Mloed Refrigeramt Heat Pump, report NISTIR 4597, National Institute of Standards and Technology, Gaithersburg, MD, June 1991 (64 pages with 10 figures and 7 tables, avallable from NTIS at price code A04, RDB3337)

This report evaluates the performance of an innovative heat pump, equipped with a distillation column to shit the composition of a zeotropic refrigerant mixture. This product was commerclalized in Japan on a limited basis, but has since been withdrawn. The report contrasts loads to equipment capactity and shows the composition shifting strategy schematically. It outlines equilibrium (or flash) and continuous rectification approaches for distillation. It reviews prior work in the area and describes the test model, which uses a blend of 20\% R-13B1 
and $80 \%$ R-22 by weight. Measured performance at standard rating conditions and seasonal energy calculations are summarized for both the heating and cnaing modes. No composition shifting was observed in the tests. Simulations using an ideal-cycle model are described to demonstrate the potential value of composition control. While heating seasonal performance gains were found to be small, avoidance of auriliary heat requirements were substantial. Cooling performance is indicated to be appruximately $2 \%$ lowar with R-13B1/22 $(20 / 80)$ blend than with R-22 alone.

K. Ushimaru (Energy International, Incorporated), Inipact of CFC Curtaliment on Refrigeration and Mitigation Research in Japan, C'FCs: Today's Options - Tomorrow's Solutions (proceedings of ASHRAE's 1989 CFC Technolog'y Conference, Gaithersburg, MD, 27-28 September 1989), Amerlcan Society of Heating, Refrigerating, and Air-Conditioning Engineers (ASHRAE), Atlanta, GA, pages 107-1 i7, 1990; republished in International Journal if Refrigeration, Paris, France, volume 13, number 3. paiges 131-141, March 1990 (10 paiges with 10 figures and 2 tables, RחB1205)

This paper focuses on efforts in Japan to develop technical optlons for rejucing CFC emissions. Aiternative refrigerants for R-12 (used in automobile air-conditioners and residential $r \theta-$ frigerators) and R-113 (used extensively as a solvent and cleaning agent) are presented. CFC mitigation options are discussed for control technologies, work practices and economics, chemical substitutes, and product substitutes. Japan's usage profile and historical background on its environmental responsiveness are addressed. The article notes that $R-i 13$ recovery and recycling equipment are already marketed in Japan and that the demand for this equipment is projected to grow to $\$ 15$ billion by 1998 . Additionally, leading Japanese chemical producers are moving forward with plans for the production of R-134a as a substitute for R-12.

Assignment of Retrigeramt Container Colors, ARI Guideline N-1992, Alr-Conditioning and Refrigeration Institute (ARI), Arlington, VA, 1992 (8 pages, with 1 tables, avallable from ARI for $\$ 15.00, R D B$ 3101)

This guidelline sets color standarc's fo: containers for existing, new, and reclaimed refrigerants. It further provides a means by which ARI can assign colors as new refrigerants are introduced, and maintains a record of those assigned and available. The guideline also recommends a container color (light green grey) for refrigerants that are not produced in sufficient quentities to qualify for individual colors. While color coding is not intenced as a substi- tute for reading cylinder labels and markings, the guideline facilitates distinction among refrigerant containeis by content. Four groups are identified, namely those for liquids at $20^{\circ} \mathrm{C}(68$ $\left.{ }^{\circ} \mathrm{F}\right)$ normally packaged in drums, low-pressure fluids, high pressure fluids, and flammable (red band) refrigerants or mixtures. A table summarizes color assignments and corresponding color matching data. Refrlgr,rants with assigned colors include R-11 (orange), R-12 (white), R-13 (light blue, sky), R-13B1 (pinkish-red, coral), R14 (yellow-brown, mustard), R-22 (light green), R-23 (light blue grey), R-113 (dark purple, violet), R-114 (dark blue, navy), R-116 (dark grey, battleship), R-123 light blue grey), R-134a (light blue, sky), R-500 (yellow), R-502 (light purple, lavender), and R-503 (blue-green, aqua).

JICOP Guide, Japan Industrial Conference for Ozone Layer Protection, Tokyo, Japan, January 1991 (8 pages, availabla from JMC as RDB1204)

JICOP was formed in 1988 as the Promotion Conference for Rational Use of Specified CFCs and renamed in June 1990. It is an organization of industrial producers and consumers addressing ozone-ayer protection in Japan. Its main activities include publicity, informaicion sharing, surveys of actions by other countries, preparation of guides, and training. This leaflet introduces the organization and lists the 55 current members. Included are the Japan Association of Refrigeration, Japan Association of $R \theta-$ frigeration and Air-Conditioning Contractors, Japan Flon Gas Association, and Japan Refrigeration and Air-Conditioning Industry Association.

Manual for Reductions in the Use of Ozone Depleting Substances, Japan Industrial Conference for Ozone Layer Protection, Tokyo, Japan, second edition, February 1992 (140 pages, avallable from JMC as RDB2705)

This manual outlines technologies for reduction and substtution of chlorofluorocarbons (CFCs) and other ozone-depleting substances (ODSs). It is intended to assist ODS users to develop the most effective measures for each application. Section III. 4 addresses leak prevention and use reduction for refrigerarts as well as research and development of substitute refrigerants and technologies to use them. It brieffy summarizes reduction measures for centrifugal chillers, automobile air conditioners, commerclal refrigeration. transport refrigeration, and refrigerators. Other sections of this document review regulatory measures for refrigerants, toxicity and safety evaluation of alternatives, and the physical properties of ODSs and their alternathes. 
Specifications for Fluorocarbon Refrigeramts, ARI Standard 700-1988, Air-Conditioning and Refrigeration Institute (ARI), Anlington, VA, 1988 (12 pages with two tables and 1 appendlx, available from ARI for \$12.50, RDB3103)

The intent of this standard is to define a level of quality for new, reclaimed, and/or repackaged refrigerants for use in new and existing refrigeration and air-conditioning products. Specified contaminant levels were chosen to be within the sensitivity of recommended test methods, to be economically achievable, and to provide satisfactory performance. The standard does not apply where refrigerant captured from a particular system is returned on site to the same system. It defines and classifles contaminants based on standard test methods. It also specifies acceptable purity requirements for various fluorocarbon refrigerants, regardless of source. These refrigerants include $R-11, R-12, R-13, R$ 22, R-113, R-114, R-500, R-502, and R-503. It addresses the boilling point and range as well as allowable content of vapor-ohase contaminants, and water, chloride ion, acidlty, high-boiling residues, particulates and sjlids, and other refrigerants. It identifies acc pted industry test procedures for these determir. ations. 


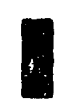

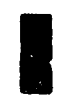

I

I

I

I

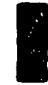

I

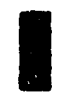

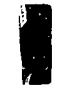

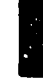

I

I

I

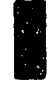

I

I

I 
The Refrigerant Database is supported in part by U.S. Department of Energy grant number DE-FG02-91CE23810, Materials Compatibility and Lubricant Research (MCLR) on CFC-Refrigerant Substitutes. Federal funding supporting the MCLR program constitutes $93.67 \%$ of allowable costs. Funding from nongovernment sources supporting this program consists of direct cost sharing of $6.33 \%$ of allowable costs and in-kind contributions from the air-conditioning and refrigeration industry. Funding for the Refrigerant Database constitutes less than $2 \%$ of the total and is supplemented by inkind cost sharing by James M. Calm, Engineering Consultant. Support of the MCLR Program by the U.S. Department of Energy and the air-conditioning and refrigeration industry does not constitute an endorsement of the views expressed herein. 

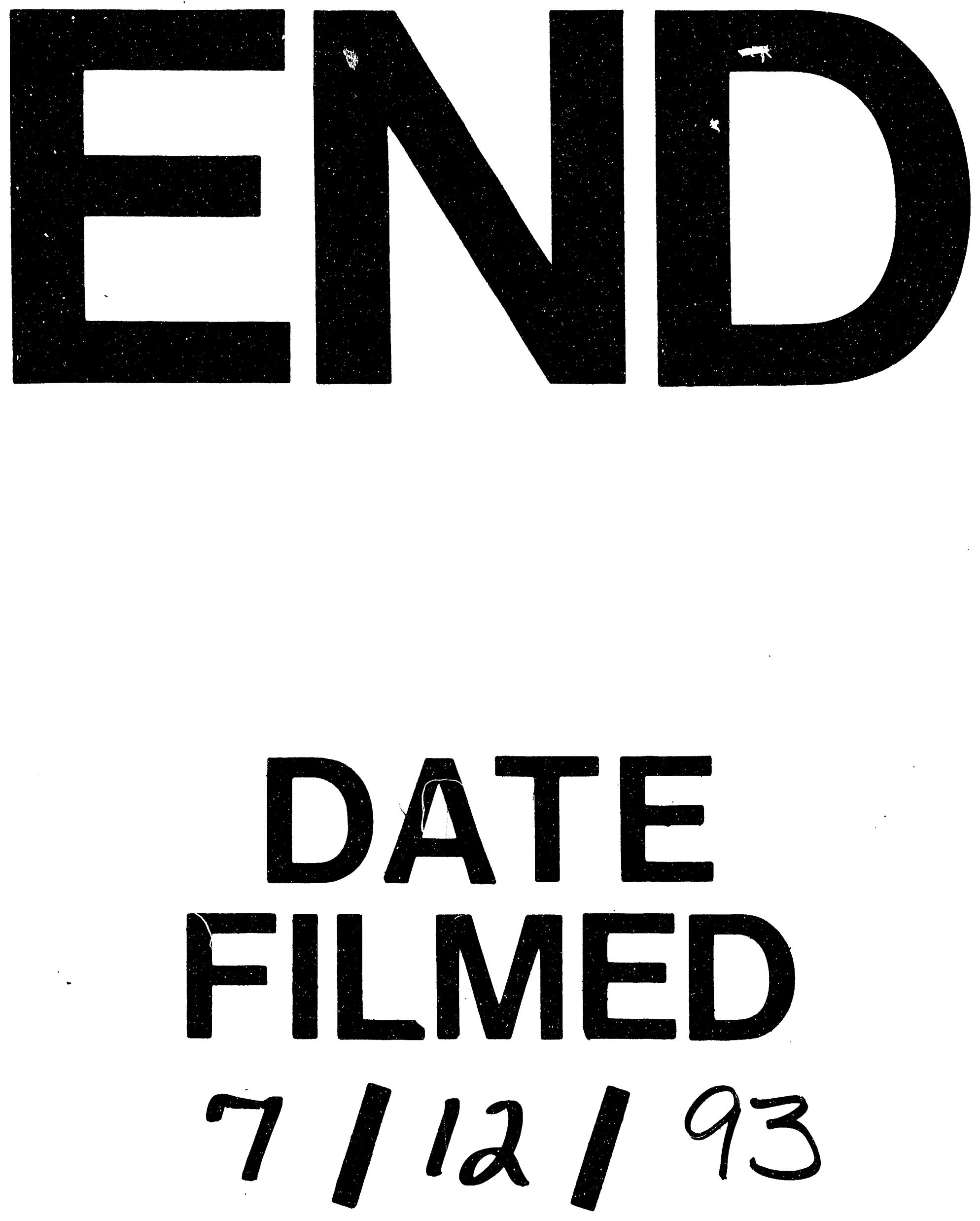

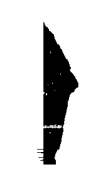


